\title{
A Call For Context: Exploring The Situational And Relational Characteristics Of Heavy Drinking By Canadian Adults
}

\author{
By
}

Lee W. Gomes

A thesis submitted to the Faculty of Graduate Studies and Research in partial fulfillment of the requirements for the degree of

\section{Master of Arts}

Department of Sociology and Anthropology

\author{
Carleton University \\ Ottawa, Ontario \\ January, 2008
}

(C) Copyright

2008, Lee Gomes 


$\begin{array}{ll}\begin{array}{l}\text { Library and } \\ \text { Archives Canada }\end{array} & \begin{array}{l}\text { Bibliothèque et } \\ \text { Archives Canada }\end{array} \\ \begin{array}{l}\text { Published Heritage } \\ \text { Branch }\end{array} & \begin{array}{l}\text { Direction du } \\ \text { Patrimoine de l'édition }\end{array} \\ \begin{array}{l}\text { 395 Wellington Street } \\ \text { Ottawa ON K1A 0N4 } \\ \text { Canada }\end{array} & \begin{array}{l}\text { 395, rue Wellington } \\ \text { Ottawa ON K1A 0N4 } \\ \text { Canada }\end{array}\end{array}$

Your file Votre référence ISBN: 978-0-494-40601-4 Ourfile Notre référence ISBN: 978-0-494-40601-4

NOTICE:

The author has granted a nonexclusive license allowing Library and Archives Canada to reproduce, publish, archive, preserve, conserve, communicate to the public by telecommunication or on the Internet, loan, distribute and sell theses worldwide, for commercial or noncommercial purposes, in microform, paper, electronic and/or any other formats.

The author retains copyright ownership and moral rights in this thesis. Neither the thesis nor substantial extracts from it may be printed or otherwise reproduced without the author's permission.
AVIS:

L'auteur a accordé une licence non exclusive permettant à la Bibliothèque et Archives Canada de reproduire, publier, archiver, sauvegarder, conserver, transmettre au public par télécommunication ou par l'Internet, prêter, distribuer et vendre des thèses partout dans le monde, à des fins commerciales ou autres, sur support microforme, papier, électronique et/ou autres formats.

L'auteur conserve la propriété du droit d'auteur et des droits moraux qui protège cette thèse. $\mathrm{Ni}$ la thèse ni des extraits substantiels de celle-ci ne doivent être imprimés ou autrement reproduits sans son autorisation.
In compliance with the Canadian Privacy Act some supporting forms may have been removed from this thesis.

While these forms may be included in the document page count, their removal does not represent any loss of content from the thesis.
Conformément à la loi canadienne sur la protection de la vie privée, quelques formulaires secondaires ont été enlevés de cette thèse.

Bien que ces formulaires aient inclus dans la pagination, il n'y aura aucun contenu manquant.

\section{Canada}




\begin{abstract}
This thesis seeks to explore the gap in knowledge of the drinking context and its impact on the propensity for heavy drinking by Canadian adults. This gap is positioned as the result of interrelated trends in the individualization of social problems within epidemiological research and neo-liberal forms of governance. Secondary analysis of data from the 2004 Canadian Addiction Survey was conducted to examine the importance of situational and relational characteristics of the drinking context in accounting for heavy drinking. The impact of drinking context was examined separately for men and women. Consistent with previous research, drinking at parties, in larger groups, at bars, and with friends was predictive of heavy drinking. Gender differences were apparent, and a number of unexpected results were observed. The findings were considered in relation to emerging theories that suggest occasions of heavy alcohol consumption are linked to general shifts towards individualization and determined states of intoxication (Measham 2006).
\end{abstract}




\section{ACKNOWLEDGEMENTS}

This thesis could not have been completed without the support of a number of people. Dr. Colleen Dell has been my academic supervisor since the start of the program, and has been influential in seeing me through the thesis process. I am most thankful for her insightful comments and suggestions to various drafts of my work, as well as her guidance in focusing my research. I am indebted to the other member of my thesis committee, Dr. Zhiqiu Lin. Dr. Lin provided invaluable feedback on my initial analysis that helped redirect and improve my entire approach to this study. He played an instrumental role in the development of my knowledge of quantitative analysis, and helped a great deal with the organization of my findings.

I would like to extend a thank you to my family and friends for their support and interest throughout the last two years. Without the on-going support and encouragement from my parents, Barbara and Fernando, I would not be where I am today. Some time ago, they helped shape the confidence and endurance needed to succeed in many aspects of life, including education, and for that I am truly grateful. I am also deeply thankful to my fellow students and friends who helped at various stages of this process, including Sheryl Peters, Tara Beauchamp, Karen Garabedian and Kristy Timco. Aimée Campeau offered enormous moral and organizational support in this endeavour. I am also grateful to fellow graduate student Andre Solecki. He provided me with invaluable advice for my data analysis, and volunteered his time to help me with some of the intricacies of SPSS. I am grateful for his continued support throughout the data analysis phase of my project.

I will forever treasure the extraordinary support of Kathleen Simmons, for her patience in listening to every detail about alcohol consumption, drinking contexts and social theory she never knew she wanted to know. Many nights and entire stretches of time were spent away from her working on this thesis. This project would not have been possible without her patience and understanding. 


\section{TABLE OF CONTENTS}

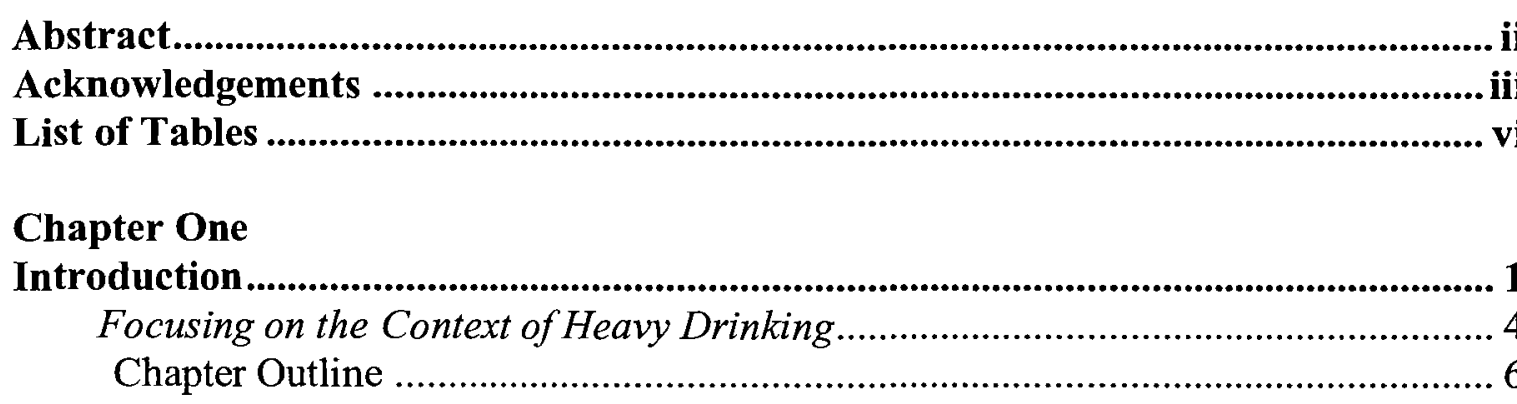

\section{Chapter Two}

Epistemological and Theoretical Framework ......................................................9

Attending to the gap in research on the drinking context ..................................... 10

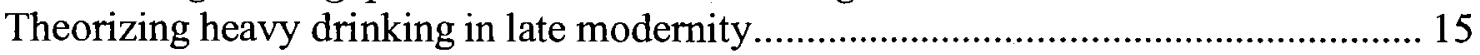

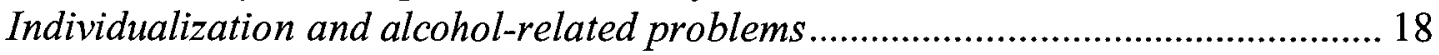

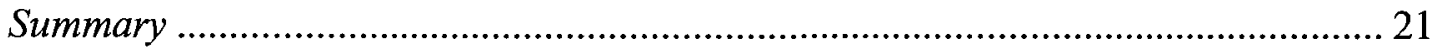

\section{Chapter Three}

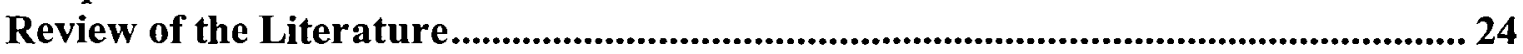

3.1 Heavy Drinking as a Social Problem ............................................................ 24

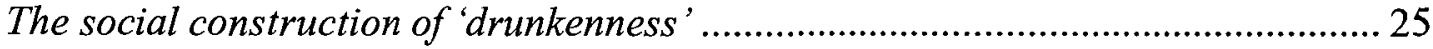

The cultural component of alcohol consumption in Canada ................................ 27

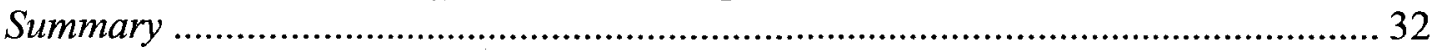

3.2 Gaps in Contextual Knowledge of Alcohol Consumption .................................. 33

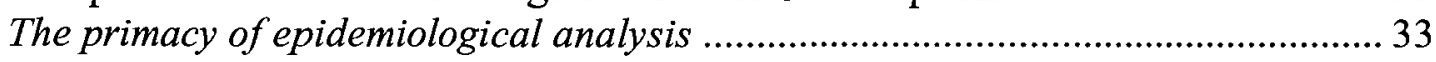

Methodological individualism and 'drug' discourses ......................................... 36

The individualized nature of modern regimes of government ................................. 38

Emphasizing the reduction of alcohol-related harms in Canada ............................ 40

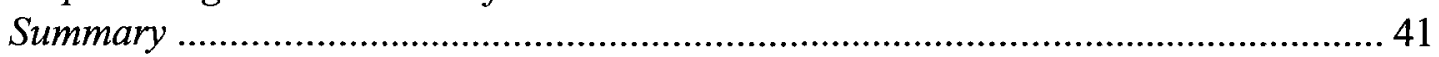

3.3 The Drinking Context and Heavy Drinking................................................ 42

Hazardous drinking practices and occasions of alcohol consumption ................... 43

Heavy drinking and alcohol-related consequences ............................................. 47

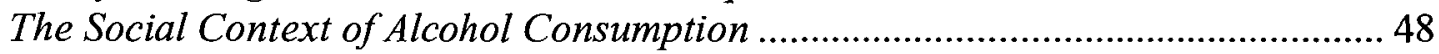

The Influence of relational characteristics of the drinking context ......................... 50

The Influence of situational characteristics of the drinking context........................ 54

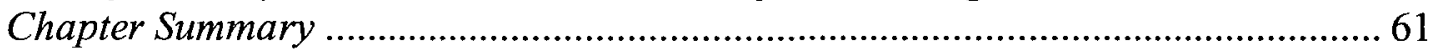

\section{Chapter Four}

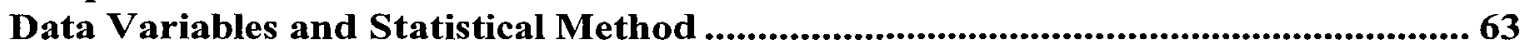

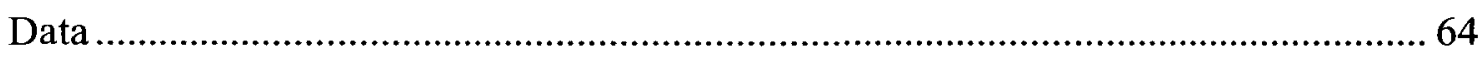

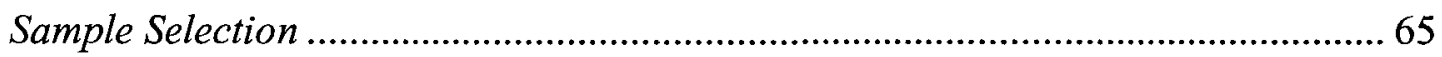

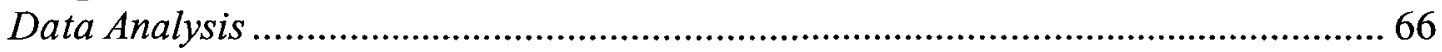

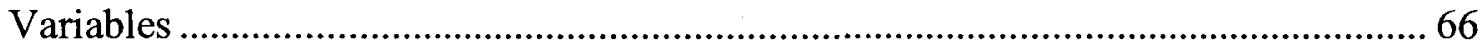

Dependent Variable - Heavy Alcohol Consumption ..............................................6. 67

Independent Variables - the Social Context of Alcohol Consumption .................... 67 


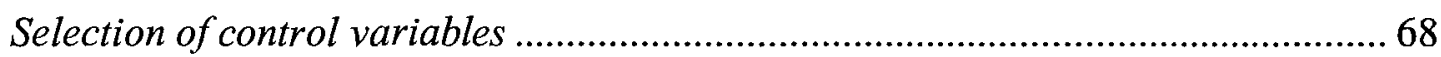

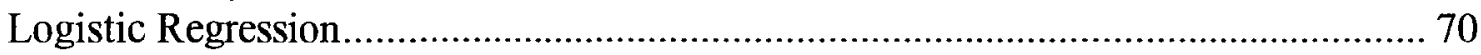

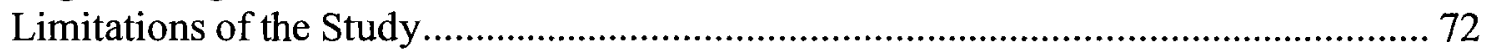

Research Questions and Hypotheses....................................................................... 74

\section{Chapter Five}

Analysis of the Relational and Situational Context of Heavy Drinking ..................... 77

Social Characteristics of the Research Population ………..................................... 77

Description of Drinking Behaviour ...................................................................... 80

Description of Characteristics of the Drinking Context …….................................. 81

Heavy Alcohol Consumption and the Drinking Context........................................... 84

Situational versus Relational Characteristics of the Drinking Context ......................... 89

The Drinking Context and Heavy Drinking.......................................................... 100

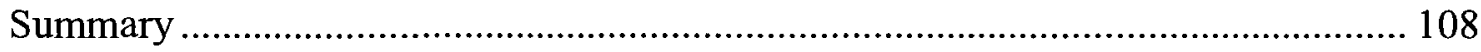

\section{Chapter Six}

Gender Differences between Heavy Drinking and the Drinking Context ................ 110

Description of Drinking Behaviour by Gender ................................................... 110

Description of Characteristics of the Drinking Context by Gender ....................... 112

Gender, Heavy Alcohol Consumption and the Drinking Context ........................... 115

Examining Gender Differences in the Drinking Context and Heavy Drinking........... 122

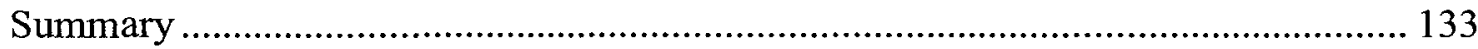

\section{Chapter Seven}

Discussion............................................................................................................................... 135

The Drinking Context and Heavy Drinking by Canadians .......................................... 136

Gender differences on the influence of the drinking context...................................... 145

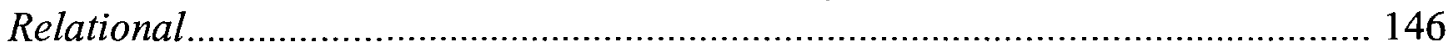

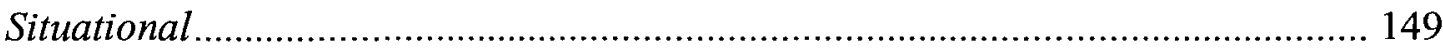

Re-imagining heavy drinking as contextually-specific behaviour.............................. 153

Promoting moderation and reducing harm: a place for 'context'? ............................. 162

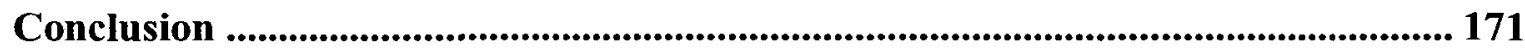

Summary of key findings and implications .............................................................. 172

Implications for future research on the context of alcohol consumption..................... 174

Appendix A: Survey Instrument, CAS (2004) ............................................................. 182

Appendix B: Variable Information and Coding Decisions .............................................. 187

References ............................................................................................................................. 200 


\section{LIST OF TABLES}

Table 4.1: Predictor and outcome variable definitions and proposed variable coding for "Heavy drinking during the last drinking occasion". 69

Table 5.1: Distribution of population by socio-demographic characteristics, CAS (2004)....

Table 5.2: Distribution non-heavy drinkers and heavy drinkers (5+ drinks) on the last drinking occasion, CAS (2004)

Table 5.3: Distribution of population by characteristics of the drinking context, CAS (2004)

Table 5.4: Distribution of heavy alcohol consumption (5+ drinks) by characteristics of the drinking context, CAS (2004) 86

Table 5.5: Heavy drinking (5+ drinks) by relational characteristics of the drinking context, CAS (2004) 92

Table 5.6: Heavy drinking by situational characteristics of the drinking context, CAS (2004)

Table 5.7: Heavy drinking by characteristics of the drinking context, CAS (2004)

Table 6.1: Distribution non-heavy drinkers and heavy drinkers (5+ drinks) on the last drinking occasion, by gender, CAS (2004)

Table 6.2: Distribution non-heavy drinkers and heavy drinkers (4+ females $/ 5+$ males) on the last drinking occasion, by gender, CAS (2004) 112

Table 6.3: Characteristics of the drinking context by gender, CAS (2004) 114

Table 6.4: Distribution of heavy alcohol consumption (5+ drinks) by characteristics of the drinking context, males, CAS (2004) 117

Table 6.5: Distribution of heavy alcohol consumption (4+ drinks) by characteristics of the drinking context, females, CAS (2004). 118

Table 6.6: Heavy drinking by characteristics of the drinking context, by gender, CAS (2004) 


\section{CHAPTER ONE}

\section{INTRODUCTION}

Differing patterns of alcohol consumption have formed the basis for a substantial body of literature in both sociology and epidemiology. Researchers in both fields have generally been concerned with documenting trends in the drinking habits of individuals and their associated problems. Modern epidemiological research on alcohol, which emerged alongside the medicalization of alcohol and drug issues in the $1970 \mathrm{~s}$, stresses the need for knowledge of individual-level correlates of alcohol consumption in order to address problems with addiction and abuse. The focus on individual behaviour found within the epidemiologic method reflects a shift in modern studies of alcohol consumption away from examinations of social factors that contribute to increased rates of alcohol consumption or intoxication. As such, modern epidemiology can be characterized as individualistic, a result of its emphasis on separating individual behaviour from the "social and situational context in which it occurred" (Duncan et al. 1996: 817). While epidemiological research continues to shed light on new trends in the way Canadians consume alcohol, a gap in knowledge of the social factors that contribute to hazardous patterns of drinking has occurred as a result of the over-emphasis on individual correlates of drinking behaviour.

Room (1978) has argued that the focus on alcoholism and treatment of the individual was the principle 'governing image' of alcohol problems in the $1980 \mathrm{~s}$. The notion of 'drunkenness' was paramount at the time, with both quantity and frequency of 'drunkenness' being integral to the disease concept of alcohol-related problems in adults. In the 1990 s, concern over intoxication from alcohol consumption remained, albeit with a 
more limited scope, as a significant portion of the research and policy focus was aimed specifically at youth and young adults. Instead of addressing 'drunkenness' in individuals - a classification that is inherently imprecise - scholars re-defined problematic use in terms of specific quantities and frequencies of drinking, with the emergence of concepts such as 'binge' drinking' in the study of youth drinking, (Cooley et al. 1994; Johnston et al. 1996; cited in Wechsler et al. 1999), and 'heavy' drinking in the study of drinking among the general population. In most cases, heavy alcohol consumption or heavy drinking reflects an individual's consumption of five or more (5+) drinks of alcohol on a single occasion (Adlaf et al. 2005: 21). According to the 2004 Canadian Addiction Survey (CAS), $16.0 \%$ of Canadians, 15 years of age or older, reported heavy drinking as their usual level of alcohol consumption on drinking occasions, while $6.2 \%$ of past-year drinkers reported consuming this amount at least once a week, and $25.5 \%$ reported this pattern of drinking at least once a month. ${ }^{2}$ Recently, a number of researchers have put forth a gender-specific measure of heavy drinking, which uses the measure of five or more drinks consumed by men on a single occasion, and four or more drinks by women (Demers 1997; Dowdall \& Wechsler 2002; Wechsler 1995).

Indeed, the consumption of alcohol remains a significant public health issue in Canada. Data from 2002 estimates the social cost attributable to alcohol in this country is $\$ 14.6$ billion, or $\$ 463$ per Canadian (Rehm et al. 2006: 1). While the social costs associated with alcohol are high, efforts in the research and governance of alcohol-related problems, including those affecting individuals other than the drinker, have been

\footnotetext{
${ }^{1}$ Binge drinking is defined as occasions where an individual consumed five or more alcoholic drinks on a single drinking occasion (Cooley et al. 1994; Johnston et al. 1996; cited in Wechsler et al. 1999). It is most often associated with consuming this quantity within a set period of time, such as the past two weeks or month (Wechsler et al. 1994a).

2 'Usual' consumption is used here to reflect the usual number of drinks a survey respondent consumed on the days in which they drank alcohol, and is consistent with its use in the 2004 CAS (Adlaf et al. 2005: 21).
} 
systematically redefined as private matters of individuals, as opposed to matters of a social concern (Gusfield 1981). Alcohol consumption has come to be associated with "the sphere of private life" (Room 1996: 384), with the implicit assumption that understandings of alcohol and drinking should necessarily be individualized in nature. It is argued here that this process is consistent with a general shift towards 'individualization', which represents a late modern social structure where risk becomes increasingly individualized and people are expected to self-manage emergent risks in their everyday practices (Beck 1992; Beck 1999). ${ }^{3}$ Knowledge of heavy alcohol consumption in the current phase of modernity has also become individualized, resulting in a lack of research on 'social' influences on drinking, such as the 'context' of alcohol consumption.

Given Harford's contention that "the antecedents of alcohol consumption are to be found in the interactions between the individual and his environment...", meaning "the consumption of alcoholic beverages is situationally specific, rather than a trans-situational property of specific individuals" (1979: 289), it would seem that additional research examining the 'contexts' in which heavy drinking occurs is warranted.

\footnotetext{
${ }^{3}$ This perspective perceives a shift in social life as a result of the process of modernization, whereby the current phase of modernity in characterized by an abundance of global risks, which have evolved from the industrial risks inherent in the first phase of modernity (i.e., late $19^{\text {th }}$, early $20^{\text {th }}$ centuries). Thus, "modernity reduces the overall riskiness of certain areas and modes of life, yet at the same time introduces new risks parameters largely or completely unknown to previous eras" (Giddens 1991:4). The use of 'phase' was introduced by Beck (1992) in reference to the catastrophic potential of risks that characterize late modernity, which he uses synonymously with the former concept. Late modern societies reflect the institutional transitions and cultural developments from previous eras, but consist of a general skepticism among the public, and a realization by the subject of the inability of modern institutions to deal with many contemporary risks. Individualization, which redefines 'risk' in terms of individual action and responsibility, emerges as the new social order in response to the state's withdraw from the management of certain social problems.
} 


\section{Focusing on the Context of Heavy Drinking}

Given Harford's claim, it is surprising that few studies have examined in great detail the effect of different contexts on alcohol intake by individuals. The context of drinking has been conceptualized as "where one drinks, with whom one is drinking, and when one drinks" (Calahan et al. 1969, cited in Clapp et al. 2000: 141). The term drinking context is employed sociologically within this research to refer to the immediate environment in which drinking occurs. It contains several different dimensions related to the physical nature of the drinking occasion, as well as the drinkers who comprise this situation, ${ }^{4}$ and includes characteristics that are both situational (i.e., the circumstance, time, or location of drinking) and relational in nature (i.e., drinking partners, friends, or size of the drinking group). The differentiation between situational and relational characteristics follows research by Demers (1997) on Montreal adults, which determined that heavy drinking is contingent upon a number of characteristics of the drinking context, including the circumstances, location, time, relationship and gender similarity among drinking partners. Other studies using Canadian data have found that certain characteristics of drinking contexts are important explanatory variables in a variety of drinking measures, including heavy drinking (Single \& Wortley 1993; Kairouz \& Greenfield 2007). Nevertheless, research on the context of heavy alcohol consumption remains a relatively unexplored terrain in Canada, particularly with adult populations. These studies provide a foundation from which to explore the impact of the drinking

\footnotetext{
${ }^{4}$ The 'context' differs from drinking occasions in that it refers to descriptive characteristics of the drinking environment, as opposed to simply denoting the a single drinking event within surveys of alcohol consumption. Further discussion pertaining to characteristics of the drinking context, and their use in studies of alcohol consumption and alcohol-related harms, is provided in Chapter Three.
} 
context on heavy drinking by Canadian adults, using data from the 2004 Canadian Addiction Survey (CAS).

\section{Purpose and Organization of Study}

This thesis has two main objectives: (1) to examine the gap in knowledge on the social context of alcohol consumption in relation to understanding contemporary trends in heavy drinking; and (2) to explore the impact of the drinking context on heavy drinking, using the most current and available national data on drinking in Canada. This shift is positioned here as being reflective of broader socio-cultural changes in the transition to late modernity, towards the individualization of a host of social problems including those related to alcohol consumption. As such, the aims of this thesis are meant to be both theoretical and practical.

To address the lack of attention paid to the drinking context in both sociological and epidemiological research on alcohol, a number of separate, yet related tasks have been undertaken. First, this thesis situates the current gap in knowledge of social factors that contribute to heavy drinking by outlining interrelated trends in the individualization of social problems within practices of research and governance. Second, it details existing scholarship related to characteristics of the drinking context, and its effect on heavy drinking. Finally, to examine the influence of the drinking context on the propensity for heavy drinking, secondary analysis of cross-sectional data from the 2004 CAS is conducted. Approaching the topic in this manner enabled a detailed understanding of the importance of the drinking context to emerge. 


\section{Working Argument}

Beginning from the position that the drinking context is an under-researched area within the study of alcohol consumption, this gap must be understood and research on its impact undertaken, particularly given its importance in accounting for patterns of heavy drinking and drinking-related harms. The primary focus of this thesis is to address the following question: How important is the 'context' of alcohol consumption in accounting for heavy drinking by Canadian adults? From this, a number of other questions are considered to specifically examine characteristics of the drinking context, as well as the research and governance possibilities related to knowledge of the drinking context. These include: Do situational characteristics of the drinking context such as the circumstance, location, or time of drinking, provide greater explanatory value than relational characteristics such as drinking partners, friends, size of the drinking group? What differences exist in the contextual influence on heavy drinking between men and women when incorporating gender-specific measures of heavy drinking? How is data on the characteristics of the context of alcohol consumption relevant to governing strategies aimed at reducing the harms associated with alcohol?

\section{Chapter Outline}

This introduction outlined the general focus of this thesis, and outlined the specific research questions to be answered. It also highlighted the desire of this researcher to examine the gap in knowledge of contextual factors that has emerged as a result of the over-emphasis placed upon individual factors to account for drinking behaviours. Chapter Two outlines the ontological and epistemological positions from which this researcher approaches an examination of the gap in knowledge on the drinking context, and analyzes the impact of the drinking context on heavy alcohol consumption. This chapter is presented separately from Chapter Four, which details the statistical method used to 
analyze the CAS data. This allows the researcher to explore the processes of individualization of alcohol consumption (Chapter Three), and to demonstrate how knowledge of the drinking context has been shaped historically. This was done to provide the reader with a clearer understanding of how this researcher is approaching the gap in knowledge and interpreting the data from the $2004 \mathrm{CAS}$ - data that may begin to address aspects of this gap. Chapter Two also outlines the theoretical framework used to discuss the findings.

Chapter Three is divided into three separate, yet related, sections. The first section presents alcohol as a constructed social problem, and details information on Canadian drinking patterns. It provides a sociological account of the emergence of heavy drinking as a social problem, in order to explore the constructed nature of knowledge in this area. The second section offers a "micro social construction" (Hacking 1999: 56) of the individualization of knowledge on substance consumption, in order to situate the current gap in knowledge of 'social' influences of drinking practices. ${ }^{5}$ Here, I identify the process of individualization that emerged in research and governing activities around alcohol, and argue that the under-researched nature of the drinking context has created a gap in knowledge of social factors that influence drinking behaviour. The third section details current scholarship on heavy drinking, as well as situational and relational characteristics of the drinking context.

In Chapter Four the statistical method used to analyze data from the 2004 CAS is presented. The chapter details the data collection procedures used for the CAS, the study population, and the predictor and outcome variables under examination in this study. The

\footnotetext{
${ }^{5}$ The analysis is micro in the sense that it presents our knowledge of substance consumption in terms of knowledge of the individual as a historically contingent process, but does not seek to supplant this knowledge with an alternate construction. This point is discussed in greater detail in Chapter Two.
} 
chapter also describes the data analysis techniques used in this study, including information on the use of descriptive and logistic regression analysis.

Chapter Five and Six are substantive chapters that assess the impact of the drinking context on heavy drinking. Chapter Five presents the results from the descriptive and exploratory logistic regression analyses for a sample of Canadian adults. Sociodemographic characteristics of this sample, as well as data on the prevalence of heavy drinking on the last drinking occasion are provided. Descriptive statistics on the drinking context are then presented, followed by analysis of heavy drinking in relation to characteristics of the drinking context. Finally, data models for the full sample, and separated according to characteristic of the drinking context (relational vs. situational), are provided. The findings are then interpreted in relation to the research questions, exploring the impact of the drinking context on the propensity for heavy drinking in the general population. In Chapter Six, results from the descriptive and exploratory logistic regression analyses are presented for sub-samples of Canadian men and women. Similar analyses are conducted separately on males and females, and findings are interpreted in relation to the research questions exploring differences in the impact of the drinking context on the propensity for heavy drinking according to gender.

In Chapter Seven, a discussion of the key findings is presented. The findings are discussed in relation to contemporary theoretical work by Measham and her colleagues regarding the emergence of a 'culture of intoxication', with the drinking context presented as an area where policy can intervene to reduce the harms associated with heavy drinking in Canada. Concluding statements are then provided in the final section, along with the implications for future research on the drinking context. 


\section{CHAPTER TWO}

\section{EPISTEMOLOGICAL AND THEORETICAL FRAMEWORK}

To address the theoretical and practical aims of this thesis, the gap in knowledge of heavy drinking in relation to the drinking context is approached from two separate yet related perspectives: social constructionism and post-positivism. Applying elements from these perspectives to an analysis of the impact of the drinking context in Canada simultaneously accounts for the constructed nature of social knowledge, as well as the utility of quantitative data in examining relationships and filling existing research voids. The constructionist element of this analysis is used to challenge the overuse of individualistic perspectives in understanding drinking behaviour, and to situate the gap in knowledge of the drinking context as a new space for understanding heavy drinking. To examine the impact of drinking context on heavy drinking by Canadians, a post-positivist perspective is applied to the data analysis and interpretation phases of this project. The ontological and epistemological underpinnings of such an approach are presented in this chapter, and as such occur separately from details of the statistical method used to examine data on the drinking context and heavy drinking found within the CAS. In the last part of this chapter, an overview of Beck's notion of individualization is provided, along with some background information on contemporary sociological theory that looks at broader, social influences on practices of substance consumption. Parker (2003) argues that traditional theories of substance consumption fail to account for hazardous substance consumption by a range of social groups in late modernity, and that we should instead consider that the conditions in which individuals are living are becoming more and more 
organized around consumption and risk. This perspective is described in detail, and will be considered in studying the drinking context.

\section{Attending to the gap in research on the drinking context}

In situating the claim that a dearth in knowledge of the drinking context exists, a number of terms must first be clarified. The use of social constructionism as an approach to research involves examining the intersections of knowledge and power as they relate to current understandings of complex social action. Ontologically, this perspective perceives knowledge of the social world as re-produced by individuals in everyday activity, with numerous 'realities' emerging from the commonplace language and constructs used to classify social situations. The 'reality' of drinking situations or occasions can include a range of characteristics, given the diversity with which alcohol is consumed socially. Individuals consume alcohol because it is a complex good that contains desirable intoxicating effects, and can be consumed in different forms with varying qualities, in varying locales, and with a variety of amenity values attached to its consumption (Treno et al. 2000: 538). The social constructionist perspective takes these 'realities' as contested, as they are often solidified within specific institutional frameworks. In this sense, the researcher seeks to critique the 'taken-for-granted' constructions of social knowledge and individual action. For this study, contemporary understandings of alcohol consumption are presented in a constructionist fashion to demonstrate how individualized perspectives on drinking have been taken for granted. As a socially constructed phenomenon, heavy drinking has been explained epidemiologically with reference to characteristics of individuals, as opposed to characteristics of the context. This has 
particularly been the case within nations characterized by advanced liberal rule. ${ }^{6}$ At the same time, gender differences associated with consumption are often not implicitly recognized, leading to a male-centred view of drinking behaviour (Garabedian 2006).

By approaching this problem from a social constructionist perspective, this researcher is able to highlight the "convergence of the contexts of investigation and the contexts of application" (Danzinger 1990, cited in Hacking 1999: 52) around drinking practices, which have contributed to the dearth in research on the impact of the drinking context on heavy alcohol consumption. Points of convergence, for the purposes of this project, consist of displaying parallel practices in the use of epidemiological knowledge for understanding alcohol-related behaviour, and neo-liberal rationalities and technologies of governance that draw upon this base. ${ }^{7}$

Hacking (1999) sees this task as one that uncovers the subjective processes involved in the creation of social knowledge, and points to alternative constructions that may supplement or supplant our current conceptualizations. In applying a social constructionist perspective to an issue such as heavy drinking, I am able to challenge the individualized nature of current knowledge and theory around drinking - processes that are often disassociated with the immediate environment or social surroundings in which this behaviour occurs - noting the ways that such knowledge has been reified

\footnotetext{
${ }^{6}$ Synonymous with advanced liberalism or neo-liberalism, this concept is employed here in reference to a regime of rule that is characteristic of many Western democracies including the United Kingdom (UK), Australia, Canada, and to a certain extent, the United States (US). It is different from classic or early liberalism in that it seeks to utilize and instrumentalize forms of authority other than the traditional 'state' apparatus to govern individuals 'at a distance' (Dean 1999). Additional discussion of the link between neoliberal governance and the individualization of drinking is provided in Chapter Three, section 3.2.

${ }^{7}$ Here, I contend that epidemiologic investigations of substance consumption practices are individualist in nature, and argue that such a practice creates inherent difficulties for sociology in intervening theoretically at this level (see Adrian 2003 and Roman 1991). The application of this knowledge under neo-liberal regimes of government is also presented as an institutional force that has influenced the gap in social contextual knowledge. Such an account makes note of the shifts in conceiving of the modern subject as a rational, self-responsibilizing actor in late modernity, and governing through these characteristics of the self.
} 
institutionally, and now "appears to be inevitable" (Hacking 1999: 12). This assumes an epistemological position that knowledge can come from different sources, and is continuously evolving. Thus, knowledge is subject to continuous revision, with different constructions often coming into conflict (Guba \& Lincoln 1998). It is the "acceptability of created knowledges" that emerges as the issue for social constructionism (Bryman 1988), with more-informed accounts of the social world reflecting increased consensus on an issue, and greater sophistication in social inquiry. While starting from a critique of the individualized nature of knowledge around heavy drinking, this thesis does not seek to supplant current epidemiological frameworks that focus on individual-level variables, but to supplement this knowledge with information on the importance of the drinking context. While approaching the gap in knowledge of the drinking context in this manner is necessary to re-imagine the context where consumption occurs as a consequence of social influences on individual behaviour, exploring data on the drinking context reflects the primary aim of this thesis project. This exploratory research will approach the statistical examination of the impact of the drinking context on heavy drinking from a postpositivist perspective. A post-positivist lens is applied in this project to analyze and interpret data pertaining to the drinking practices of Canadian adults. Post-positivism represents a refutation of the epistemological tenets of positivism, and a critique of the applicability of scientific methods in the analysis of social action. This approach is consistent with post-modern attempts at quantitatively understanding causation in the social world, and incorporates interpretivist concerns with subjectivity and meaning in processes of data collection and analysis (Seale 1999: 22). Social knowledge and social theory are in essence fallible, reflecting a view of 'the social' - as well as the subjects that constitute, and are constituted by, the social world - as dynamic in nature. The acquisition 
of knowledge, in this sense, becomes contextual and based upon pre-existing language, concepts, and histories which are themselves socially constructed. Data on the drinking contexts can therefore be viewed as theory-laden, and comprised of specific biases and values from existing practices/knowledge in the research community. ${ }^{8}$

Previous research on Canadian data has found that certain characteristics of drinking contexts are important explanatory variables in a variety of drinking measures, including heavy drinking (Demers 1997; Kairouz \& Greenfield 2007; Single \& Wortley 1993). Gender differences may also exist in the contexts where heavy drinking occurs. Theses studies provide the foundation for the data analysis portion of this study, which is discussed in greater detail in Chapter Four, with results following in Chapters Five and Six. While post-positivism is critical of our ability to know reality with certainty, it remains useful in analyzing and interpreting cross-sectional data on drinking occasions. This perspective recognizes that the concepts being explored, as well as the statistical methods being applied, have varying levels of interpretation. This includes decisions involving the incorporation of questions related to the drinking context as part of the survey instrument, decisions taken by this researcher in re-coding variables as situational or relational characteristics, as well as the inclusion of heavy drinking as the outcome variable. Employing this perspective also allows for recognition that the knowledge resulting from surveys and their subsequent analysis represents constructions of 'reality', and that the findings are the result of multiple layers of interpretation (Alvesson \& Sköldberg 1999). As such, realist claims on the nature of the observed relationships will

\footnotetext{
${ }^{8}$ Such a position is critical of the ability to provide an 'objective' view of the drinking context, since substance abuse theory shapes - and is shaped by - our pre-existing understandings. This position is not inconsistent with social constructionism, which takes reality as perceptible, but only as multiple, socially and experientially based knowledge (Guba \& Lincoln 1998).
} 
be tempered, since the accounts provided by survey respondents - as well as the subsequent statistical relationships between variables from data - are only a snapshot of drinking practices by Canadians in time and space.

By approaching the gap in knowledge of the drinking context in this manner, I am able to conduct a quantitative exploration of drinking contexts, while being mindful of the processes that have contributed to the gap, and shaped available information. While I am attempting to capture the nature of the relationship between the social context and consumption practices, the knowledge derived from this analysis cannot reflect the 'true' nature of experience for the drinkers surveyed. This approach takes the variables pertaining to the drinking context as a representation of a reality of the drinking occasion for Canadians, which may be at least partially captured by the researcher. While this may clash with the constructionist ontological position of multiple social realities, it is argued here that certain characteristics of the social context - those which reflect more general elements of where, when, and with whom one was drinking - can be generalized across a range of individuals' occasions of drinking ${ }^{9}$. Canadian experiences with alcohol consumption are interpreted in a standardized way, allowing this researcher to statistically examine whether a relationship exists between variables of the drinking context and heavy alcohol intake. The drinking context - as well as individuals' experience within this social context - is thus presented as discernable through a set of survey questions

\footnotetext{
${ }^{9}$ This analysis recognizes many of the limitations inherent in both constructionism and post-positivism. Nevertheless, employing a post-positivist epistemological lens enables examination of specific relationships between certain variables of study, in order to speak of 'social reality' in a definitive sense. In secondary analysis, the 'reality' of individuals' experiences with alcohol is captured in a standardized way, meaning that such drinking practices can be generalized across the population. This involves making realist claims on the nature of significant relationships between variables, even though they may not necessarily reflect the reality of the experience for the individual drinker. Alvesson \& Sköldberg note the utility of such an approach when dealing with quantitative data, and argue that it is pragmatic to assume the existence of some social reality that exists beyond the researchers pre-conceived notions, and that something meaningful can be said about this reality (1999: 1$)$.
} 
about physical and social characteristics of the occasion. In doing so, further theorizing on the nature of the observed relationships, and their significance in light of broader changes around the individualization of consumption and risk, becomes possible.

\section{Theorizing heavy drinking in late modernity}

Sociological perspectives have often been concerned with broader societal trends, as well as more micro-relations associated with individuals' living and working environments. Theories of social action struggle when dealing with behaviour that may be considered 'normal' by a large segment of the population, particularly when it involves environments that are fluid in nature, or consisting of changing physical and social characteristics. This is apparent when considering heavy drinking, and the role of the drinking context in facilitating or preventing this behaviour. In light of some of the challenges in theorizing non-deviant behaviour in adults, such as heavy drinking, Parker and his colleagues have argued convincingly that a sociological framework with 'risk' as its focus may account for macro changes in substance consumption in Western societies (Measham 1996; Measham 2004a; Measham 2004b; Measham 2006; Measham et al. 2001; Measham \& Brain 2005; Parker et al. 1998; Parker et al. 2002; Parker 2003).

Others have commented that this 'postmodern' approach is more valuable to developing a gendered notion of substance consumption than more classical theoretical perspectives (Etorre 2004).

The risk society perspective put forth by Ulrich Beck is presented as one such framework, in that modern risks are increasingly individualized, and no longer considered to be social in nature. Beck's concept of individualization represents a shift, not only in the decline from previous social support systems in addressing everyday problems, but 
also in the distribution of these problems across the social sphere. Notions of social class, which were characteristic of social distinction in the first stage of modernity, are no longer relevant; they are replaced instead by stratification according to individuals' risk. Beck and Beck-Gernsheim (2002) argue that these stratifications are socially constructed within certain institutional risk environments, in order to categorize subjects according to their 'social risk position'. Linkages to traditional social collectivities, such as family, the community, or even subcultures, are also weakened in favour of strengthened ties to secondary agencies and institutions. ${ }^{10}$ It is here that individuals can choose the appropriate means to address the risks they face. Previous social relationships and commitments - even to the nation state - are altered in favour of connections as a consumer in society, and to the labour market, both of which entail their own institutionally generated risks (Beck 1992). This process of individualization forces people to live in more individualized ways, and to self-manage emerging risks which are global in nature.

In conceptualizing changes in drinking practices in late modernity, one must also consider broader changes around gratification, identity formation, and social integration which are endemic of a consumer society (Measham \& Brain 2005). Levi-Martin has stated that, "cultures of consumption seem always to precede the actual mass distribution of consumer goods, and not vice versa" (1999: 439). It is demonstrated in the first section of Chapter Three that the consumption of alcohol is of great cultural importance to most Western societies including Canada, and that instances of drinking to the point of intoxication have occurred with regularity amongst the adult population over the past two

\footnotetext{
${ }^{10}$ For Beck, these late modern connections, which contain processes of standardization, market relations, and consumerist ethic, reflect the shift towards individualization as the dominant social structure of the second phase of modernity.
} 
centuries. At the same time, the frequency, quantity, and various patterns of substance consumption - including alcohol - often vary by sex of the individual, and remain gendered today (Measham 2002).

The emergence of a consumer society, in response to market-based rationalities inherent within advanced liberal rule, seemed to have an impact on the drinking practices of Westerners, particularly young adults. In the late 1980s and into the 1990 s, the traditional consumer base for alcohol, particularly in public places - that being of mixedage, single-sex drinking groups - were replaced with both mixed- and single-sex, agespecific drinking groups. This led to a diversification of the alcohol market (Measham \& Brain 2005). For the alcohol industry, the new focus was on appealing to the search by modern consumers for identity construction and gratification within institutionalized environments of leisure. According to Measham (2004b), this primarily involved the recommodification of alcohol to appeal to a new generation of psychoactive substance consumers, who were now capable of discerning amongst a wide range of licit and illicit substances associated with leisure and 'time out' pursuits. ${ }^{11}$ For women in late modern times, this not only involved a shifting between use of licit and illicit substances, but also an association between consumption and pleasure, often linked to dancing, social interaction, auto-eroticism and flirtation found in modern club scenes (Measham 2002). Consistent with the process of individualization, the resultant harms from episodes of

\footnotetext{
${ }^{11}$ The recommodification of alcoholic beverages occurred in response to the emergence of the 'rave culture' and dance scene in the early $1990 \mathrm{~s}$, which reconfigured youthful consumption of psychoactive substances towards illicit substances such as ecstasy. A wide array of new alcohol products were marketed to diverse groups of consumers, with different products advertised as 'lifestyle markers' for the population involved. A concomitant alteration of the space for drinking - from the local pub to a wider (and more plentiful) array of cafes and lounges - occurred, along with a liberalization of much of the licensed leisure venues in the UK.
} 
heavy drinking were also changed, and were re-imagined in terms of individual responsibility for both the personal and social consequences of consumption.

\section{Individualization and alcohol-related problems}

Governmental strategies on issues of public health have also come to reflect a risk-based paradigm, moving away from notions of 'public good' and more towards individual well-being as symbolic of the health of the population. In the second phase of modernity, expertise is fragmented, and decisions on techniques to intervene in these 'social' problems remain 'at-a-distance'. These techniques no longer appeal through social mechanisms: “...the ideals of progress, individualism, or the good of the nation no longer seem to be acceptable, valid justifications for government interference in private moral choices" (Sulkunen et al. 2004: 428). One framework that has emerged within neoliberal rationalities is the focus on lifestyle approaches to issues of public health. Most lifestyle choices are now considered private matters, reflecting the need for individuals to take control of any factors that impinge upon healthy development of the self (Sulkunen et al. 2004). With market freedom and consumer choice becoming entrenched values within advanced liberal societies, health-related problems became re-imagined in terms of 'lifestyle'. They take on alternative meanings and considerations for the individual in late modernity. Individual lifestyles become increasingly organized around incalculable insecurity. Lifestyles incorporate a number of facets such as individual personality, family and social environments, and labour and leisure practices, as well as the risks that such practices entail.

With adults, this emphasis on managing the risks on one's lifestyle seem to clash with late modernity's reliance on market-based solutions to individual problems. Each 
and every risk environment is conceived of in market-based terms, with individuals considered capable of negotiating the risks inherent within practices of consumption. The individual is presented with a set of 'precarious freedoms' (Beck \& Beck-Gernsheim 2002), by which they may choose the proper course in which to address the risks they face. As social life becomes increasingly fragmented and individualized, individuals must rely on the market for contemporary markers of identity and leisure, which are organized more and more around consumption (Measham $\&$ Brain 2005). Indeed, as part of the process of individualization, neo-liberal subjects - re-imagined as rational-choice consumers - are free to engage in actions for pleasure and stress relief, as a means for dealing with an uncertain world. Within contemporary consumer society, pleasure becomes commodified, and associated with hedonistic spaces and behaviours.

This theoretical perspective contends that increased use of illicit substances, as well as more hazardous practices around drinking, are linked to broader trends in the shift from first to second modernity. In second modernity, the consumption of leisure - tied to personal lifestyles and individual identity formation - is paramount, and linked with pleasurable experiences for the individual. Leisure is also contingent upon specific spaces and groups, and increasingly, the consumption of substances such as alcohol. Parker $e t$ al. (1998) sought to examine how the role of recreational substance consumption fits in individuals' notions of 'time out' as a mechanism to manage the stresses and strains of growing up in an uncertain and 'risky' post-modern world. For alcohol in particular, the diversification of the alcohol market - including the expansion of new products, venues, and lifestyle-appropriate opportunities for drinking - created a plethora of contexts from which heavy drinking can emerge. Emphasis is placed on one's ability to offset late modern stress with leisure practices, and to deal with the various risks that may emerge in 
the environments where leisure takes place. Practices that incorporate 'calculated hedonism', such as those involving 'particular altered or heightened states of physical pleasure though pharmacological and behavioural means" have become prioritized, and are realized within specific boundaries of time, space, interpersonal interaction and intensity (Measham 2004b: 319). ${ }^{12}$ These actions nevertheless contain risks themselves, and are found to be part of institutionally constructed environments of risk, and realized within the contexts of alcohol consumption. Parker (2003) and Measham (2004b; 2006) contend that a process of normalization has occurred with regards to substance consumption by youth, and to a lesser extent, young adults, whereby previously unacceptable activities become included in many features of everyday lifestyles. ${ }^{13}$ For alcohol, Measham (2006) notes that practices of self-regulation are apparent amongst younger heavy drinkers, even if their practices of alcohol consumption are hazardous. Heavy drinking still occurred during weekend leisure times, and restraint was exhibited on weekdays. In this sense, their cost-benefit assessment reflects the values of consumption and self-control, which are emblematic of the contemporary phase of modernity. In relation to the ability of young adults to apparently manage instances of 'drunkenness' with normal, everyday commitments, she notes:

\footnotetext{
${ }^{12}$ Here, Measham is linking alcohol consumption practices that are hedonistic or leisurely to specific occasions where such practices are tolerated or even encouraged. She makes note that her study pointed to weekend leisure (time), clubs/bars and private parties (space) and friends who were supportive of respondents' level of intoxication (company) as factors that comprise the setting where such behaviours take place. They may also involve a range of intensities of drinking, or a combination of alcohol and other drug consumption.

${ }^{13}$ It "highlights the way illicit drug consumption, particularly by conventional 'ordinary' young people, has grown in importance within lifestyles which are themselves evolving in response to structural and global changes in post-modern societies" (Parker 2005: 206). Individuals in post-modern societies are required to take a reflexive approach to their substance consumption, and according to Parker et al. (1998), are beginning to exhibit cost-benefit practices into their decision-making around consumption. By adopting hazardous substance consumption behaviours as part of their leisure practices, individuals are actively engaging the culture of risk, and responding with the same values of risk consciousness and selfresponsibility in structured risk contexts. It is through markets of leisure and 'pleasure' that young people in particular can form their personal and social identities (Parker et al. 1998).
} 
These drinking practices reflect "a more recent post-industrial ethos of hedonistic consumption super-imposed on earlier rural/pagan traditions of finite periods of carnival within the agricultural calendar" (Measham 2006: 259).

This theoretical perspective is applied in this thesis to understand the contexts in which heavy alcohol consumption occurs. Since alcohol intake is not an innate property of individuals, and is positioned as contingent upon the context in which drinking occurs, it would be expected that individuals exhibit moderation in certain contexts, and determined states of intoxication in others. Individuals would also be expected to manage the risks inherent within certain drinking contexts. As Room notes, in advanced liberal societies, "[c]ontrolling consumption and any harms related to it becomes a responsibility solely of the individual consumer, rather than also a societal responsibility" (1997: S10). Measham argues, however, that neo-liberal rationalities of self-control, moderation and restraint seem to be "culturally at odds with a contemporary emphasis on economic deregulation and excessive consumption" (2006: 258$)$. This is particularly the case with alcohol use in late modernity, which has seen shifts in the manner in which risk is both perceived and consumed during drinking occasions. Since drinking behaviour is likely to vary according to the context within which it occurs, the desired states of intoxication must be negotiated by the individual drinker.

\section{Summary}

This chapter detailed the perspectives that are used in the analysis and interpretation of contexts of heavy drinking. A social constructionist approach is used to provide a "micro social construction" (Hacking 1999: 56) of the individualization of 
epidemiological and governmental responses to heavy drinking. ${ }^{14}$ Contemporary understandings of alcohol consumption practices are also presented in a constructionist fashion to demonstrate how individualized perspectives have been taken for granted. This allows this researcher to critique epidemiological knowledge in the field, and position the drinking context as an area that has been theoretically and empirically under-explored. To address this gap, I will be employing a post-positivist perspective to the analysis of situational and relational characteristics of the drinking context. Details on the benefits of this approach in providing a critical examination of heavy drinking by the general Canadian adult population were discussed. This is important, as this population has not been the focus of a great deal of research. This approach allows the researcher to explore the emergence of heavy drinking as a social problem, to situate the gap in social knowledge related to alcohol intake, and attempt to attend to this gap through secondary analysis of the 2004 CAS. A theoretical perspective for understanding the impact of the drinking context was also described, with individualization positioned as a late modern social order within which individual and social risks are situated. This perspective allows for an examination of whether gender plays a significant role in differentiating drinking occasions for Canadian adults. Indeed, while little research exists on the impact of drinking contexts, even less is available on women's experiences in various drinking contexts. It is important to examine whether alcohol consumers contextualize their

\footnotetext{
${ }^{14}$ The analysis is micro in the sense that it presents our knowledge of substance consumption in terms of knowledge of the individual as a historically contingent process, but does not seek to supplant this knowledge with an alternate construction. This aspect of the analysis is also micro in that the historical determinants referenced in this study are the product of some linked studies on trends in alcohol research and epidemiology. Current knowledge around heavy drinking, nor the forms of analysis that position the individual as the unit of analysis, is not taken as incorrect or in need of radical transformation. However, this researcher submits that the current gap in knowledge about contextual factors that influence hazardous drinking practices is the result of socially constructed political and empirical trends, "which could well have been different" (Hacking 1999: 7).
} 
experiences in gendered ways (Ettore 2004), and which relational and situational characteristics are associated with these occasions. With research pointing to increasing rates of heavy drinking amongst the general population - particularly among women -, establishing moderation with regards to alcohol may require interventions that target the contexts in which consumption occurs (Adlaf et al. 2005; Bloomfield et al. 2006; Room 1997). Research on heavy drinking as well as the drinking context is presented in the next chapter, as is an analysis of the gap in knowledge of social factors that influence drinking behaviour. 


\section{CHAPTER THREE}

\section{REVIEW OF THE LITERATURE}

The following chapter is divided into three sections. The first section provides a detailed discussion of the problematization of heavy drinking, including: 1) the construction of drunkenness as a social problem; 2) the emergence of heavy drinking occasions in areas of research and government; and 3) patterns of heavy alcohol consumption by Canadian men and women. This is done to provide context to the use of 'heavy drinking' as the outcome measure for this study. The second section explores the emergence of a gap in knowledge of the drinking context, in both theory and in practice, by outlining: 1) trends towards methodological determinism in epidemiological examinations of alcohol and other drug use; and 2) shifts in governing through the individual, as opposed to 'the social'. This section is designed to identify the process of individualization that took place in research and governing activities around alcohol, and to situate the gap in knowledge of the drinking context as a social factor that has gone under-researched. The drinking context is presented as a space for new insight into understanding heavy drinking behaviour. The third section highlights existing research on: 1) heavy drinking; and 2) the context of alcohol consumption, including situational and relational characteristics influencing heavy alcohol consumption.

\subsection{HEAVY DRINKING AS A SOCIAL PROBLEM}

The consumption of alcohol is positioned here as an issue that has required intervention from various research disciplines and governmental regimes. Over time, governments have deployed different rationales and techniques to address the social 
problem of 'drunkenness' or intoxication with some regularity. A discussion of the problematization of alcohol consumption during the first modernity is presented first, followed by an examination of contemporary alcohol consumption by Canadians.

\section{The social construction of 'drunkenness'}

Concern over the copious consumption of alcohol has been present for centuries, and has been manifest in a wide array of public and professional responses to the perceived social problem. A great deal of unease with alcohol - and with the patrons who frequent public drinking establishments - rested with its impact on the labour productivity of the working classes in Europe, and with a general preoccupation with drunkenness and disorder in the streets. In the $18^{\text {th }}$ and $19^{\text {th }}$ centuries, both drinkers themselves and the practice of drinking at certain times and locales were characterized in terms of 'beastliness', 'idleness' and 'vice', or the primary moral weaknesses of the poorer classes (O'Malley \& Valverde 2004: 27). While this 'panic' may have emerged as a result of bourgeois concern over the consumption practices of the lower classes, of primary importance in this history is the distinction between the victual nature of ale, and the classification of heavy spirit consumption as 'vice'. The former was originally viewed as an essential commodity for strong and laborious individuals, while the latter was viewed as a source of waste that contributed only to violence and lost productivity ( $\mathrm{O}^{\prime}$ Malley \& Valverde 2004). Thus, ale could be consumed for pleasure by the masses, contributing to a virile sociality amongst the citizens of a state, whereas consumption of gin, for instance, was viewed as a contributor to a host of social ills. It would seem that concern over the perils of a 'culture of intoxication' - apart from the distinctions along race and class lines 
in the past - are not unique to late modernity, and also emphasize the hazards associated with drinking to intoxication.

In the twilight of the $19^{\text {th }}$ century, however, temperance advocates began to broaden their focus on alcohol in general, challenging discourses that proposed regular alcohol ingestion as a normal way of life. The temperance movement was successful in pushing for legislative steps to be taken against the consumption of alcohol, and compelling a federal referendum on prohibition in Canada in 1898 (Smart \& Ogborne 1996). This movement had the backing of others concerned with domestic working-class reform at the time, including officials in academics and government (O'Malley \& Valverde 2004). Two organizations heavily involved in the Canadian temperance movement were the Dominion Alliance for the Total Suppression of the Liquore Traffic and the Women's Christian Temperance Union (Smart \& Ogborne 1996). As opposed to singling out the detrimental effects of a certain alcoholic substance, a certain class of drinkers, or a particular type of drinking pattern, these groups were instrumental in the early parts of the $20^{\text {th }}$ century in situating the consumption of alcohol as a crisis in need of regulation. The overarching panic that emerged contained familiar rhetoric pertaining to the deleterious nature of alcohol on labour productivity under capitalist systems of production, as well as a renewed focus on the social disorder, crime, and family violence created by those afflicted with this 'disease of the will' (Room 1996; Valverde 1998).

It is clear that the temperance mentality was fostered in the concern over the pharmacological effects of the drug on individuals, who were rendered incapable of properly exercising their duties as citizens. This perceived effect on individuals supported imposing strict prohibition of the sale and use of substances containing ethanol. Measures included the targeting of public, licensed drinking establishments - which were viewed as 
a source of the overall misery of alcohol use - and the pervasiveness of drunkenness in Canadian society (Smart \& Ogborne 1996). In this instance, there was a convergence between the research community and authorities on a "crisis over the consumption of alcohol" (Goode 1990: 14). The possession or consumption of alcoholic beverages in public venues was prohibited by the provinces starting with Prince Edward Island in 1900. The importance of the drinking context as a source of drunkenness was implicitly recognized, since provisions were maintained for consumption within the home (Smart \& Ogborne 1996).

The failure of prohibition in Canada during the 1920s marked the dissipation of moral panic around the general consumption of alcohol, in favour of increased scrutiny on those who consumed too much. In general, new public discourses emerged, involving the "civilized enjoyment of alcoholic beverages" through mechanisms of regulation, both in terms of liquor and beer licensing and regulations aimed at individuals (O'Malley \& Valverde 2004). In the 1930s ale and spirit companies worked to alter the perceptions of drinking through innovative marketing, seeking now to validate alcohol's moderate use by the wider population (O'Malley \& Valverde 2004: 26).

\section{The cultural component of alcohol consumption in Canada}

The consumption of alcohol is an important part of the everyday lives of many Canadians. More recently, it would seem to benefit from "enormous popularity and special social and cultural significance in Canada", among a variety of social groups (Reducing Alcohol-Related Harm in Canada 2007: 1). Drinking is associated to a great degree with leisure and pleasure in Canadian society; alcohol can be found during times of relaxation or socialization, and is particularly common during holiday celebrations and 
events such as births and weddings. As such, it is certainly "no ordinary commodity" (Reducing Alcohol-Related Harm in Canada 2007: 3). Nevertheless, as a commodity in high demand, alcoholic products are an important part of the Canadian economy. In 2004, approximately $\$ 16$ billion was generated through the sale of alcoholic beverages (Reducing Alcohol-Related Harm in Canada 2007).

Consuming alcohol is not without risk, and in Canada, there have been substantial costs associated with drinking in society. Room has noted that "throughout Canadian history, drinkers and those around them have struggled with preventing or controlling [the social and health] costs" associated with alcohol consumption (Smart \& Ogborne 1996: ii). As noted previously, the cost to Canadian society from alcohol was $\$ 14.6$ billion in 2002. This includes a total cost of $\$ 7.1$ billion in lost productivity due to illness and premature death, $\$ 3.3$ billion in direct health care, and $\$ 3.1$ billion in law enforcement (Rehm et al. 2006: 9). The costs associated with alcohol consumption seemed to have increased significantly within the past decade. In 1992, Single et al. (1996) estimated the costs of alcohol abuse at $\$ 7.5$ billion. While estimation methods have improved since then, making the results difficult to compare, the observed differences in social costs in the last 10 years was enough for Rehm and colleagues to conclude that "there is no doubt that costs have risen" (2006: 9). This is significant, and certainly supports the contention that Canadians have a 'problem' with alcohol consumption.

Not surprisingly, other Westernized nations have also experienced problems associated with alcohol consumption. In a review of international cross-sectional research comparing the drinking patterns of different countries, Bloomfield et al. (2003) determined that substantial differences exist in the drinking practices of North Americans and Europeans, and significant variation occurs amongst European states. In studies 
comparing various European nations, it was found that individuals from the United Kingdom (UK) had the highest annual frequency of heavy drinking among six European Union nations, whereas Danish men and women had the highest frequency of heavy drinking within the past year among the Scandinavian countries (Leifman 2002; Mäkelä et al. 2001, cited in Bloomfield et al. 2003). These findings are consistent with research in the UK (Measham 2006; Parker et al. 1998), which shows patterns of increased quantities of alcohol consumption per drinking occasion by Britons. Indeed, it would seem that Measham and her colleagues' contention of an emergent 'culture of intoxication', at least with respect to alcohol, is supported by the data.

Midanik and Room note that "alcohol consumption statistics tell us something about patterns of drinking at a societal or cultural level"' (1992: [2]). They elaborate on trends of leisure and pleasure related to alcohol, as well as the potential for consequences. In 2004, Canada ranked $43^{\text {rd }}$ of 185 countries in total adult per-capita alcohol consumption, recording absolute alcohol consumption at 7.9 litres per person aged 15 years and older. This represents an increase in overall levels of consumption, from 7.2 litres in 1997 (Reducing Alcohol-Related Harm in Canada 2007). Increasing alcohol consumption in the population can have a direct impact on the amount of harm reported by individuals. While high per capita rates of alcohol consumption can create issues in the long-term health of the population, other patterns of consumption, such as 'heavy' or 'binge' drinking, present an entirely different set of challenges. Room has argued elsewhere that the dominant pattern of alcohol consumption in Western societies is "sporadic intoxication, often interspersed for some drinkers with periods of abstinence" (1996: [3]). Suuorinen (1973, cited in Heath 2000) and Cunningham and Mäkelä (2003) have noted that in Nordic countries, the dominant pattern of drinking is infrequent 
'drunkenness' among the adult population (particularly young adults), with individuals consuming large quantities of alcohol on single occasions, usually spaced out weeks apart. Wilsnack and colleagues (2000) found that Canadian men comprised the highest percentage of drinkers who had engaged in heavy episodic drinking in the past year, compared with ten other countries. This finding, and other research noting similar patterns of drinking in the general Canadian population, is important, since "...heavy, single-occasion and episodic binge drinking by the much larger population of nondependent drinkers produces far greater and wider-reaching impacts on the health, safety and well-being of individuals and communities" (Reducing Alcohol-Related Harm in Canada 2007: 4).

The findings presented here are also consistent with data released from the 2004 CAS, including the prevalence of occasions of consumption where heavy drinking occurred. The proportion of drinkers who are both frequent- and infrequent-heavy drinkers $^{15}$ was significantly higher in $2004(12.5 \%$ ) than in $1994(8.7 \%$ ) (Adlaf et al. 2005: 89). Across the provinces, residents from Newfoundland and Labrador who reported consuming five or more drinks per drinking day were the highest $(30.8 \%)$, with residents of Quebec reporting the lowest proportion consuming this amount $(11.3 \%)$. Heavy drinking is also associated with being single, and was least likely to occur for Canadians with a university degree. ${ }^{16}$ Differences exist, however, in the rates of heavy

\footnotetext{
${ }^{15}$ Frequent-heavy drinkers are defined as those individuals who drank more than once a week, and consumed five drinks or more when they drank. Infrequent-heavy drinkers are defined as those individuals who drank less than once a week, but consumed five drinks or more when they drank (Adlaf et al. 2005). ${ }^{16}$ Data from the detailed report of the 2004 Canadian Addiction Survey (CAS) comparing findings from the 1994 Canada's Alcohol and Other Drugs Survey (CADS) did not separate heavy drinking for gender (i.e., $5+$ drinks for men, $4+$ drinks for women). The same was true in discussions of heavy drinking by major demographic factors.
} 
drinking for men and women. Almost a quarter of men (23.2\%), compared to only $8.8 \%$ of women, reported five or more drinks as their usual level of consumption.

The drinking situation for women in Canada is markedly different than for men. Results from the 2001 Canadian Community Health Survey noted that approximately $11 \%$ of female past-year alcohol consumers reported occasions of heavy drinking. Similarly, nearly twice as many Aboriginal women as non-Aboriginal women reported this outcome (CIHI 2003). Other factors, such as poverty, violence, parenting and pregnancy, can have significant effects on the manner in which alcohol is consumed (Poole \& Dell 2005). Indeed, such factors ultimately affect the contexts in which alcohol is consumed, as well as the consequences of more hazardous consumption practices, such as heavy drinking.

Heavy drinking per occasion increases the risk of individuals experiencing problems related to their drinking (Adlaf et al. 2005: 23). Just over a tenth (10.5\%) of males reported problems from their own alcohol consumption within the past year, compared with $7.1 \%$ of women. A total of $32.7 \%$ of all Canadians reported some form of harm in the last 12 months from another person's drinking (Adlaf et al. 2005: 36-37). These findings have led Kellner to conclude that, while most occasions of alcohol consumption have "positive or neutral consequences and do not entail pathology of any kind" (Adlaf et al. 2005: 39), the high incidence of alcohol-related harms is "enough to conclude that alcohol problems are part of Canadian life" (Adlaf et al. 2005: 35). ${ }^{17}$

\footnotetext{
${ }^{17}$ Data from the detailed report of the 2004 Canadian Addiction Survey (CAS) did not separate reported harms according to the gender of the respondent. (i.e., 5+ drinks for men, 4+ drinks for women) when discussing heavy drinking by major demographic factors.
} 


\section{Summary}

Alcohol consumption continues to play an important role in the leisure pursuits of Canadians. Drinking is incorporated in a number of functions, including formal events and celebrations, as well as during informal gatherings and socialization. However, concern remains over the social costs associated with drinking occasions, more specifically, drinking to the point of intoxication. This section outlined some of the factors that contributed to early concerns over intoxication, as well as patterns of drunkenness associated with licensed venues. During the first phase of modernity, a number of factors associated with drinking were targeted, including particular beverage types, public drinking venues, as well as the individual drinker. Following the repeal of prohibition, the consumption of alcohol was re-imagined; its promotion was associated more with moderate use and civilized enjoyment, shifting the concern back to individuals who consumed 'too much'. Such concern is retained in the contemporary phase of modernity, with a focus on occasions of heavy drinking, and the harms that are associated with this behaviour. The notion that Canadians are actively engaged in practices of 'determined drunkenness' was presented, including reference to research on prevalence rates for heavy drinking by Canadians. With the focus of a great deal of sociological and epidemiological research - not to mention governmental interventions - set on the individual, earlier convergence on the drinking context as a social space linked to problematic drinking seems to have been abandoned. The next chapter furthers this discussion, positioning the drinking context as an under-researched area, and integral to developing a culture of moderation around drinking in Canadian society. 


\subsection{GAPS IN CONTEXTUAL KNOWLEDGE OF ALCOHOL CONSUMPTION}

There exists a substantial body of literature on factors that can contribute to harmful or hazardous drinking practices. Variations in drinker types and drinking patterns are said to result from risk factors that exist as part of the individual's perceptions, peer and parental associations, and socio-demographic or economic characteristics. The prolonged focus on uncovering individual-level correlates of alcohol and other drug consumption has meant that research on social factors that contribute to negative outcomes has been relegated to a small number of epidemiological studies that focus extensively on the individual as the unit of analysis. This shift towards individualized understanding of substance consumption is a result of a parallel shift away from socialstructural influences, both in addictions research and governmental rationales focussed on substance consumption. While epidemiology has found a unifying source in studying the individual, sociology has experienced a fragmenting of knowledge, which reflects an ongoing debate on the role of agency and structure in accounting for human action. As methodological individualism becomes further entrenched in research practices and governing strategies around substance consumption, there is a great need to explore factors affecting the consumption of alcohol and other drugs apart from the individual.

\section{The primacy of epidemiological analysis}

Traditional sociological analysis is rooted in structural accounts of human action, stressing the importance of macro-social processes such as general strain, class conflict, or the concentration of political and economic power in influencing individual behaviour. In many cases, sociological explanations are concerned with relating substance use to broader institutional, cultural or normative factors, which are difficult to implement 
specifically into interventions or public policies (Adrian 2003). Theorists like Becker sought to bridge this divide between structural accounts in sociology and emerging individualistic perspectives in competing disciplines by focusing on "psychological phenomena that were influenced by the social context in which behaviour occurred" (Adrian 2003: 1408).

More recent sociological examinations into the drug field have sought to explain the 'pathological' nature of substance consumption, and in doing so, have emphasized the role of interpersonal relations, social networks, or social learning processes in accounting for 'abnormal' substance consumption practices. Many times, they highlight problems which are systemic in nature, and difficult to implement in practical terms. As such, the addictions field has come to be dominated by pharmacological or medical models of substance consumption that provide stability in understandings of the effects of general substance use. Broader theories of individual action tend to come from psychological perspectives, whereas the contributions of sociology in modern research are often limited to discussions on the use of the methods of sociological investigation or population surveys (Adrian 2003: 1385).

Sociological knowledge on alcohol consumption, particularly consumption that borders on deviant or abnormal, appears fragmented, and may be poorly reflected in contemporary understandings of 'problem' consumption. The emergence of the medical model - in conjunction with the move towards individualized perspectives on human behaviour - has entrenched the use of epidemiological methods in collecting and analyzing data on substance consumption. Any factors that existed outside of the individual, their actions, or their interactions with others were removed from analytic models that looked at negative outcomes related to substance consumption. Duncan et al. 
characterize the epidemiological approach as "reductionist and individualistic", and criticise it for ensuring "that individual behaviour [is] entirely divorced from the social and situational context in which it occurred" (1996: 817). Where sociological theory has attempted to elaborate on macro-societal factors affecting individuals' and their alcohol consumption, epidemiology's emphasis has been on studying the individual as the primary unit of analysis.

The transition from classic epidemiology, which housed a concern with uncovering socioeconomic and other 'social' factors related to disease causation, to epidemiology in its modern form, occurred in the late 1970s. Modern epidemiology is rarely concerned with relating problem outcomes to socioeconomic factors, and has taken even less of a role in attempting to decipher new means of attaining knowledge that is inherently social in nature. In some cases, modern epidemiology will simplistically adjust findings for social class (Pearce 1996) based on the idea that social factors cannot be viewed as 'real' causes of problem behaviour. The decline in infectious disease in the mid- $20^{\text {th }}$ century brought about a shift towards noncommunicable disease as the primary focus of epidemiological work. ${ }^{18}$ As a result, the new focus became the targeting of 'lifestyle' or 'behavioural' characteristics, which have emerged within the last few decades as the primary targets of governmental responses (Pearce 1996). Epidemiologic research on alcohol issues has been geared towards primary prevention initiatives through the search for 'risk' (chaotic home environment, ineffective parenting, anti-social behaviour) and 'protective' factors (strong bonds with family, school and religious

\footnotetext{
${ }^{18}$ This critique is directed at issues of substance use and abuse generally, and alcohol consumption specifically. While epidemiological analysis has been a primary focus for the study of communicable diseases in developing nations (e.g., tuberculosis, malaria, measles) it is also paramount in the study of HIV/AIDS and Hepatitis. In discourses of drug abuse, the focus on lifestyle has been integral in understanding and addressing issues of HIV/AIDS transmission, particularly in intravenous drug users.
} 
organizations, parental involvement) in individuals, which are linked to the presence or absence of substance consumption (O’Malley 2004: 156).

\section{Methodological individualism and 'drug' discourses}

Since epidemiological methods have dominated studies related to public health issues, and alcohol and other drugs are often framed in medical terms, the study of drinking practices has been analyzed from an individualized lens. In essence, the shift has been away from studying macro-societal factors, in favour of analysis at the level of the individual. Diez-Roux argues that the 'individualization of risk' can be counterproductive when examining public health issues. She notes, "lifestyles' and 'behaviours' are regarded as matters of free individual choice and disassociated from the social contexts that shape and constrain them" (Diez-Roux 1998: 216).

An underlying effect of this shift has been the methodological individualization of the 'drug problem' itself, whereby the 'risks' associated with substance consumption are seen as a result of characteristics of individuals, as opposed to factors which are social or structural in nature (Diez-Roux 1998). For substance consumption, the emphasis on methodological individualism has meant that important aspects of the social environment - variables related to the setting of use, or to particular occasions of consumption for all types of drugs - have received less attention than individual-level factors. What has emerged is a range of epidemiological studies on substance consumption that describe a myriad of risk and protective factors, but do little to help explain hazardous substance consumption practices, particularly among adults.

The configuration of social knowledge in the realm of individual characteristics represents a key debate within the sociology of knowledge. Epidemiological research - 
often relying solely on cross-sectional survey data, and examining social relationships through statistical inference - presents itself as ontologically individualistic, or reductionist to the point of attributing social knowledge to knowledge of the individual (Agassi 2004). Understandings of human behaviour become further entrenched in the study of individual action, which ultimately "views behaviour as being fixed and unchanging and its focus is entirely upon the individual" (Duncan et al. 1996: 817). The individualistic underpinnings of the epidemiologic method function to situate the risk of disease - or in the addictions field, the occurrence of a problem outcome such as heavy drinking - as a matter of free choice and individual responsibility (Duncan et al. 1996), addressed only through a shift in 'lifestyle' choices by the individual. When applied to alcohol consumption, which resides within the realm of public health, these elements of 'risk' are seen as autonomous, and disconnected from broader socio-structural or situational factors.

Significant critique has been levied at methodological individualism primarily as the result of the limited view of human behaviour and social action it implies, whereby "facts about society and social phenomena are to be explained solely in terms of facts about individuals" (Diez-Roux 1998). Many of the limitations that characterize epidemiology reflect its exclusive focus on individualistic conceptions of social action, and have been noted in the research literature. Such issues regarding the ontological underpinnings of the new paradigm in epidemiology, as well as the continued presence of methodological individualism in social science research, are longstanding issues in sociology, and speak to the divide in theorizing along macro and micro lines. However, van Bouwel notes that such issues can be approached when considering social theories 
that attempt to discuss individual action and societal change, or when specific research tasks require their acknowledgement (2003: 533).

In the latter sense, the incorporation of this discussion situates the gap in knowledge of contextual factors that influence substance consumption, including alcohol. According to Pearce (1996), the shift in epidemiologic methodology has occurred in combination with other influences in the broader research community - shifts away from social-structural accounts, for instance - as well as changes in the manner in which public health problems are imagined and governed. As governments at various levels are involved in recognizing and addressing health-related concerns among the population, these problems are likely to be subject to particular rationalities of rule.

\section{The individualized nature of modern regimes of government}

Emphasis on the individual is essential in modern 'problematizations of rule' (Rose 1993). It can contain a number of pitfalls and possibilities related to social problems such as heavy drinking. Liberalism, as a political rationality, perceived the individual as a rational, interest-motivated economic ego, who was connected to society as a result of communitarian bonds, friendships and associations. The maintenance of 'civil society' reflected the economic interest of the liberal state, and required that the individual be governed through the generation of specific norms of individual and collective life that shape the way in which subjects may pursue their economic activities. For liberalism then, the experiences of individuals - their freedoms and actions - were constituted in a social form (Rose 1993: 285), with individuals expected to exhibit the qualities of self-responsibility and self-control, and to be active in their own government. 
While beginning with a similar conception of the subject of government as a rational-choice actor, advanced (neo-)liberalism wishes to construct certain kinds of subjects - as opposed to constructing normative elements through society at-large - so that market rationality is a condition of their active freedom. Instead of governing the ills of society through the engagement of individuals in the normative rationalities and strategies of government, neo-liberalism seeks to shape the wills of autonomous subjects to be active in their own government. Rose notes,

"Whilst welfare sought to govern through society, advanced liberalism asks whether it is possible to govern without governing society, that is to say, to govern through the regulated and accountable choices of autonomous agents - citizens, consumers, parents, employees, managers, investors" (1993: 298, emphasis original)

The new norms of neo-liberalism are those of competition and consumer demand, reflecting a particular mode of calculation required of subjects to engage with expanded markets in a variety of life areas. The governing of neo-liberal problems - as well as the individuals comprising the problem - is made thinkable through this rationality of market-principles: actions of individuals become reduced to a drive for self-fulfilment and self-enterprise, actualized by the freedom to pursue their individual needs through the expanded market system. Problems occur within this schema when this pursuit conflicts with the other requirements of neo-liberal subjects, such as 'responsibility', 'rationality', 'reasonableness', and ‘independence' (O’Malley \& Valverde 2004: 27). For neoliberalism, such problems are governed by situating them directly with individuals. The strategies invoked to achieve such a form of rule include the devolution of governing activities and responsibilities to local governments and communities (Mugford 1998), and the empowerment of citizens to act in a rational and disciplined manner towards their social and economic interests. In doing so, neo-liberal regimes seek to govern through the 
freedoms of individuals in society, appealing to the logic of the market in everyday practices and activities.

\section{Emphasizing the reduction of alcohol-related harms in Canada}

As alcohol is a legal commodity in advanced liberal democracies such as Canada, the implication that alcohol consumption will occur for the individual is accepted, and is less contentious than similar arguments made for illicit drug consumption. Nevertheless, the individual is still held responsible for their actions surrounding consumption, and the consequences that may occur (Single 1996). Single (1994) has argued that an emphasis on "reducing heavy-drinking occasions among all drinkers" is an important goal, and remains consistent with research on reducing alcohol-related harms. A recent report by the National Alcohol Strategy Working Group also identified heavy drinking occasions as an important area for intervention:

"...heavy, single-occasion and episodic binge drinking by the much larger population of non-dependent drinkers produces far greater and widerreaching impacts on the health, safety and well-being of individuals and communities" (Reducing Alcohol-Related Harm in Canada 2007: 4)

In fact, many of the principles of a proposed National Alcohol Strategy for Canada reflect the philosophical underpinnings of the harm reduction perspective: that substance consumption - either licit or illicit - be considered a public health issue, that the human rights of individuals are respected, and that drinking behaviour is "shaped by social and other factors" (Reducing Alcohol-Related Harm in Canada 2007: 5). Indeed, in order to effectively reduce the harm associated with alcohol, the strategy argues that a full range of health promotion, prevention, treatment, enforcement and harm reduction approaches require implementation. It is only through a multifaceted approach to the problem that a culture of moderation can be achieved. While the previously mentioned techniques of 
harm reduction are consistent with neo-liberalism's re-imagining of the individual as 'consumer', attempts to engender self-control face opposition in practice from groups more concerned with the moral management of the self (Sulkunen et al. 2004). As Single notes:

Practices of harm reduction reflect the "often acrimonious debate concerning controlled drinking versus abstinence as a treatment goal for people with alcohol problems parallels the conflict between harm reduction and zero-tolerance approaches in drug-use prevention" (1996: 240[4])

While the context of alcohol consumption may be an appropriate area to target drinking-related harms, little research exists on the extent of drinking by Canadian men and women in different contexts.

\section{Summary}

The shifts in research on substance consumption and the strategies for governing the consequences of such consumption revolve around the individual. We see a privileging of knowledge based on pharmacological or biomedical perspectives, and the diminishing importance of sociological theories of human action. These perspectives are individualized, re-framing research into the occurrence of 'disease' or 'sickness' as a matter of free choice and individual responsibility (Duncan et al. 1996). At the same time, problems related to alcohol have been re-defined in terms of 'lifestyle', with individuals becoming responsibilized around choices to consume alcohol. This reflects a shift towards neo-liberal rationales and techniques of governing, which function to substantiate the search for individualistic connections to problematic behaviour. While practices in epidemiologic research and neo-liberal government have individualized alcohol-related behaviours, stimulating a gap in knowledge of contextual factors that impact on consumption, new research and government approaches are emerging that challenge these 
'taken for granted' understandings. As opposed to narrowly focusing on the drinking behaviours of individuals, support for a 'culture of moderation' can benefit from attention to "interventions that seek to modify the environment where drinking takes place" and reduce the potential for intoxication and its associated harms (Reducing Alcohol-Related Harm in Canada 2007: 17).

\subsection{THE DRINKING CONTEXT AND HEAVY DRINKING}

The previous section examined complementary trends in research and governance that have produced a gap in our knowledge of contextual factors that impact upon drinking behaviour. The 'new public health' model approaches the issue of alcohol consumption as a problem to be researched and governed through the individual. The focus of prevention and intervention efforts is on 'lifestyles', or more properly, those lifestyles that come into conflict with the renewed focus on personal health and wellbeing. Individuals can still consume alcohol as they see fit; however, they must be made aware of its negative impacts on health, and take steps to avoid such harms. Room has argued that attributing 'harm' to individuals' drinking can be viewed as "challenging their social competence and questioning their moral worthiness" (1996: 384). Thus, interventions have not sought to impose restrictions on individuals' drinking, instead appealing to individuals as citizens to manage their consumption in a healthy way. One such way has been to study and develop guidelines on acceptable levels of per-week or per occasion drinking (Bondy et al. 1999). Studies have employed a number of measures to capture 'heavy' drinking, with a similarly diverse set of definitions accompanying the term. At the same time, research on heavy alcohol consumption often take characteristics 
of the individual as the focus of study, with an implicit assumption that "drinking occasions are fairly invariant within individuals" (Demers et al. 2002: 416).

The purpose of this section is to review the literature related to heavy drinking particularly among adults - and the social contexts in which alcohol consumption generally, and heavy drinking specifically, take place. Attention has been paid to capturing existing research from studies on heavy drinking and the drinking context in Canada. The section is divided into two parts: 1) 'heavy' drinking, its measures, correlates, and associated consequences; and 2) knowledge pertaining to relational and situational contexts of heavy drinking. Where possible, distinctions are made on the association between contextual drinking factors and rates of heavy drinking by males and females.

\section{Hazardous drinking practices and occasions of alcohol consumption}

Research on drinking patterns in North America has often focused on instances of intoxication in study participants. This may be partly attributable to differences in cultural norms around drinking, where the consumption of small amounts of alcohol is viewed as a routine daily activity in many European nations, while in North America, alcohol consumption is often relegated to weekends. It has been argued that such patterns are associated with leisure pursuits in North American populations, and are more likely to result in occasions of heavy episodic drinking (Wechsler 1994b). Analyses that examine heavy drinking occasions, particularly in relation to instances of alcohol-related harm amongst the population, have been the primary focus of North American epidemiological research on alcohol (Cunningham \& Mäkelä 2000). 
Much of the literature on alcohol consumption has emphasized that certain patterns of drinking can be hazardous to individual drinkers and/or those around them. Hazardous drinking is primarily concerned with instances of episodic intoxication in individuals. According to the Center for Substance Abuse Treatment protocol (CSAT 1999), "[h]azardous drinking refers to a level of alcohol consumption or pattern of drinking that, should it persist, is likely to result in harm to the drinker" (Fromme \& Orrick 2004: 336). These practices contain the potential for harm, but may not necessarily result in adverse consequences to the individual or others. This differs from harmful drinking, which refers to alcohol consumption that has already resulted in adverse mental or physical effects. Measures of harmful drinking have recently included social consequences as part of the measurement tool (Fromme \& Orrick 2004). Hazardous drinking practices can be targeted through primary prevention strategies aimed at educating drinkers about the risks associated with different patterns of consumption. These risks contain both quantity and frequency dimensions, but can also contain risks associated with the pharmacological or social elements of drinking. For example, Rogers and Greenfield (1999) found that the consumption of beer accounts for a disproportionate amount of hazardous drinking in the US in both younger and older populations. The practice of "buying rounds" has also been shown to increase levels of weekly and per occasion consumption (Hilton 1987).

Understanding 'heavy' drinking, then, requires knowledge of various factors of 'risk' that may occur from consuming alcohol in certain ways. In measuring heavy alcohol consumption, researchers seek to determine the level at which the consumption of alcohol becomes problematic for individuals, or those drinking with them. Studies have looked at the maximum amount of alcohol consumed by individuals, the rate at which 
they drink weekly (either through estimated averages on the part of the respondent, or through 7-day drinking indexes), and the maximum daily intake reported by respondents during drinking days.

In their influential studies of the drinking practices of university students, Wechsler and colleagues examined the amount of alcohol consumed by individuals on single days as an indication of heavy drinking - measured as the number of standard drinks consumed on the drinking occasion. They identified 'heavy drinking days' as the best predictor of alcohol-related problems for this population, and proposed that this measure be carried over to the examination of drinking by other populations (Wechsler $e t$ al. 1999). Heavy drinking days often reflect instances where individuals have consumed enough alcohol to warrant even low-levels of impairment. In their review of crosssectional studies of alcohol consumption, Auth \& Warheit (1983) noted that in all the earlier studies, five or more drinks per sitting was the minimum amount of alcohol considered to be reflective of heavy drinking occasions. More recent scholarship has defined heavy drinking occasions as anywhere between four and 13 drinks, reflecting a desire to measure episodes of intoxication in respondents (Delk \& Meilman 1996; Knupfer 1984; Li et al. 1994; Moore et al. 1994; Nezlek et al. 1994; O'Callaghan et al. 1990; Saunders et al 1993; Schulenburg et al. 1996; Wechsler \& Isaac 1992; Wechsler et al. 1994a; Wechsler et al. 1995). Authors have also used various labels to describe 'heavy drinking occasions', including episodic intoxication, binge drinking (Cooney et al. 1994; Epstein et al. 1995; Johnston et al. 1996) or high-intensity drinking (Babor et al. 1994). Two key reviews have determined that the consumption of five drinks in a single drinking occasion represents a valid cut-off point for measuring heavy drinking days (Epstein et al. 
1995; Room 1990). This measure has also has been used in studies of adult drinking (Britton 2004; Demers 1997; Demers et al. 2002; Midanik et al. 1996; Room et al. 1995).

Defining an exact and consistent measure for a 'heavy drinking day' has been difficult, given that the effects of alcohol can manifest themselves differently in different people. Matano et al. (2003: 1300), citing a review of pharmacological research on alcohol intake, note,

"Individual variations in responsiveness to alcohol are partly attributable to variations in blood volume as a function of weight, age, gender, metabolic differences, and psychological factors such as expectancies about alcohol".

It would seem that women metabolize alcohol differently than men, resulting in higher blood-alcohol levels (BAL) with comparable quantities of alcohol (Johnson 1991; Lieber 1993), meaning similar measures across gender categories may not adequately capture actual patterns of heavy drinking in a population. More recently, researchers have determined that a gender specific measure of heavy drinking, which uses the consumption of five or more drinks by men and four or more drinks by women on a single occasion, is required when exploring differences between men and women (Demers 1997; Dowdall \& Wechsler 2002; Wechsler et al. 1995). For most researchers relying on cross-sectional data pertaining to drinking in specific populations, the use of the amount of drinking per occasion has been a particularly valid measure.

Bondy et al. (1999), noting earlier research on measures of alcohol consumption and alcohol-related harm (Knupfer 1984; Room 1990), argue that the incorporation of 'five or more drinks' as a measure of heavy drinking in a number of studies was an arbitrary decision, based more on tradition rather than empirical study. They contend that recent studies have pointed to important differences in the quantity of drinking and related harms for men and women. Sanchez-Craig (1995) found that men who drink no 
more than four drinks, and women who drink no more than three drinks, per drinking occasion were significantly less likely to report problems associated with their drinking, challenging the previous logic that levels of alcohol intake were equal across genders. Recent studies of student drinking patterns have also employed separate cut-off points for men and women, preferring to use the incidence of five or more drinks for men, and four or more drinks for women, as indicators of heavy drinking occasions (Demers 1997; Wechsler et al. 1999). This distinction between the quantities of alcohol required to initiate impairment for men and women has been recognized in recent attempts to capture data on heavy episodic drinking in adults. In the $2004 \mathrm{CAS}$, for example, the cut-off for 'heavy drinking' on a particular drinking occasion was listed as five or more drinks for males on a single occasion, and four or more drinks for females on a single occasion (Adlaf et al. 2005: 23). This distinction is consistent with other research on alcohol consumption patterns by students and adults in Canada (Demers 1997; Demers et al. 2002), and is employed within this thesis project as part of the analysis on the impact of the drinking context on heavy drinking by gender of the respondent.

\section{Heavy drinking and alcohol-related consequences}

The study of hazardous drinking practices - of which heavy drinking occasions represents an important temporal measure of quantity and frequency of heavy alcohol intake - is concerned with identifying problems related to alcohol consumption. Heavy drinking occasions have been associated with acute consequences for the drinker, such as physical and verbal altercations, unintentional injuries, and unwanted or unprotected sex. For younger adults, alcohol-related harms such as poor academic or work performance have been associated with the consumption of five or more drinks on an occasion. In a 
recent study of drinking patterns and related problems among UK adults, Duffy found that the maximum daily intake of alcohol was strongly associated with the experience of a work-related problem, as well as being positively associated with the likelihood of experiencing other problems related to this drinking pattern (2003: 202). Heavy drinking occasions have been linked to increased incidence of domestic and marital problems, as well as economic difficulties (Bondy 1996).

Room, Bondy and Ferris (1995) demonstrated that the consumption of five or more drinks on a single occasion was at least as important as overall consumption to predict alcohol-related problems. The likelihood of negative consequences may also be greater for females than for males (Kranzler et al. 1990; Bondy 1996; Rehm et al. 1996), and among younger populations (Duffy 2003). Research on heavy drinking occasions has pointed out that the consequences of heavy drinking may not only affect the individual drinker, but can also affect non-drinkers indirectly (Wechsler et al. 2001; Kairouz \& Adlaf 2003). Given that this body of research has consistently identified that "there is something about heavier drinking occasions that is predictive of adverse consequences" (Bondy 1996: 1669), the examination of heavy drinking by Canadian adults in relation to contextual variations in their consumption would inform the aetiology of alcohol consumption in this country.

\section{The Social Context of Alcohol Consumption}

The notion of a 'context' associated with the consumption of alcohol has been present in research on drinking for some time; however, its precise definition is complex. Psychological studies of substance use have used 'context' to refer to characteristics of the individual that can be aggregated at the population-level, forming distinct sub-groups 
for analysis. Thus, theories regarding individuals' personality, perceptions or behaviour around drug 'risks' are considered in relation to aspects of their social position, including age, gender, or socio-economic status. Sociological studies, in turn, have used the term to emphasize the importance of setting or group influences on the comportment of individuals in substance-using situations. While an individual's beliefs and expectations surrounding substance use are a factor, they nevertheless are shaped by the socio-cultural elements of the individual's surrounding.

The latter stance is consistent with Harford's contention that "The antecedents of alcohol consumption are to be found in the interactions between the individual and his environment... the consumption of alcoholic beverages is situationally specific, rather than a trans-situational property of specific individuals" (1979: 289). While a range of studies have examined alcohol consumption in different settings (see Single 1985 for pre1984 review), this diverse body of literature generally suggests that the likelihood of individuals consuming heavy amounts of alcohol on any given occasion depends on various factors pertaining to the environment where consumption occurs. Jessor (1982) has suggested various ways in which the context of alcohol consumption can be explored, including research on the location of the drinking occasion, descriptive information regarding characteristics of the event or participants, or social controls and norms present in various contexts. Such diversity in the characterizations of the setting or environment where drinking takes place inhibits the development of a consensus on precisely what constitutes the 'drinking context'. As Stockwell et al. note, "The concept of a 'drinking setting' is beguilingly simple until examined more closely" (1993: 1520).

The drinking context has been shown to have a significant effect in predicting hazardous drinking patterns by Canadians. In their recent cross-national comparison of 
national survey data from the mid-1990s, Kairouz and Greenfield (2007) found that the impact of drinking contexts was more profound in accounting for drinking behaviour in Canada than in the U.S. The drinking context was conceptualized early on in broad terms, as "where one drinks, with whom one is drinking, and when one drinks" (Calahan et al. 1969, cited in Clapp et al. 2000: 141). Others have suggested it be characterized according to more specific dimensions, including the circumstances, time, location, and the relational aspects - those involving other persons, whether they be partners, peers, or relatives - of the setting of use (Demers 1997). Demers (1997), in a study of Montreal adults, found that heavy drinking is contingent upon a number of characteristics of the drinking context, including characteristics that are situational in nature (i.e., the circumstance, location, or time of drinking), as well as those that are relational in nature (i.e., drinking partners, friends, size of the drinking group). The distinction between situational and relational characteristics is employed in this thesis, and is explored below.

\section{The Influence of relational characteristics of the drinking context}

The influence of one's peers on his or hers substance consumption behaviour is well recognized in the literature (Dewit et al. 1995). At the same time, social norms are also influential in conditioning social action, including behaviours that involve interaction with other individuals. Normative behaviour is often influenced by the context in which such behaviour is found; in relation to alcohol consumption, the context helps define normal versus deviant drinking, as well as the appropriateness of drinking in certain circumstances and with certain groups. Drinking behaviour is therefore reinforced through social interaction, which operates to normatively regulate alcohol intake (Kairouz \& Greenfield 2007). The social interaction inherent in occasions of alcohol consumption 
contain a range of relational dimensions (Kairouz \& Greenfield 2007), including the relationship between the individual and their drinking partners, the size and gender composition of the drinking group, and the presence of one's romantic partner.

Relationship with Drinking Partners. The relationship with drinking companions has been shown to be an important factor in drinking occasions. Kilty (1980) noted in his study of meanings associated with drinking contexts that the presence of other individuals was important for drinking occasions that were at least potentially positive for respondents. Drinking while alone was considered to be 'negative' by those surveyed. People are more likely to drink with friends rather than family members (Orcutt 1991), although drinking with family remains frequent among women and older adults. Heavy drinking among adolescents has been shown to be more when drinking with friends, and least likely when drinking with parents (Mayer et al. 1998). In the U.S., individuals tend to drink less in social gatherings when neighbours, family or church members are present (Calahan et al. 1969). The transition towards friends as the preferred drinking companion was noted by Hilton (1987), in his analysis of drinking behaviour data from 1964 to 1984 . Drinking with friends is associated with being in a good mood during drinking occasions (Kilty 1980). This relationship has been show to depend on the gender of the individual. Harford determined that men are more likely to drink heavily with friends in a variety of settings, whereas heavier drinking among women, particularly in bars, occurred only when friends were present (1983: 832).

Elements of the Drinking Group. The size of the drinking group has been explored using cross-sectional survey techniques, as well as through observational studies of drinking locations. Early studies point to a relationship between the amount of alcohol consumption and the number of drinking companions present during drinking occasions 
(Cutler \& Storm 1975; Sommer 1965). Single (1985) noted that individuals drinking in larger groups tended to consume more alcohol, particularly in public settings. Others have confirmed that the size of the drinking group can have a positive effect on total alcohol consumption, and operate to informally regulate the rate of consumption (Clark 1981a, Clark 1981b; Reid 1978, cited in Hennessy \& Saltz 1993). They argue that larger groups may influence alcohol consumption through the dynamic nature of their composition, and presence of different types of drinkers, including heavy ones (Hennessy \& Saltz 1993). Research from observational studies have confirmed this relationship, indicating a diffusion process in the relational properties of drinking occasions, where increased consumption by one individual impacts positively on alcohol intake by other members of the group (Single 1985). More recently, Mayer et al. (1998) established that high school drinkers who consumed five or more drinks reported being in groups of 11 or more when drinking significantly more often than other young heavy drinkers consuming in groups of two or less.

Harford (1983) warns against overstating the relationship between group size and heavy alcohol intake. His findings suggest the relationship between the number of drinking companions and consumption level was not significant, and that an independent effect of group size may not exist apart from the larger group's tendency to stay longer at establishments. In addition, Skog (1981) cautions that there may not be an independent relationship for group size outside of the drinking pattern of the individual. He found that heavy drinkers tend to favour large drinking groups and may therefore be overrepresented in such groups. Research on a Finnish population of drinkers also determined that large-group drinking was associated with an increase in the number of negative experiences related to the occasion of drinking (Mustonen \& Mäkelä 1999). While the 
relationship between group size and level of alcohol consumption has been shown amongst young adults in university (Demers et al. 2002), reflecting the results of earlier Canadian studies (Storm \& Cutler 1981; Ratcliffe et al. 1980), there remains a need for additional research on the general adult population.

The gender composition of the drinking group is also relevant, and for men at least, results indicate a moderating effect on alcohol consumption when women are present in the group (Demers 1997). The effect of women on the consumption of alcohol by men is generally negative and consistent across various public drinking locations (Hennessy \& Saltz 1993). Thus, alcohol consumption does appear to be affected, not only by the gender mix of the drinking group, but also based upon the gender of the individual. Demers found that for men under 25 years of age, drinking with a same-gender reference partner doubled the likelihood of having five or more drinks on that occasion (1997: 462). This may be a result of modeling drinking behaviour between drinking companions. Collins \& Marlatt found that “an individual's consumption of alcohol will vary to match that of a drinking partner" (1981: 235). In the Netherlands, men drank more quickly when in all-male groups, whereas women consumed alcohol faster when the gender composition of the group shifted between men and women drinking partners (Van der Goor et al. 1990). Such results may reflect properties of the setting, or the size of the drinking group. It may also reflect differences in usual consumption between men and women, with women working to match the drinking levels of men in their drinking group. Conversely, psychosocial properties of the drinking context may play a role in this relationship. O'Hare, in research on young adults and personal-intimate encounters, found those with a high expectancy of enhanced sexual pleasure from alcohol use were significantly more likely to drink excessively during occasions with the opposite sex 
(O’Hare 1998: 47-48). Nevertheless, results from Quigley and Collins' recent metaanalytic review of the model-participant drinking dyad indicate "the links between gender and the drinking partner to volume of alcohol consumed is unclear" (1999: 96).

Presence of spouse/romantic partner. Similarly, the presence of an individual's spouse or romantic partner may also act as a moderating factor, negatively impacting upon levels of alcohol consumption. Research by Hennessy and Saltz (1993) confirmed the existence of a moderating effect on consumption in mixed couples, as they tend to exhibit lower levels of consumption, as well as time spent at a drinking location. It has previously been shown that an individual's consumption can vary to match that of the primary drinking partner (Collins and Marlatt 1981), which may account for some of the difference in consumption level when a romantic partner is present.

\section{The Influence of situational characteristics of the drinking context}

The study of social contexts related to alcohol consumption has invariably captured information on certain physical characteristics of the setting where drinking takes place. Stockwell et al. (1993) commented that most studies have looked at certain common elements, such as whether consumption occurred in private versus public settings, the hour of operation or types of beverages served, as well as the nature of the licensed outlet where different patterns - and clientele - are to be found. As noted previously, situational aspects of the drinking context can have substantial impacts on the drinking rates of consumers (Single 1985), even greater than other individual and social factors. Knibbe et al. (1993) found situational variables to be stronger predictors of alcohol consumption than beliefs and norms around alcohol. As such, situational characteristics have been the focus of some study, including drinking situations such as 
parties or other social gatherings, various drinking locations, temporal characteristics associated with drinking, as well as more ordinary contexts, such as with meals.

Drinking circumstances. The purpose of the drinking occasion can also contribute to the amount of alcohol consumed (Clapp et al. 2000). Occasions such as 'parties' incorporate "contextual dimensions found to be associated with higher drinking amounts" (Harford et al. 1980), and have been examined with some frequency. Treno et al. (2000) found drinking at parties to be most common among those under 21 , as well as individuals who are single and unemployed. Studies have also found drinking circumstances to be influenced by race. Research by Herd \& Grube (1993) found that white women tend to drink more at parties than black women; however, Treno et al. (2000) concluded that whites are less likely than blacks and Hispanics to drink at parties and special events. Drinking at parties can increase the likelihood of reporting alcoholrelated problems, particularly among younger drinkers (Clapp et al. 2000). Research on Canadians adults, however, has also found levels of alcohol consumption to be consistently high at parties (3.17 drinks on average per drinking occasion) (Single \& Wortley 1993). Other circumstances for drinking, such as during festivals or celebrations, are also occasions for "drinking more than usual” (Clark 1985: 49).

Additional circumstances, such as outdoor activities, private/small social gatherings, or more general life circumstances, have not been explored in great depth. Research from Finland suggests that levels of alcohol consumption are lower in everydaylife contexts than in contexts which are 'non-ordinary' (Simpura 1987), and that consumption in private and intimate situations had the least number of negative experiences (Mustonen \& Mäkelä 1999). Nevertheless, this remains an area for further exploration in Canada, as circumstances such as "evenings at home, watching TV and 
having visitors together" account for approximately 30 percent of all drinks taken during an average month, and occur with greater frequency than at 'parties' or drinking occasions in a bar setting(Clark 1985).

Temporal characteristics. Arfken (1988) determined that American drinking patterns follow a specific rhythm, with most drinking taking place in the evening hours and on weekends. Research on adolescent drinking showed that heavier consumption of alcohol was more likely to occur in the evening and on weekends (Mayer et al. 1998). These findings are consistent with data reviewed by Single, although he noted that exact data on temporal variations rarely show up in most research, and are needed to provide a full understanding of drinking occasions for Canadians (1985: 19).

The drinking location. A situational variable that has been covered in some depth in the alcohol literature is the location where drinking takes place. Public drinking places, such as bars, taverns, cocktail lounges and clubs are recognized as important locales in the study of drinking settings, as they are sites where relatively heavy drinking can occur, and are populated by a large proportion of current drinkers (Clark 1985). In Canada, these venues represent spaces of leisure where social interaction - as well as a higher tolerance for intoxication - is commonplace. A national survey of Canadians indicated that $72.3 \%$ of adults 'always' drank at these locations, with $96.9 \%$ reporting drinking at least some of the time (Single \& Wortley 1993). More recent analysis of national survey data from Canada indicated a decline in alcohol intake across age groups for all drinking locations (Kairouz \& Greenfield 2007). Socio-demographic factors such as sex, age, and marital status have been linked to public drinking in bars and taverns (Clark 1966). Previous research has pointed to increased levels of education - and to a certain degree, income as associated with bar and restaurant patronage, noting that these individuals have 
"greater opportunity to consume in higher cost venues (e.g. bars and restaurants) and appear to avail themselves of that opportunity" (Treno et al. 2000: 545). Others have similarly found that drinking at bars and taverns was most prevalent among young, unmarried males, but that most were of low-income status (Single \& Wortley 1993). Among women, those with lower education and more liberal drinking norms, and those who were either wealthy or unemployed reported more frequent drinking in public areas than other women (Herd \& Grube 1993).

As noted previously, researchers have found that heavier drinking levels were associated with consumption in public settings such as bars or taverns (Caetano \& Herd 1988; Harford 1979; Herd \& Grube 1993). Canadian adults were more likely to report frequently drinking five or more drinks, as opposed to never drinking more than five drinks on an occasion, when their consumption takes place at a bar or tavern (Single \& Wortley 1993). Jones-Webb et al. (1997) recently established that the relationship between drinking in public settings and level of alcohol consumed was as apparent for 18 to 20 year olds as it was among older adults. For adults, these public drinking environments are strongly associated with harmful drinking, independent of individual demographic characteristics (Casswell et al. 1993; Curran et al. 1996; Harford \& Mills 1978). Licensed drinking venues often promote heavy drinking through interpersonal dynamics, such as treating individuals to drinks and sharing rounds. They are also spaces where more tolerant attitudes towards intoxication and heavier drinking patterns can be found (Kairouz \& Greenfield 2007).

Hazardous drinking practices are also more likely in venues that are crowded and/or frequented by large groups of people (Stockwell et al. 1993). These researchers also found that licensed premises which permit the continued service of obviously 
intoxicated persons are particularly risky. Survey data from Australia and New Zealand showed that the number of self-reported alcohol-related problems varied as a function of both level of alcohol consumed and drinking environment (i.e., bars, taverns, clubs) (Treno et al. 2000). Situational characteristics of the public drinking location, such as duration of drinking, décor, noise level, cleanliness, atmosphere and other aspects of the physical environment, were associated with aggressiveness among clientele (Single 1985), and led to incidents of violence. Canadian observational data also found that situational variables such as layout and atmosphere, combined with the rate of alcohol consumption, accounted for a substantial percentage of the aggression found in bars and taverns (Graham et al. 1980; Graham \& Homel 1997).

Restaurants are another public drinking location where a high proportion of alcohol is consumed. Harford (1983) has argued that these locales are a space where heavier drinking occurs, but cautions that the amount of 'time spent' in any drinking environment can impact upon the level of consumption. Pertanen (1975) also reported higher amounts of alcohol consumption in restaurants, although this relationship was not apparent among the rural Finnish population. Restaurants tend to be frequented by younger adults (age 21 to 30 years of age), with this group consuming similar levels of alcohol as in other public settings (Jones-Webb et al. 1997; Treno et al. 2000). Treno et al. (2000) also found that drinking at restaurants was highest among older, more highly educated females with higher incomes, as well as white women (more so than black or Hispanic). Additional demographic factors may influence this relationship. Herd \& Grube (1993) determined that the mean number of alcohol beverages consumed by white women in restaurants was over three times more than the average for black women. Men still drink more on average than women at this particular location, although the presence of 
women in the drinking group, or as a reference partner, can sometimes act as a moderating influence (Hennessy \& Saltz 1993). Cross-national research by Kairouz and Greenfield (2007) established important similarities between drinking in the U.S. and Canada, with the lowest levels of consumption being reported by both nations in restaurants (Kairouz \& Greenfield 2007).

Finally, drinking in residential settings has been shown to be a common location for alcohol consumption. This is certainly the case among adolescents, who more often reported heavy drinking on their last drinking occasion when at another person's home or an open field as the setting. Heavy drinkers were also less likely than other drinkers to report drinking at home (Mayer et al. 1998). More generally, some have found that twothirds of adults reporting the consumption of alcohol at home as the most frequent drinking environment (Knupfer et al.1963, cited in Clark 1985). Data in the US has shown a shift over time in the acceptance of drinking - and to a stronger degree, 'drunkenness' - at home with friends. For men and women, acceptance of "feeling the effects" of alcohol when drinking at home with friends grew in the $1980 \mathrm{~s}$, and by the 1990 s, was the "most accepted situation for drinking enough to feel the effects" (Greenfield \& Room 1996: 6). Such findings are consistent with recent scholarship on drinking locations, which showed that "most drinking occurred within relatively domestic contexts" (Treno et al. 2000: 541). 'Home' usage is more prevalent with older adults, women, and those with middle-incomes, as well as among members of Black and Hispanic communities (Treno et al. 2000). Research by Single \& Wortley (1993) established that drinking in private settings, such as quiet evenings at home, having friends or relatives visit, attending a residential social gathering, or spending time at someone else's home, accounted for the highest proportion of alcohol consumption by 
Canadian adults. Additional Canadian data show that individuals reported higher consumption when drinking 'at home with visitors', more so than during 'a quiet evening at home' (Kairouz \& Greenfield 2007).

Gender differences related to this contextual characteristic are also apparent. Herd and Grube (1993) argue that women who drank more often at home reported heavy alcohol intake - eight or more drinks on the reported drinking occasion - more frequently than other women. They also reported that younger women, poorer women, as well as those with more liberal norms, were more likely to drink frequently at home. Kairouz \& Greenfield (2007) found that, in comparison to drinking by US males, men's higher level of alcohol intake was most pronounced when drinking in a social private location ('at home with visitors'), in comparison to women. The largest difference in Canada, however, was observed for drinking levels by men \& women when consuming in bars, followed by private locations and then restaurants, where consumption levels were more similar for men and women (Kairouz \& Greenfield 2007).

Additional situational factors. Other characteristics of the social context of drinking that appear to moderate levels of alcohol consumption include the provision of food during occasions of drinking. While not reported on a great deal in the literature, where the provision of food is noted, it has been associated with more moderate consumption (Demers 1997; Simpura 1987). Single and Wortley noted that drinking with meals in restaurants accounted for $12.7 \%$ of total alcohol consumption by Canadian adults (1994: 592). It is also conceivable that food is provided during situations where drinking occurs at home, or at the residence of another drinking companion. Additional research into its moderating effects, if any, is required. 
In addition, a contextual factor that has received scholarly attention more recently is the consumption of alcohol by individuals in more than one location. This may affect younger adults generally, or university students in particular, who consume alcohol in private settings prior to 'going out' to a bar or club as part of their cost-benefit analysis. This has been shown to be the case in weekend leisure pursuits around alcohol consumption for Britons (Parker et al. 1998). Thus, drinking in multiple locations as part of a single drinking occasion may have implications on driving after drinking, for example, as it relates to moving from one location to another.

\section{Chapter Summary}

The previous section provided a traditional review of existing literature on the effects various characteristics of the drinking context have on drinking by individuals. Measures of heavy drinking were presented, along with research linking the consumption of five or more drinks on a single occasion with a host of acute alcohol-related problems. Recently, other researchers have noted the importance of employing gender-specific measures of heavy drinking when examining differences between men and women. At the same time, a diverse body of literature suggests that the likelihood of individuals consuming heavy amounts of alcohol on any given occasion depends on various factors pertaining to the environment where consumption occurs. These characteristics of the drinking context, however, have not been the focus of a great deal of sociological research, resulting in a gap in our knowledge of social influences on drinking behaviour. This is problematic, as Single and Wortley (1993) note: "Given the import of situational variables to drinking rates, it is essential to the epidemiology of alcohol use to have a 
complete description of the extent of drinking in different situations [as this]... will contribute to our understanding of the etiology of alcohol-related problems" (590).

The relative paucity of data and research pertaining to the impact of the drinking context on alcohol intake is a result of the emphasis placed upon the individual within discourses on substance consumption. Along with a review of the literature, this chapter offered a socio-historical account of the gap in knowledge of the social context where alcohol consumption takes place. It situated this gap as a function of complementary practices in research and governing of hazardous drinking, which have effectually individualized our current understandings of consumption practices related to psychoactive substances. It was argued that a 'micro-social construction' of heavy alcohol consumption occurred (Hacking 1999: 56), whereby facts about heavy drinking reflected the aggregate, individualized knowledge of populations, which was required for neoliberal governing regimes, and was produced through epidemiological study and analysis. This analysis provided an understanding of the intersections of knowledge and power, and pointed out some possibilities for addressing concerns with alcohol consumption and associated harm through governmental techniques consistent with neo-liberalism's focus on self-enterprise and self-responsibility. Approaching a study of the drinking context and heavy drinking from a social constructionist perspective allowed this researcher to explore many of the challenges inherent in researching and governing social influences on individual behaviour. The following chapters contain the substantive portion of this thesis, which involves an analysis of the impact of relational and situational characteristics of the drinking context on heavy drinking by Canadian adults. 


\section{CHAPTER FOUR}

\section{DATA VARIABLES AND STATISTICAL METHOD}

Chapters Two and Three in this study aimed to provide a thorough discussion of the current gap in knowledge on the social context of alcohol consumption, and its importance in understanding contemporary trends in heavy drinking. Chapter Two identified the epistemological position taken in this study to examine the intersections in academia and government that were conducive to a dearth in research on 'social' influences of drinking behaviour. The previous chapter approached this gap from a social constructionist perspective, arguing that the previously mentioned gap is the result of processes of individualization inherent in research and governing techniques aimed at understanding drinking behaviour. It provided a rationale and framework from which to approach this gap in knowledge, highlighting the need for critical exploration into data on drinking contexts. This chapter seeks to approach this gap by employing a post-positivist framework to the analysis of heavy drinking in various contexts by Canadian adults. It describes the data and analytic methods used to explore the impact of characteristics of the drinking context on the propensity for heavy alcohol consumption, which represents the primary practical task of this research project. The present study used cross-sectional data from the 2004 Canadian Addiction Survey (CAS) to (a) describe the prevalence of heavy drinking in a sample of Canadian adults, as reported during their last drinking occasion, (b) determine what characteristics of the drinking context were associated with the risks of heavy drinking, (c) establish whether situational or relational characteristics are more influential in predicting heavy drinking, and (d) to assess the stability of these findings when controlling for gender. 
Data

This research project employed secondary survey analysis on drinking occasion data using the 2004 Canadian Addiction Survey (CAS). This survey represents the first national survey of Canadian's alcohol and other drug use in over a decade, and builds on the findings of the 1994 Canada's Alcohol and other Drugs Survey (CADS), and the 1989 National Alcohol and other Drugs Survey (NADS). The CAS provides information on the prevalence, incidence and frequency of alcohol use in the Canadian population, as well as capturing detailed information on the social context of alcohol consumption in a sample of respondents. ${ }^{19}$ While previous national surveys have also captured information on the context of alcohol consumption, the CAS took assessment of the context of substance use as a key objective, using various questions and measures from previous survey attempts. $^{20}$

The CAS was conducted between December 2003 and April 2004. The survey was based on a two-stage random sample of households and respondents, which was stratified by 21 regional units. A random sample of households was contacted by telephone (using random digit dialling methods) to secure interviews with respondents. One respondent per household, 15 years of age or older was interviewed about their attitudes and behaviours concerning the use of alcohol and other drugs. A total of 13,909

\footnotetext{
${ }^{19}$ The CAS provides cross-sectional data, which allows for the examination of relationships between select variables attributable to individuals and a range of outcome measures at a single point in time. Conducting secondary analysis on the CAS enables this researcher to conduct a correlational analysis of variables relating to measures of heavy drinking with an array of variables related to the drinking context.

${ }^{20}$ Questions pertaining to the social context of drinking have been a part of all three national surveys on alcohol and drug use in Canada. However, this researcher is only aware of two studies which used national data on drinking contexts to research patterns of alcohol consumption by Canadian adults (Kairouz \& Greenfield 2007; Single \& Wortley 1993). Given the importance of their findings, and that more recent survey analysis has focused only on populations of Montreal adults (Demers 1997) and university-aged students (Demers et al. 2002), a decision was made to pursue this research using national data on Canadian adults. While information on the drinking context is routinely collected as part of survey attempts in Canada and abroad, little research examining its impact on drinking behaviour seems to emerge.
} 
respondents participated in the survey, with weighted values representing approximately 24,214,815 Canadians aged 15 and older. The response rate was 47.0\% (Canadian Centre on Substance Abuse 2004).

\section{Sample Selection}

The survey questionnaire was separated into three random sub-samples (Panel A through C) in order to maximize survey content areas without increasing the length of the interview (Canadian Centre on Substance Abuse 2004). ${ }^{21}$ Respondents from Panel C of the CAS were asked 15 questions about different situations they had when they consumed alcohol. They were queried on their last, second last, and third last drinking occasion.

Individuals reporting consumption of one or more drinks on their last drinking occasion were the primary sample population for this study. ${ }^{22}$ Individuals who responded to questions on the drinking context, but who did not consume alcohol, were removed from the study. While abstainers represent an important population in an overall understanding of drinking in a culture, having not consumed alcohol on the occasion, they could not be conceptually linked with the outcome measure, and others who reported drinking. Also, given that the focus of this study is on exploring situational and relational characteristics of the drinking context, solitary drinking occasions were excluded (see

\footnotetext{
21 'Panel items' were one of the four categories of questions that were created as part of the questionnaire used in the CAS. Items related to the social context of alcohol consumption were allocated to Panel $\mathrm{C}$, in order to maximize the content areas of the survey while maintaining an appropriate interview length (Canadian Centre on Substance Abuse 2004: 3).

22 Given the exploratory nature of this research, only data from the last occasion of drinking is used in analysis for this study. This is consistent with the method used by Demers (1997) in her study of Montreal adults, and examination of relational and situational contexts of heavy drinking. Since this analysis is exploratory, and reflects a basis for preliminary study of the effect of drinking contexts on heavy drinking within a master's thesis, second and third last drinking occasions were excluded. Demers et al. (2002) and Kairouz et al. (2002) have noted the value of employing more sophisticated statistical methodology when examining multiple drinking occasions reported by individuals, as they can account for differences in individual-level variants (i.e., drinker-type, demographic, etc.), although for the purpose of this thesis research, only one occasion is considered.
} 
Appendix $B$ for details on coding decisions involving solitary drinking occasions). A lower limit of 18 years of age was set for theoretical purposes. Adult populations are traditionally overlooked in favour of youth or university-aged student populations in research on alcohol consumption, and remain the focus of this analysis. This study is primarily concerned with examining the impact of the drinking context on heavy drinking, and as such, it could be anticipated that individuals under the age of 18 would not reflect a range of social contexts, since drinking in bars and restaurants by younger individuals in Canada is prohibited. ${ }^{23}$ Following these inclusion criteria, a sub-sample of 2,160 Canadian adults aged 18 years of age and older remained.

\section{Data Analysis}

The data were obtained as an SPSS data file from the Carleton Data Centre. This file contained pre-existing variable and value labels for a number of demographic and alcohol consumption variables, including 15 variables related to the drinking context (AF1 to AF15). All data recodes and analyses were performed using the SPSS software program, version 10.0. Statistical analyses were conducted on weighted data from the CAS, as the weighted distribution most accurately reflects the general Canadian population.

\footnotetext{
${ }^{23}$ While drinking norms carry a high degree of universality within a given national boundary (Room 1997), limits are often placed on the legal age which drinking can occur. This has been shown to reduce the level of drinking, as well as rates of alcohol-related problems in the population (Babor et al. 2003, cited in Room et al. 2003). Within Canada, most provinces and territories have established 19 as the legal drinking age, although Alberta, Manitoba and Québec allow drinking for individuals 18 years of age or older (see http://www.ccsa.ca/CCSA/EN/Topics/Legislation/LegalDrinkingAgeByProvCan.htm). To remain consistent with previous research on the drinking context (Demers 1997), and given that past-year drinking is highest among 18-19 year olds in Canada (Adlaf et al. 2005: 25), a decision was made to use this cut-off.
} 


\section{Variables}

The CAS contained questions on the drinking context, as well as the quantity of alcohol consumed during the last drinking occasion. This study examined the relationship between (1) situational characteristics and (2) relational characteristics of the drinking context and heavy alcohol consumption. The measures that form these predictor variables, as well as the outcome variable, are described in detail in this section.

\section{Dependent Variable - Heavy Alcohol Consumption}

Previous research has shown that factors related to the drinking context, such as those that are situational or relational in nature, are predictive of heavy drinking (Clapp et al. 2000; Demers 1997; Demers et al. 2002; Harford 1979). In this study, the outcome variable of interest was self-reported heavy drinking, with characteristics of the drinking context serving as the predictor variables. As noted in the previous chapter, occasions of heavy alcohol consumption have been associated with a variety of alcohol-related risks or problems (Bondy 1996; Duffy 2003; Room et al. 1995; Wechsler et al. 2001). Consistent with this body of research, this measure - having consumed five or more drinks $(5+)$ on a single occasion - will be employed as the primary outcome variable in this study. A dichotomous variable was constructed, based on whether the respondent consumed five or more drinks on the last drinking occasion (see Table 4.1). In Chapter Six, to examine differences between men and women, a separate regression was run using a separate outcome measure of four or more drinks $(4+)$ on the last occasion for women. 


\section{Independent Variables - the Social Context of Alcohol Consumption}

As previously noted, the drinking context is employed sociologically in this thesis in reference to the environment in which the act of consuming alcohol occurs, which is comprised of situational characteristics from the physical setting of consumption, as well as relational characteristics of individuals' drinking partners (Demers 1997; Demers et al. 2002). The situational characteristics of the drinking context are measured using survey data from respondents' last drinking occasion, with specific reference to: the circumstance in which drinking occurred, the type of location where drinking occurred, whether drinking occurred in multiple locations, the day of the week the occasion took place, and whether drinking occurred with a meal. Relational characteristics encompass the interpersonal nature of drinking contexts, and are captured with questions on: the relationship with other drinking partners, the size of the drinking group, whether the group was composed of a same-gender or mixed-gender group, and whether drinking occurred in the presence of one's partner.

A full list of definitions for the predictor variables is provided in Table 4.1. The research presented in the literature review chapter has shown that various elements of the drinking context have an effect on alcohol intake. The measures of drinking context employed here reflect those which were found in the literature, mediated by constraints placed by analysis of secondary data. In some cases, a binary measure (yes $=1$, no $=0$ ) was used to indicate the presence of the variable of interest, such as drinking with a meal, drinking at multiple locations, or with one's partner or spouse. For the other variables, dummy variables were created for each category of the variable, in order to be inputted 
into a logistic regression model. Details of the coding of each variable are provided in

Table 4.1 .

Selection of control variables

Existing research showing increased patterns of heavy drinking among younger

populations compared to older populations (Adlaf et al. 2005; Matano et al. 2003; Auth \&

Warheit 1982-1983) and with men as opposed to women (Adlaf et al. 2005; Bloomfield

Table 4.1: Predictor and outcome variable definitions and proposed variable coding for "Heavy drinking during the last drinking occasion"

\begin{tabular}{|c|c|c|}
\hline Dependent: & \multicolumn{2}{|c|}{ Variable Definition. Variable Coding } \\
\hline Heavy Drinking & $\begin{array}{l}5+\text { drinks consumed during the last drinking } \\
\text { occasion for the full sample; } \\
5+\text { drinks for males/ } 4+\text { drinks consumed during } \\
\text { the last drinking occasion for females }\end{array}$ & $\begin{array}{l}\text { This variable is coded as a dummy variable } \\
\text { (Yes }=1, N o=0 \text { ) }\end{array}$ \\
\hline Independent: & \multicolumn{2}{|c|}{ Yariable Definition } \\
\hline \multicolumn{3}{|c|}{ Relational characteristics of the drinking context } \\
\hline Relationship & $\begin{array}{l}\text { The relationship to the majority of drinking } \\
\text { partners during the last drinking occasion }\end{array}$ & $\begin{array}{l}\text { This variable is represented by three dummy } \\
\text { variables; drinking with Family is the reference } \\
\text { category. } \\
\text { Dco-workers (drink with }=1 \text {, Other }=0 \text { ) } \\
\text { Dfriends (drink with }=1, \text { Other }=0 \text { ) } \\
\text { Dcombination (drink with }=1 \text {, Other }=0 \text { ) }\end{array}$ \\
\hline $\begin{array}{l}\text { Gender } \\
\text { composition }\end{array}$ & $\begin{array}{l}\text { Gender composition of the drinking group } \\
\text { during the last drinking occasion }\end{array}$ & $\begin{array}{l}\text { This variable is coded as a dummy variable (Gender } \\
\text { mixed }=1 \text {, Gender non-mixed }=0 \text { ) }\end{array}$ \\
\hline Group size & $\begin{array}{l}\text { The number of drinking partners during the } \\
\text { last drinking occasion }\end{array}$ & $\begin{array}{l}\text { This variable is represented by three dummy } \\
\text { variables; drinking with } 4-9 \text { persons is the reference } \\
\text { category. } \\
\text { D1 person (drink with }=1 \text {, Other }=0 \text { ) } \\
\text { D2-3 persons (drink with }=1 \text {, Other }=0 \text { ) } \\
\text { D10+ persons (drink with }=1 \text {, Other }=0 \text { ) }\end{array}$ \\
\hline Partner Present & $\begin{array}{l}\text { Presence of spouse/partner/romantic(non- } \\
\text { cohabitating)partner during the last } \\
\text { occasion }\end{array}$ & $\begin{array}{l}\text { This variable is coded as a dummy variable (Yes }=1 \text {, } \\
N_{0}=0 \text { ) }\end{array}$ \\
\hline
\end{tabular}

\begin{tabular}{|c|c|c|}
\hline \multicolumn{3}{|c|}{ Situational characteristics of the drinking context } \\
\hline $\begin{array}{l}\text { Circumstance of } \\
\text { drinking }\end{array}$ & $\begin{array}{l}\text { The circumstance when drinking last } \\
\text { occurred }\end{array}$ & $\begin{array}{l}\text { This variable is represented by three dummy } \\
\text { variables; drinking at a party is the reference } \\
\text { category. } \\
\text { Dget together (drink at }=1 \text {, Other }=0 \text { ) } \\
\text { Ddaily life circumstances (drink at }=1, \text { Other }=0 \text { ) } \\
\text { Dother circumstances (drink at }=1, \text { Other }=0 \text { ) }\end{array}$ \\
\hline Day of the week & $\begin{array}{l}\text { The day of the week when drinking last } \\
\text { occurred }\end{array}$ & $\begin{array}{l}\text { This variable is represented by six dummy variables; } \\
\text { drinking on Saturday is the reference category. } \\
\text { DSunday (drink on }=1 \text {, Other }=0 \text { ) } \\
\text { DMonday (drink on }=1 \text {, Other }=0 \text { ) } \\
\text { DTuesday (drink on }=1 \text {, Other }=0 \text { ) }\end{array}$ \\
\hline
\end{tabular}




\begin{tabular}{|c|c|c|}
\hline & & $\begin{array}{l}\text { DWednesday (drink on }=1, \text { Other }=0 \text { ) } \\
\text { DThursday (drink on }=1, \text { Other }=0 \text { ) } \\
\text { DFriday (drink on }=1, \text { Other }=0 \text { ) }\end{array}$ \\
\hline Type of Location & $\begin{array}{l}\text { The type of location where drinking last } \\
\text { occurred }\end{array}$ & $\begin{array}{l}\text { This variable is represented by three dummy } \\
\text { variables; drinking at respondent's home is the } \\
\text { reference category. } \\
\text { Dother's home (drink at }=1 \text {, Other }=0 \text { ) } \\
\text { Drestaurant (drink at }=1 \text {, Other }=0 \text { ) } \\
\text { Dbar, disco or nightclub (drink at }=1, \text { Other }=0 \text { ) }\end{array}$ \\
\hline Drink with Meal & $\begin{array}{l}\text { Whether food was consumed during the last } \\
\text { drinking occasion }\end{array}$ & $\begin{array}{l}\text { This variable is coded as a dummy variable (Yes }=1 \text {, } \\
\text { No=0) }\end{array}$ \\
\hline $\begin{array}{l}\text { Drink at Multiple } \\
\text { Locations }\end{array}$ & $\begin{array}{l}\text { Whether drinking occurred at more than } \\
\text { one location }\end{array}$ & $\begin{array}{l}\text { This variable is coded as a dummy variable }(\mathrm{Yes}=1 \text {, } \\
\text { No }=0 \text { ) }\end{array}$ \\
\hline
\end{tabular}

et al. 2003; Bondy et al. 1999; Demers et al. 2002) drove the selection of 'age' and 'gender' as control variables for this study. Existing sex variables from the CAS were used to construct a binary measure for gender $($ Female $=0$, Male $=1)$, in order to examine differences between men and women in relation to heavy drinking and the drinking context. Women generally tend to metabolize alcohol differently than men, resulting in higher blood-alcohol levels (BAL) with comparable quantities of alcohol (Johnson 1991; Lieber 1993), necessitating a separate outcome measure for heavy drinking. Consistent with Demers (1997) study of Montreal adults, a dichotomous age variable (18 to 24 years of age $=0 ; 25$ years of age and older $=1$ ) was also used to control for differences between younger and older adults.

\section{Logistic Regression}

Binary logistic regression modeling was used in this study to examine the impact of the drinking context on the propensity for heavy drinking. This form of regression analysis is designed to analyze dichotomized outcome variables. The outcome variable of interest was heavy drinking, as reported by Canadian adults the last time drinking occurred, with the reference category being "no heavy drinking". The use of 
dichotomized predictor and outcome measures is particularly useful if measures are likely to have skewed distributions (Farrington \& Loeber 2000). This is the case in this project, with "heavy alcohol consumption" as the dependent variable, respondents reported from 1 to 35 drinks on the last occasion of drinking. Dichotomous measures are also often utilized in research on substance use where the main focus of the research is to examine certain risk or protective factors for specific outcome behaviours (Farrington \& Loeber 2000). Logistic regression is particularly suited for the analysis of independent variables that are categorical in nature, which is the case when examining the social context of alcohol consumption (Menard 2001; Selvin 1995).

Binary logistic regression produces a set of estimated Odds Ratios (OR) that is associated with each coefficient (Menard 2001). The Odds Ratio (OR), which is computed as the exponential $b$, in the logistic regression analyses, ${ }^{24}$ provides an easily interpretable measure of the strength of the association between predictor and outcome variables. An odds ratio of 1 indicates no association between the outcome variable (e.g., heavy alcohol consumption) and the predictor variables (e.g., the social context). An odds ratio greater than 1 indicates an increased risk of the outcome of interest, given the presence of a particular predictor variable, whereas an odds ratio of less than 1 indicates a decreased risk of the outcome of interest, given the presence of the predictor variables.

Kleinbaum (1994) notes that logistic regression is aptly suited for the study of cross-sectional data. Secondary analysis of the cross-sectional data provided in the CAS sought to examine changes in the dependent variable of interest, or heavy alcohol consumption on the last drinking occasion. The constructed models indicated the odds of

\footnotetext{
${ }^{24}$ The odds ratio estimates that are associated with each regression coefficient in the analysis are presented as $\operatorname{Exp}(\beta)$ in SPSS, as opposed to OR in SAS. This represents the odds of reporting heavy drinking for each statistically significant independent variable entered into the model.
} 
heavy alcohol consumption $(5+$ drinks $=1)$, compared to the reference category $(1$ to 4 drinks $=0$ ). The two sets of predictor variables that are considered in the models are the situational and relational characteristics of the drinking context. Odds ratios were computed for each of the independent variables (coded as dummy measures, with a specific reference category), which were forced into the logistic regression model using an enter method. ${ }^{25}$ This method is preferred over stepwise regression (Menard 2001) in testing the theoretical claims that the social context impacts upon individuals' consumption of alcohol. For each odds ratio, a $95 \%$ confidence interval was computed to indicate statistical significance. Some researchers have argued that the use of an odds ratio as a measure of strength of association between independent and dependent variables is a more useful and efficient approach for research studying predictors, than is measuring the percentage of variance explained (Rosenthal \& Rubin 1982). Nevertheless, for the purpose of this study, both odds ratios and pseudo R-square scores are reported, to provide the reader with complimentary measures to interpret the relationships.

\section{Limitations of the Study}

Several limitations in this study should be considered. One limitation involves the cross-sectional nature of the data derived from the CAS. While serving as a cost-effective

\footnotetext{
${ }^{25}$ The enter method is the default method for entering predictor variables into a binomial logistic regression in SPSS. This was used in this study to explore the impact of the drinking context on reported heavy drinking, as opposed to stepwise regression, which seeks to narrow down the best predictors from a larger set of independent variables. Using this method, I was able to specify which predictor variables to run against the dichotomous outcome variable, "heavy drinking", and enter the dummy variables that were created from the original categorical variables provided with the 2004 CAS dataset. This was important, as it allowed this researcher to determine which categories would be used as reference categories, and remain consistent with both theory and previous research in the area (Demers 1997; Demers et al. 2002). It was also useful in considering the effects of relational and situational characteristics, as well as the full model of predictors. Since there were a limited number of predictors, all nine variables related to the drinking context were forced into the logistic regression analysis to observe their effect on the odds of reporting heavy drinking by Canadian adults. This is consistent with the methodology employed by Demers (1997) in her study of Montreal adults and the effect of the drinking context on reported heavy drinking.
} 
method of obtaining data on the alcohol and other drug use of Canadians, this design does not permit the establishment of temporal relationships between variables that could be used to establish causal relationships (Gordis 1996). It only provides a view of Canadians' heavy drinking, as well as the social context of alcohol consumption, as a snapshot in time. Analysis of this data was therefore relegated to the search for correlations between variables of the drinking context - as well as differentiations according to gender, for instance - and the outcome measure of heavy drinking. Similarly, having conducted secondary analysis of the data from the CAS, operationalization of the variables for the social context of alcohol consumption was limited to the questions posed to respondents about their last occasion of drinking. It must therefore be recognized that this dataset may contain certain errors or biases associated with the survey construction, and that certain questions, and their subsequent responses, were intended for alternative research purposes than are employed here. As Dale notes, "It is very easy for survey analysts, especially those conducting secondary analysis, to overlook the fact that they are using a dataset containing various kinds of error and biases" (2006: 144). While these limitations are recognized, the questions posed to CAS respondents seem to correspond with those from other studies on the drinking context, and appear suitable for answering the specific research questions posed in this study. Also, the CAS does not sample Canadian residents from the Yukon, Nunavut and Northwest territories. Data on patterns of substance consumption for the territories is compiled separately through the Northwest Territories Addiction Survey and the Yukon Addictions Survey (YAS). This is important limitation, as preliminary research from these populations show that $31.1 \%$ of NWT respondents aged 15 years and older indicated they normally consume five or more drinks on a typical drinking day. Also, the 
rate of heavy drinking among residents in the Yukon is higher (18\%) than the Canadian average (13\%) (Yukon Department of Health and Social Services 2005: 8). Thus, while referring to the sample as representative of the Canadian adult population in this study, it still misses a theoretically significant portion of Canadian drinkers in the analysis.

Finally, two additional considerations are required in relation to the collection of the data and the focus of analysis. First, since the CAS was conducted in December of 2003 and April of 2004, the data may reflect seasonal patterns of alcohol consumption. Both Christmas and New Year's Eve are traditional days of celebration (Lemmens \& Knibbe 1993), and may have had an effect on the amount of alcohol consumed during occasions of drinking, as well as the contexts within which drinking occurred. While the analysis in this thesis is meant to be exploratory, future research on this dataset may wish to consider the last three drinking occasions when examining the drinking context. Second, this analysis is also exploratory in the demographic variables that were considered for control. Both gender and age have been shown to explain differences in heavy drinking, and were included in this study. However, other socio-demographic factors, such as race and income, have also been shown to impact drinking rate and quantities. Given the exploratory nature of this study, not all individual characteristics could be examined within the limits of this thesis.

\section{RESEARCH QUESTIONS AND HYPOTHESES}

The objective of this thesis is twofold: to examine the gap in knowledge on the social context of alcohol consumption in relation to understanding contemporary trends in heavy drinking, and to explore the impact of the drinking context on heavy drinking, using the most current and available national data on drinking in Canada. The previous 
chapter provided a review of existing literature on relational and situational contexts of heavy drinking, while also positioning the gap in knowledge that has occurred in relation to social influences on drinking behaviour. The next two chapters are designed to address the latter objective, and explore the following research questions and related hypotheses: How important is the 'context' of alcohol consumption in accounting for heavy drinking by Canadian adults?

Hypothesis 1: The drinking context is important in understanding contemporary patterns of heavy drinking, and will account for a significant portion of heavy drinking by Canadian adults.

Do situational characteristics of the social context provide greater explanatory value than relational characteristics?

Hypothesis 2: Given research by Demers (1997), Demers et al. (2002), and Knibbe et al. (1993), it is anticipated that situational characteristics will account for the greatest proportion of heavy drinking by Canadian adults.

Which relational characteristics are associated with the greatest likelihood of heavy drinking by the general population?

Hypothesis 3: Adults who consume alcohol with friends are more likely to drink heavily than with other drinking companions.

Hypothesis 4: Drinking in larger groups is conducive to heavy drinking, and those adults who report drinking in the largest groups are more likely to drink heavily than when drinking in smaller groups.

Hypothesis 5: Adults who consume alcohol in the presence of their partner are less likely to report heavy drinking than those whose partners are not present at the drinking occasion.

Which situational characteristics are associated with the greatest likelihood of heavy drinking by the general population?

Hypothesis 6: Adults who consume alcohol at parties are more likely to drink heavily than under other drinking circumstances.

Hypothesis 7: Adults who consume alcohol on weekends are more likely to drink heavily than on other days of the week, such as weekdays.

Hypothesis 8: Adults who consume alcohol at bars are more likely to drink heavily than those who drink at other drinking locations.

Hypothesis 9: Adults who consume alcohol with a meal are less likely to report heavy drinking than those who do not have a meal. 
Given the exploratory nature of this research, differences in the contextual influence on heavy drinking according to gender is the only additional relationship examined. While not explicitly stated within each of the hypotheses listed above, it is anticipated that differences will emerge according to the gender of the respondent. Limited research on gender differences related to the drinking context were found, meaning predictions on gender differences for Canadian adults must be tempered. Men are hypothesized to be more likely to report heavy drinking when drinking with friends, in same-gendered drinking groups, and in bars, whereas women are hypothesized to be more likely to report heavy drinking when drinking in private settings (i.e., at home).

Overall, descriptive statistics will provide a picture of the contextual preferences for Canadians, as well as those characteristics associated with heavy drinking. Furthermore, logistic regression analyses on the general Canadian adult population will supply valuable information on the impact the drinking context has on the propensity for heavy drinking by Canadians. Information on the general adult population is presented first in Chapter Five, followed by analyses according to the gender of the individual in Chapter Six. The characteristics of the drinking context that are associated with heavy drinking for men and women will be presented, and will help to determine what differences exist for populations of Canadian men and women. 


\section{CHAPTER FIVE}

\section{ANALYSIS OF THE RELATIONAL AND SITUATIONAL CONTEXT OF HEAVY DRINKING}

This chapter presents the findings of the analysis of relational and situational characteristics of the drinking context on the propensity for heavy drinking. It consists of both descriptive analysis and logistic regression analysis on a sub-population of Canadian adults $(n=2,160)$ surveyed in the CAS, taking heavy drinking (5+ drinks) as the outcome variable of interest. The chapter is divided into two main sections: (1) descriptive information on the research population, as well as situational and relational characteristics of the drinking context, with particular emphasis on specific characteristics of the drinking context in relation to heavy drinking; and (2) information from a logistic regression of the drinking context on heavy drinking. To determine which variables related to the drinking context had an impact on heavy drinking, odds ratios are presented first for the sub-population of Canadian adults.

\section{Social Characteristics of the Research Population}

Table 5.1 outlines the socio-demographic characteristics of the population. Of the total sample of 2,160 , the study population contained 1,208 males and 952 females. The mean age of the population was approximately 43 years of age, with $14.4 \%$ of the population being young adults (18-24). Roughly two-thirds (65.0\%) of the population is currently employed, with $17.0 \%$ indicating that they were retired. The large number of retirees may reflect the large percentage of adults over the age of $55(24.3 \%)$ that were 
Table 5.1: Distribution of population by socio-demographic characteristics, CAS (2004)

\begin{tabular}{|c|c|c|}
\hline & $\begin{array}{c}\text { Population }(n=2,160) \\
\text { Frequency }(f)\end{array}$ & $\begin{array}{c}\text { Population }(n=2,160) \\
\text { Percentage }(\%)\end{array}$ \\
\hline \multicolumn{3}{|l|}{ Gender } \\
\hline Male & 1208 & $55.9 \%$ \\
\hline Female & 952 & $44.1 \%$ \\
\hline \multicolumn{3}{|l|}{ Age } \\
\hline $18-24$ & 312 & $14.4 \%$ \\
\hline $25-34$ & 443 & $20.5 \%$ \\
\hline $35-44$ & 458 & $21.2 \%$ \\
\hline $45-54$ & 421 & $19.5 \%$ \\
\hline $55+$ & 525 & $24.3 \%$ \\
\hline \multicolumn{3}{|l|}{ Province } \\
\hline Newfoundland \& Labrador & 34 & $1.6 \%$ \\
\hline Prince Edward Island & 7 & $0.3 \%$ \\
\hline Nova Scotia & 70 & $3.2 \%$ \\
\hline New Brunswick & 48 & $2.2 \%$ \\
\hline Quebec & 553 & $25.6 \%$ \\
\hline Ontario & 799 & $37.0 \%$ \\
\hline Manitoba & 77 & $3.6 \%$ \\
\hline Saskatchewan & 63 & $2.9 \%$ \\
\hline Alberta & 220 & $10.2 \%$ \\
\hline British Columbia & 290 & $13.4 \%$ \\
\hline \multicolumn{3}{|l|}{ Household Location } \\
\hline Rural & 357 & $16.5 \%$ \\
\hline Urban & 1802 & $83.5 \%$ \\
\hline \multicolumn{3}{|l|}{ Marital Status } \\
\hline Married & 982 & $45.7 \%$ \\
\hline Partner & 282 & $13.1 \%$ \\
\hline Previously married & 336 & $15.6 \%$ \\
\hline Never married & 552 & $25.7 \%$ \\
\hline \multicolumn{3}{|l|}{ Highest Education } \\
\hline Less than high school & 214 & $10.0 \%$ \\
\hline Completed high school & 641 & $30.1 \%$ \\
\hline Some post-secondary & 657 & $30.8 \%$ \\
\hline University degree & 619 & $29.0 \%$ \\
\hline \multicolumn{3}{|l|}{ Employment Status } \\
\hline Currently employed & 1403 & $65.0 \%$ \\
\hline Unemployed & 88 & $4.1 \%$ \\
\hline Student & 164 & $7.6 \%$ \\
\hline Retired & 367 & $17.0 \%$ \\
\hline Other & 135 & $6.2 \%$ \\
\hline \multicolumn{3}{|l|}{ Income Adequacy } \\
\hline Lowest income & 195 & $9.0 \%$ \\
\hline Lower middle & 254 & $11.8 \%$ \\
\hline Upper middle & 691 & $32.0 \%$ \\
\hline Highest income & 577 & $26.7 \%$ \\
\hline Refused/Don't Know & 443 & $20.5 \%$ \\
\hline
\end{tabular}

Note: Total population $(n=2,160)$. Frequency $(f)$ represents the maximum number of adults providing data to questionnaire on last drinking occasion (af1 to af15A). Frequencies vary per characteristic due to missing data. 
captured as part of the research population. Individuals who were married comprised the largest percentage of the population $(45.7 \%)$, followed by those who were never married $(25.7 \%)$, previously married $(15.6 \%)$ and with a partner $(13.1 \%)$. The study population represents a higher proportion of married, and a lower proportion of never married, individuals than is normally found in the general Canadian population. This trend was also found for the overall CAS sample, compared to data on the Canadian population (Canadian Centre on Substance Abuse 2004: 12). Similarly, individuals who had attained at least some post-secondary education were slightly over-represented in this study population $(59.8 \%)$, compared to what is normally found among the Canadian population. Trewin \& Lee (1988) argue that such differences are common among telephone surveys. Since these factors are not the primary focus of this study, they should not influence the results to any great degree. Consideration should be given, however, to data reported on the presence of one's drinking partner, as a higher proportion of married respondents may be more likely to drink with their romantic partner than non-married Canadians. Finally, respondents situated themselves primarily in the upper middle (32.0\%) and highest $(26.7 \%)$ income categories, although a large percentage of the population did not provide information on this characteristic. The majority of the population resides in urban areas $(83.5 \%)$. Since the data is weighted, the percentage of respondents by province matches the percentage noted in the 2001 Canadian Census (Canadian Centre on Substance Abuse 2004)..$^{26}$

\footnotetext{
${ }^{26}$ For full definitions of the sociodemographic variables mentioned in this section, please see Appendix $B$. Certain risk factors which can contribute to substance abuse by women are not captured in the 2004 CAS, and as such, were not reported here. This can include a greater susceptibility for sexual and physical abuse for women than men, which can have adverse effects on the ways alcohol is used, and the types of problems that may ensue (Poole \& Dell 2005).
} 


\section{Description of Drinking Behaviour}

This section describes the drinking practices of the population, as reported by respondents for the last drinking occasion. A number of measures for assessing drinking behaviour have been applied in measuring the amount of alcohol consumed during a single episode of drinking. Cross-sectional surveys often query respondents on the number of alcoholic beverages consumed during a set period of time, usually capturing the amount of alcohol consumed on a given occasion of drinking. ${ }^{27}$ For this study, participants were asked the following: "Now thinking back of the last three occasions you drank alcohol over the past 12 months [for] the most recent occasion... How many drinks did you have?" (see Appendix A for the survey instrument used in the CAS to capture factors related to the drinking occasion).

Table 5.2 presents the mean number of drinks reported by the population, and distinguishes between individuals who report heavy drinking ( 5 or more drinks) on their last drinking occasion, and those who do not (4 drinks or fewer). The population consumed 3.15 drinks on average, with $19.6 \%$ reporting consuming five drinks or more during their last drinking occasion. The standard deviation of reported number of drinks was 2.7 , meaning the reported quantity of alcohol consumption varied between relatively low levels of intake. The consumption of five or more drinks on a single drinking occasion can potentially be hazardous for the individual drinker, or those drinking with them. Heavy alcohol consumption is associated with a variety of drinking-related harms, including physical assault, marital difficulties, and school or work problems. As such,

\footnotetext{
${ }^{27}$ As mentioned previously, only data from the last occasion of drinking is used in analysis for this study. This is consistent with the method used by Demers (1997) in her study of Montreal adults, and examination of relational and situational contexts of heavy drinking. Details on the rationale for this decision are provided as a footnote on page 66 .
} 
Table 5.2: Distribution of non-heavy drinkers and heavy drinkers (5+ drinks) on the last drinking occasion, CAS (2004)

\begin{tabular}{lccc}
\hline \multirow{2}{*}{ Alcohol intake per occasion } & \multicolumn{2}{c}{$(n=2,160)$} \\
& Frequency $(f)$ & Percentage (\%) \\
\hline Four drinks or fewer & 1737 & $80.4 \%$ \\
Five or more drinks $(5+)$ & 423 & $19.6 \%$ \\
\hline \multirow{2}{*}{ Number of drinks reported on the last occasion of drinking } & Mean & (s.d.) \\
& 3.15 & 2.69 \\
\hline
\end{tabular}

Note: Total population $(n=2,160)$. Frequency $(f)$ represents the maximum number of adults providing data to questionnaire on last drinking occasion.

almost a fifth of Canadians consumed enough alcohol on their last drinking occasion to put them at an elevated risk of experiencing harms related to their drinking.

\section{Description of Characteristics of the Drinking Context}

As noted previously, the context of alcohol consumption can be defined as "where one drinks, with whom one is drinking, and when one drinks" (Clapp et al. 2000: 141). In this study, the drinking context is operationalized through factors of the relational and situational characteristics of the last occasion where drinking took place. Table 5.3 presents descriptive information on the different characteristics of the drinking occasion, as captured in the CAS. Among the relational characteristics of the drinking occasion, almost half (48.3\%) of the respondents reported consuming alcohol with friends, with family (36.8\%) accounting for the second largest relationship among the drinking group. Drinking with co-workers was only reported by a small percentage of the research population (5.4\%), as was drinking with a combination of individuals $(9.5 \%)$ from the different categories. The size of the drinking group varied considerably among the population, with most respondents (39.2\%) reporting consuming alcohol with between four and nine people. This was followed by groups of ten or more people (23.9\%), two to 
Table 5.3: Distribution of population by characteristics of the drinking context, CAS (2004)

\author{
Weighted Population \\ $(n=2160)$ \\ Frequency $(f) \quad$ Percentage $(\%)$
}

\begin{tabular}{|c|c|c|}
\hline \multicolumn{3}{|l|}{ Relational Characteristics } \\
\hline \multicolumn{3}{|l|}{ Type of Relationship } \\
\hline Family & 757 & $36.8 \%$ \\
\hline Co-workers & 110 & $5.4 \%$ \\
\hline Friends & 994 & $48.3 \%$ \\
\hline Combination & 195 & $9.5 \%$ \\
\hline \multicolumn{3}{|l|}{ Group Size } \\
\hline 1 person & 330 & $15.7 \%$ \\
\hline $2-3$ persons & 442 & $21.1 \%$ \\
\hline 4-9 persons & 821 & $39.2 \%$ \\
\hline 10 or more & 500 & $23.9 \%$ \\
\hline \multicolumn{3}{|l|}{ Presence of Partner } \\
\hline Yes & 1324 & $61.3 \%$ \\
\hline No & 835 & $38.7 \%$ \\
\hline \multicolumn{3}{|l|}{ Gender Composition } \\
\hline Mixed & 1958 & $90.7 \%$ \\
\hline Non-mixed & 201 & $9.3 \%$ \\
\hline \multicolumn{3}{|l|}{ Situational Characteristics } \\
\hline \multicolumn{3}{|l|}{ Circumstance of the occasion } \\
\hline Party & 692 & $32.1 \%$ \\
\hline Get together & 769 & $35.6 \%$ \\
\hline Daily Life Circumstance & 445 & $20.6 \%$ \\
\hline Other Circumstance & 252 & $11.7 \%$ \\
\hline \multicolumn{3}{|l|}{ Day of the week } \\
\hline Sunday & 226 & $11.4 \%$ \\
\hline Monday & 81 & $4.1 \%$ \\
\hline Tuesday & 129 & $6.5 \%$ \\
\hline Wednesday & 134 & $6.8 \%$ \\
\hline Thursday & 218 & $10.9 \%$ \\
\hline Friday & 402 & $20.2 \%$ \\
\hline Saturday & 800 & $40.2 \%$ \\
\hline \multicolumn{3}{|l|}{ Drink with Meal } \\
\hline Yes & 1669 & $77.3 \%$ \\
\hline No & 491 & $22.7 \%$ \\
\hline \multicolumn{3}{|l|}{ Location } \\
\hline Your home & 808 & $39.7 \%$ \\
\hline Others' home & 711 & $35.0 \%$ \\
\hline Restaurant & 284 & $14.0 \%$ \\
\hline Bar & 230 & $11.3 \%$ \\
\hline \multicolumn{3}{|l|}{ Drink at Multiple Locations } \\
\hline Yes & 154 & $7.2 \%$ \\
\hline No & 1998 & $92.8 \%$ \\
\hline
\end{tabular}

Note: Total sample $(n=2,160)$. Frequency $(f)$ represents the maximum number of adults providing data to questionnaire on last drinking occasion. Frequencies vary per characteristic due to missing data. 
three people $(21.1 \%)$, and only one person $(15.7 \%)$. The majority $(61.3 \%)$ of respondents reported having their partner present during the last drinking occasion, and almost all reported drinking in mixed-gender groups (90.7\%). Results also show that for the situational characteristics of the drinking occasion, the most common circumstance for drinking was a get together (35.6\%), followed closely by a party $(32.1 \%)$. Drinking as part of daily life circumstances was reported by a fifth of the research population $(20.6 \%)$, whereas drinking for other circumstances accounted for just over a tenth of the drinking circumstances for this population (11.7\%). Drinking tended to occur on Friday or Saturday $(20.2 \%$ and $40.2 \%$ respectively), with other days closely preceding (Thursday $=$ $10.9 \%$ ) or following (Sunday $=11.4 \%$ ) the weekend accounting for a large percentage of last drinking occasions. The consumption of alcohol also tended to accompany a meal (77.3\%). Most drinking took place at the respondents' own home $(39.7 \%)$, with $35.0 \%$ of respondents reporting drinking at another persons' home. Finally, the other locations where alcohol consumption took place were restaurants (14.0\%) and bars/clubs $(11.3 \%)$. Most alcohol was consumed in one primary location $(92.8 \%)$ for this study population.

As noted previously, the high percentage of respondents who are married in this sample population may affect the proportion of individuals who report drinking with their partner. This may also be apparent in the percentage of individuals reporting 'family' as the main 'relationship' to the drinking partners present. Consistent with the research literature (Harford 1983; Hilton 1987; Orcutt 1991), drinking with friends continues to be the dominant drinking relationship for this population of Canadian adults. By contrast, drinking with 'co-workers' was the least reported category. This data suggests that Canadians are unlikely to mix leisure and work pursuits, at least to the degree that coworkers are included as the bulk of the drinking partners. Additional research may want 
to further examine the 'combination' category, which may include a higher proportion of co-workers as drinking partners. Drinking in larger groups remained the norm for Canadian adults, with just under two-thirds of respondents drinking in groups of 4 people or more.

In addition, most drinking was relegated to a single drinking location, with only a small percentage indicating they consumed alcohol in more than one location. The results clearly show that drinking at a residential location is the preferred location for alcohol consumption by Canadian adults, with approximately three-quarters of respondents reporting this situational characteristic. This is consistent with data from the U.S. pointing to the decreasing prevalence of public venues as locations for alcohol consumption (Treno et al. 2000). Finally, drinking at parties continues to be well represented among this population, although the proportion of Canadians drinking at a 'get together' was reported slightly more than drinking at a 'party'. It is unclear whether drinking at a 'get together' constitutes a culturally-specific context for drinking and leisure for Canadians, or what other elements of the drinking context are associated with drinking under this circumstance. Given it's popularity for Canadian adults, further analysis on the relationship between this characteristic and drinking quantity should help determine if this represents a new context for concern.

\section{Heavy Alcohol Consumption and the Drinking Context}

To determine which characteristics of the drinking context were most significantly associated with the occurrence of heavy drinking, univariate analyses were conducted on the full sub-population of Canadian adults $(n=2,160)$. Chi-square tests were utilized to test the null hypothesis that characteristics of the drinking context are not related to heavy 
drinking by Canadian adults. A probability $(p)$ of 0.05 or less indicates that an associated relationship between the independent and dependent variable exists, leading to a rejection of the null hypothesis. In examining the characteristics of the drinking context in relation to heavy drinking, significant differences were found for the relationship with the drinking group, the size of the drinking group, the circumstance of the last drinking occasion, the location where drinking last occurred, the day of the week consumption took place, and whether consumption occurred in multiple locations (see Table 5.4). For example, respondents who drank with family were the least likely to report heavy drinking (11.8\%), compared with co-workers $(26.4 \%)$, friends $(27.0 \%)$, or a combination (16.8\%) of the above $\left(x^{2}=65.194, p<.001\right)$. Differences were also found in the size of the drinking group on the last drinking occasion, with adults drinking in larger groups (10 or more) reporting heavy drinking in over a third of occasions (34.8\%). As the size of the drinking group decreased, the percentage reporting heavy alcohol consumption also decreased significantly $\left(x^{2}=146.234, p<.001\right)$. A total of $33.5 \%$ of respondents who consumed alcohol at a party reported consuming five or more drinks on the last drinking occasion $\left(x^{2}=173.630, p<.001\right)$. This is significantly higher than those who reported drinking under different circumstances, such as at a get together (18.2\%), and during other $(14.7 \%)$ or daily life (2.5\%) circumstances. Adults who consumed alcohol on Fridays (28.4\%) and Saturdays (20.3\%) reported a higher percentage of heavy drinking than on weekdays. However, roughly a fifth of those drinking on Tuesday (19.4\%) and Thursday $(20.2 \%)$ also reported heavy drinking. In fact, the results show that for this study population, the consumption of five or more drinks would occur for one in ten drinkers, regardless of the drinking day $\left(x^{2}=33.479, p<.001\right)$. Canadian adults also reported significantly more heavy alcohol consumption when drinking at a bar (33.9\%) or 
Table 5.4: Distribution of heavy alcohol consumption (5+ drinks) by characteristics of the drinking context, CAS (2004)

\begin{tabular}{|c|c|c|c|}
\hline & $\begin{array}{c}\text { Non-heavy alcohol } \\
\text { consumption } \\
(\mathrm{N}=1737) \\
\text { Percentage (\%) Frequency }(f)\end{array}$ & $\begin{array}{c}\text { Heavy alcohol } \\
\text { consumption } \\
(\mathrm{N}=422) \\
\text { Percentage }(\%) \text { Frequency }(f) \\
\end{array}$ & $p\left(x^{2}\right)$ \\
\hline \multicolumn{4}{|l|}{ Relational Characteristics } \\
\hline Type of Relationship & & & $<.001(65.194)$ \\
\hline Family & $88.2 \%(668)$ & $11.8 \%(89)$ & \\
\hline Co-workers & $73.6 \%(81)$ & $26.4 \%(29)$ & \\
\hline Friends & $73.0 \%(726)$ & $27.0 \%(268)$ & \\
\hline Combination & $83.2 \%(163)$ & $16.8 \%(33)$ & \\
\hline Group Size & & & $<.001(146.234)$ \\
\hline 1 person & $93.3 \%(308)$ & $6.7 \%(22)$ & \\
\hline 2-3 persons & $91.6 \%(405)$ & $8.4 \%(37)$ & \\
\hline 4-9 persons & $77.0 \%(632)$ & $23.0 \%(189)$ & \\
\hline 10 or more & $65.2 \%(326)$ & $34.8 \%(174)$ & \\
\hline Presence of Partner & & & $.484(0.491)$ \\
\hline Yes & $80.0 \%(1058)$ & $20.0 \%(265)$ & \\
\hline No & $81.2 \%(678)$ & $18.8 \%(157)$ & \\
\hline Gender Composition & & & $.240(1.379)$ \\
\hline Mixed & $80.1 \%(1569)$ & $19.9 \%(389)$ & \\
\hline Non-mixed & $83.6 \%(168)$ & $16.4 \%(33)$ & \\
\hline \multicolumn{4}{|l|}{ Situational Characteristics } \\
\hline Circumstance of the occasion & & & $<.001(173.630)$ \\
\hline Party & $66.5 \%(460)$ & $33.5 \%(232)$ & \\
\hline Get together & $81.8 \%(628)$ & $18.2 \%(140)$ & \\
\hline Daily Life Circumstance & $97.5 \%(434)$ & $2.5 \%(11)$ & \\
\hline Other Circumstance & $85.3 \%(215)$ & $14.7 \%(37)$ & \\
\hline Day of the week & & & $<.001(33.479)$ \\
\hline Sunday & $88.1 \%(199)$ & $11.9 \%(27)$ & \\
\hline Monday & $88.9 \%(72)$ & $11.1 \%(9)$ & \\
\hline Tuesday & $80.6 \%(104)$ & $19.4 \%(25)$ & \\
\hline Wednesday & $85.8 \%(115)$ & $14.2 \%(19)$ & \\
\hline Thursday & $79.8 \%(174)$ & $20.2 \%$ & \\
\hline Friday & $71.6 \%(288)$ & $28.4 \%(114)$ & \\
\hline Saturday & $79.8 \%(638)$ & $20.3 \%(162)$ & \\
\hline Drink with Meal & & & $.877(0.024)$ \\
\hline Yes & $80.3 \%(1340)$ & $19.7 \%(328)$ & \\
\hline No & $80.7 \%(396)$ & $19.3 \%(95)$ & \\
\hline Location & & & $<.001(161.551)$ \\
\hline Your home & $90.5 \%(732)$ & $9.5 \%(77)$ & \\
\hline Others' home & $69.0 \%(491)$ & $31.0 \%(221)$ & \\
\hline Restaurant & $91.2 \%(259)$ & $8.8 \%(25)$ & \\
\hline Bar & $66.1 \%(152)$ & $33.9 \%(78)$ & \\
\hline Drink at Multiple Locations & & & $<.001(191.336)$ \\
\hline Yes & $37.7 \%(58)$ & $62.3 \%(96)$ & \\
\hline No & $83.6 \%(1671)$ & $16.4 \%(327)$ & \\
\hline
\end{tabular}

Note: Total sample $(n=2,160)$. Frequency $(f)$ represents the maximum number of adults providing data to questionnaire on last drinking occasion. Frequencies vary per characteristic due to missing data. 
at another person's home $\left(x^{2}=161.551, p<.001\right)$. Thirty-one percent of those drinking at another person's home consumed five or more drinks on the last drinking occasion, which was much higher in comparison to those drinking in their own homes (9.5\%). Finally, while representing only a small number of cases $(f=154)$, those individuals who drank at more than one location reported heavy alcohol consumption in $62.3 \%$ of the drinking occasions $\left(x^{2}=191.336, p<.001\right)$.

Consuming alcohol in the presence of one's partner, as well as with a meal, were not significantly associated with heavy drinking. Also, adults who drank with samegendered drinking partners were no more likely to report heavy drinking than those adults who consumed alcohol in gender-mixed groups.

As expected, a significantly higher percentage of heavy drinking occurred when Canadians consumed alcohol with friends, in larger groups, on weekends, in bars, and at parties. These findings are consistent with existing literature which indicates heavier drinking for these traditional companions and contexts. There were, however, a number of surprising results. For instance, although they represent only a small number of occasions $(n=110)$, individuals who consumed alcohol with co-workers reported heavy drinking just as often as those individuals who consumed alcohol with friends. While the research literature has shown a positive association between heavy alcohol consumption and drinking with friends (Harford 1983), most studies have also found that drinking with one's co-workers reduces the amount of alcohol consumed during episodes of drinking. Further examination of this relationship, particularly in consideration of some of the more traditional characteristics of the drinking context that are linked with higher percentages of heavy drinking, should provide insight into its importance with regards to heavy drinking. 
Similarly, drinking on weekdays is generally associated with a lower frequency of drinking occasions, as well as instances of heavy drinking. Indeed, a substantial portion of the heavy drinking occasions reported by this population occurred on the weekend (i.e. Friday or Saturday), which is consistent with previous research in this area (Arfken 1988; Single 1985). This would suggest that, for the most part, weekends could be considered 'blow-out nights' for a large group of adults, which is consistent with drinking trends in the UK over the past decade (Harnett et al. 2000). However, the results clearly show that heavy drinking is also becoming prevalent on days such as Tuesday and Thursday, suggesting that heavy drinking and leisure pursuits are becoming more normalized during the week for a significant portion of the study population.

The percentage of Canadian adults reporting heavy drinking at another person's home was also high. This finding is consistent with research pointing to increasing acceptance of intoxication when drinking in private settings (Greenfield \& Room 1996). Previous national survey data found that drinking in private settings accounted for the highest proportion of alcohol consumption by Canadians (Single \& Wortley 1993), and it would appear that such occasions routinely include instances where individuals drink heavy amounts of alcohol. This data tells us that this particular situational characteristic may be taking on a greater role in leisure pursuits by Canadians, at least to the degree that alcohol consumption in general, and heavy consumption in particular, are included as part of the occasion. Research by Kairouz and Greenfield (2007) suggests that such a relationship may be predicated upon relational elements of the drinking context as well, including the types of drinking companions present during the occasion. Additional research examining the combined effect of these characteristics of the drinking context should provide some insight into the predictive capacity of these factors. 
While results showing that drinking at another person's home seems to produce similar rates of heavy drinking as found in licensed establishments, perhaps unsurprisingly, bars and taverns were also reported as locations where heavy drinking tends to occur. This finding is consistent with a great deal of existing research on the drinking context (Caetano \& Herd 1988; Casswell et al. 1993; Curran et al. 1996; Harford \& Mills 1978; Harford 1979; Harford 1983; Herd \& Grube 1993; Single \& Wortley 1993). However, drinking in restaurants - another licensed establishment which had been associated with heavy drinking (Harford 1983) - had the lowest percentage of respondents report heavy drinking. This finding is consistent with recent cross-national data from the mid-1990s showing this context produced the lowest levels of consumption compared with other private and public drinking locations (Kairouz \& Greenfield 2007).

\section{Situational versus Relational Characteristics of the Drinking Context}

In order to determine the impact of situational and relational characteristics of the drinking context on the propensity for heavy drinking, logistic regression analysis was conducted. Logistic regression produces a series of odds ratios, which provide an easily interpretable measure of the strength of the association between predictor and outcome variables. ${ }^{28}$ The data model for this study was constructed using heavy drinking (5+ drinks) on the last drinking occasion as the outcome of interest, and predictors related to the drinking context as the independent variables. The logistic regressions were conducted on the study population in order to answer the following research questions: which relational characteristics are associated with the greatest likelihood of heavy

\footnotetext{
${ }^{28} \mathrm{An}$ odds ratio greater than 1.00 indicates that the predictor variable is associated with an increased likelihood of heavy drinking, whereas an odds ratio less than 1.00 indicates that the presence of the predictor variable is associated with decreased likelihood of heavy drinking.
} 
drinking? Which situational characteristics are associated with the greatest likelihood of heavy drinking? Do situational characteristics of the drinking context provide greater explanatory value than relational characteristics?

Separate logistic regression analyses were conducted for variables that compose the relational characteristics of the drinking context, and those that compose the situational characteristics of the drinking context. This was done in order to determine which characteristics of the drinking context - the relational or the situational - helped account for the propensity of heavy drinking in Canadian adults. Variables were placed into the models as blocks, using an enter method. ${ }^{29}$ The full models containing the relational or situational sets were adjusted for gender and age. A dichotomous measure of male/female was used for the gender variable, while under 25 years of age/over 25 years of age served as the measure for the age variable. The full models contain all relevant variables for each characteristic, with bivariate models examining the relationship between individual independent measures and the outcome variable only. To address the above-mentioned research question, an R-square measure is calculated to provide an approximation of the variance explained by each of the full models. ${ }^{30}$ The following results are presented first for the relational variables (Table 5.5), and then for the situational variables (5.6).

Relational characteristics of the drinking context were significantly predictive of heavy drinking, contributing to approximately $18 \%$ of the variance in drinking behaviour

\footnotetext{
${ }^{29}$ The enter method is the default method for entering predictor variables into a binomial logistic regression in SPSS. Details of this method were provided previously in Chapter Four (page 72).

${ }^{30}$ Nagelkerke R-square is analogous to R-square in multiple linear regression. However, it does not have the same variance interpretation as R-square for linear regression because the variance of a dichotomous dependent variable depends on the frequency distribution of that variable. As such, caution should be taken with interpreting these variance scores.
} 
by Canadian adults. Situational characteristics of the drinking context, however, accounted for a total $28 \%$ of the variance in heavy drinking by Canadian adults, meaning its predictive value was greater than for the former set of contextual variables. This was consistent with this author's hypothesis, and with previous research examining the relationship between the majority of these variables and heavy drinking occasions (Demers 1997; Demers et al. 2002; Knibbe et al. 1993).

A number of variables were predictive of heavy drinking when considering relational characteristics of the drinking context (Table 5.5). In analyzing the full subpopulation of Canadian adults, those who reported drinking with co-workers or with friends were over twice as likely to report heavy drinking on their last occasion of alcohol consumption $(\mathrm{OR}=2.26, p=.004$ and $\mathrm{OR}=2.24, p=<.001$, respectively), than when drinking with family members. Drinking with a combination of drinking companions that is, a combination of friends, co-workers, and/or family members - was not significantly different from the reference category (drinking with family) when placed in an analysis of all relational variables. Since drinking with family members is associated with lower levels of alcohol consumption (Calahan et al. 1969), it could be surmised that having a mixture of different drinking companions may also reduce the chances of consuming five or more drinks during drinking occasions. However, the bivariate model examining the association between this relational characteristic and heavy drinking showed a significant positive association. Although the number of individuals drinking with a combination of drinking companions is small $(n=74)$, the likelihood of reporting heavy drinking was still high $(\mathrm{OR}=1.80, p=<.05)$, meaning further research into this category and its related drinking patterns may be needed. 


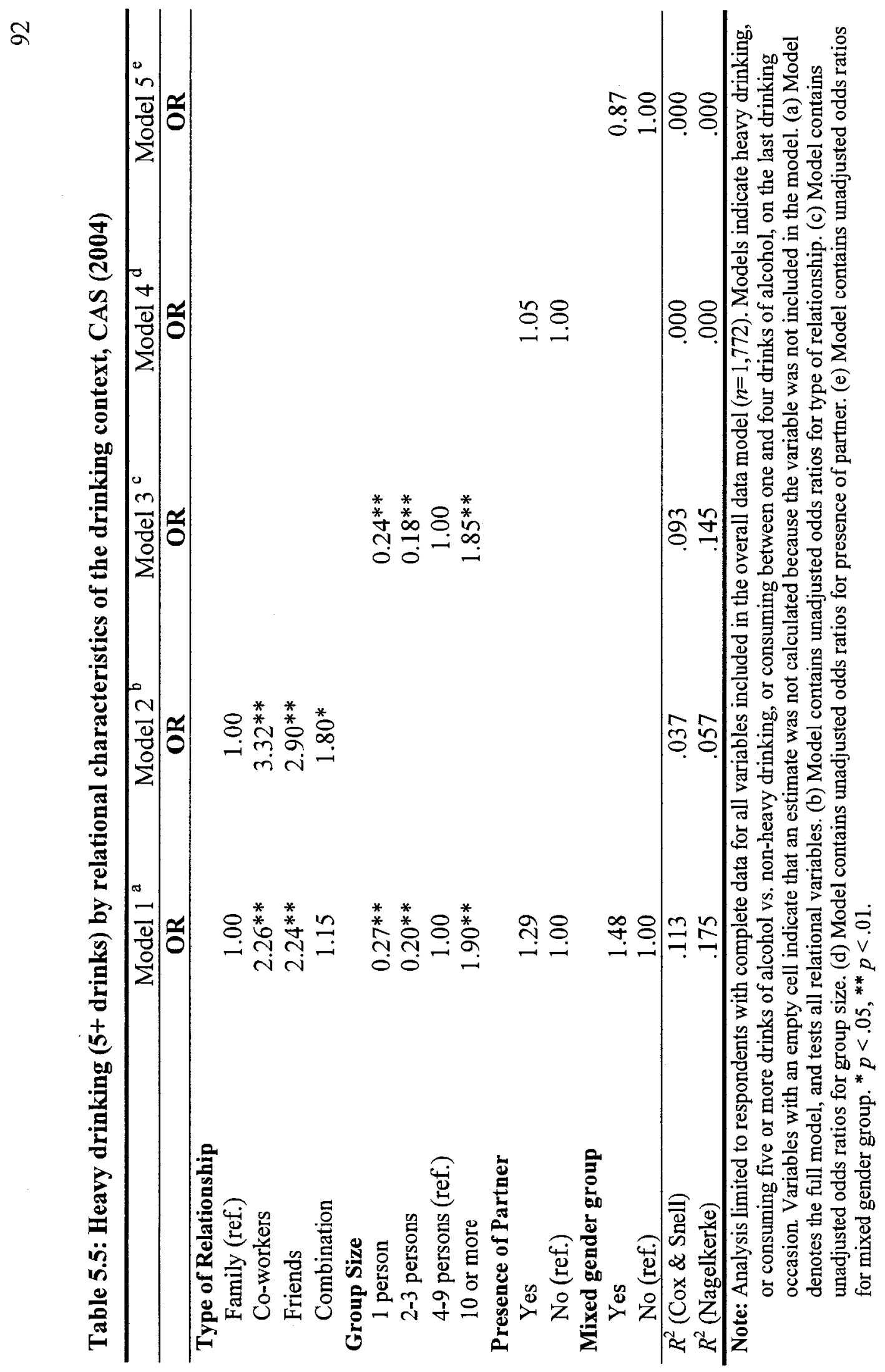


Consistent with previous research on heavy alcohol consumption (Harford 1983; Mayer et al. 1998), drinking with friends was predictive of heavy drinking for this research population. Since friends remain the primary drinking group for Canadian adults, future research and prevention work may wish to emphasize the influence of peers on drinking behaviour, even amongst adults. Currently, much of the focus around peers and substance abuse emphasizes these relationships for adolescents, noting that characteristics of certain peer groups can present as a risk factor for alcohol consumption. The findings here suggest this relationship persists among adults as well. Further, examination of drinking norms and expectations when drinking with friends may provide some insight into ways to promote more moderate drinking behaviour through friend/peer networks. At the same time, drinking with co-workers also displayed a positive association with consuming five or more drinks on the last drinking occasion. Results showed that this characteristic was the strongest predictor of heavy drinking within the relationship variable $(\mathrm{OR}=3.32$, $p=<.001$ ), as well as the full model comparing all relational characteristics. Moderate drinking has traditionally been associated with drinking occasions with other groups, such as co-workers. However, for this subset of respondents, the odds of reporting heavy drinking were approximately the same as drinking with friends. This finding is interesting, although it is difficult to make any conclusions as to its significance. Few studies have examined drinking with co-workers in any detail, and the studies that do look at alcohol and the workplace have examined patterns of consumption before or during work, during business meetings or "the business lunch", or alcohol-related consequences such as lost productivity (Kilty 1980; Blum \& Roman 1997). Recent research on the drinking practices of Alberta workers found drinking with co-workers to be predictive of heavy drinking, although in many cases this was relegated to certain types of occupations 
(Garabedian 2006). The National Alcohol Strategy Working Group noted that alcohol consumption by workers may be affected by the presence of a work-place culture that promotes heavy drinking (Reducing Alcohol-Related Harm in Canada 2007). Research into such trends may help explain the results found here.

The only other relational characteristic that showed significant results for heavy drinking was the size of the drinking group. Among Canadian adults, drinking in smaller groups was associated with a decreased likelihood of heavy drinking. Those consuming alcohol with one other person $(\mathrm{OR}=0.27, p=<.001)$ or two to three people $(\mathrm{OR}=0.20$, $p=<.001)$ were significantly less likely to report heavy drinking. Consequently, those adults drinking in groups of 10 or more people were almost twice as likely $(\mathrm{OR}=1.90$, $p=<.001)$ to consume five or more drinks on their last drinking occasion, compared to the reference category. Bivariate models produced similar results, meaning this relationship held fairly constant even when incorporating other relational variables into the model. The findings from this study are consistent with previous research on the effect of group size on levels of alcohol consumption (Cutler \& Storm 1975; Single 1985; Sommer 1965). The odds of heavier drinking will be less for Canadian adults who consume alcohol in small groups. Drinking in larger groups may increase the chances of having more heavy drinkers included as part of the drinking occasion. Single's (1985) research showed that increased consumption by one individual within the group can impact positively on the levels of alcohol consumption by other members of the drinking group. This may be linked to interactional dynamics, such as the purchasing of 'rounds' (Kairouz \& Greenfield 2007), or the incorporation of other social drinking elements, such as 'drinking games' (Borsari 2004). Further analysis of the strength of this variable in relation to others in the drinking context - particularly situational characteristics such as 
drinking location or drinking at parties - may impact upon the statistical association observed here.

Drinking in the presence of one's partner, or with only same-gendered drinking partners, were not associated with heavy drinking. Given research by Demers (1997) and Hennessy and Saltz (1993) showing an association between drinking with same-gendered drinking partners and levels of consumption, it was anticipated that Canadian adults might exhibit similar patterns when drinking with their same-sex peers. However, the data here do not support this conclusion. Additional analysis examining whether gender plays a role in this relationship - if it is only observed among men, as suggested by Van der Goor et al. (1990) - may provide further insight into any possible associations. However, given that coding for this variable was designed to capture males drinking in all-male groups, or women drinking in all-female groups, further distinction according to the gender of the respondent may not produce findings that are any different.

When examining the situational characteristics of the drinking context, four of the five variables tested were predictive of heavy drinking in the full model (Table 5.6). The three drinking circumstances that were tested as part of this analysis were significantly related to a decreased likelihood of heavy drinking on drinking occasions. Drinking at a party has traditionally been associated with higher levels of alcohol consumption on single occasions (Harford et al. 1980; Single \& Wortley 1993), and the results clearly show that it is linked to heavy alcohol consumption, at least in relation to other circumstances. Drinking at a 'get together' $(\mathrm{OR}=0.60, p=<.001)$, during daily $(\mathrm{OR}=0.09$, $p=<.001)$ or other $(\mathrm{OR}=0.63, p=.042)$ circumstances were all associated with reduced odds of consuming five or more drinks. The results on drinking in 'daily life' circumstances are consistent with research by Simpura (1987), which found everyday-life 


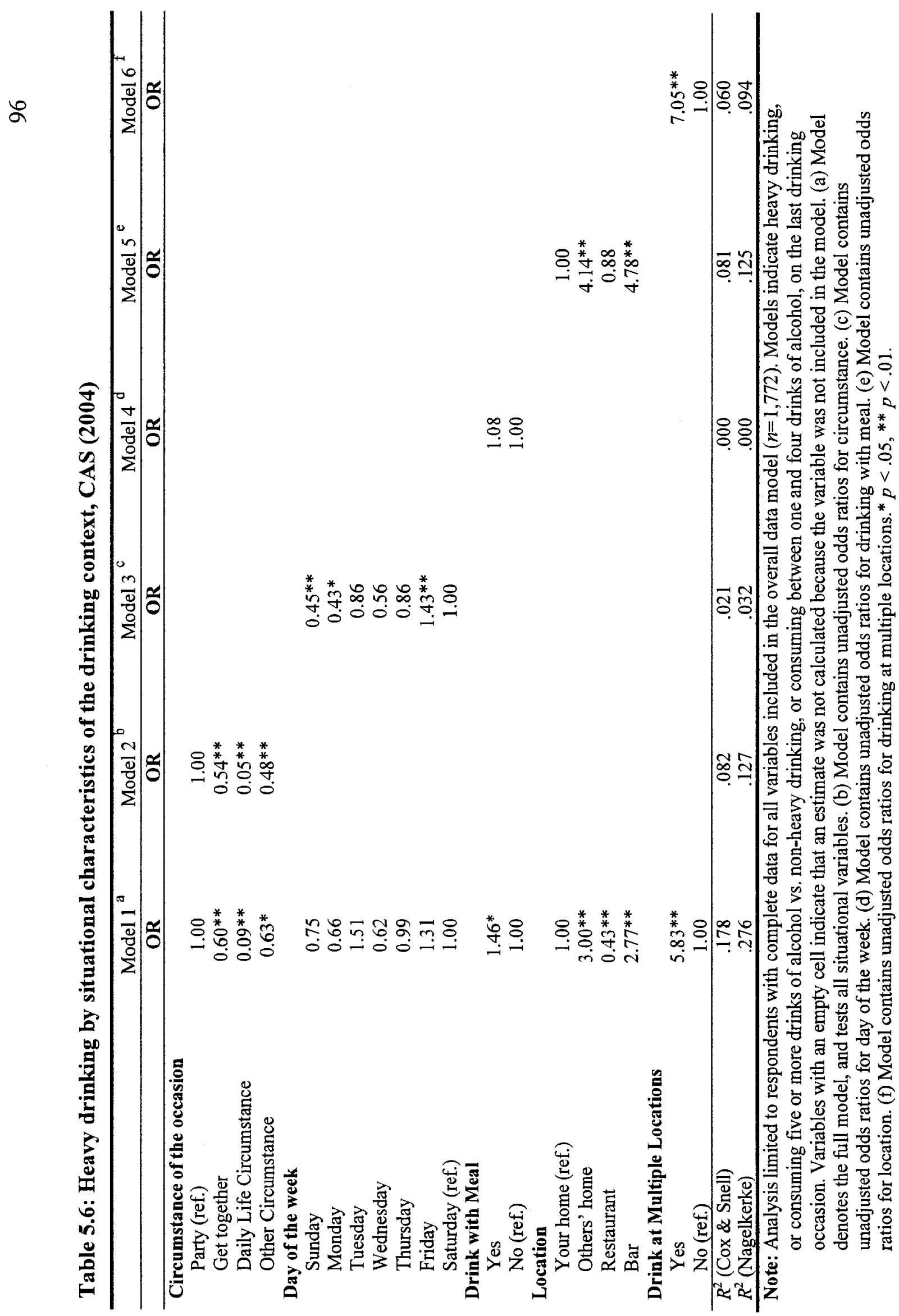


contexts to be associated with lower levels of alcohol consumption. At the same time, the odds of reporting heavy drinking during 'a get together' was also less likely than at parties, meaning Canadian adults engaged in drinking occasions with other adults seem to be imposing limits on their drinking. This is important, considering drinking at a 'get together' was the most common drinking circumstance reported by this population. These findings are promising considering the aims of a National Alcohol Strategy in promoting sensible and responsible alcohol use among Canadians (Reducing Alcohol-Related Harm in Canada 2007).

In terms of location, drinking at someone else's home $(\mathrm{OR}=3.00, p=<.001)$ was associated with the highest odds heavy drinking for this variable, when considering the full situational context model. This finding was unexpected, given that public settings have generally been associated with higher levels of alcohol intake that private settings (Harford 1983). It is nonetheless consistent with research by Greenfield and Room (1996), pointing to greater acceptance of drinking 'to feel the effects' when drinking at a home residence with friends. It would seem that, for Canadian adults, a similar relationship exists, although it instead involves drinking at the home of someone else when seeking to drink to the point where they can arguably 'feel the effects'. As expected, a significantly higher odds of heavy drinking was reported for Canadians who consumed alcohol at a bar, disco or nightclub during their last drinking occasion $(\mathrm{OR}=2.77, p=<.001)$. This is consistent with the research literature on heavy drinking and public drinking establishments (Caetano \& Herd 1988; Clark 1985; Harford 1979; Herd \& Grube 1993). The odds of drinking heavily increased by 2.8 times when at a public, licensed venue such as this, in comparison to consuming at their own home. This finding is also consistent with previous research on national survey data from Canada, which 
found adults to be more likely to report heavy drinking on a drinking occasion when it took place at a bar or tavern (Single \& Wortley 1993). Other national survey data pointed to restaurants as contexts where lower levels of consumption occurred (Kairouz \& Greenfield 2007). The results here show a decreased odds of heavy drinking when alcohol consumption occurred at a restaurant $(\mathrm{OR}=0.43, p=<.001)$. While the literature has shown conflicting findings in relation to the propensity for heavy drinking in public drinking venues such a restaurants, for this study population, it functioned as a protective factor. Canadian adults were half as likely to report consuming five or more drinks at a restaurant, than in their own home. This suggests that while drinking at bars and pubs are conducive to occasions of intoxication - or as Measham would argue, spaces where 'determined drunkenness' is considered appropriate - restaurants act as a public space which still maintains an atmosphere of civilized and sensible drinking in Canada.

Two other situational characteristics, drinking with a meal, and drinking at multiple locations, were associated with higher odds of heavy drinking. While not significant as a bivariate relationship, when considering other situational characteristics, drinking with a meal increased the likelihood of heavy drinking by approximately 50 percent $(\mathrm{OR}=1.46, p=.039)$. Contrary to existing literature in the area (Demers 1997; Simpura 1987), Canadian adults were more likely to drink heavily when consuming alcohol with a meal. Also, the odds of heavy drinking when consuming alcohol at multiple locations was over 5 times greater than those consuming alcohol at a single location $(\mathrm{OR}=5.83, p=<.001)$. While this situational characteristic was the most predictive of heavy drinking in the model, this finding should be interpreted with caution, given the small percentage of respondents $(n=156)$ reporting this contextual variant. Additional 
research into both these findings, and their implications on the intake of alcohol by Canadians, is required.

Research on temporal factors associated with drinking have generally found the amount of alcohol consumed on weekends to be substantially higher than that consumed during the week (Arfken 1988). However, for this subset of respondents, there was no significant relationship observed between the day of the week and heavy drinking, when considering the situational context model. While bivariate models on the day of the week showed that Canadian adults were more likely to report heavy drinking on Fridays $(\mathrm{OR}=1.43, p=<.001)$, and less likely to report heavy drinking on Sundays $(\mathrm{OR}=0.45$, $p=<.001)$ and Mondays $(\mathrm{OR}=0.43, p=<.05)$, this relationship disappeared once other situational variables were considered. The lack of differentiation in the odds of heavy alcohol consumption on weekdays and weekends suggests that the 'day of the week' may not influence heavy drinking as originally thought. Traditionally, weekends served as appropriate contexts for heavy drinking (Single 1985), with individuals reserving their Friday and Saturday nights for leisure pursuits involving alcohol. This has also been observed more recently with adolescents and youth in the U.S. and U.K., who reported heavier consumption of alcohol on weekends (Mayer et al. 1998; Harnett et al. 2000). Nevertheless, for Canadian adults, it would seem that none of the days of the week from the model were significantly different from the reference category, or drinking on Saturday. This finding could be related to a number of factors. For example, elements pertaining to the coding of this situational characteristic may have be involved, as Saturday - a day of the week associated with a high proportion of drinking occasions was used as the reference category. While the decision to use Saturday as a reference for this variable was consistent with the coding of the day of the week in the two main 
studies that inform this research (Demers 1997; Demers et al. 2002), it nevertheless represents a substantial percentage of the last drinking occasions for Canadian adults (40.2\%). Given the number of adults reporting consuming alcohol on this day, and previous research findings on the propensity for heavier intake on weekends, it is somewhat surprising that other days of the week were not related to less drinking, as was the case in the bivariate model. It would seem that other situational characteristics of the drinking context are more predictive of heavy drinking for this population, and may deserve a larger focus in future research.

\section{The Drinking Context and Heavy Drinking}

In order to determine which characteristics of the drinking context carried the most predictive value in accounting for heavy drinking, logistic regression analyses were run after entering all variables that compose the drinking context. The data model for this analysis was constructed using heavy drinking (5+ drinks) on the last drinking occasion as the outcome of interest, and predictors related to all nine variables of the context of alcohol consumption as the independent variables. The logistic regressions were conducted on the study population in order to address the primary research question, or the impact of characteristics of the drinking context on the propensity for heavy drinking by Canadian adults. Variables were placed into the model as blocks, using an enter method. ${ }^{31}$ This data model was also adjusted for gender and age. ${ }^{32}$ The following results are presented in Table 5.7.

\footnotetext{
${ }^{31}$ The enter method is the default method for entering predictor variables into a binomial logistic regression in SPSS. Details of this method were provided previously in Chapter Four (page 71).

${ }^{32}$ As noted previously, age and gender are important in accounting for differences in drinking behaviour amongst populations, including both the frequency and intensity of alcohol consumption. Heavy drinking is more likely among younger populations compared to older populations, and with men as opposed to
} 
A number of variables were predictive of heavy drinking ( $5+$ drinks) for the study population in relation to the drinking context, including the type of relationship with drinking companions, the size of the drinking group, the presence of one's romantic partner, the drinking circumstance, the day of the week, drinking with a meal, the location of the drinking occasion, and whether drinking took place at multiple locations. Overall, eight of the nine variables tested were predictive of heavy drinking in this study population.

When considering the full model - which incorporated both relational and situational characteristics of the drinking context - drinking with co-workers was significantly predictive of heavy drinking. Canadian adults who reported drinking with this type of drinking companion had over a four-fold increase in the likelihood of heavy drinking $(\mathrm{OR}=4.39, p=<.001)$, than when drinking with family members. The strength of this finding was unexpected, particularly in light of the absence of a relationship between consuming with friends and heavy drinking. Based on the available literature, drinking with friends is usually associated with higher levels of alcohol consumption in both youth (Mayer et al. 1998) and adults (Harford 1983). However, the data tells us that Canadian adults are over 4 times more likely to drink heavily when having co-workers as their drinking companions. The association between heavy drinking and drinking with coworkers is unclear. The studies that have examined this relationship have focused mainly on other contextual factors, such as drinking on the worksite or during business events.

women. As such, attempts were made to control for these influences by including them within the model. For age in particular, individuals under 25 years of age may not have entered into traditional adult roles (i.e., students), and as a result, are likely to engage in riskier practices associated with alcohol. As one progresses through the life course, and takes on additional responsibilities such as marriage or parenthood, there is an associated decrease in alcohol consumption, frequency of heavy drinking, and alcohol-related problems (Neve et al. 2000). Consistent with previous research on the drinking context (Demers 1997), a decision was made to include a dichotomous measure of age in this analysis. 
Table 5.7: Heavy drinking by characteristics of the drinking context, CAS (2004)

\begin{tabular}{|c|c|c|}
\hline & \multicolumn{2}{|c|}{ Full Model ${ }^{a}$} \\
\hline & OR & $p$ \\
\hline \multicolumn{3}{|l|}{ Type of Relationship } \\
\hline Family (ref.) & 1.00 & \\
\hline Co-workers & $4.39^{* *}$ & $<.001$ \\
\hline Friends & 1.33 & .125 \\
\hline Combination & 0.73 & .296 \\
\hline \multicolumn{3}{|l|}{ Group Size } \\
\hline 1 person & 0.65 & .189 \\
\hline $2-3$ persons & $0.31^{* *}$ & $<.001$ \\
\hline 4-9 persons (ref.) & 1.00 & \\
\hline 10 or more & 1.38 & .060 \\
\hline \multicolumn{3}{|l|}{ Presence of Partner } \\
\hline Yes & $1.72 * *$ & .001 \\
\hline No (ref.) & 1.00 & \\
\hline \multicolumn{3}{|l|}{ Mixed gender group } \\
\hline Yes & 1.23 & .466 \\
\hline No (ref.) & 1.00 & \\
\hline \multicolumn{3}{|l|}{ Circumstance of the occasion } \\
\hline Party (ref.) & 1.00 & \\
\hline Get together & 0.83 & .265 \\
\hline Daily Life Circumstance & $0.16^{* *}$ & $<.001$ \\
\hline Other Circumstance & 1.05 & .840 \\
\hline \multicolumn{3}{|l|}{ Day of the week } \\
\hline Sunday & 0.93 & .787 \\
\hline Monday & 0.77 & .563 \\
\hline Tuesday & $1.94^{*}$ & .024 \\
\hline Wednesday & 0.53 & .078 \\
\hline Thursday & 1.15 & .577 \\
\hline Friday & $1.58^{*}$ & .015 \\
\hline Saturday (ref.) & 1.00 & \\
\hline \multicolumn{3}{|l|}{ Drink with Meal } \\
\hline Yes & $1.58 *$ & .015 \\
\hline No (ref.) & 1.00 & \\
\hline \multicolumn{3}{|l|}{ Location } \\
\hline Your home (ref.) & 1.00 & \\
\hline Others' home & $2.14^{* *}$ & $<.001$ \\
\hline Restaurant & $0.26^{* *}$ & $<.001$ \\
\hline Bar & $1.83^{*}$ & .026 \\
\hline \multicolumn{3}{|l|}{ Drink at Multiple Locations } \\
\hline Yes & $5.99 * *$ & $<.001$ \\
\hline No (ref.) & 1.00 & \\
\hline$R^{2}($ Cox \& Snell $)$ & \multicolumn{2}{|c|}{.237} \\
\hline$R^{2}$ (Nagelkerke) & \multicolumn{2}{|c|}{.369} \\
\hline \multicolumn{3}{|c|}{$\begin{array}{l}\text { Note: Analysis limited to respondents with complete data for all variables included in the overall data } \\
\text { model }(n=1,772) \text {. Models indicate heavy drinking, or consuming five or more drinks of alcohol vs. } \\
\text { non-heavy drinking, or consuming between one and four drinks of alcohol, on the last drinking } \\
\text { occasion. (a) Model denotes the full model, and tests all situational variables, controlling for age. } \\
{ }^{*} p<.05,{ }^{* *} p<.01 \text {. }\end{array}$} \\
\hline
\end{tabular}


With sixty-five percent of the research population being employed, additional research into the types of occupations that comprise those reporting heavy drinking when drinking with co-worker(s) may provide some insight on the reasons for such an elevated propensity for heavy drinking in this population. Roman and Blum (1997) found that individuals who were employed in traditionally male occupations were more likely to engage in drinking activities with their co-workers than were those working in female dominated or mixed gender occupations. It may be that certain occupations are prone to a workplace culture that fosters convivial atmospheres for drinking with colleagues generally, or engaging in heavy drinking more specifically. Alternatively, the relationship observed here may be dependent upon other factors such as gender, as suggested by the work of Roman and Blum (1997).

Only one characteristic relating the size of the drinking group was predictive of heavy alcohol consumption. The odds of heavier drinking will be less for individuals drinking with two to three people $(\mathrm{OR}=0.31, p<.001)$. While all three characteristics were related to the likelihood of reporting heavy drinking for the model containing only relational characteristics, only drinking with two to three people proved to be significant once all characteristics of the drinking context were considered in the model. This finding is consistent with existing literature on the impact group size has on levels of alcohol consumption (Cutler \& Storm 1975; Single 1985; Sommer 1965). Specifically, past research has found drinking in larger groups to be predictive of heavy drinking, whereas consuming alcohol in small groups is associated with more moderate consumption. When analyzing the effect of group size on drinking, in relation to other contextual variables, drinking in larger groups (i.e., 10+) was not significantly different from drinking in groups of four to nine persons. This finding contradicts existing research showing a 
positive effect of larger drinking groups on alcohol intake. Given a higher critical p-value $(\mathrm{OR}=1.38, p=.060)$, however, the findings may be relevant for Canadian adults. It would seem that the size of the drinking group remains an important characteristic related to the context of alcohol consumption. Whereas heavy drinking was less likely when consuming alcohol in small groups, as the number of drinking partner's increases, one may be more likely to consume greater amounts of alcohol. This may reflect appropriate situations to engage in 'calculated hedonism', with adults seeking to achieve a "structured and controllable altered state of intoxication" (Measham 2004b) when surrounded by a number of drinking partners, and more moderate states around smaller numbers of individuals. Further research on the reasons and motivations for drinking in certain contexts, and to certain levels of intoxication, may serve to illuminate this relationship. Those adults who reported drinking with their partner on the last drinking occasion were 1.7 times more likely $(p=.001)$ to report heavy alcohol consumption than those adults whose partners were not present at the drinking occasion. This finding seems to contradict the research by Hennessy and Saltz (1993), which determined that consumption in gender-mixed drinking couples was generally low. The results presented here are unexpected, and require further analysis to determine if other factors, such as gender, affect this relationship. Again, the likelihood of heavy drinking does not decrease in the presence of one's partner, which may be a result of the high proportion of individuals that reported being married or having a partner. As almost 60 percent of the study population falls under this category, and a similar percentage reported having their partner present during the last drinking occasion, it is reasonable to expect a higher proportion of heavy drinking occasions to be reported alongside this variable. The use of 
future survey attempts around heavy drinking and the drinking context could be used to confirm or refute this relationship.

With regards to the circumstance of the drinking occasion, the likelihood of heavy drinking at a 'get together' was not significantly different from reporting this behaviour at a party. The same can be said of occasions that involved 'other circumstances'. Drinking at 'parties' is usually linked to occasions of heavy alcohol consumption (Harford et al. 1980; Single \& Wortley 1993), meaning the odds of heavy drinking in different circumstances would likely be decreased. For this study population, this was not the case. It is unclear exactly what these circumstances are comprised of in terms of activities and meaning, and as such, delving into the cultural importance of these drinking circumstances for Canadians may prove useful. Drinking as a daily life circumstance, however, was associated with a decreased likelihood of heavy drinking $(\mathrm{OR}=0.16$, $p=<.001)$. This is consistent with research from Finland showing decreased levels of alcohol consumption during everyday-life drinking occasions (Simpura 1987). Emphasis, in their case, was placed on the 'non-ordinary' nature of the context. Given Clark's (1985) research, which found circumstances such as evenings at home, watching TV, and having visitors together account for roughly 30 percent of all drinks taken during an average month, additional analysis on the circumstances of drinking by this study population is required.

Most of the days of the week from this model were not significantly different from the reference category, or drinking on Saturday, except for drinking that occurred on Tuesdays ( $\mathrm{OR}=1.94, p=.024)$ or Friday's $(\mathrm{OR}=1.58, p=.015)$. Given the large body of research pointing to increased alcohol intake on weekends, which are associated with leisure pursuits, the finding that drinkers who consumed alcohol on Tuesday were almost 
twice as likely to report heavy drinking was surprising. These findings suggest that heavy drinking and leisure pursuits might be more normalized during the week for Canadian adults. Some survey data from the UK indicates that changes in drinking patterns may be occurring, with a preference towards increased propensity for drinking and consuming higher quantities of alcohol on weekdays among younger adults (Goddard 1997a; Goddard 1997b; Roberts et al. 1997). With the expansion of peer groups that occurs as one becomes an adult (Harnett et al. 2000), and with the transition towards adulthood becoming evermore elongated (Neve et al. 2000), opportunities for drinking may be expanding to include non-traditional days of the week. If weekends are to be designated for controlled intoxication and hedonistic pursuits, weekdays may offer opportunities for other socialization efforts, such as drinking with co-workers, or pursuing intimate relationships through dating occasions. Given O'Hare's (1998) research on heavy drinking and personal-intimate encounters, further exploration into weekday drinking contexts may provide some insight into this relationship.

Also surprising was the finding that, once all the drinking context variables were included in the model, adults who consumed alcohol at another person's home $(\mathrm{OR}=2.14$, $p=<.001$ ) were more likely to report heavy drinking than those adults whose drinking occasion occurred at a bar, disco or nightclub ( $\mathrm{OR}=1.83, p=.026)$. Drinking at someone else's home was one of the strongest predictors of heavy drinking in this study population. At the same time, drinking in other licensed venues such as restaurants was associated with more moderate consumption of alcohol $(\mathrm{OR}=0.26, p=<.001)$. Existing research in the field has found restaurants to be places of both heavy drinking (Harford 1983 ) as well as lower levels of alcohol consumption (Kairouz \& Greenfield 2007). This finding confirms research by Kairouz and Greenfield (2007) that this public venue seems 
to be a space where sensible drinking is the norm. Additional analysis looking specifically at males and females should determine if this relationship is consistent across genders for Canadian adults. In terms of location, a greater propensity for heavy drinking in both private and public spaces represents a challenge for goals of cultural moderation with regards to alcohol consumption (Reducing Alcohol-Related Harm in Canada 2007. Drinking at the home of other individuals may no longer represent a context in which responsible drinking is taking place, at least to the extent to which respondents are reporting hazardous levels of consumption. Given the large number of Canadians reporting alcohol consumption at others' homes, this finding may have policy implications around acute harms from alcohol, including alcohol poisoning, unwanted sexual advances or assaults, and drunk driving (Reducing Alcohol-Related Harm in Canada 2007. Additional analysis will need to determine to what extent this relationship is mitigated by factors such as age or gender of the respondent.

Also contrary to what was expected, drinking with a meal was associated with approximately a 1.6 times higher likelihood of heavy drinking on the last drinking occasion ( $\mathrm{OR}=1.58, p=.015)$, than when drinking without having a meal. This finding runs contrary to research by Demers (1997), which showed decreased odds of heavy drinking when Montrealers consumed alcohol with a meal. The data tells us that a moderating effect of having a meal is not present amongst the general Canadian population. Given Demers' findings, however, additional analysis of the CAS data may wish to examine whether cultural differences in the way alcohol is consumed can account for a higher likelihood of heavy drinking by adults. As noted previously, individuals from Quebec reported the lowest proportion of consuming five or more drinks during drinking occasions in Canada, suggesting that moderate alcohol use may be incorporated into more 
ordinary drinking situations, such as with meals. This may account for why the odds of heavy drinking with meals were lower among Montrealers than the general Canadian population. Additional research in this area, as well as along gender lines, is required to help explain these results.

Of particular note in this study was the association between consuming alcohol at multiple locations and heavy drinking. The presence of this contextual predictor increased the likelihood of heavy drinking almost six-fold ( $O R=5.99, p=<.001)$. Given the dearth in literature on this subject, future research should aim to determine whether similar results are observed for other populations. This should include particular attention to youth and young adults, most specifically those currently enrolled in post-secondary studies. These factors may also be economic. While seeking to minimize the costs associated with becoming intoxicated, individuals may consume alcohol in a residential location before moving to more public venues, thus reducing the amount spent at higher-cost drinking establishments. A discussion of this point in relation to Measham's notion of 'calculated hedonism' is presented in Chapter 7.

\section{Summary}

Overall, characteristics of the drinking context were found to be important variables at predicting heavy drinking among Canadian adults. A key finding from this chapter identified that situational variables accounted for a higher proportion of variance in drinking behaviour than relational variables. Taking all variables of the drinking context into account, the odds of heavy drinking increased for relational characteristics, such as when consuming alcohol with co-workers as drinking companions and drinking in the presence of their romantic partner. Another major finding was that drinking with co- 
workers significantly increased the odds of heavy drinking. Situational characteristics were also predictive of consuming five or more drinks on the last drinking occasion. Variables pertaining to the day of the week, whether drinking occurred with a meal, the location and when consuming in multiple locations were associated with an increased likelihood of heavy drinking. In particular, Canadians who reported drinking on Tuesday or Friday, or at a bar or the home of someone else, were between 1.5 and 2.1 times more likely to consume five or more drinks, compared to their relevant reference categories. Finally, the odds of heavy drinking decreased when drinking during daily life circumstances, in smaller groups of people, and consuming alcohol in restaurants. 


\section{CHAPTER SIX}

\section{GENDER DIFFERENCES BETWEEN HEAVY DRINKING AND THE DRINKING CONTEXT}

This chapter presents the findings of a gender analysis of relational and situational characteristics of the drinking context on the propensity for heavy drinking. The first section contains descriptive analysis on the sample populations of Canadian females and males. Descriptive information on the situational and relational characteristics of the drinking context, as well as data on specific characteristics of the drinking context in relation to heavy drinking, are presented for 952 females and 1,207 males. Following this, the findings of the logistic regression analysis that was conducted for males and females, taking heavy drinking as the outcome variable, are presented. To remain consistent with emerging research on gender differences in heavy alcohol consumption, as well as previous research on the drinking context, separate measures of heavy drinking are employed for men ( $5+$ drinks) and women (4+drinks). To determine which variables related to the drinking context had an impact on heavy drinking, odds ratios are presented, with results separated based on the gender of the respondent. Odds ratios greater than 1.00 indicate that the presence of the predictor variable was associated with increased likelihood of heavy drinking, whereas odds ratios less than 1.00 indicate that the presence of the predictor variable were associated with decreased likelihood of heavy drinking.

\section{Description of Drinking Behaviour by Gender}

This section describes the drinking practices of males and females from the study population, as reported for the last occasion of drinking. Since men generally consume 
more alcohol than women, it would be expected that a higher proportion of men would report consuming five or more drinks per occasion than women. Table 6.1 shows that

Table 6.1: Distribution non-heavy drinkers and heavy drinkers (5+ drinks) on the last drinking occasion, by gender, CAS (2004)

\begin{tabular}{lcc}
\hline Alcohol intake per occasion & $\begin{array}{c}\text { Females } \\
(n=952) \\
\text { Percentage (Frequency) }\end{array}$ & $\begin{array}{c}\text { Males } \\
(n=1,207) \\
\text { Percentage (Frequency) }\end{array}$ \\
\hline Four drinks or fewer & $85.7 \%(816)$ & $76.3 \%(921)$ \\
Five or more drinks (5+) & $14.3 \%(136)$ & $23.7 \%(286)$ \\
\hline
\end{tabular}

Note: Total population $(n=2,160)$. Frequency $(f)$ represents the maximum number of adults providing data to questionnaire on last drinking occasion.

$23.7 \%$ of men reported consuming 5 or more drinks on the last drinking occasion, compared to only $14.3 \%$ of women. However, researchers have noted differences in the way women and men metabolize alcohol (Johnson 1991; Lieber 1993), as well as the quantity of alcohol associated with alcohol-related problems (Wilsnack et al. 2000). Many support a lower cut-off for heavy drinking among women (Adlaf et al. 2005; Dowdall \& Wechsler 2002; Wechsler et al. 1995). Indeed, when comparing heavy drinking between men and women using a modified outcome measure to reflect heavy alcohol consumption ( $5+$ drinks for men, $4+$ drinks for women), the rates of heavy drinking between the genders is more comparable. Table 6.2 presents the proportion of heavy alcohol consumption by gender, using gender-specific measures of heavy alcohol consumption. Mean consumption for males is 3.45 drinks, whereas for women it is 2.77 drinks. The standard deviation of reported number of drinks was 3.04 for men and 2.12 for women, meaning the dispersion of the number of drinks around the mean was higher among males. However, the percentage of women reporting heavy drinking is higher (24.9\%) than the percentage reported by males $(23.7 \%)$ when the cut-off is adjusted for 
Table 6.2: Distribution non-heavy drinkers and heavy drinkers (4+ females/5+ males) on the last drinking occasion, by gender, CAS (2004)

\begin{tabular}{lcc}
\hline Alcohol intake per occasion & $\begin{array}{c}\text { Females } \\
(n=952) \\
\text { Percentage (Frequency) }\end{array}$ & $\begin{array}{c}\text { Males } \\
(n=1,207) \\
\text { Percentage (Frequency) }\end{array}$ \\
\hline Non-heavy drinking & $75.1 \%(715)$ & $76.3 \%(921)$ \\
Heavy drinking & $24.9 \%(237)$ & $23.7 \%(286)$ \\
\hline $\begin{array}{l}\text { Number of drinks reported on the last drinking } \\
\text { occasion }\end{array}$ & Mean (s.d.) & Mean (s.d.) \\
\hline
\end{tabular}

Note: Total population $(n=2,160)$. Frequency $(f)$ represents the maximum number of adults providing data to questionnaire on last drinking occasion.

gender. The consumption of five or more drinks for men, or four or more drinks for women, on a single drinking occasion has been shown to increase the risk of experiencing alcohol-related harms. Given Johnson (1991) and Lieber's (1993) research on differences in levels of blood-alcohol between men and women consuming the same number of drinks, women reporting heavy drinking (4+ drinks) seem to have a greater chance of being intoxicated at this level of consumption. Also, with research noting that women may experience a greater likelihood of negative consequences related to their alcohol consumption (Kranzler et al. 1990; Bondy 1996; Rehm et al. 1996), the similarities in relative heavy drinking between men and women is of concern.

\section{Description of Characteristics of the Drinking Context by Gender}

As noted previously, the drinking context is operationalized here as where, when and with whom drinking occurred. This includes characteristics that are both relational and situational in nature, and related to the last drinking occasion where drinking took place. Table 6.3 presents descriptive information on the different characteristics of the 
drinking occasion, separated according to the gender of the respondent. Differences in reported characteristics of the drinking context can be observed between males and females in this study population. Among the relational characteristics of the drinking occasion, the type of drinking companion produced moderately significant differences by gender $\left(x^{2}=7.706, p .052\right)$. A slightly higher percentage of men reported consuming alcohol with friends (49.6\%) and with a combination of drinking companions (10.6\%), than women ( $46.8 \%$ and $8.1 \%$ respectively). Women, however, reported a slightly higher proportion of drinking with family members (39.4\%) than men (34.7\%). Drinking with co-workers was reported by a similar proportion of males and females in this study population. Of note was the finding that women were more likely to consume alcohol in the presence of their partner than were men (64.5\% vs. 58.8\%), and well as in mixedgender drinking groups ( $94.7 \%$ vs. $87.4 \%$ ). These results tell us that Canadian men seem to prefer drinking with other males more than women with other females, at least to the degree that they report their partner or other opposite-gender companions are present during the drinking occasion. Results also show that for the situational characteristics of the drinking occasion, gender differences could be observed in the days and locations where the drinking occasion took place. Men were more likely than women to report drinking on Saturdays ( $42.0 \%$ vs. $37.9 \%$ ) and Sundays (13.8\% vs. $8.4 \%$ ), whereas a higher proportion of women reported drinking on Thursdays (12.5\% vs. 9.7\%) and Fridays (23.8\% vs. $17.3 \%)$. A slightly higher percentage of women, however, reported drinking on other weekdays, including Monday (5.7\%) and Tuesday (7.8\%), whereas Canadian men (9.1\%) seemed to prefer Wednesday more for weekday drinking occasions. Men were most likely to drink at the home of someone else (39.8\%), and women most likely at their own home (41.5\%). Significant gender differences were 
Table 6.3: Characteristics of the drinking context by gender, CAS (2004)

\begin{tabular}{|c|c|c|c|}
\hline & $\begin{array}{c}\text { Females } \\
(n=952) \\
\text { Percentage (Frequency) } \\
\end{array}$ & $\begin{array}{c}\text { Males } \\
(n=1208) \\
\text { Percentage (Frequency) } \\
\end{array}$ & $p\left(x^{2}\right)$ \\
\hline \multicolumn{4}{|l|}{ Relational Characteristics } \\
\hline $\begin{array}{l}\text { Type of Relationship } \\
\text { Family } \\
\text { Co-workers } \\
\text { Friends } \\
\text { Combination }\end{array}$ & $\begin{aligned} 39.4 \% & (362) \\
5.7 \% & (52) \\
46.8 \% & (430) \\
8.1 \% & (74)\end{aligned}$ & $\begin{aligned} 34.7 \% & (395) \\
5.1 \% & (58) \\
49.6 \% & (564) \\
10.6 \% & (121)\end{aligned}$ & $.052(7.706)$ \\
\hline $\begin{array}{l}\text { Group Size } \\
1 \text { person } \\
2-3 \text { persons } \\
4-9 \text { persons } \\
10 \text { or more }\end{array}$ & $\begin{array}{ll}14.9 \% & (139) \\
20.1 \% & (187) \\
41.2 \% & (384) \\
23.8 \% & (222)\end{array}$ & $\begin{array}{l}16.4 \%(190) \\
22.0 \%(255) \\
37.6 \%(437) \\
24.0 \%(279)\end{array}$ & $.354(3.257)$ \\
\hline $\begin{array}{l}\text { Presence of Partner } \\
\text { Yes } \\
\text { No }\end{array}$ & $\begin{array}{l}64.5 \%(613) \\
35.5 \%(338)\end{array}$ & $\begin{array}{l}58.8 \%(710) \\
41.2 \%(497)\end{array}$ & $.008(7.120)$ \\
\hline $\begin{array}{l}\text { Gender Composition } \\
\text { Mixed } \\
\text { Non-mixed } \\
\end{array}$ & $\begin{aligned} & 94.7 \%(902) \\
& 5.3 \%(50) \\
&\end{aligned}$ & $\begin{array}{c}87.4 \%(1056) \\
12.6 \%(152) \\
\end{array}$ & $<.001(33.751)$ \\
\hline \multicolumn{4}{|l|}{ Situational Characteristics } \\
\hline $\begin{array}{l}\text { Circumstance of the occasion } \\
\text { Party } \\
\text { Get together } \\
\text { Daily Life Circumstance } \\
\text { Other Circumstance }\end{array}$ & $\begin{array}{l}33.1 \%(315) \\
33.8 \%(322) \\
20.1 \%(191) \\
13.0 \%(124)\end{array}$ & $\begin{array}{l}31.3 \%(377) \\
37.1 \%(447) \\
21.1 \%(254) \\
10.6 \%(128)\end{array}$ & $.170(5.030)$ \\
\hline $\begin{array}{l}\text { Day of the week } \\
\text { Sunday } \\
\text { Monday } \\
\text { Tuesday } \\
\text { Wednesday } \\
\text { Thursday } \\
\text { Friday } \\
\text { Saturday }\end{array}$ & $\begin{aligned} & 8.4 \%(75) \\
& 5.7 \%(51) \\
& 7.8 \%(70) \\
& 3.9 \%(35) \\
& 12.5 \%(112) \\
& 23.8 \%(213) \\
& 37.9 \%(340)\end{aligned}$ & $\begin{array}{c}13.8 \%(151) \\
2.7 \%(30) \\
5.4 \%(59) \\
9.1 \%(100) \\
9.7 \%(106) \\
17.3 \%(189) \\
42.0 \%(459)\end{array}$ & $<.001(63.486)$ \\
\hline $\begin{array}{l}\text { Drink with Meal } \\
\text { Yes } \\
\text { No }\end{array}$ & $\begin{array}{l}77.7 \%(740) \\
22.3 \%(212)\end{array}$ & $\begin{array}{l}76.9 \%(929) \\
23.1 \%(279) \\
\end{array}$ & $.649(.207)$ \\
\hline $\begin{array}{l}\text { Location } \\
\text { Your home } \\
\text { Others' home } \\
\text { Restaurant } \\
\text { Bar }\end{array}$ & $\begin{array}{l}41.5 \%(369) \\
28.8 \%(256) \\
15.8 \%(141) \\
13.9 \%(124)\end{array}$ & $\begin{array}{l}38.5 \%(440) \\
39.8 \%(455) \\
12.5 \%(143) \\
9.3 \%(106)\end{array}$ & $<.001(32.134)$ \\
\hline $\begin{array}{l}\text { Drink at Multiple Locations } \\
\text { Yes } \\
\text { No }\end{array}$ & $\begin{array}{c}7.2 \%(69) \\
92.8 \%(883)\end{array}$ & $\begin{array}{c}7.1 \%(85) \\
92.9 \%(1115)\end{array}$ & $.883(.022)$ \\
\hline
\end{tabular}

Note: Total sample $(n=2,160)$. Frequency $(f)$ represents the maximum number of adults providing data to questionnaire on last drinking occasion. Frequencies vary per characteristic due to missing data. 
observed in the percentage reporting drinking at the home of someone else $\left(x^{2}=32.134\right.$, $p<.001$ ), with men preferring this location much more than women. This may account for this situational characteristic being associated with an increased odds of heavy drinking for the general Canadian population, as males are both more likely to consume heavier amounts of alcohol, and more frequently report drinking at this location. Logistic regression analysis will provide further information in this regard. Finally, and somewhat unexpectedly, more women reported consuming alcohol at a bar for their last drinking occasion than men (13.9\% vs. $9.3 \%)$.

\section{Gender, Heavy Alcohol Consumption and the Drinking Context}

In terms of determining gender differences in the relationship between the drinking context and heavy drinking, univariate analysis was employed using the subpopulation of Canadian males $(n=1,208)$ and females $(n=952)$. Table 6.4 describes heavy drinking for males (five or more drinks) on the last drinking occasion, by characteristic of the drinking context. Table 6.5 describes heavy drinking for females (four or more drinks) on the last drinking occasion, by characteristic of the drinking context. Chi-square tests were utilized to test the null hypothesis that characteristics of the drinking context are not related to heavy drinking by Canadian men and women. A probability $(p)$ of 0.05 or less indicates that an associated relationship between the independent and dependent variable exists, leading to a rejection of the null hypothesis.

For adult men, significant differences were found for the relationship with the drinking group, the size of the drinking group, the presence of their partner, the circumstance of the last drinking occasion, the day of the week consumption took place, location where drinking last occurred, and whether consumption occurred with a meal or 
in multiple locations. For example, those reporting drinking with friends (33.2\%) were significantly more likely to report heavy drinking on the last drinking occasion $\left(x^{2}=42.418, p<.001\right)$. Just over a fifth $(22.0 \%)$ of males who drank with co-workers reported heavy drinking, whereas drinking with companions from one's family (16.7\%), or a combination of the above $(16.8 \%)$ reported a lower percentage of heavy drinking occasions. Heavy drinking was also significantly related to the size of the drinking group, with $38 \%$ of respondents who drank in groups of 10 or more reporting heavy drinking. As the size of the drinking group decreased, the percentage of males reporting heavy alcohol consumption also decreased significantly $\left(x^{2}=77.947, p<.001\right)$. Contrary to previous research (Demers et al. 2002; Hennessy \& Saltz 1993), the presence of one's partner did not have a protective effect on men's heavy drinking, and in fact, showed the opposite effect $\left(26.4 \%\right.$ versus $\left.19.9 \%, x^{2}=6.966, p .008\right)$. Among the situational characteristics of the drinking context, almost half (45.6\%) the adult men who indicated 'a party' as the circumstance for drinking reported consuming five or more drinks. This was significantly higher than those who reported drinking under different circumstances, such as at a get together $(18.4 \%)$, and during other $(17.3 \%)$ or daily life $(3.1 \%)$ circumstances $\left(x^{2}=169.891, p<.001\right)$. While a relatively high percentage of men reported heavy drinking on most days of the week (except Sunday and Wednesday), Thursday (32.1\%) and Friday $(36.0 \%)$ were the days with the highest occurrence of heavy drinking. The data shows that for most days of the week, over 20 percent of males would report heavy drinking on that day $\left(x^{2}=32.744, p<.001\right)$. Canadian males also reported significantly greater heavy alcohol consumption when drinking at another person's home or at a bar $(38.7 \%$ and $21.7 \%$ respectively, $x^{2}=96.088, p<.001$ ). The results indicated that almost 40 percent of 
Table 6.4: Distribution of heavy alcohol consumption (5+ drinks) by characteristics of the drinking context, males, CAS (2004)

\begin{tabular}{|c|c|c|c|}
\hline & $\begin{array}{c}\text { Non-heavy alcohol } \\
\text { consumption } \\
(\mathrm{N}=921) \\
\text { Percentage (Frequency) }\end{array}$ & $\begin{array}{c}\text { Heavy alcohol } \\
\text { consumption } \\
(\mathrm{N}=286) \\
\text { Percentage (Frequency) }\end{array}$ & $p\left(x^{2}\right)$ \\
\hline \multicolumn{4}{|l|}{ Relational Characteristics } \\
\hline $\begin{array}{l}\text { Type of Relationship } \\
\text { Family } \\
\text { Co-workers } \\
\text { Friends } \\
\text { Combination }\end{array}$ & $\begin{array}{l}83.3 \%(329) \\
78.0 \%(46) \\
66.8 \%(377) \\
85.8 \%(103)\end{array}$ & $\begin{array}{c}16.7 \%(66) \\
22.0 \%(13) \\
33.2 \%(187) \\
14.2 \%(17)\end{array}$ & $<.001(42.418)$ \\
\hline $\begin{array}{l}\text { Group Size } \\
1 \text { person } \\
2-3 \text { persons } \\
4-9 \text { persons } \\
10 \text { or more }\end{array}$ & $\begin{array}{l}90.1 \%(172) \\
88.2 \%(224) \\
70.2 \%(306) \\
62.0 \%(173)\end{array}$ & $\begin{array}{c}9.9 \%(19) \\
11.8 \%(30) \\
29.8 \%(130) \\
38.0 \%(106)\end{array}$ & $<.001(77.947)$ \\
\hline $\begin{array}{l}\text { Presence of Partner } \\
\text { Yes } \\
\text { No }\end{array}$ & $\begin{array}{l}73.6 \%(523) \\
80.1 \%(399)\end{array}$ & $\begin{array}{c}26.4 \%(188) \\
19.9 \%(99)\end{array}$ & $.008(6.966)$ \\
\hline $\begin{array}{l}\text { Gender Composition } \\
\text { Mixed } \\
\text { Non-Mixed } \\
\end{array}$ & $\begin{array}{l}75.4 \%(796) \\
82.2 \%(125) \\
\end{array}$ & $\begin{array}{c}24.6 \%(260) \\
17.8 \%(27) \\
\end{array}$ & $.063(3.450)$ \\
\hline \multicolumn{4}{|l|}{ Situational Characteristics } \\
\hline $\begin{array}{l}\text { Circumstance of the occasion } \\
\text { Party } \\
\text { Get together } \\
\text { Daily Life Circumstance } \\
\text { Other Circumstance }\end{array}$ & $\begin{array}{l}54.4 \%(205) \\
81.6 \%(364) \\
96.9 \%(246) \\
82.7 \%(105)\end{array}$ & $\begin{array}{c}45.6 \%(172) \\
18.4 \%(82) \\
3.1 \%(8) \\
17.3 \%(22)\end{array}$ & $<.001(169.891)$ \\
\hline $\begin{array}{l}\text { Day of the week } \\
\text { Sunday } \\
\text { Monday } \\
\text { Tuesday } \\
\text { Wednesday } \\
\text { Thursday } \\
\text { Friday } \\
\text { Saturday }\end{array}$ & $\begin{array}{c}82.8 \%(125) \\
77.4 \%(24) \\
74.6 \%(44) \\
89.9 \%(89) \\
67.9 \%(72) \\
64.0 \%(121) \\
76.7 \%(353)\end{array}$ & $\begin{array}{c}17.2 \%(26) \\
22.6 \%(7) \\
25.4 \%(15) \\
10.1 \%(10) \\
32.1 \%(34) \\
36.0 \%(68) \\
23.3 \%(107)\end{array}$ & $<.001(32.744)$ \\
\hline $\begin{array}{l}\text { Drink with Meal } \\
\text { Yes } \\
\text { No }\end{array}$ & $\begin{array}{l}74.2 \%(689) \\
83.2 \%(232)\end{array}$ & $\begin{array}{c}25.8 \%(239) \\
16.8 \%(47) \\
\end{array}$ & $.002(9.415)$ \\
\hline $\begin{array}{l}\text { Location } \\
\text { Your home } \\
\text { Others' home } \\
\text { Restaurant } \\
\text { Bar } \\
\end{array}$ & $\begin{array}{l}87.0 \%(382) \\
61.3 \%(279) \\
88.1 \%(126) \\
78.3 \%(83)\end{array}$ & $\begin{array}{c}13.0 \%(57) \\
38.7 \%(176) \\
11.9 \%(17) \\
21.7 \%(23)\end{array}$ & $<.001(96.088)$ \\
\hline $\begin{array}{l}\text { Drink at Multiple Locations } \\
\text { Yes } \\
\text { No }\end{array}$ & $\begin{array}{c}38.8 \%(33) \\
78.9 \%(881)\end{array}$ & $\begin{array}{c}61.2 \%(52) \\
21.1 \%(235)\end{array}$ & $<.001(69.904)$ \\
\hline
\end{tabular}

Note: Total sample $(n=1,207)$. Frequency $(f)$ represents the maximum number of adults providing data to questionnaire on last drinking occasion. Frequencies vary per characteristic due to missing data. 
Table 6.5: Distribution of heavy alcohol consumption (4+ drinks) by characteristics of the drinking context, females, CAS (2004)

\begin{tabular}{|c|c|c|c|}
\hline & $\begin{array}{c}\text { Non-heavy alcohol } \\
\text { consumption } \\
(n=715) \\
\text { Percentage (Frequency) }\end{array}$ & $\begin{array}{c}\text { Heavy alcohol } \\
\text { consumption } \\
(n=237) \\
\text { Percentage (Frequency) }\end{array}$ & $p\left(x^{2}\right)$ \\
\hline \multicolumn{4}{|l|}{ Relational Characteristics } \\
\hline $\begin{array}{l}\text { Type of Relationship } \\
\text { Family } \\
\text { Co-workers } \\
\text { Friends } \\
\text { Combination }\end{array}$ & $\begin{array}{c}86.7 \%(314) \\
65.4 \%(34) \\
68.5 \%(294) \\
54.1 \%(40)\end{array}$ & $\begin{array}{c}13.3 \%(48) \\
34.6 \%(18) \\
31.5 \%(135) \\
45.9 \%(34)\end{array}$ & $<.001(54.964)$ \\
\hline $\begin{array}{l}\text { Group Size } \\
1 \text { person } \\
2-3 \text { persons } \\
4-9 \text { persons } \\
10 \text { or more }\end{array}$ & $\begin{array}{l}96.4 \%(135) \\
79.7 \%(149) \\
77.3 \%(297) \\
51.8 \%(115)\end{array}$ & $\begin{array}{c}3.6 \%(5) \\
20.3 \%(38) \\
22.7 \%(87) \\
48.2 \%(107)\end{array}$ & $<.001(100.167)$ \\
\hline $\begin{array}{l}\text { Presence of Partner } \\
\text { Yes } \\
\text { No }\end{array}$ & $\begin{array}{l}75.9 \%(466) \\
73.6 \%(248)\end{array}$ & $\begin{array}{c}24.1 \%(148) \\
26.4 \%(89)\end{array}$ & $.432(0.618)$ \\
\hline $\begin{array}{l}\text { Gender Composition } \\
\quad \text { Mixed } \\
\text { Non-Mixed } \\
\end{array}$ & $\begin{array}{l}74.6 \%(673) \\
85.7 \%(42) \\
\end{array}$ & $\begin{array}{c}25.4 \%(229) \\
14.3 \%(7) \\
\end{array}$ & $.080(3.070)$ \\
\hline \multicolumn{4}{|l|}{ Situational Characteristics } \\
\hline $\begin{array}{l}\text { Circumstance of the occasion } \\
\text { Party } \\
\text { Get together } \\
\text { Daily Life Circumstance } \\
\text { Other Circumstance }\end{array}$ & $\begin{array}{l}69.7 \%(219) \\
69.9 \%(225) \\
88.0 \%(168) \\
82.3 \%(102)\end{array}$ & $\begin{array}{l}30.3 \%(95) \\
30.1 \%(97) \\
12.0 \%(23) \\
17.7 \%(22)\end{array}$ & $<.001(29.782)$ \\
\hline $\begin{array}{l}\text { Day of the week } \\
\text { Sunday } \\
\text { Monday } \\
\text { Tuesday } \\
\text { Wednesday } \\
\text { Thursday } \\
\text { Friday } \\
\text { Saturday }\end{array}$ & $\begin{array}{c}98.7 \%(74) \\
76.5 \%(39) \\
85.7 \%(60) \\
71.4 \%(25) \\
89.2 \%(99) \\
57.7 \%(123) \\
72.9 \%(248)\end{array}$ & $\begin{array}{c}1.3 \%(1) \\
23.5 \%(12) \\
14.3 \%(10) \\
28.6 \%(10) \\
10.8 \%(12) \\
42.3 \%(90) \\
27.1 \%(92)\end{array}$ & $<.001(72.729)$ \\
\hline $\begin{array}{l}\text { Drink with Meal } \\
\text { Yes } \\
\text { No } \\
\end{array}$ & $\begin{array}{l}78.8 \%(583) \\
62.3 \%(132)\end{array}$ & $\begin{array}{c}21.2 \%(157) \\
37.7 \%(80)\end{array}$ & $<.001(24.052)$ \\
\hline $\begin{array}{l}\text { Location } \\
\text { Your home } \\
\text { Others' home } \\
\text { Restaurant } \\
\text { Bar }\end{array}$ & $\begin{array}{l}84.8 \%(313) \\
71.1 \%(182) \\
84.4 \%(119) \\
43.5 \%(54)\end{array}$ & $\begin{array}{l}15.2 \%(56) \\
28.9 \%(74) \\
15.6 \%(22) \\
56.5 \%(70)\end{array}$ & $<.001(93.275)$ \\
\hline $\begin{array}{l}\text { Drink at Multiple Locations } \\
\text { Yes } \\
\text { No }\end{array}$ & $\begin{array}{c}21.7 \%(15) \\
79.4 \%(700)\end{array}$ & $\begin{array}{c}78.3 \%(54) \\
20.6 \%(182)\end{array}$ & $<.001(113.898)$ \\
\hline
\end{tabular}

Note: Total sample ( $n=952$ ). Frequency $(f)$ represents the maximum number of adults providing data to questionnaire on last drinking occasion. Frequencies vary per characteristic due to missing data. 
occasions involving consumption at another person's home resulted in intake of five or more drinks, which was much higher than in other drinking locations. The relatively low percentage of 'bar' occasions resulting in heavy drinking is somewhat surprising for a male population. Also surprising was the finding that drinking with a meal was significantly related to heavy alcohol consumption $\left(25.8 \%\right.$ versus $16.8 \%, x^{2}=9.415$, p.002), which is inconsistent with previous research (Demers 1997). Finally, men who drank at more than one location reported a much higher percentage of heavy drinking than those consuming alcohol in only one setting $\left(61.2 \%, x^{2}=69.904, p<.001\right)$.

For adult women, heavy drinking occurred frequently when drinking with coworkers (34.6\%) and friends (31.5\%), and was the highest among women who consumed alcohol with a combination of people from different categories (45.9\%). While friends and family are overwhelmingly the most frequent drinking companions for women, the small but statistically significant $\left(x^{2}=54.964, p<.001\right)$ number reporting heavy drinking with co-workers $(n=18)$ and a combination of companions $(n=34)$ warrants further study. Again, as the size the drinking group increases, reported heavy drinking among women also increased significantly $\left(x^{2}=100.167, p<.001\right)$, with almost half $(48.2 \%)$ who report drinking with ten or more people consuming heavy amounts of alcohol. The decrease in the percentage reporting heavy drinking when in groups of four to nine $(22.7 \%)$ and two to three (20.3\%) persons was fairly substantial compared with much larger groups, as was drinking with a single partner $\left(x^{2}=146.234, p<.001\right)$. A total of $30.3 \%$ and $30.1 \%$ of adult women reported heavy drinking when at a party or get together, respectively $\left(x^{2}=29.782\right.$, $p<.001)$. Only twelve percent of women who reported drinking as part of daily life circumstances reported heavy drinking during their last occasion of alcohol consumption. Women were significantly more likely to drink heavily on Friday (42.3\%) and Saturday 
(27.1\%) than on other days of the week $\left(x^{2}=72.782, p<.001\right)$. Drinking with a meal displayed a protective effect for females, with $37.7 \%$ of those who didn't drink with a meal reporting heavy drinking, compared to only $21.2 \%$ reporting heavy drinking when accompanied by a meal $\left(x^{2}=24.052, p<.001\right)$. Perhaps most interesting was the finding that over half the women who reported consuming alcohol at a bar reported heavy drinking (56.5\%), followed by those who consumed alcohol at someone else's home $\left(28.9 \%, x^{2}=113.898, p<.001\right)$. All other locations were associated with more moderate consumption, compared to those who reported 'bars' as the location of their last drinking occasion. Similarly, while representing only a small number of cases $(f=54)$, women who drank at more than one location reported heavy alcohol consumption in almost eighty percent $(78.3 \%)$ of the drinking occasions $\left(x^{2}=191.336, p<.001\right)$.

While most variables associated with the drinking context were linked to heavy drinking by males and females, some variables were not significant. Drinking in mixedgender groups was not significant for both men and women, although with higher critical limits (i.e., $p^{=} .10$ ), they would have been considered influential. In particular, $25.4 \%$ of women who drank in mixed-gender groups consumed four drinks or more, compared with only $14.3 \%$ who drank with an all-female drinking group, suggesting the presence of opposite-gender drinking partners increases the chances of heavy alcohol consumption. Also, no significant differences related to the presence of one's partner and heavy drinking were found among the female group in this study population.

As expected, a significantly higher percentage of heavy drinking occurred when both men and women consumed alcohol with friends, in larger groups, on weekends, in bars, and at parties. These findings are consistent with existing research that show heavier drinking associated with these contexts, regardless of the gender of the individual. There 
were, however, a number of unexpected findings, as well as differences between men and women, and the percentage of men and women reporting heavy drinking in certain contexts. For example, a higher percentage of females than males reported heavy drinking when consuming alcohol with co-workers as well as a 'combination' of companions from the friends, family, and co-worker categories. Also, while drinking in groups of ten was associated with a higher percentage of heavy drinking occasions for both genders, nearly half of women reported consuming four or more drinks in this situation. Reported heavy alcohol consumption with drinking with only one companion was much smaller for women $(3.6 \%)$ than men $(9.9 \%)$, although both remain relatively low. One relational characteristic that exhibited some difference between men and women was heavy drinking in the presence of one's partner, with men reporting significantly more heavy drinking with their partner than without. Among situational characteristics of the drinking context, gender differences were observed in the circumstances of the drinking occasion. While drinking at a party was associated with a higher percentage of heavy drinking, which is consistent with the literature (Harford 1983), reported heavy drinking among females was much higher at a 'get together' $(30.1 \%)$ or during 'daily life' $(12.0 \%)$ circumstances, than for their male counterparts (18.4\% and 3.1\%, respectively). Drinking on weekdays is generally associated with fewer instances of heavy drinking, and the results here support this assertion. Most heavy drinking occasions occurred for men and women on weekends (i.e. Friday or Saturday), which is consistent with previous research in this area (Arfken 1988; Single 1985). However, drinking on Thursday for men, and Wednesday for women were two weekdays significantly related to heavy drinking. One important finding was the difference having a meal had on rates of heavy drinking for men and women. For men, it was associated with a higher percentage of heavy drinking, 
whereas for women, the opposite was true. Additional analyses should help determine the strength of this variable on drinking according to the gender of the respondent. An interesting finding was the percentage of women reporting heavy alcohol consumption at bars, and the percentage of men reporting heavy drinking at other peoples' homes. This data tells us that the location of heavy drinking may differ between men and women, signifying a shift in the appropriate places for leisure pursuits associated with alcohol consumption in general. Clearly, licensed drinking establishments such as bars, taverns and nightclubs play an important part in women's heavy consumption of alcohol, and may now be the space where 'determined drunkenness' by females is most exhibited. Similarly, drinking in multiple locations for both men and women was associated with a higher percentage of heavy drinking occasions, although the effect seems to be more pronounced for women.

\section{Examining Gender Differences in the Drinking Context and Heavy Drinking}

Logistic regression analyses were performed to examine the significance of the drinking context variables on heavy drinking, taking into account the gender of the respondent. Logistic regression produces a series of odds ratios, which provide an easily interpretable measure of the strength of the association between predictor and outcome variables, and help in interpreting differences in the odds of heavy drinking by characteristic of the drinking context for men and women. ${ }^{33}$ The logistic regressions were conducted separately on the population of men and women in this study in order to answer the following research questions: what differences exist in the contextual

\footnotetext{
${ }^{33}$ An odds ratio greater than 1.00 indicates that the predictor variable is associated with an increased likelihood of heavy drinking, whereas an odds ratio less than 1.00 indicates that the presence of the predictor variable is associated with decreased likelihood of heavy drinking.
} 
influence on heavy drinking between men and women when incorporating genderspecific measures of heavy drinking? Which relational characteristics are associated with the greatest likelihood of heavy drinking by males and females? Which situational characteristics are associated with the greatest likelihood of heavy drinking by males and females?

The data model for this part of the study was constructed using heavy drinking with a separate measure of five or more drinks for men, and four or more drinks for women - on the last drinking occasion as the outcome of interest, and predictors related to the social context of alcohol consumption as the independent variables. Gender is used as a control in this analysis, with separate models running for men and women based on the variables mentioned above. Variables were placed into the model as blocks, using an enter method. ${ }^{34}$ The full model contains all relevant variables of the context of alcohol consumption, in relation to heavy drinking by Canadian men and women. The full model for both men and women was adjusted for age, using a dichotomous measure of under 25 years of age/over 25 years of age. The following results are presented in Table 6.6.

Results from the logistic regression analyses show that characteristics of the drinking context were significantly predictive of heavy drinking for both males and females. For males, the drinking context accounted for approximately $42 \%$ of the occupations of these individuals may help explain some of the differences in their odds of heavy drinking. Drinking with friends for women was not significantly different than the reference group of family members. However, females reported an increased likelihood of heavy drinking when drinking with a combination of drinking partners $(\mathrm{OR}=2.28$,

\footnotetext{
${ }^{34}$ The enter method is the default method for entering predictor variables into a binomial logistic regression in SPSS. Details of this method were provided previously in Chapter Four (page 71).
} 
Table 6.6: Heavy drinking by characteristics of the drinking context, by gender, CAS (2004)

\begin{tabular}{|c|c|c|c|}
\hline & \multirow{2}{*}{ Gender } & \multicolumn{2}{|c|}{ Full Model $^{a}$} \\
\hline & & $\mathbf{O R}$ & $p$ \\
\hline \multicolumn{4}{|c|}{ Type of Relationship (ref. Family) } \\
\hline \multirow{2}{*}{ Co-workers } & Male & 5.05 & .002 \\
\hline & Female & 1.37 & .485 \\
\hline \multirow{2}{*}{ Friends } & Male & 2.01 & .006 \\
\hline & Female & 1.07 & .789 \\
\hline \multirow{2}{*}{ Combination } & Male & 0.85 & .696 \\
\hline & Female & 2.28 & .036 \\
\hline \multicolumn{4}{|l|}{ Group Size (ref. 4-9 persons) } \\
\hline \multirow{2}{*}{1 person } & Male & 0.93 & .857 \\
\hline & Female & 0.18 & .005 \\
\hline \multirow{2}{*}{$2-3$ persons } & Male & 0.34 & .002 \\
\hline & Female & 1.40 & .258 \\
\hline \multirow{2}{*}{10 or more } & Male & 0.90 & .668 \\
\hline & Female & 5.68 & .000 \\
\hline \multicolumn{4}{|l|}{ Presence of Partner (ref. No) } \\
\hline \multirow{2}{*}{ Yes } & Male & 3.68 & .000 \\
\hline & Female & 0.59 & .029 \\
\hline \multicolumn{4}{|l|}{ Mixed gender group (ref. No) } \\
\hline \multirow{2}{*}{ Yes } & Male & 1.25 & .520 \\
\hline & Female & 0.61 & .324 \\
\hline \multicolumn{4}{|c|}{ Circumstance of the occasion (ref. Party) } \\
\hline \multirow{2}{*}{ Get together } & Male & 0.38 & .000 \\
\hline & Female & 1.85 & .022 \\
\hline \multirow{2}{*}{ Daily Life Circumstance } & Male & 0.08 & .000 \\
\hline & Female & 1.88 & .101 \\
\hline \multirow{2}{*}{ Other Circumstance } & Male & 0.55 & .100 \\
\hline & Female & 0.87 & .730 \\
\hline \multicolumn{4}{|c|}{ Day of the week (ref. Saturday) } \\
\hline \multirow{2}{*}{ Sunday } & Male & 2.63 & .003 \\
\hline & Female & 0.00 & .000 \\
\hline \multirow{2}{*}{ Monday } & Male & 3.41 & .036 \\
\hline & Female & 0.70 & .436 \\
\hline \multirow{2}{*}{ Tuesday } & Male & 2.64 & .026 \\
\hline & Female & 0.34 & .023 \\
\hline \multirow{2}{*}{ Wednesday } & Male & 0.72 & .455 \\
\hline & Female & 0.44 & .171 \\
\hline \multirow{2}{*}{ Thursday } & Male & 2.06 & .032 \\
\hline & Female & 0.26 & .001 \\
\hline \multirow{2}{*}{ Friday } & Male & 2.14 & .004 \\
\hline & Female & 1.35 & .249 \\
\hline Drink with Meal (ref. No) & & & \\
\hline & Male & 1.79 & .040 \\
\hline Yes & Female & 0.44 & .005 \\
\hline
\end{tabular}

Note: Analysis limited to respondents with complete data for all variables included in the data model $(n=$ $967)$ for men, and $(n=805)$ for women. Model indicates heavy drinking $(5+$ drinks for men $/ 4+$ drinks for women) of alcohol vs. non-heavy drinking ( 1 to 4 drinks for men/1 to 3 drinks for women), on the last drinking occasion. (a) Model denotes the full model, and tests all situational variables, controlling for age and gender. 


\begin{tabular}{|c|c|c|c|}
\hline \multicolumn{4}{|c|}{ Table 6.4: (continued) } \\
\hline & \multirow{2}{*}{ Control } & \multicolumn{2}{|c|}{ Full Model $^{\mathrm{a}}$} \\
\hline & & OR & $p$ \\
\hline \multicolumn{4}{|c|}{ Location (ref. Your home) } \\
\hline \multirow{2}{*}{ Others' home } & Male & 2.53 & .000 \\
\hline & Female & 0.63 & .103 \\
\hline \multirow{2}{*}{ Restaurant } & Male & 0.16 & .000 \\
\hline & Female & 0.67 & .007 \\
\hline \multirow{2}{*}{ Bar } & Male & 1.24 & .624 \\
\hline & Female & 1.02 & .953 \\
\hline \multicolumn{4}{|c|}{ Drink at Multiple Locations (ref. No) } \\
\hline \multirow{2}{*}{ Yes } & Male & 7.38 & .000 \\
\hline & Female & 7.14 & .000 \\
\hline \multirow{2}{*}{$R^{2}($ Cox \& Snell) } & Male & \multicolumn{2}{|c|}{.288} \\
\hline & Female & \multicolumn{2}{|c|}{.302} \\
\hline \multirow{2}{*}{$R^{2}$ (Nagelkerke) } & Male & \multicolumn{2}{|c|}{.422} \\
\hline & Female & \multicolumn{2}{|c|}{.440} \\
\hline
\end{tabular}

Note: Analysis limited to respondents with complete data for all variables included in the data model $(n=$ $967)$ for men, and $(n=805)$ for women. Model indicates heavy drinking $(5+$ drinks for men $/ 4+$ drinks for women) of alcohol vs. non-heavy drinking ( 1 to 4 drinks for men/ 1 to 3 drinks for women), on the last drinking occasion. (a) Model denotes the full model, and tests all situational variables, controlling for age and gender.

$p=.036$ ). Drinking with family members is linked with lower levels of alcohol consumption (Calahan et al. 1969), so the finding that drinking with friends was variance in behaviour around heavy drinking. Similarly, for females, the drinking context accounted for a total $44 \%$ of the variance in heavy drinking. This is consistent with this author's hypothesis, and with previous research examining the relationship between situational variables and heavy drinking during occasions of alcohol consumption (Demers 1997; Demers et al. 2002; Knibbe et al. 1993).

A number of variables were predictive of heavy drinking by males and females in relation to the drinking context. In fact, the results indicate that the only contextual variable not predictive of heavy drinking for men and women was the gender composition of the drinking group. Overall, eight of the nine variables tested were predictive of heavy drinking for males and females in this study population. In analyzing the sub-population 
using gender as a control, Canadian males reported a five-fold increase in the likelihood of heavy drinking when drinking with co-workers ( $\mathrm{OR}=5.05, p=.002)$, and a two-fold increase when drinking with friends ( $\mathrm{OR}=2.01, p=.006)$. While the number of men reporting heavy drinking with co-workers is small $(n=13)$, further analysis on the associated with a higher odds of heavy drinking than with family for males is not surprising, and is consistent with previous research (Harford 1983; Mayer et al. 1998). However, the finding that men who drank with co-workers were five times more likely to drink heavily than with companions considered 'family' was unexpected. It is difficult to extrapolate on this relationship, given the dearth of research on drinking with co-workers. Research has found that individuals who were employed in male-dominated occupations had 1.4 and 1.2 times more opportunities to engage in drinking activities with their coworkers than were those working in female-dominated mixed-gender occupations respectively (Roman and Blum 1997). Certain occupations have been linked with alcohol abuse, including those found in the food and service, forestry and technical industries (Kraft et al. 1993). The consumption of alcohol can often be affected by the presence of a work-place culture that promotes heavy drinking, and attention to such an issue among Canadian males is warranted (Reducing Alcohol-Related Harm in Canada 2007). Research into such trends may help explain the results found here. Also, the results showed that odds of heavy drinking increased by over 2 times for females who drank with a combination of drinking companions. This finding may help account for the significance of this characteristic as part of the bivariate model examining the relational characteristics of the drinking context and heavy drinking. Further research into this category, including consideration of what constitutes the combined category for women 
(i.e., drinking with friends and co-workers, for example) may further illuminate the types of companions that are linked with heavy drinking by Canadian women.

The size of the drinking group was also significant in predicting heavy drinking based on the gender of the respondent. Generally, drinking in smaller groups was associated with a decreased likelihood of heavy drinking for both men and women. The odds of heavy drinking was significantly less for men when drinking with two to three people $(\mathrm{OR}=0.34, p=.002)$, and for women when drinking with only one person $(\mathrm{OR}=0.18, p=.005)$. Women who consumed alcohol on the last drinking occasion in a group of 10 or more people were over five times more likely to report heavy drinking $(\mathrm{OR}=5.68, p=.000)$. The results here are consistent with previous research on the effect of group size on levels of alcohol consumption (Cutler \& Storm 1975; Single 1985; Sommer 1965). However, women drinking in the largest groups were over five times more likely to report heavy drinking than in smaller groups of four to nine people, which acted as the reference category. While not unexpected, given existing literature, this characteristic was nevertheless the second strongest predictor of heavy drinking this sub-population of women. Other research has confirmed an effect between heavy drinking by one individual within a group, and increased alcohol consumption by other members of the drinking group (Single 1985). The size of the drinking group thus operates to informally regulate the rate of consumption (Clark 1981a, Clark 1981b; Reid 1978, cited in Hennessy \& Saltz 1993). The presence of other heavy drinkers in the larger drinking group may be influencing the consumption levels of Canadian women. Since males are likely to consume higher quantities of alcohol, their presence in these groups may invariably push the levels of drinking - not to mention the types of drinking behaviour (i.e., purchasing of shots or rounds) - higher for some women. As drinking in groups of 10 or more was the 
second most prevalent group size reported by Canadian women, future research and interventions should focus on this contextual dynamic. For example, additional analysis of the 2004 CAS could help determine what other contextual variants are associated with drinking in large groups, or whether drinking in even larger groups (i.e., 15 or 20) produce similar or elevated findings.

Significant differences were observed between men and women in the odds of heavy drinking in the presence of one's partner. Males who reported drinking with their partner on the last drinking occasion were roughly 3.7 times more likely to report heavy alcohol consumption than men whose partners were not present at the drinking occasion $(p=.000)$. Women who reported consuming alcohol with their partner, however, reported significantly reduced odds of heavy drinking $(\mathrm{OR}=0.59, p=.029)$. Once again, these results run contrary to the research by Hennessy and Saltz (1993) - that alcohol consumption by gender-mixed couples is reduced on drinking occasions - at least for men in this population. That the same context produces an opposite effect for women suggests that the positive relationship between the presence of one's partner and predicted heavy drinking for Canadian adults is mitigated by the gender of the individual. Heavy drinking is associated with an increased incidence of domestic and marital problems (Bondy 1996), while heavy drinking occasions have been linked to various acute consequences, including physical and verbal altercations, unintentional injuries, and unwanted or unprotected sex (Reducing Alcohol-Related Harm in Canada 2007). Many of these harms occur disproportionately in younger populations of drinkers. Further research using this dataset should examine whether consequences such as arguments or physical altercations are linked with the drinking occasions where a males' partner is present, as this would 
provide valuable information on whether this trend is associated with alcohol-related harm for drinker, as well as those intimately involved with them.

When examining the situational characteristics of the drinking context, the circumstance of the drinking occasion was predictive of heavy drinking for both males and females. For Canadian men, the likelihood of heavy drinking at a get together $(\mathrm{OR}=0.38, p=.000)$ or as part of daily life circumstances $(\mathrm{OR}=0.08, p=.000)$ was associated with a decreased likelihood of heavy drinking. The data suggests that these are contexts where more sensible levels of consumption occur for men, especially given the reference category, drinking at a party, is related to higher odds of heavy drinking (Harford et al. 1980; Single \& Wortley 1993). Among Canadian women, however, these two circumstances were associated with an increased likelihood of heavy alcohol consumption on the last drinking occasion (get together, $\mathrm{OR}=1.85, p=.022$; daily life circumstance $\mathrm{OR}=1.88, p=.101$ ), though the latter circumstance was not significant at the critical $p$-value used in this study. Even though the finding was not significant at the predetermined 05 level, the differences observed between men and women remains interesting and suggests important differences in the circumstances in which men and women tend to consume heavy amounts of alcohol. The findings that drinking under 'daily life' circumstances are associated with lower levels of alcohol consumption by men consistent with previous research by Simpura (1987), although the findings for women seem to challenge this position. With regards to drinking at a 'get together', men and women differ when it comes to heavy drinking, with the odds of heavy drinking increasing 1.8 times for women, and decreasing the odds for men by almost a third. As drinking at a 'get together' is the most common drinking circumstance reported by Canadian men and women, additional research may want to explore the cultural 
significance of this context, including any expectations around alcohol consumption generally linked to this circumstance, as well as specific tolerance of certain drinking levels and behaviour that arise during such occasions.

The odds of heavy drinking varied considerably between males and females dependent on the day of the week the occasion occurred. For Canadian men, consuming alcohol on every day except Wednesday was associated with a 2.0 to 3.4 times greater likelihood of heavy drinking, compared to drinking on Saturday's (Sunday, $\mathrm{OR}=2.63$, $p=.003$; Monday, $\mathrm{OR}=3.41, p=.036$; Tuesday, $\mathrm{OR}=2.64, p=.026$; Thursday, $\mathrm{OR}=2.06$, $p=.032$; Friday, $\mathrm{OR}=2.14, p=.004)$. These findings contradict research by Arfken (1988) regarding weekends as the dominant temporal pattern for heavy drinking. In contrast, women reported decreased odds of heavy drinking for Tuesday $(\mathrm{OR}=0.34, p=.023)$ and Thursday $(\mathrm{OR}=0.26, p=.001)$, with drinking on other days of the week not significantly different from the reference category. For Canadian women at least, there is support for the notion that occasions of alcohol consumption that fall on a weekday work to reduce the likelihood of heavy drinking. It is difficult account for these trends in the data on Canadian men. Recent research from the UK identified the presence of sophisticated techniques of 'risk-analysis' for young men in their patterns of alcohol consumption. For young men who were already involved with the labour market, some of the risks from drinking - particularly risks related to one's occupation, or requiring one to 'get up' at earlier times - were minimized as a result of decisions favouring heavy consumption on Friday's (Harnett et al. 2000). Further examination of the work status of those reporting heavy drinking during the week may provide an indication as to whether being a student or being retired provides more time to pursue leisure activities associated with alcohol. In addition, future survey attempts at understanding the context of alcohol consumption may 
wish to employ an activities scale, which would help to determine exactly what types of activities men are engaged in on weekdays when they drink five drinks or more. Such patterns may involve certain recreational or sporting activities, for example. Finally, a number of considerations in relation to data collection and analysis are needed. The 2004 CAS was collected between December 2003 and April 2004 - periods that may inevitably capture seasonal patterns of alcohol consumption. It is feasible, for example, that a number of respondents' last drinking occasion were part of a work-related function, such as an office Christmas party, or other holiday event. This may account for some of the higher odds of reported heavy drinking during weekdays in this population. Also, since forty-two percent of men reported drinking on Saturdays, these findings should be interpreted with caution. These results may reflect characteristics of the individual, including those individuals who might be classified as more frequent drinkers. Analysis of the drinking context by drinker-type was not included as part of this study, and may work to substantiate the findings on heavy drinking days.

Once again, drinking with a meal was associated with a higher likelihood of heavy drinking on the last drinking occasion, but only for males in this population $(\mathrm{OR}=1.79$, $p=.040$ ). This finding counters research by Demers (1997) and Simpura (1987), which found meals to have a moderating effect on the quantity of alcohol consumed during occasions of alcohol consumption. The opposite effect was observed for females, who were half as likely to report heavy alcohol drinking when consumption was accompanied by a meal $(\mathrm{OR}=0.44, p=.005)$. This finding conforms to existing literature on the relationship between having meals and non-heavy drinking. A key finding from this data pertains to the role of gender in predicting heavy drinking in certain contexts. Being male or female has a substantial effect on the moderating aspects of consuming food while 
drinking, and requires further examination. Differences may exist in the way Canadian men and women classify 'meals' as part of drinking occasions. Are snacks and finger foods such as nachos, wings, and fries being reported by men as meals during occasions of heavy drinking? Do women have qualitatively different conceptions of drinking when eating, and adjust alcohol intake accordingly? It is unclear from the data presented here what could be accounting for these differences. Future observational or survey research may help in this regard.

Findings related to the location where alcohol was consumed seemed to show some convergence between male and females. Drinking at a restaurant, for example, was associated with more moderate consumption of alcohol in both males $(\mathrm{OR}=0.16, p=.000)$ and females $(\mathrm{OR}=0.67, p=.007)$. Previous national survey data from Canada also found restaurants to be contexts where lower levels of consumption occurred (Kairouz \& Greenfield 2007). The results suggest that the effect of drinking in restaurants and reduced odds of heavy drinking is stronger for Canadian males than females. The only other characteristic of the drinking location that reached appropriate levels of significance was drinking in others' homes for males. Men who consumed alcohol at another person's home were 2.5 times more likely to consume five or more drinks $(p=.000)$ when at this residential location, compared with drinking at their own home. The data indicates that drinking at the home of someone else is conducive to heavy drinking for males, and that the acceptability of drinking to 'feel the effects' at this location is perhaps also increasing (Greenfield and Room 1996). This may, however, be attributable to the gender of the individual, as this context showed evidence of more moderate consumption by Canadian women $(\mathrm{OR}=0.63, p=.103)$. While not statistically significant at the predetermined cut-off for this study, differences do seem to exist between men and women with regards to 
heavy drinking in this location. Greenfield and Room (1996) suggest that heavy drinking in this context may be the result of both relational and situational characteristics, as heavier drinking was linked with both private drinking locations and consuming with friends. Harford's (1983) research also suggests that men are more likely to drink heavily in a variety of settings when friends are present, meaning it may be difficult to attribute heavy drinking to location alone. It is conceivable that men may have 'friends' as drinking companions when consuming alcohol at some else's home, and further analysis should attend to understanding these effects.

The final variable tested as part of this model was consumption of alcohol at multiple drinking locations. This situational characteristic was again significant for both men and women, and was associated with over a seven-fold increase in the odds of heavy alcohol consumption (Men, $\mathrm{OR}=7.38, p=.000$ vs. Women, $\mathrm{OR}=7.14, p=.000$ ). As such, it was the strongest predictor of heavy drinking in both sub-populations, although very few respondents reported this situation. Given the paucity of research on reported drinking in more than one drinking location, it is difficult to make conclusions as to what this signifies for men and women in Canada. Again, attention should be paid to determining whether similar results are observed for younger compared to older populations of adult men and women.

\section{Summary}

Based on the findings from this chapter, one key finding is that drinking at multiple locations is an important predictor of heavy drinking, regardless of one's gender. This variable was also strongest predictor of heavy drinking among all characteristics of the drinking context. Although drinking with co-workers was found to be predictive of 
heavy drinking in the general population, when considering gender of the individual, the associations were found to be predictive only among males. This suggests that the drinking companions of males may reflect particular cultures found at work that promote intoxication. When drinking with one's romantic partner, or with a meal, significant associations between these variables and heavy drinking were more common among male than female respondents.

Differences were observed between Canadian men and women with regards to other situational characteristics of the drinking context. Moreover, it appears that weekdays are associated with more moderate consumption of alcohol for women, but for men, drinking on these days is linked with higher odds of heavy drinking. A second key finding shows that the location is key to predicting heavy drinking among adults. As predicted, drinking in restaurants does not influence men and women to consume heavy amounts of alcohol. However, heavy drinking when at the home of someone else was strongest among males, suggesting the previous association between heavy drinking and this context may be mediated by factors related to gender. 


\section{CHAPTER SEVEN DISCUSSION}

"The social setting, with its formal and informal controls, its capacity to develop new informal social sanctions and rituals, and its transmission of information in numerous ways, is a crucial factor in the controlled use of any intoxicant" (Zinberg 1985: 15).

The overall aims of this study were to highlight the current gap in knowledge of social contextual factors that contribute to heavy drinking occasions, and explore potential links between the drinking context and heavy drinking by Canadian adults. In Chapter Three, complementary trends in public health research and neo-liberal governing techniques were presented as influential in the reification of individualized understandings of alcohol-related behaviour. Nevertheless, social elements present in the contexts of drinking have been recognized as an important factor in relation to heavy drinking in the alcohol policy field (Mosher 1999). This discussion chapter has three purposes: (1) to discuss the study's main findings in relation to the research questions and related hypotheses; (2) to highlight links between the contexts of heavy drinking and broader changes in the consumption of risk and leisure; and (3) to point to policy options that seek to reduce the harms from drinking by targeting the contexts where consumption occurs.

A note of caution for the reader on the theoretical interpretation of data from the CAS is required: while this researcher feels that the data from this study support some of the components of the theoretical perspective put forth earlier, it must be stressed that the links between this theoretical perspective and the data from this study are not direct. Original research in support of the risk framework, including emerging trends related to individualization, determined drunkenness, and a 'culture of intoxication' contained data 
that was both longitudinal and qualitative in nature, and geared towards eliciting a greater understanding of the ways in which substance consumption patterns were changing. Secondary data analysis on the CAS dataset could not obtain similar information for a study of the drinking context. As such, claims to the importance of the theoretical concepts discussed in relation to the findings are tempered.

\section{The Drinking Context and Heavy Drinking by Canadians}

Similar to other studies, characteristics of the 'context' of alcohol consumption were predictive of heavy drinking in this study population (Demers 1997; Demers et al. 2002; Harford 1983; Kairouz \& Greenfield 2007; Single \& Wortley 1993). When examining the model that made up the drinking context in this study, eight of the nine variables were predictive of heavy drinking by Canadian adults. In fact, the only variable that proved to be non-significant when testing this model was the gender composition of the drinking group. The full model containing the nine study variables accounted for 37 percent of the overall variance in consuming five or more drinks on the last occasion of drinking, which represents a significant portion of heavy drinking reported by Canadian adults. The findings from this study support the first hypothesis, that the drinking context is important in understanding heavy drinking by Canadian adults. The findings are also consistent with Harford's contention that the consumption of alcohol is situationally specific, as opposed to "a trans-situational property of specific individuals" (1979: 289).

Results from the current study also show that situational characteristics accounted for a greater proportion of heavy drinking than relational characteristics, which coincides with the second hypothesis of this thesis. When separating the effects of the relational and situational context of heavy drinking, the situational context explained 28 percent of the 
variance in heavy drinking, whereas the relational context accounted for only 18 percent. This finding was consistent with previous research by Demers (1997), Demers et al. (2002), and Knibbe et al. (1993), which suggests that physical and temporal elements of the drinking context were more influential in accounting for drinking behaviour than demographic factors, relational characteristics, or expectations related to one's drinking.

Relationship with drinking partners. A number of interesting associations were observed when examining which relational characteristics increased the likelihood of reporting heavy drinking. There was little support for Hypothesis 3, which stated that adults who consume alcohol with friends are more likely to drink heavily than with other drinking companions. Friends are the primary drinking companions for Canadian adults, and most studies have found a positive relationship between heavy alcohol intake and drinking with members of this drinking group. While significant when considering only relational characteristics, this relationship disappeared when additional variables pertaining to situational characteristics of the drinking context were included, indicating its lack of importance as a predictor of heavy drinking. In fact, Canadians who drank with friends were no more likely to drink heavily than when drinking with family. Consequently, the odds of heavy drinking were much higher among Canadian adults when consuming with co-workers (over 4 times as high). Reported alcohol consumption with this type of drinking companion, however, was only reported by a small percentage of the research population. This suggests that Canadians are not mixing work and leisure pursuits, at least to the degree that co-workers have become a group with which to consume alcohol. However, for those drinking with this group, it substantially increased the odds in favour of heavy drinking. As noted previously, few studies have examined drinking with co-workers, with most focusing on issues related to drinking on the 
worksite or during business events (Kilty 1980; Trice \& Sonnenstuhl 1988). Future research and policy efforts should attend to drinking at work, as well as consumption with co-workers, as both situational and relational factors may be contributing to heavy drinking by these individuals. This can include occasions where alcohol is readily available, such as at conferences, business lunches or office parties (Trice \& Sonnenstuhl 1988).

Size of the drinking group. Data from this study partially supported Hypothesis 4, which states, "drinking in larger groups is conducive to heavy drinking, and those adults who report drinking in the largest groups are more likely to drink heavily than when drinking in smaller groups." Consuming alcohol with smaller groups of people particularly with two to three partners - was related to a decreased likelihood of heavy drinking. This was certainly the case when considering only relational characteristics of the drinking context, whereby drinking with one person, or two to three persons functioned to protect against heavy drinking, and drinking with $10+$ people served to predict heavy drinking. This finding is consistent with previous research on the effect of group size on quantities of alcohol consumed (Cutler \& Storm 1975; Hennessy \& Saltz 1993; Single 1985; Sommer 1965). However, when considering all variables related to the drinking context, adults who reported drinking with groups of ten or more were not significantly different from those consuming alcohol in groups of four to nine people. As other researchers have suggested (Single 1985; Skog 1981), the observed relationship may be contingent upon other relational characteristics of the drinking context, such as the presence of heavier drinking companions in larger drinking groups. This study could not account for alcohol consumption by those drinking with the respondent, nor did it control for the drinking pattern of the individual. Research has shown that heavier 
consumption by one individual within the group can have an impact on alcohol intake by the drinking group, and that heavy drinkers are predisposed to consuming alcohol large drinking groups. Additional qualitative or ethnographic examinations of the drinking context may provide some insight into the role played by heavy drinkers in large groups. It would be useful in determining the pressures faced by drinkers in large groups to conform to others' alcohol intake, and the ways in which individuals resist heavier drinking when in large groups. Since drinking in larger groups (i.e., four or more people) is the norm for Canadians, attention to this relational characteristic is warranted in further understanding the propensity for heavy drinking during occasions of alcohol consumption.

Presence of partner. In contrast to Hypothesis 5, which predicted a lower likelihood of heavy drinking among adults who consumed alcohol in the presence of their partner, the results from this study found heavy drinking to be more likely when drinking with one's partner than in their absence. This was an unanticipated finding, and is counterintuitive given previous research that showed drinking with one's partner as having a protective effect on consuming five or more drinks on a single occasion (Demers et al. 2002; Hennessy \& Saltz 1993). Consuming alcohol with a romantic partner as compared to without them increases the likelihood of heavy drinking by $70 \%$ for Canadian adults. It is proposed that this is due to the fact that a high percentage of respondents from the study population reported being married, which would lead to a higher proportion drinking with their partners than would normally be found in the Canadian population. Possibly, given surveying efforts of the 2004 CAS took place from December to April, the presence of the holidays may have had an effect on the number of individuals drinking with their partners on the last reported drinking occasion. Christmas 
and New Year celebrations are often spent with loved ones - and can be considered festive occasions where excess in the form of food and drink is tolerated, if not encouraged - meaning the observed associations may reflect seasonal variations in drinking, as opposed to long-standing trends in the drinking of Canadians.

Drinking circumstances. Based on the research literature, it was hypothesized that adults who reported consuming alcohol at a party during their last drinking occasion would be more likely to drink heavily than when drinking under other circumstances. Using drinking at a party as the reference category, it was expected that all other circumstances would be associated with lower odds of heavy drinking. As predicted, drinking at a 'get together', during 'daily life' or 'other' circumstances resulted in between a 37 to 89 percent decrease in the likelihood of heavy drinking when considering only situational characteristics of the drinking context. Only one significant relationship emerged when considering both situational and relational characteristics of the drinking context, and that was drinking as part of daily life circumstances. This finding was consistent with previous research on this situational characteristic (Simpura 1987). Single and Wortley (1993) noted previously that most drinking occurs during relatively common, daily circumstances and that these circumstances - while protecting against occasions of heavy drinking - are connected with a high proportion of total alcohol consumed by Canadians. The results from this study are nevertheless consistent with previous research showing a link between heavy alcohol intake and drinking at parties (Clapp et al. 2000; Harford 1983; Harford et al. 1980; Single \& Wortley 1993). Since almost a third of respondents reported drinking at parties during their last drinking occasion, concern over heavy alcohol intake in this context remains. 
Day of the week. Hypothesis 7 states, "adults who consume alcohol on weekends are more likely to drink heavily than on other days of the week, such as weekdays". Overall, the findings from this thesis show some support for such a statement, although the relationship may be more complex than originally anticipated. The positive association between heavy drinking and consuming alcohol on Friday is consistent with a number of studies pointing to increased consumption practices during weekends (Arfken 1988; Demers 1997; Demers et al. 2002). Weekends have long been considered to be temporally linked with leisure pursuits for many individuals in Western society, and have served as appropriate contexts for heavy drinking (Single 1985). Indeed, the number of weekday drinking occasions reported by this study population was small, in comparison to the proportion that occurred on Fridays and Saturdays. However, the findings point to heavier consumption by those adults who reported drinking on Tuesday - almost twice the odds of consuming five or more drinks as compared to Saturday - as well as other days during the week. Quantities of alcohol consumed by Canadians who drank on Thursday and Sunday were not significantly different from drinking on Saturday, which remains a cause for concern. It was anticipated that these days would be associated with a lower likelihood for heavy drinking, but this was not the case for this study population. As discussed previously in Chapter Five, this suggests that heavy drinking and leisure pursuits are becoming more normalized as weekday activities for Canadian adults. Additional factors relating to the drinking context may be at play here. This relationship may be mediated by particular socialization activities that warrant the consumption of alcohol, including consumption to the point where individuals "feel the effects". As noted earlier, the findings here are consistent with research from the UK, which suggests younger adults are gaining preference for drinking during the week, and when going out, 
consuming higher quantities of alcohol (Goddard 1997a; Goddard 1997b; Roberts et al. 1997). Further qualitative and statistical exploration of temporal elements, such as the time and day of the week drinking occurs, is required to determine whether similar trends bear for Canadian adults. If heavy drinking has been broadened to include weekday drinking occasions, this may have a negative effect on promoting moderation with regards to alcohol in Canada.

Drinking location. Continuing with the examination of situational characteristics that were associated with a higher likelihood of heavy drinking, there is some support for the position that adults who consume alcohol at bars are likely to report heavy drinking than when drinking in other locations (Hypothesis 8). This is consistent with international research pointing to higher rates of heavy drinking at public drinking establishments (Caetano \& Herd 1988; Clark 1985; Harford 1979; Herd \& Grube 1993). The findings here are also consistent with previous research from Canada, showing higher quantities of alcohol consumption at bars or tavern (Demers 1997; Demers et al. 2002; Kairouz \& Greenfield 2007; Single \& Wortley 1993). Data from this study showed nearly a third of drinking occasions at a bar resulted in the consumption of five or more drinks, and that the chances of heavy drinking increased by $80 \%$ when drinking at a bar, compared to drinking at one's own home. Drinking in venues such as bars, pubs, taverns, nightclubs or lounges is one context that has received a great deal of attention in the literature.

Generally, public settings have been associated with higher levels of alcohol intake that private settings (Harford 1983). However, significant associations emerged for two other drinking locations: drinking at the home of someone else, and drinking at a restaurant.

Consuming alcohol at the home of someone else was unexpectedly predictive of heavy drinking for Canadian adults. The findings were consistent throughout the bivariate 
and full models, with the associations holding firm when adding additional variables pertaining to the drinking context. This would suggest that drinking at the home of someone else is a key variable at predicting the consumption of five or more drinks by Canadians, during occasions of drinking. This finding is consistent with research by Greenfield and Room (1996), as well as Kairouz and Greenfield (2007) showing greater acceptance of heavy drinking when in private contexts, and contradicts the earlier hypothesis that public venues would be a larger source of heavy drinking occasions. Of note is the large proportion of Canadian adults who reported drinking within this particular context. This suggests not only is this context a space where heavy drinking is more likely to occur, but it is also a heavily frequented context for occasions of consumption. Indeed, it would seem that responsible drinking - at least to the degree that recommended limits to daily alcohol consumption are observed - are not practiced by a significant portion of adults who drink in residential locations. The opposite findings arise when examining alcohol consumption at restaurants. Drinking at this venue was associated with a significantly lower likelihood of heavy drinking compared to drinking at one's own home. This runs contrary to research by Harford (1983) and Pertanen (1975), which found higher levels of consumption in these drinking locations, but confirms earlier research showing a protective effect for restaurants and heavy drinking by Canadians (Kairouz \& Greenfield 2007). While drinking at the home of someone else seems to be linked to periods of excess with regards to alcohol, restaurants continue to reflect an atmosphere of civilized and sensible drinking.

Meals. The results form this thesis do not support earlier research indicating an association between having a meal during the drinking occasion and lower quantities of alcohol consumption. It was hypothesized (Hypothesis 9) that drinking with a meal would 
exhibit a moderating effect on the propensity for heavy drinking by Canadian adults. In fact, the opposite was true. When considering only situational characteristics, drinking with a meal increased the likelihood of heavy drinking by approximately 50 percent, with this relationship becoming stronger upon inclusion of all variables pertaining to the drinking context. This finding is counterintuitive, given research showing protective effects of having a meal on alcohol intake (Demers 1997). As was noted previously, there is a need to examine this contextual variant across different regions of Canada, and to take into account cultural differences in the way alcohol is consumed. Quebecers, for example, reported the lowest usual consumption of five or more drinks, suggesting more moderate consumption of alcohol. In this instance, drinks may be consumed to enjoy a meal, as opposed to simply drinking as an end itself. For Canadians as a whole, drinking with a meal was surprisingly frequent, with almost 8 in 10 reporting this situational characteristic on their last drinking occasion.

Multiple Locations. An interesting finding that emerged when considering situational variables of the drinking context was the predictive strength of drinking at multiple drinking locations and reported heavy drinking. Over 60 percent in this context reported consuming five or more drinks, and those drinking in two or more locations were found to have significantly increased odds of heavy drinking, as compared to those drinking only at one location. While little research exists on this contextual variant, it was nonetheless the most indicative variable for heavy drinking, increasing the likelihood of this outcome by approximately 6 times. Given the lack of available literature on the subject, it is difficult to conclude why this occurred, however, a number of possibilities exist. This context may be connected to organized or more informal efforts to visit a number of alcohol venues during a short period of time, as part of a weekend "blow-out" 
event, or going "all out" (Harnett et al. 2000). There is evidence of this in the UK, where such practices at bars and pubs are commonplace. "British institutions such as the round and the pub crawl encourage group boozing and clusters of outlets - a trend that has accelerated since the early 1990s as a result of more liberalizing licensing" (Economist 01/08/2005: 49). The diversification of the alcohol market at that time created new products and drinking venues, often times in areas with a high density of public drinking establishments. These offered consumers more choice with which to fulfill leisure pursuits. The expanding array of lifestyle options and markers coincided with increasing lifestyle-appropriate opportunities for drinking - as well as public drinking contexts for an increasing diverse set of alcohol consumers - meaning more leisure options were available to larger numbers of drinkers within smaller boundaries of space.

As noted previously, this relationship could also be a function of sociodemographic variants such as age, or whether these individual comprise a certain group, such as students. These groups may seek to offset the high costs of becoming intoxicated by consuming a significant proportion of their alcohol in cheaper places (i.e., residential locations), before moving onto higher-cost public drinking venues such as bars, nightclubs, and lounges. As such, drinking in multiple locations may coincide with other contexts examined in this study, such as consuming alcohol at the home of someone else, or reported heavy drinking on Friday nights. Additional analysis on this data set may provide further insight into some of these relationships.

\section{Gender differences on the influence of the drinking context}

The gender of the individual has been identified as an important factor when researching heavy drinking by adults (Wilsnack et al. 2000). As such, this thesis 
examined gender differences in the relationship between heavy drinking and relational and situational characteristics of the drinking context. The current data suggest support for the importance of the drinking context when examining patterns of heavy drinking generally, and gender appears to be a factor in some of the results. To reiterate, there is limited research examining the effects of characteristics of the drinking context on heavy drinking, and there is even less research that considers gender differences associated with such variables. To enhance scholarship in the field, and examine whether a convergence in drinking contexts between Canadian men and women exists, the study population was separated according to gender in this research, and gender-specific measures of heavy drinking employed. The results from this thesis do not support earlier research indicating a convergence of drinking behaviour between men and women (Ferrence 1980; Fillmore 1984; Measham \& Brain 2005) at least to the degree in which contextual similarities exist. While data from this study support the notion that the likelihood of heavy drinking by Canadian men and women during drinking occasions is relatively equal, results from the CAS have previously determined that men are more likely to consume heavy amounts of alcohol more frequently, and drink a higher quantity overall (Adlaf et al. 2005).

\section{Relational}

Among relational characteristics of the drinking context, gender seems to account for the findings pertaining to heavy drinking with co-workers. While drinking with coworkers was reported by a similarly small percentage of males and females in this study population, drinking with this companion was associated with a five-fold increase in the likelihood of drinking for men, whereas a positive association between this relational characteristic and heavy drinking was not observed among Canadian women. Research 
has shown that the consumption of alcohol at days end with co-workers is relatively common, with men tending to consume with co-workers more often then women (Blum \& Roman 1997). Also, men employed in male-dominated occupations have been shown to have more opportunities to drink with co-workers, and may increase intake during such occasions as part of ritual demonstrations of masculinity, stamina, non-conformity, risktaking or even self-control (Driessen 1992; Gotoh 1994; McDonald 1994). Nevertheless, friends constitute approximately half the drinking companions for both men and women, which is consistent with a large body of literature showing this relationship to be important in leisure attempts related to alcohol, as well as elevated rates of alcohol intake when with such companions.

Group size proved to be influential in accounting for heavy drinking among both men and women. Generally speaking, as the size the drinking group increases, reported heavy drinking also increased, although the relationship was most pronounced among women from the study population. The odds of consuming four or more drinks when drinking in groups of ten or more increased the likelihood of women's heavy drinking by $500 \%$. This relationship was not as apparent among men, who reported similar odds of heavy drinking with slightly smaller groups. The results of this study reflect research by Cutler \& Storm (1975) and Single (1985) showing a link between large group size and heavy alcohol consumption. Again, it is difficult to ascertain the reasons for the observed odds among women in this study. Canadian women may take solace in knowing they have a large number of companions in their drinking group and respond with higher levels of alcohol intake. Alternatively, this relationship may be a product of a greater likelihood of higher-drinking companions being included in larger groups, with modelling effects accounting for some of the discrepancy. Additional research examining the 
expectancies associated with consuming alcohol in smaller or larger groups of drinking companions may provide some insight into the relationships observed here.

The only significant findings that were in the direction of the proposed hypothesis for drinking in the presence of one's partner were found among women in the study population. While women were more likely to consume alcohol in the presence of their partner than were men, this context was protective against the consumption of four or more drinks during that occasion. For men, however, drinking with a partner was associated with a 3-fold increase in the odds of heavy drinking. At least for men, this effect contravenes existing research that examines heavy drinking in the presence of a romantic partner, and may indicate a shift in the acceptance of heavy consumption in a widening array of drinking situations. As noted previously, heavy drinking has been linked with the experience of domestic and marital problems, physical and verbal altercations, and unwanted or unprotected sex (Bondy 1996; Reducing Alcohol-Related Harm in Canada 2007). Consequently, other research has found the likelihood of negative consequences from heavy drinking may also be greater for females than for males (Kranzler et al. 1990; Bondy 1996; Rehm et al. 1996). As such, higher reported heavier alcohol consumption by Canadian males when drinking with their partner is an area of concern. Wilsnack and Wilsnack note that, "Heavy drinking by her husband or partner may increase a woman's risk of problem drinking by providing a heavy-drinking model, increasing the availability of alcohol, and contributing to relationship conflict or violence" (1991: 151). Research has shown a strong relationship between women's levels of alcohol consumption and those of their husbands or partners (Wilsnack $\&$ Wilsnack 1991). Heavy-drinking male companions may also be more inclined to provoke or participate in drinking-related violence, including violence with other patrons at licensed 
establishments or fights with an intimate partner (Wilsnack et al. 2000). Again, further research on consequences experienced by Canadians, including those specifically experienced by women as a result of the alcohol intake of their drinking companion, would provide further insight into this trend.

\section{Situational}

Differences were observed for men and women in relation to situational characteristics of the drinking context. Of note was the significant association between drinking at a 'get together' and heavy drinking for women, and the decreased likelihood among men. The odds of heavy drinking for women increased by 70 percent when drinking in this context, and decreased the odds by roughly 60 percent for men. In general, these findings suggest parties may be situations where the highest alcohol intake can be expected for men, but for women, heavy drinking is probable in a wider range of circumstances. Particularly among younger women, the transition to adulthood may change the types of contexts in which alcohol consumption is likely to occur (Wilsnack \& Wilsnack 1991). Increased roles relating to employment, marriage, and parenthood may lead to fewer opportunities for fiesta-type drinking events, with occasions of heavy drinking shifting to more 'low-key' circumstances, such as at a 'get together'. Future studies on the drinking context should attend to defining this drinking circumstance in greater detail, including how it fits within contemporary leisure pursuits by adults, and the expectancies for alcohol consumption associated with this situational characteristic.

Regarding the day of the week in which heavy drinking is most likely to occur, results from this study reflect previous research showing Friday and Saturday as days associated with increased alcohol intake (Arfken 1988; Single 1985). However, results 
showing increased odds of heavy drinking for men who consume on other days of the week may indicate that temporal boundaries for drinking intensity may be eroding. A number of potential explanations for these findings were provided previously, including potential drinking on weekdays by individuals with fewer early morning work responsibilities (e.g., students). For U.S. adults, heavy drinking into the night can often lead to hangovers and lateness, which could increase the odds of experiencing problems at work or school (Dawson 1996). The findings may simply reflect those individuals with problem drinking patterns (e.g., heavy-frequent drinker), given the relatively low number of men reporting drinking on those days. Consideration should be given to analyzing this set of variables by drinker-type to see what relationships emerge. Alternatively, some of the drinking occasions captured in the CAS may include holiday parties or events which may occur on non-traditional drinking nights. Lemmens and Knibbe (1993) found alcohol consumption in the last two weeks of December to be approximately 70 percent higher than consumption during normal weeks. They note that Christmas and New Year's Eve are traditional days of celebration, with a higher prevalence of current drinkers choosing to drink during this period, and reporting a higher frequency of drinking (number of days) as well as higher average quantity per occasion (1993: 159). While it may seem, at least for this population of males, that a culture of intoxication may be emerging amongst the general adult population in Canada, as has been argued with other advanced liberal democracies (Measham 2006), given the above mentioned limitations of the survey the findings should be interpreted with caution.

In contrast to expected findings, males who reported consuming alcohol with a meal were much more likely to report heavy drinking than their male counterparts who drank without a meal. For Canadian women, however, drinking to accompany a meal 
reduces the likelihood of heavy drinking. While the incorporation of food into drinking occasions may have only limited effects on impairment, it has been shown to reduce overall blood alcohol level (BAL), lower the peak BAL and delay the elimination of alcohol from the blood (Finnigan et al. 1998). Research has demonstrated that having a meal can slow the absorption of alcohol as a result of the individual having a full stomach (Schultz et al. 1980), and meals consisting of fixed energy, fat, protein and carbohydrate content - or particularly high-carbohydrate meals - can reduce both peak BAL and consequent performance impairment when consumed prior to drinking (Millar et al. 1992; Welling et al. 1977). One possible explanation for the discrepancy between males and females is that males may be engaging in 'calculated hedonism', in that altered states of pleasure through pharmacological and behaviour practices - in this sense, feeling the effects from alcohol on occasions of drinking - are prioritized, with individuals partaking in techniques of self-regulation to avoid negative consequences. In this sense, commonsense knowledge of perceived benefits from eating when drinking may permeate their cost-benefit assessments regarding alcohol intake (Measham 2004b). Additional research examining the circumstances where food are consumed, as well as expectations for alcohol consumption when having a meal, could help determine whether such processes are occurring for this population.

Finally, the type and number of locations where drinking takes place were key variables in predicting heavy drinking for both male and female respondents. The current data suggests support for the importance of the location when examining all characteristics of the drinking context. Findings showing alcohol consumption in restaurants to be associated with more moderate drinking emerged regardless of gender, signifying the importance of such a variable. Differences between men and women in this 
context were small, and may be the result of women's higher BAL per unit of alcohol consumed compared to men. Women may drink less than men, but obtain relatively the same effects when consuming alcohol in restaurants (York \& Welte 1994). Fostering a sense of 'moderation' with regards to alcohol is a key goal of policy efforts aimed at addressing alcohol-related harm in Canada. Such an ethic "signals a new way of thinking about alcohol use that includes an understanding of when, when not, and how much to drink, appropriate motivations for drinking and settings in which responsible drinking should take place" (Reducing Alcohol-Related Harm in Canada 2007: 1). By continuing to promote some of the expectations and norms found in this context, more moderate drinking practices may be wise to encourage when consuming alcohol in other public drinking locations.

Larger differences were observed, however, in reported heavy drinking at the home of someone else. As noted previously, drinking at the home of someone else was predictive of heavy drinking for Canadian males, whereas for women this context was marginally linked with more moderate consumption. Other research found residential locations to be increasingly frequented areas for drinking (Treno et al. 2000), and as acceptable spaces for which to feel the effects from alcohol (Greenfield \& Room 1996). For Canadian men at least, the findings from this study seem to support such a claim. Measham and Brain (2005) argue that as part of the re-commodification of alcohol in the 1990s, a range of new contexts emerged in which drinking - even to the point of intoxication - was accepted. For a certain segment of the adult population who may view the 'bar scene' as an undesirable locale, drinking in more private locations may represent a safer alternative for which to engage in riskier drinking behaviour. Wilsnack and colleagues note that for men, drinking with other men is an "important way to escape 
control by others, ignore social differences, and form personal and social support networks" (2000: 253). Drinking at another person's home may provide the situational context for such interaction, with the result being higher than normal alcohol intake. Again, future qualitative research examining the beliefs and expectations around alcohol consumption for women and men may provide some understanding of gender differences with regards to drinking location. While gender continues to be an important concept in sociology, gender as a theme in research on drinking contexts is still quite marginal. The findings from this study suggest that the contexts of alcohol consumption are gendered, with apparent differences in where and with whom heavy drinking occurs.

One situational characteristic that exhibited some gender similarity was reported heavy drinking when drinking at multiple locations. For both men and women, this context was associated with over a 7-fold increase in the likelihood of drinking, although the number of Canadians reporting this characteristic was small. As noted previously, it is likely that other factors such as age or work status may be involved in this relationship. Again, qualitative or ethnographic research on drinking behaviour involving 'pub crawls' or 'bar-hopping' may provide some insight into the dynamics of these drinking occasions.

\section{Re-imagining heavy drinking as contextually-specific behaviour}

The results of this study coincide to a certain extent with the proposed theoretical perspectives on risk and leisure practices. A framework with 'risk' as its focus can help account for broader changes in substance consumption in neo-liberal societies, and provide a foundation from which to understand social influences on heavy drinking. Stockwell and colleagues have described the contexts in which drinking takes place as “'stages' upon which social, economic, cultural and legal forces exert their separate and 
collective influences on drinking behaviour" (1993: 1520). The drinking context represents a territory for individual and collective action, including both relational and situational influences on alcohol consumption. As noted previously, the risk perspective emphasizes the individualized nature of late modern risks, which must now be selfmanaged by individuals in their everyday practices. This includes risks associated with the consumption of alcohol and other drugs. The individualization of modern life - which Beck argues is the new social order in response to the shift in the problems of late modernity being characterized from social to individual risks - requires greater selfresponsibility on the part of individuals to deal with problems previously considered social in nature. This process, it is argued, is emblematic of advanced liberal rule, which seeks to engender a greater sense of self-responsibility among members of society. Individuals are re-imagined as rational-choice consumers, and must be active in their own government, including the governing of their own alcohol intake and the risks such intake entail.

It has been argued that alcohol intake is not an innate property of individuals, and is instead contingent upon the context in which drinking occurs. As such, it could be anticipated that individuals would exhibit moderation in certain contexts, and determined states of intoxication in others, during occasions of drinking. Occasions of alcohol consumption for Canadian adults are increasingly being characterized by risk, at least to the degree in which individuals report hazardous levels of alcohol intake. Nearly 20 percent of Canadians report consuming five or more drinks on their last drinking occasion, with rates rising to almost 25 percent among males and females when accounting for gender-specific measure of heavy episodic drinking. While this data cannot say whether a quarter of Canadians are drinking to the level of intoxication when 
they engage in alcohol consumption, it is enough to suggest that a significant portion of the population is 'feeling the effects' from drinking on these occasions.

This is noteworthy, given the association between heavy drinking and the experience of acute alcohol-related harms. Sporadic intoxication is the dominant pattern of substance consumption in advanced liberal societies, with previous research finding the highest percentage of heavy episodic drinkers internationally to be Canadian men (Wilsnack el al. 2000). The risk perspective posits that consumption associated with individual lifestyles are increasingly organized around incalculable insecurity, and that this uncertainty permeates everyday decisions. This study suggests that any 'uncertainty' characteristic of the contemporary phase of modernity may have been translated to drinking occasions for Canadians. Heavy drinking is appearing in a range of drinking contexts, with the potential for alcohol-related risks in the ever-expanding market spaces characteristic of advanced liberal societies. Neo-liberal rationales of government aimed to engender a sense of self-responsibility in the modern, governable subject. This demands that leisure pursuits not conflict with other duties of neo-liberal subjects, such as those requiring individuals to be of clear-mind and exhibit rational behaviour during practices of leisure and consumption. Heavy drinking threatens both of these expectations (Room 1997), and leads to a greater sense of uncertainty for the individual with regards to drinking occasions and potential consequences. This can include a greater chance of experiencing physical and verbal altercations, unintentional injuries, unwanted or unprotected sex, or problems associated with work, economic or domestic responsibilities (Bondy 1996; Duffy 2003; Reducing Alcohol-Related Harm in Canada 2007). This uncertainty with regards to heavy drinking is likely not consistent across contexts; data from this study suggests that certain contexts, as a result of their association to heavy 
drinking, provide a greater sense of risk when specific relational and situational characteristics are present. This is particularly true for women and men.

Consistent with developments from the risk perspective on contemporary patterns of alcohol consumption (Measham 1996; Measham 2004a; Measham 2004b; Measham 2006; Measham et al. 2001; Measham \& Brain 2005; Parker et al. 1998) ${ }^{35}$, evidence from this study suggests a shift in the way risk may be perceived and consumed, based on the context in which drinking occurs. The risk perspective would classify drinking contexts as linked to institutional risk environments, in that connections to society in the current phase of modernity must be made between the individual consumer and various institutions associated with ones lifestyle, with each containing its own institutionallygenerated risks. Individuals must negotiate the risks of their leisure practices around alcohol based on their social risk position, which is shaped by institutional forces associated with ones lifestyle, as well as the immediate context in which such behaviour occurs. With the diversification of the alcohol market, the emergence of a wide array of drinking contexts - each influenced by the social, economic and legal risks associated with particular situations and relations of drinking - has altered the traditional spaces where heavier drinking patterns are tolerated. Measham contends that leisure pursuits associated with alcohol are situated within particular "boundaries of time, space, interpersonal interaction and intensity" (2004b: 319), and as such, contain various risks -

\footnotetext{
${ }^{35}$ In Chapter Two, the risk perspective on substance consumption was described, including the focus by Measham on changes in the way alcohol in consumed in the contemporary phase of modernity. This perspective identifies heavy drinking as a response to the strains and uncertainties of living in advanced liberal societies, and positions substance consumption as invariably linked to the development of a consumerist ethic around leisure pursuits. More specifically, the consequences from such consumption, it is argued, have been re-imagined in terms of individual responsibility and self-enterprise, with a great deal of uncertainty becoming attached to drinking behaviour. Late modern leisure pursuits around alcohol consumption must take into account the environment - and all the risks and consequences associated with these spaces - in which consumption occurs in order to minimize the likelihood for harm, while remaining consistent with the goals of the particular leisure pursuit.
} 
separate and combined - that are associated with each of these environments. When the analysis of relational characteristics related to heavy drinking was conduced, males with co-workers as their primary drinking companions were much more likely to drink heavily than with any other companion, meaning interpersonal boundaries around alcohol may be shifting in Canada. The National Alcohol Strategy Working Group argues that alcohol consumption by workers may be affected by the presence of a work-place culture that promotes heavy drinking (Reducing Alcohol-Related Harm in Canada 2007). Other researchers have noted that working in all-male work environments, in bars and restaurants, or particular industries are linked with heavy episodic drinking (Parker \& Harford 1992; Kraft et al. 1993; Svare et al. 2004). It is possible that heavy drinking - as well as the potential for alcohol-related risks - may be related to a workplace culture that fosters convivial atmospheres for drinking with colleagues generally, or engaging in heavy drinking more specifically. Loxley et al. argue that employers have a general responsibility to address issues of substance consumption in their work-force, and that "the culture of drinking within a work-place" may represent an area for intervention (2005: 564). They note that employers are likely to incur substantial savings from effective interventions that address these cultural issues. With the results of this study showing an elevated risk of heavy drinking when accompanied by co-workers, interventions targeted at this context may prove beneficial in reducing some of the economic and social consequences associated with on-site intoxication or hangovers. In addition, results of this study provide some evidence that certain contexts are linked with what Measham has termed 'calculated hedonism' and 'determined drunkenness'. While Measham has argued these trends are related to the emergence of a 
'culture of intoxication ${ }^{36}$, they are also prioritized within particular leisure pursuits involving alcohol consumption. For Canadian adults, most leisure pursuits around drinking involve sensible levels of consumption. Drinking in smaller groups for both males and females, as well as with one's partner present for females, reflected occasions where more moderate consumption was appropriate for the type of leisure being undertaken. Similarly, restraint was exhibited when consuming alcohol in restaurants which suggests possible rational cost-benefit analysis occurring with regards to alcohol intake in this context. Most heavy drinking occurred on weekends, particularly among Canadian women. This suggests that Canadians may be willing to expand their risktaking behaviour when it is unlikely to interfere with routine weekday responsibilities, such as those associated with work or family. This also suggests that, in certain contexts, moderate drinking is recognized as having greater benefits than heavier drinking.

In other contexts, Canadians may view the pursuit of intoxication as a desired aspect of their particular leisure experience. Drinking with friends and in larger drinking groups for females, or in the presence of one's romantic partner for males, produced higher odds of heavy drinking. These relational characteristics of the context may represent the types of interpersonal interactions that are most associated with states of intoxication for Canadians. At the same time, individuals are likely to be engaging in some form of risk-analysis, weighing the costs and benefits associated with heavy drinking. For women, drinking in larger groups may increase the number of companions

\footnotetext{
${ }^{36}$ It should be noted that this researcher is not arguing that a culture of intoxication has or is emerging in Canada, nor that the current study speaks directly to such an event. Rather, 'calculated hedonism' is raised in order to highlight that the prioritization of altered states of pleasure around alcohol consumption is still mitigated by contextual factors. While intoxication may be prioritized in certain combinations of relational and situational contexts, in others, lower quantities of alcohol can still result in pleasurable leisure experiences. Thus, practices of risk management are likely present during occasions of drinking, with the "shifting sands of moderation and excess" (Measham 2004b: 343) characteristic of late modern society operating within the contexts of drinking.
} 
who would help in the event that some alcohol-related problem emerged. Measham (2004a) argues that during occasions of substance consumption, individuals may practice certain techniques to avoid an undesired state of intoxication. Drinking with friends, and/or in large groups may help reduce the uncertainty involved with heavy drinking by providing women with an appropriate support network. This calculative approach to heavy drinking may help facilitate a 'controlled loss of control' when consuming a higher number of drinks (Measham 2004b). For Canadian men, their romantic partner may represent the ideal individual to provide support when drinking heavily, and to reduce some of the risks associated with alcohol-related leisure pursuits. This rationale provides one possible explanation for the higher than expected odds of heavy drinking associated with these relational characteristics, however future research should examine such associations more closely. This could include researching drinking expectations linked to similar interpersonal interactions found in the drinking context, or expanding theory that is better suited to explaining gender differences in the relational characteristics of drinking occasions.

Certain drinking contexts could also be perceived as situations where consumer excess is expected, and even encouraged. Drinking at bars or on weekends are traditional spaces associated with heavier alcohol intake. Parties are also circumstances where higher than normal quantities of alcohol are consumed. As such, these contexts represent spaces where heavy drinking is likely to occur for a significant portion of Canadians. To a certain extent, the results of this study support previous findings and theory showing these contexts as linked with heavy drinking. Further, the risks associated with heavy drinking are likely to be found in contexts that are associated with more leisurely attitudes towards intoxication - contexts which are heavily frequented or contain a large number of heavy 
drinkers, such as bars or parties (Stockwell et al. 1993; Graham \& Homel 1997). The uncertainty involved with heavy drinking in these contexts, however, is likely an important aspect of the pleasure they experience as part of the drinking occasion. As Mustonen \& Mäkelä note, "[d]rinking is inherently risky behaviour, but if one gets rid of the negative consequences, one also loses some of the benefits" (1999: 83). For certain individuals, the pursuit of 'determined drunkenness' is best realized in situations conducive to heavy drinking and its related behaviour.

The finding that drinking at the home of someone else is becoming a context for heavy drinking also has implications from this theoretical perspective. As noted previously, heavy alcohol intake has been traditionally associated with certain spaces such as bars or nightclubs, as well as specific risks linked with drinking in these contexts. With the results of this study coinciding with previous research showing residential locations to be heavily frequented and acceptable spaces for which to feel the effects from alcohol (Greenfield \& Room 1996; Treno et al. 2000), we may need to re-imagine the types of drinking situations likely to result in heavy alcohol consumption. At least for Canadian men, drinking at the home of someone else may be a culturally appropriate context where specific leisure practices around heavy drinking are accepted. In essence, drinking at other's homes may represent the ideal location for the "commodification of calculated hedonistic excess" and a space where "determined drunkenness" is normalized (Measham 2004b: 344). For a certain segment of the adult population who may view the 'bar scene' as an undesirable locale, drinking occasions in more private contexts may represent a safer alternative for which to engage in riskier drinking practices. Certain alcohol-related harms may be minimized in such contexts (i.e., verbal or physical altercations). Private settings exist outside the gaze of formal surveillance mechanisms, 
and operate instead according to informal norms which are negotiated as part of the process of interaction with drinking companions (Measham 2004b). While certain boundaries exist for drinking behaviour in public drinking locations, accepted behaviour around drinking and drunkenness when drinking at the home of someone else, for example, might be different. This situation may represent a comfortable space for Canadian men to practice hedonistic excess in relation to alcohol consumption. Other substance-related leisure practices, such as consuming alcohol in conjunction with the use of other drugs, may also be prevalent in such contexts, since these drinking occasions would be less likely to generate legal intervention compared with use in more public or licensed drinking venues. Poly-drug use may result in an increased chance of experiencing problems or harms related to one's drinking. For Canadian adults, the combined effects of alcohol and other drugs may contribute to problematic levels of intoxication. "Among cannabis users, alcohol is almost universally used on a regular basis, with most users consuming alcohol at harmful levels" (Reducing Alcohol Related Harm in Canada 2007: 10). At the same time, these situations may also offer individuals the opportunity to engage in a "pick-and-mix approach" to their substance consumption, which has been described as a desired element of contemporary leisure practices, particularly among younger adults (Harnett et al. 2000; Measham 2006).

Additional research examining the trends identified in the data from this thesis, as well as the utility of conceiving of the drinking context in relation to the risk perspective on substance consumption, seems appropriate. While most Canadians' occasions of alcohol consumption involves responsible drinking behaviours, many still experience harms from theirs and/or others' drinking. Policy efforts directed towards the relationships and situations conducive to heavy drinking occasions should not focus 
narrowly on absolute alcohol intake, but instead seek to alter the contexts in which such behaviour occurs. As many Canadians likely remain in control when consuming above the recommended daily limits of five or more drinks for men, and four or more for women, targeting should remain around reducing the risks from such behaviour.

\section{Promoting moderation and reducing harm: a place for 'context'?}

This study has several implications for policy options aimed at addressing heavy drinking by Canadians. In Chapter Three, it was noted that alcohol consumption came to be understood in individual terms as a result of complementary trends in research on, and the government of, issues related to public health. The individualization of substance consumption in general - and alcohol and its related risks more specifically - meant that interventions were designed to alter the lifestyle choices of individuals regarding alcohol consumption, as opposed to focusing on the contexts where consumption occurred. Such a position is consistent with the emphasis placed upon individual responsibility for modern risks and problems within neo-liberal states. A contradiction emerges with regards to the governing rationales and techniques of advanced liberal governments, as policy efforts around alcohol generally seek to shape the private conduct of individuals (Duff 2004) while maintaining distance from measures of overt control.

Some have argued that drug policy in general should be concerned with "limits and moderation in the fostering of a culture of responsible use" (Duff 2004: 390). In Canada, this reflects the primary aim of the proposed National Alcohol Strategy, which seeks to address the impacts of heavy, single-occasion and episodic binge drinking by the general population (Reducing Alcohol-Related Harm in Canada 2007: 4). Given the high percentage of Canadians reporting heavy drinking on their last drinking occasion in this 
study, heavy drinking occasions would certainly be an appropriate area to target for intervention. Room et al. (2003: 165) argue, however, that policy may not change popular patterns of sporadic intoxication, at least in the short to medium term.

Nevertheless, the National Alcohol Strategy Working Group identified alcohol misuse by Canadians as "an issue requiring national attention". The Working Group notes that policy should attempt to "raise public awareness about responsible alcohol use and enhance the capacity and resilience of individuals and communities to participate in a culture of moderation" (Reducing Alcohol-Related Harm in Canada 2007: 1). Governments should try to control heavy drinking, either though policies aimed at controlling overall levels of consumption, or reducing alcohol-related harms, as these types of strategies are the most effective way to counter the emergence of a perceived culture of intoxication.

Some general policy initiatives have been proposed to address heavy drinking occasions by the general population. This includes the development of national drinking guidelines, which would provide Canadians with an understanding of appropriate drinking amounts, contexts and motivations for drinking, in order to minimize alcoholrelated harm. "Establishing an understanding of what constitutes sensible or low-risk drinking is critical to achieving a culture of moderation" (Reducing Alcohol-Related Harm in Canada 2007: 7). Individual advice on consumption practices, such as interspersing alcoholic beverages with soft drinks and not mixing different types of alcoholic beverages, or unit and warning messages on alcohol containers, have proven effective as health messages, and are consistent with a focus on reducing the harms associated with heavy drinking occasions (Graham et al. 2004; Homel, Mcllwain, \& Carvolth 2004; Plant et al. 1997). Warning messages on alcohol containers have been 
applied in the Yukon and British Columbia, providing information about alcohol poisoning or 'standard serving' information to better enable drinkers to avoid occasions of intoxication, and enable drivers to be sure they are below the legal blood-alcohol level for driving (Stockwell et al. 1990, cited in Single 1994: 276).

A number of general programmes around alcohol pricing are available, and have been linked with some of the harm minimization perspectives above, or other harm reduction measures. ${ }^{37}$ This includes taxation policy designed to control the unit price of alcohol, and has been shown to have a significant effect on heavier drinkers (Kendell et al. 1983) and young alcohol consumers (Grossman et al. 1987). This type of populationbased policy is a cost-effective strategy that is likely to reduce occasions of heavy drinking, and the harms associated with consuming high quantities of alcohol (Casswell 1994).

At the same time, successful responses to heavy drinking and its related harms require a range of policy approaches, including those associated with 'harm reduction' (Reducing Alcohol-Related Harm in Canada 2007). Again, many options available under this approach accept that heavy drinking is likely to occur, but instead focus on reducing the harms for alcohol consumption, or promoting moderation to a degree to which the risks of harm are minimized. The results from this study demonstrate the importance of the drinking context in influencing how much Canadian adults drink. Understanding how and where Canadians drink is important: assessment of the contexts of alcohol

\footnotetext{
${ }^{37}$ Harm minimization has been utilized in a number of advanced liberal societies to refer to the use of demand reduction, supply reduction, and harm reduction techniques in the control of both licit and illicit substance consumption. Measham (2006) argues that while supply and demand reduction have their proper place in relation to enforcement and prevention/treatment options for alcohol, harm reduction does not. Instead, governments need to consider harm reduction approaches in addressing many of the cultural and contextual shifts towards heavier alcohol consumption.
} 
consumption and related patterns of drinking may "suggest strategies to reduce harms from drinking such as injuries, without necessarily affecting the drinking itself" (Room et al. 2003: 168). As such, interventions tied to the drinking context may provide an opportunity to reduce alcohol-related harms.

Single (1996) points to growing empirical support (Stockwell et al. 1994; Single \& Wortley 1993; Midanik \& Clark 1994) that interventions designed around more moderate drinking by individuals on occasions of drinking may be the most efficient way to reduce alcohol-related consequences in the population. As this thesis highlighted, drinking occasions occur in particular contexts, which contain characteristics that are both situational and relational in nature. Drinking occasions have been identified as a primary target for strategies aimed at addressing risky drinking practices by individuals, with the contexts of alcohol consumption representing a likely space for effective intervention (Casswell 1994; Midanik \& Room 1992). To reduce acute harms from alcohol consumption, policy targeted at the diverse drinking contexts in Canada, such as the home, workplace, school, various recreational and local settings, as well as licensed establishments, is required. A number of programs and strategies have been implemented that seek to modify or limit drinking, particularly in licensed venues, which are consistent with the harm reduction approach. These strategies start from an "acceptance that there will be consumption of alcoholic beverages and seek to modify or limit the drinking or the drinking environment so that potential harm is minimised"' (Stockwell 2003: 1358). Indeed, descriptive data from this thesis identified bars or taverns as spaces of heavy drinking, with a third of respondents who consumed alcohol in these locations reporting heavy drinking. Alcohol consumption in public locations such as bars, taverns and nightclubs are not only linked with high levels of intake, but also alcohol-related 
problems (Stockwell 1997). This suggests that the expansion of successful strategies such as server intervention programmes, and the promotion of low-alcohol alternatives in public drinking locations, may directly impact the quantity of alcohol consumed by Canadian adults (Erickson 1999; Single 1994). Server intervention strategies are quite common in the U.S. and Canada, and when backed by commercial liability regulations, have shown some success at limiting heavy drinking in public drinking locations (Mosher 1999). ${ }^{38}$ This is relevant to data from this study showing nearly twice the odds of consuming five or more drinks when drinking at a bar. However, many of these programmes involve self-regulation by licensed establishments, and often lack sufficient enforcement to be effective. ${ }^{39}$ Furthermore, in larger bars where the service occurs from a centralized location, server intervention becomes difficult, as bartenders are unlikely to have the capacity to monitor levels of intoxication of patrons as they approach the purchase area (Graham et al. 2004).

Further alterations to situational characteristics associated with heavier alcohol consumption, or focusing on the harms from heavy drinking, are likely to go unnoticed by individual consumers, and may have a significant impact on consumption and/or harm (Mosher 1999). Research on the Safer Bars programme, which provides for specialized training and workbook material for staff, has been shown to reduce levels of aggression in establishments, and consequently, acute harms from heavy alcohol consumption (Graham

\footnotetext{
${ }^{38}$ These strategies allow for damages to be sought from "the owners of licensed premises where people have been served until clearly intoxicated and who have then killed or injured a third party" (Stockwell 1997: 926). Stockwell notes, however, that there is weak evidence for the effectiveness of such strategies, and that taken alone, that they "are more than good public relations exercises for the retail alcohol industry" (Stockwell 1997: 928).

${ }^{39}$ While research on the benefits of server intervention programmes is generally positive, some research has identified issues with regards to their benefits. In particular, the critiques by Stockwell (1997), and Loxley et al. (2005) highlight many of the challenges researchers have in evaluating the effectiveness of these initiatives, and some of the impediments to regulation.
} 
et al. 2004). Greater scrutiny of an individual's level of intoxication prior to entry into the establishment is also likely to reduce severe states of intoxication and/or alcohol-related consequences. Such practices would have direct implications for individuals who drink at multiple locations, or 'pre-drink' in residential locations before moving onto more public venues. Data from this study determined that drinking at multiple locations was associated with the highest odds of heavy drinking, meaning efforts to restrict access to bars and/or nightclubs may curb overall consumption, and could in effect reduce certain harms for individuals who have clearly consumed 'too much'. Targeting pub crawls, either through information campaigns in areas where such events are likely organized, or through the provision of additional private or public security (i.e., campus security, neighbourhood watch, or police) in the high traffic areas leading to and from licensed venues are also likely to reduce additional consequences from heavy drinking, such as aggression, property damage, or unwanted sexual advances.

As noted previously, drinking at the home of someone else was unexpectedly predictive of heavy drinking, particularly among males in the study population. There is currently a policy void surrounding interventions aimed at private drinking contexts. The courts have ruled that social hosts have no duty of care to monitor individuals' drinking when at a private gathering or party, nor can they be held responsible for the actions of guests following the drinking occasion. ${ }^{40}$ Consistent with neo-liberalism's view of the

\footnotetext{
${ }^{40}$ In Childs $v$. Desormeaux, the Supreme Court of Canada ruled that social hosts are not under a duty of care to members of the public who may be injured by a guest's actions. The claim emerged from a case in which Desormeaux attended a New Year's Eve party, became intoxicated and, upon driving home, killed one individual and severely injured three others, including the claimant. The court placed sole responsibility on the individual, noting that social hosts could not reasonably foresee the consequences of his actions. Therefore, liability for hosts of social gatherings involving alcohol - whether patron supplied or provided by the host - is not the same as with commercial hosts, which can more easily monitor patrons consumption, have special knowledge pertaining to intoxication, and operate within a contractual relationship with potentially intoxicated individuals. While the potential exists for future claims involving
} 
individual, in these circumstances, emphasis is placed on individual responsibility around one's own drinking behaviour. Nevertheless, public messaging aimed at social hosts and stressing the need to consider the safety of those who consume heavy amounts of alcohol may have an effect on some of the consequences from intoxication. More specifically, information related to safe drinking practices in private locations, with a focus on preventing or dealing with physical altercations, unwanted sexual advance, or undesired social behaviour, may prove beneficial for those hosting informal 'get-together's' or parties. Similarly, messaging aimed at engendering a sense of compassion and responsibility for friends or guests at one's house, including helping them to avoid risky situations, may receive some traction with the Canadian public. Research on drinking and driving messaging has shown this type of mobilization to be effective in reducing subsequent offences over time (Reducing Alcohol-Related Harm in Canada 2007). This type of information would likely appeal to any cost-benefit considerations of individuals, as would information related to the consumption of meals during drinking occasions (i.e., the benefits of providing food during social gatherings involving alcohol). Again, the provision of such information recognizes that heavy drinking is likely to occur in our society, is likely to occur under certain relational and situational contexts, and that the harms from such behaviour can potentially be minimized by considering interventions to the contexts in which consumption occurs.

In Canada, a strong regulatory framework currently exists around the availability of alcohol, as well as its pricing and marketing, although some argue that this framework

employer-hosted social gatherings, whereby a paternalistic relationship of supervision and control may be argued, the facts of this case did not speak directly to those circumstances (Social Host Liability 2007, www.hg.org/articles/article 1441.html). As such, policy options around 'social hosts' of private drinking occasions will have to consider extra-legal options. 
has been eroded in recent times (Mosher 1999). With alcohol being considered an issue of public health - as is the case in Canada - corresponding trends in the entrenchment of alcohol as a commodity for pleasure, as well as the economic interests of the alcohol industry in further liberalizing alcohol markets, presents a great challenge for policymakers seeking to address heavy drinking. While alcohol sales resulted in an injection of $\$ 16$ billion into the Canadian economy, close to 3.3 million Canadians (or 14 percent of the population) engaged in drinking practices that are - or will likely be harmful to themselves or someone else (Reducing Alcohol-Related Harm in Canada 2007). Competing interests from those involved in the night-time economy may hamper attempts to promote moderation with regards to alcohol consumption, particularly in relation to alterations of public contexts of consumption. If trends towards further liberalization of the markets for alcohol continue (as has been experienced in the $\mathrm{UK}^{41}$ ), it will become increasingly more difficult to promote moderation at the same time as the industry promotes increased consumption.

Furthermore, it is difficult to imagine how the policy framework surrounding alcohol consumption could be strengthened towards a focus on reducing harms. With the recent announcement of Canada's National Anti-Drug Strategy, with a focus on using methods of prevention, treatment, and most importantly enforcement, to combat the illicit drug problem in Canada (Government of Canada 2007), it may be up to provincial or local levels of government or community-based organizations to push for change.

\footnotetext{
41 It was noted previously that the liberalization of alcohol policies in Britain led to a diversification of the alcohol market, and has become a staple of post-industrial economies (Measham \& Brain 2005: 268). This had led to many unanticipated consequences, including increased public intoxication, violence, and property-related offences where such markets emerge. This led Babor (2004) and Room (2003) to comment that responsibility for such problems are often distributed back to the individual, or towards the surrounding community, with little effect on behaviour. Furthermore, Babor notes that corporate responsibility and effective policy interventions have been subsumed in favour of initiatives that do not hamper industry efforts towards profit maximization
} 
Recommendations for a National Alcohol Strategy in Canada have reiterated the need to focus on drinking by older adults in order to "fashion the templates for the attitudes and practices of the younger generation" (Reducing Alcohol-Related Harm in Canada 2007: 9). With the focus of national-level policy shifting over towards youth, it is also difficult to conceive how emphasis on the consumption of a licit substance (alcohol) by rational consumers (adults) will fit into such a framework.

While this thesis explored the impact of the drinking context on heavy drinking by Canadians, it should be noted that the relationships observed were based on crosssectional data, and that conclusions related to causal and/or mediating relationships cannot be made. Nevertheless, the findings do show some links between heavy drinking and particular contexts of alcohol consumption, and have important implications related to theory and policy. 


\section{CONCLUSION}

This study examined the impact of situational and relational characteristics of the drinking context on the propensity for heavy drinking by Canadian adults, and whether the observed associations were consistent between males and females. Research on the impact of drinking contexts, and more specifically research from a Canadian perspective, remains quite limited. Data from the 2004 Canadian Addiction Survey was used to explore the connection between heavy drinking and the contexts in which such intake occurs. In Chapter Three, trends in research on, and the government of, alcohol and its related consequences were traced and a resultant gap in knowledge of contextual factors that impact consumption was identified. This gap was situated in terms of practices in epidemiological research and neo-liberal government, which have individualized understandings of alcohol consumption. This socio-historical analysis not only positioned the drinking context as an under-researched and under-utilized area in the alcohol field, but identified some of the challenges involved in implementing context-specific policy aimed at addressing the harms from drinking. These analyses reflected the primary and secondary aims of this thesis. Overall, the findings from this study provide general support for the position that alcohol-consumption is situationally-specific and not an inherent property of individual drinkers. The previous chapter discussed the implications of these findings, and put forth a number of policy options related to the reduction of alcohol-related harms from heavy drinking for men and women. This chapter contains a synopsis of the key findings, as well as recommendations for future research on the contexts of heavy drinking. 


\section{Summary of key findings and implications}

Exploratory descriptive and logistic regression analysis provided useful information on the contextual preferences of Canadians with regards to heavy drinking. One key finding involved similar rates of episodic heavy alcohol consumption when taking into account gender-specific measures for heavy drinking males (5+ drinks) and females (4+ drinks). It would seem that for drinking occasions, heavy drinking could be expected to occur at a similar proportion across genders.

With regards to the context of alcohol consumption, relational factors such as consuming alcohol with a romantic partner or drinking with co-workers were associated with heavy drinking, although further analysis determined they were a function of male drinking patterns. Canadians tend to drink in larger groups (e.g., four or more people). Consumption of alcohol in smaller groups was generally protective in relation to heavy drinking amongst the general population, and consequently for women, drinking in groups of 10 or more proved to be an important factor in increasing the odds of heavy drinking. Other findings confirm existing research showing the location of drinking to be important in accounting for heavy drinking by adults. Restaurants emerged as a space where sensible drinking by Canadians was likely to occur, whereas bars continue to be places where determined states of drunkenness could be expected. Gender differences were apparent, however, in reported heavy drinking at more private settings, with the consumption of alcohol at the home of someone else being predictive of heavy drinking for men but not women. One finding that was surprising was the reported odds of heavy drinking when consuming alcohol with a meal. This relationship also appears to be gender-specific, with Canadian men reporting much higher odds when consuming alcohol with a meal. The same context produced more moderate consumption among Canadian 
women. These results may have implications for conventional wisdom around the provision of food-stuffs as an intervention aimed at controlling alcohol intake, since the gender of the individual or drinking group may compromise effectiveness.

Additional key findings include the relationship between heavy alcohol consumption and the circumstance of drinking, as well as day of the week the drinking occasion took place. Canadian men who reported drinking on days other than Saturday reported much higher odds of heavy drinking. Only a small number of men drank during the week, however, meaning such relationships may be more a product of drinker-type, and additional research should investigate this more closely. Most Canadian adults report drinking on the weekend, which has traditionally been associated with leisure pursuits involving alcohol consumption. As expected, analysis found marginal associations showing parties to be predictive of heavy drinking for men in this study. For women, other drinking circumstances may also be important contexts for heavy drinking. Finally, consuming alcohol at multiple locations was the strongest predictor of heavy drinking in this study, although it was reported by only a small percentage of Canadians. Previous research on impaired driving has identified 'multilocation drinkers' as exhibiting higher levels of alcohol consumption on all measures compared to single-location drinkers (Wieczorek et al. 1992). This certainly has implications for future research on those situational characteristics that lead to the experience of alcohol-related harm by Canadian adults, including research on this dataset. The $2004 \mathrm{CAS}$ contains occasion-based questions on reporting driving after drinking for the last three drinking occasions (see Appendix A), and future analysis may want to examine this relationship further, given the increased odds for heavy drinking by individuals in this context. 


\section{Implications for future research on the context of alcohol consumption}

The current findings have raised a number of questions about the influence of both situational and relational characteristics of the drinking context on drinking behaviour. Some additional avenues for exploring the CAS dataset or similar research on the drinking context are described below.

Multilevel Analyses. A critique raised in this thesis involved the deterministic emphasis placed upon individual-level correlates in epidemiological research, which function to separate "individual behaviour from the social and situational context in which it occurred" (Duncan et al. 1996: 817). While this thesis "called for context" in understanding alcohol consumption, it nonetheless relied upon individual-level data and subsequent analysis techniques to explore the influence of relational and situational characteristics. Diez-Roux argues that multilevel analysis enables researchers to examine factors operating at the levels of groups or societies that affect the health of individuals, and to help "restore a population or societal dimension to epidemiologic research" (1998: 221). Multilevel studies have traditionally examined the effect of households or geographic areas on individual drinking behaviour (Rice et al. 1998). Recently, Canadian researchers have begun to explore individual behaviour in relation to alcohol consumption using multi-level techniques to study the hierarchical structure of drinking behaviour (Demers et al. 2002; Kairouz et al. 2002; Kairouz \& Adlaf 2003). This method considers the number of drinking occasions (level 1) as nested within individual drinkers (level 2), to estimate the variance from the drinking context at level 1 as well as at the individual-level (level 2). Future research should consider the benefits of employing multilevel modelling to data on drinking occasions, including additional secondary 
analyses of drinking occasions captured by the 2004 CAS. Such analyses could help decipher which characteristics of the context provide the greatest explanatory value in accounting for heavy drinking, while simultaneously considering individual-level factors such as age, gender, ethnicity or occupation.

Expectancies. What remains unclear is how well the contextual predictors used in the CAS reflect the dynamism inherent in the drinking practices of Canadians. Previous research in the United States has examined the frequency of engaging in various social activities, how often drinking accompanied these activities, and the usual quantity of alcohol consumed during these activities (Clark 1985). Given the findings showing increased odds of heavy drinking at other peoples' homes for men, the incorporation of additional questions pertaining to 'activities' into future surveys may shed some light on why heavy drinking is more likely to occur in this location. As a similar survey instrument was used in the 1994 CADS, this may also permit comparisons in Canadian adult drinking patterns over time.

Similarly, a number of researchers have found that a drinker's motives, beliefs or expectancies around drinking to be predictive of heavy drinking (Cox \& Klinger 1988; Brown 1985; Brown et al. 1987). In relation to the theoretical perspective applied in this thesis, further examination of people's motives around alcohol-related leisure pursuits, or their expectancies with regards to heavy drinking occasions, would complement research on the contexts where intoxication is likely to occur. This may also provide insight on areas to target in fostering a culture of moderation in Canada. As Room et al. note:

Becoming intoxicated is an important reason for drinking. Where such use values are well established, they tend to be quite persistent (Room 1992) and a cultural change from a pattern of heavy episodic drinking to light regular drinking is unlikely to be accomplished quickly or easily (2003: 168) 
An individual's expectancies around drinking has also been shown to vary dependent upon contextual factors of the drinking occasion (Holyfield et al. 1995; Kairouz et al. 2002). Exploring the links between an individual's expectancies for alcohol consumption, and the contexts in which such consumption occur, would provide greater understanding of how and why Canadians drink at the levels they do.

Exploring additional facets of drinking occasions, including more qualitative or ethnographic research on the contexts and expectations related to heavy alcohol intake, would also prove useful in understanding how alcohol fits with notions of identity formation and gratification for Canadians. These concepts are related to broader shifts towards consumerism in the second phase of modernity, and the way in which individuals form their identities through consumption. For alcohol in particular, it was argued earlier in this thesis that the diversification of the alcohol market had important implications for the way in which gratification and identity formation are experienced within a consumer society. Measham links these trends in the UK to a shift towards a culture of intoxication', particularly among younger alcohol consumers. While this issue was not addressed in this thesis, it is nevertheless a crucial element of the work by Measham and colleagues and deserves further study. Qualitative or longitudinal research on the way alcohol has become integrated into one's lifestyle choices around identity, leisure, friendships and consumption would be useful in deciphering whether similar trends are occurring in Canada.

Other Research Populations. Although the present study did not examine the specific influence of age, previous research by Demers (1997) has shown the likelihood for heavy episodic drinking is elevated for younger adults, and that important differences in the contexts of drinking exist between younger and older adults. Indeed, many 
contextual aspects of drinking, such as consumption at multiple drinking locations or heavy drinking on weekdays, may be contingent on the age of the respondent. For certain populations, such as college or university students, patterns of 'binge drinking' have been shown to be influenced a great deal by the context in which this behaviour occurs (Clapp et al. 2000; Demers et al. 2001; Wechsler et al. 2000). Thought should be given to exploring the impact of the drinking context on heavy drinking by these populations using other surveys, or comparing young individuals at different life stages (i.e., enrolled in post-secondary studies versus engaged with the labour market) or in different occupations.

There is also research to suggest that there are different and changing contexts associated with adolescent alcohol use, and that these contexts change as an adolescent ages (Caswell et al. 1993; Connolly et al. 1992; Donnermeyer \& Park 1995; Gibbons et al. 1986; Mayer et al. 1998). For alcohol use by adolescents, Donnermeyer and Park (1995) argue that research has emphasized psychosocial and demographic predictors, as well as variables dealing with alcohol source and availability, more than situational factors associated with the drinking context. Adolescent drinking often involves processes of socialization and can be considered important as part of an individual's general initiation into adult lifestyles and behaviours. Contexts have the potential to carry specific norms relating to alcohol consumption, including beliefs associated with heavier drinking, as well as more controlled use. Therefore, future examinations of the 2004 CAS dataset may wish to examine the contexts most associated with heavy drinking among younger Canadians.

While other demographic variables have been shown to explain differences in heavy drinking, not all individual characteristics could be examined within the limits of 
this study. These findings emphasize the importance, not only of the drinking context in accounting for heavy alcohol consumption, but also of considering gender differences in the contexts of heavy drinking. Gender has been identified as an important variable in accounting for heavy drinking (Wechsler et al. 1995; Wilsnack \& Wilsnack 1991;

Wilsnack et al. 2000), and was considered as the primary control for this thesis study. As Measham notes, the "pursuit of intoxication is bounded by gender, ethnicity, occupation, income and so forth and is not the utterly unbridled excessive consumption portrayed in media images of youth at play" (2004a: 319). This thesis identified gender as an important variable, and sought to delineate differences in the contexts of heavy drinking between Canadian men and women. Further research on the relationship of other demographic characteristics, such as work status (i.e., 'student' or 'retired') or occupation, may provide some insight into the relationships observed in this study.

As noted throughout this thesis, it is important to continue to employ a gendered lens to issues of alcohol consumption. This should include gender-specific measures of heavy drinking, as well as greater attention to the ways in which Canadian women contextualize their drinking occasions.

Poly-drug use. Future research may also want to consider incorporating a similar survey instrument for individuals reporting past month illicit substance consumption. Moore (1993) has argued convincingly for addictions theory to consider the social context where illicit substance use occurs, which is also an under-researched area. Current theorizing is dominated by subcultural models of substance consumption; the drug field, he argues, should:

seek to "develop models which conceptualize individual action as inextricably embedded within complex and diverse social contexts... [and] 
understand social contexts as being created by their constituent processes in endless, ongoing permutation" (Moore 1993: 420).

Given the diverse nature of contexts associated with alcohol consumption, it is reasonable to assume similar processes for the consumption of illicit substances. This may be the case particularly for substances that have achieved more social or normalized status, such as cannabis or ecstasy (Parker et al. 2002). Measham et al. (2001) have emphasized that drug using occasions are often accompanied by the consumption of alcohol, meaning that questionnaires designed to elicit responses of types and quantities of substances consumed, and the context(s) in which they were consumed, could prove useful in formulating broader frameworks around substance use and harms.

The 2004 CAS also includes a measure for reported illicit substance consumption by respondents on their last three drinking occasions. While approximately $5 \%$ of respondents reported the consumption of alcohol and other drugs in each of the drinking occasions, it would be interesting to see what relationships exist between illicit drug consumption and characteristics of the drinking context. Using data from the U.S., Clapp et al. found that simply having illicit drugs available in private contexts of alcohol consumption was associated with a 10 -fold increase in the likelihood of experiencing a problem on that drinking occasion (2000: 150). Confirmatory research to see if similar associations are observed for Canadians may prove useful for other substance abuse interventions. At the very least, they may help understand if trends in a 'pick-and-mix' approach to substance consumption - where multiple licit and illicit drugs are consumed by individuals as part of their leisure pursuits - are appearing in Canada (Parker et al. 1998). 
Harms. The CAS also incorporates measures pertaining to reported regrets, such as getting into an argument or fight, related to the last, second last, and third last occasion of drinking (see Appendix A). For studies on alcohol, there is a need for new estimates on what the harms would be with different patterns and levels of use. As Room notes, the "bottom line is the harm" (2003: 722). Future research should therefore focus on the harms associated within different contexts, as well as different quantities of reported alcohol consumption. Given the high proportion of Canadian males reporting heavy drinking with their partners, and in residential locations, research could determine whether such contexts result in different harms compared with more public contexts such as bars or taverns. Such research may prove useful in strengthening arguments for or against certain interventions, including those associated with the harm reduction perspective. Measham (2006) contends that practices of self-regulation are apparent in consumption behaviour by youth and young adults, even if these practices are considered hazardous. She argues that heavy drinking is still likely to occur during weekend leisure times, and that restraint was exhibited on weekdays, meaning individuals are actively engaging in risk-avoidance. In this sense, their cost-benefit assessment reflects the values of consumption and self-control, and the contemporary desire to avoid some of risks the harms associated with their leisure and consumption practices. Additional secondary analysis of the CAS may provide some insight into the types of harms Canadians are reporting, and the levels and contexts of drinking associated with such experiences. It has been stated previously that, "alcohol is no ordinary commodity" (Babor $e t$ al. 2003; Reducing Alcohol-Related Harm in Canada 2007). As such, it should not be surprising that data from this study confirmed that the context in which this commodity is consumed has a significant impact on the quantity consumed during occasions of 
drinking. The impact of 'contexts' can be considered in situational and relational terms, each reflecting broader socio-cultural changes in the way alcohol - and more importantly, leisure pursuits involving alcohol - are consumed by individuals in advanced liberal societies. This thesis approached our knowledge of the drinking context as socially constructed phenomena; a result of parallel practices in epidemiological understandings of complex social action, and neo-liberal rationalities and technologies of governance that draw upon this base. This researcher felt it important to approach the gap in knowledge of the drinking context in this manner, in order to situate how such a gap in knowledge could occur, and to identify some of the challenges inherent in addressing this gap in research and policy. In conjunction with a constructionist critique, a post-positivist perspective was employed in conducting statistical analysis of data from the 2004 CAS. A supplementary construction pertaining to the context of heavy alcohol consumption for Canadians was presented, with the aim of providing new information on the manner in which the general population utilizes drinking contexts for leisure pursuits around heavy drinking. Although this study was exploratory, and has some limitations, its findings may be useful in guiding future practice and research that seek to understand and reduce the harms from drinking. For researchers interested in investigating the role of the context in guiding individual's decisions around substance consumption, or broader socio-political changes that can be found within these social settings, it is hoped this project provides some insight into ways to re-imagine the role of the context in shaping the consumption patterns of individuals. 


\section{APPENDIX A: Survey Instrument, CAS (2004)}

AF1:

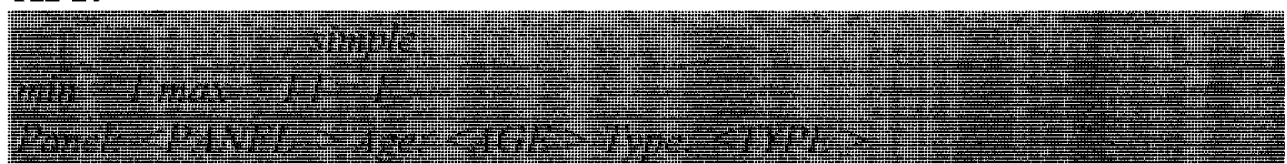

AF1. The next questions are about different situations you might have when you drank alcohol. Now thinking back of the last three occasions you drank ALCOHOL over the past 12 months. For each of these occasions... starting from the most recent occasion. Was this at...?

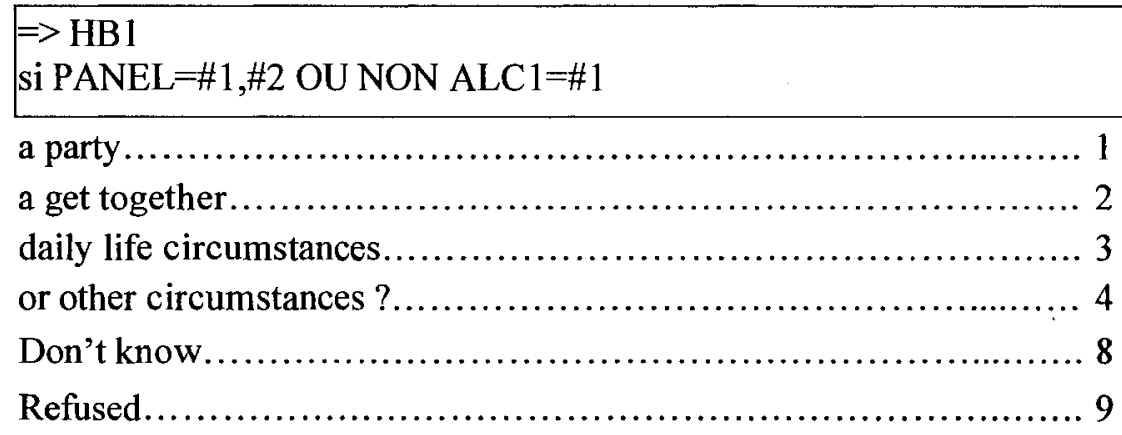

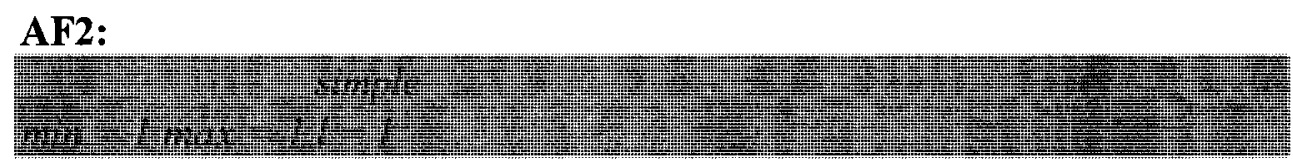

AF2. On this occasion, did you have a meal ?

Yes............................................................ 1

No......................................................... 2

Don't know...................................................... 8

Refused....................................................... 9

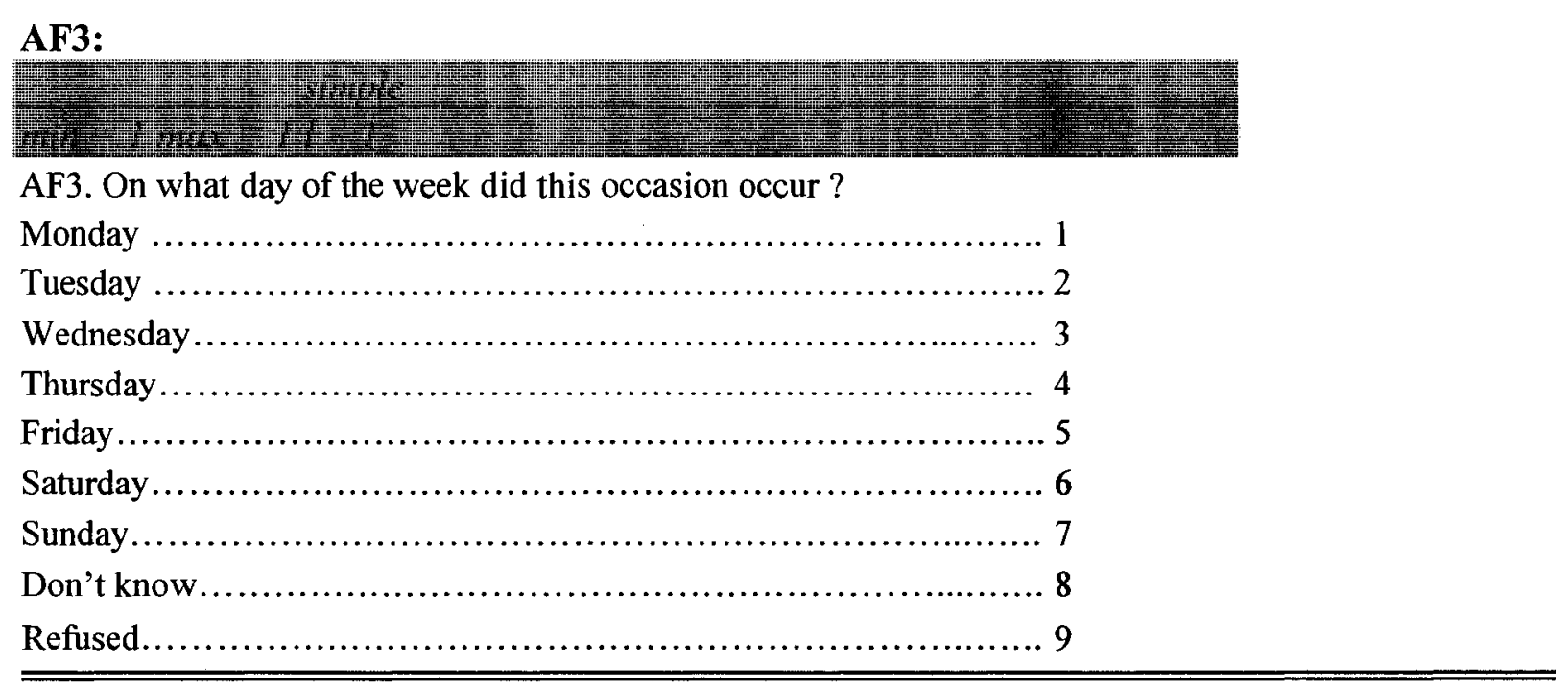


AF4:

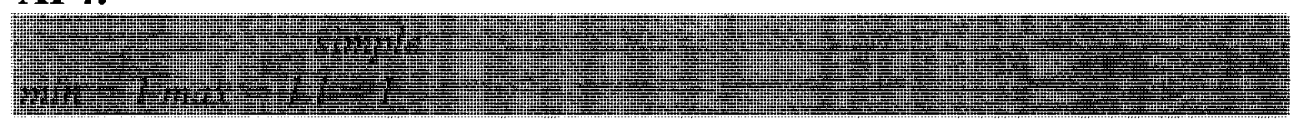

AF4. On this occasion, did drinking occur at one location or in more than one location?

All drinking at one location..................................... 1

More than one location .......................................... 2

Don't know............................................................... 8

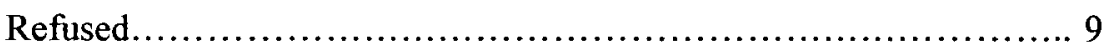

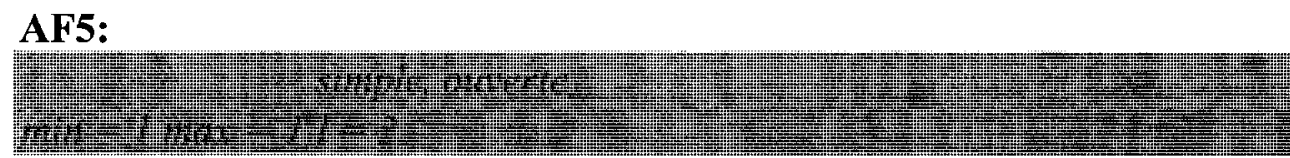

AF5. Did the drinking take place at... (If more than one location, Please think about the location where you drank the most)

your home ..................................................... 01

the home of someone else ..................................... 02

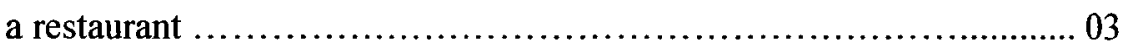

a bar, disco or nightclub ..................................... 04

or somewhere else (specify) ...................................... 05 o

Don't know........................................................... 98

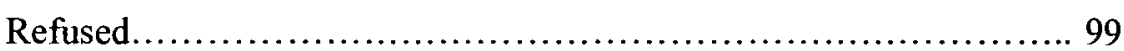

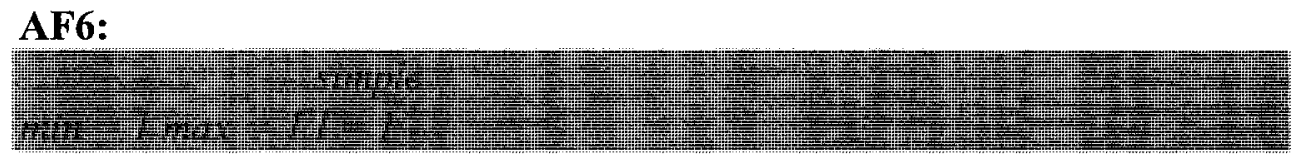

AF6. Was your spouse/partner/romantic(non-cohabiting) partner present on this occasion?

Yes............................................................... 1

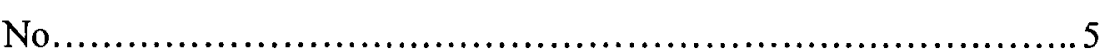

Don't know................................................... 8

Refused........................................................... 9

AF7:

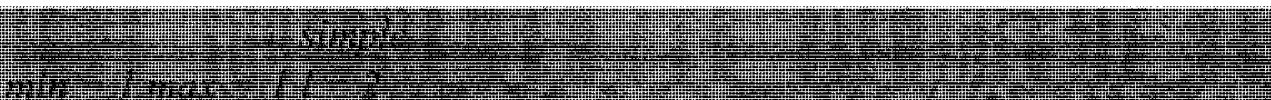

AF7. How many men were with you most of the time on this occasion?

\$E 030

Number of men

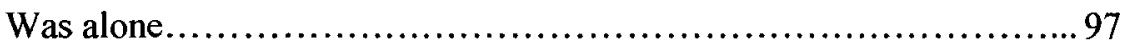

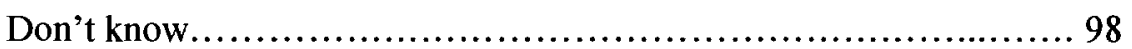

Refused........................................................... 99 
AF8:

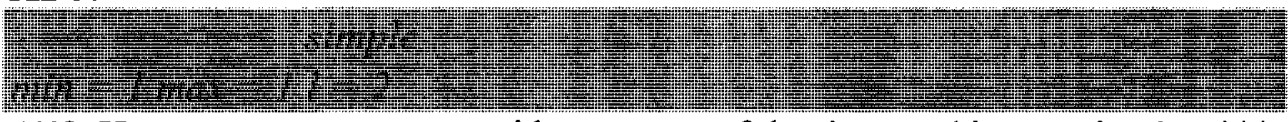

AF8. How many women were with you most of the time on this occasion?

Etait avec $<$ AF7 $>$ hommes ***

SE 030

$\Rightarrow \mathrm{AF} 10$

si $\mathrm{AF} 7=\# 2$

Number of women.

Was alone

$97 \Rightarrow \mathrm{AF} 10$

Don't know.

98

Refused.

99

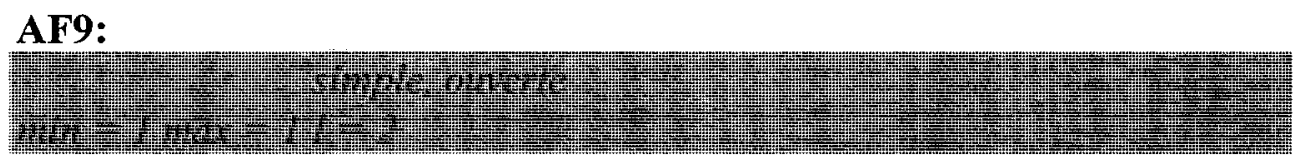

AF9. What is your relationship to most of the other people you were drinking with?

$\Rightarrow \mathrm{AF} 10$
si SOM $([\mathrm{AF} 7, \mathrm{AF} 8])=00$

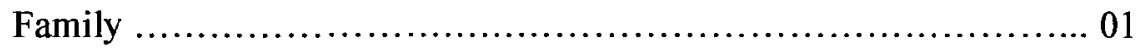

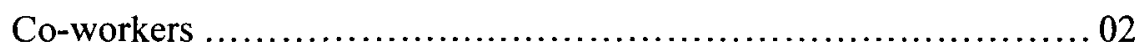

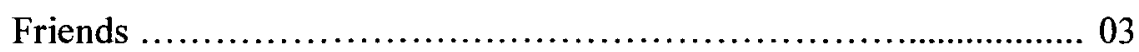

Someone else (specify) ......................................... 04 o

Combination of above (specify) ............................... $05 \quad$ o

Don't know........................................................ 98

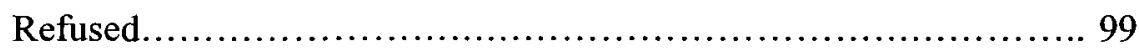

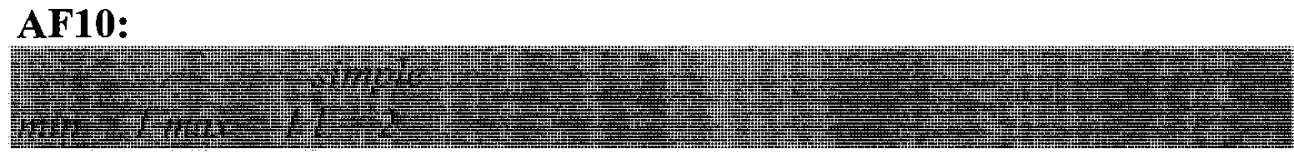

AF10. How many drinks did you have?

\$E 020

Enter number of men.

Don't know......................................................... 98

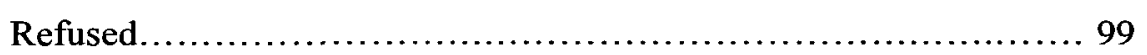

\section{AF11:}




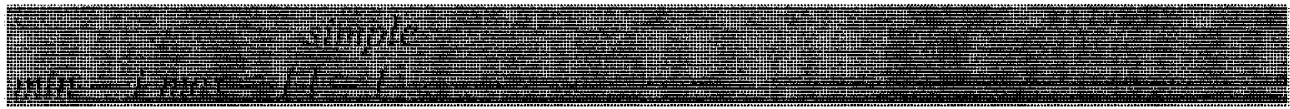

AF11. On this occasion, did you also use marijuana, cannabis or hashish ?

Yes... 1

No. 2

I don't use....................................................... 7

Don't know...................................................... 8

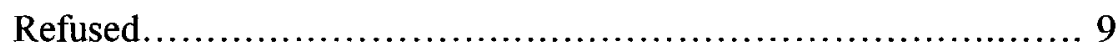

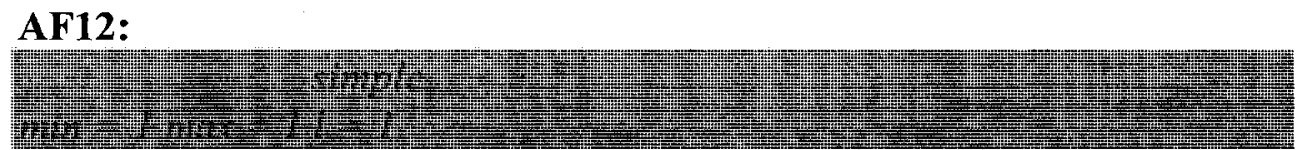

AF12. On this occasion, did you use other drugs such as cocaine, crack, speed, ecstasy, hallucinogens?

Yes............................................................... 1

No................................................................. 2

I don't use.......................................................... 7

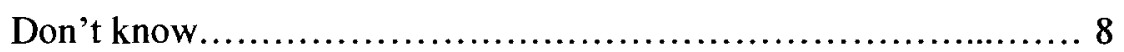

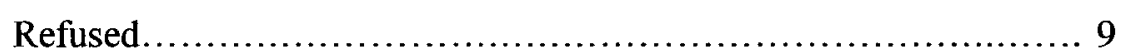

AF13:

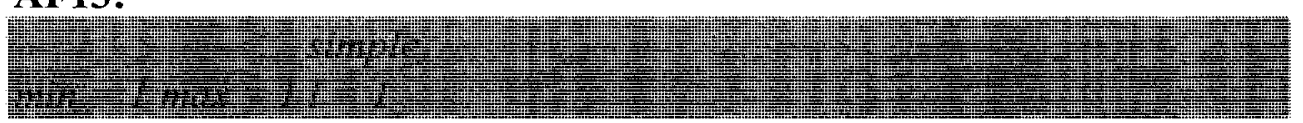

AF13. On this occasion, did you drive a car after you had been drinking ?

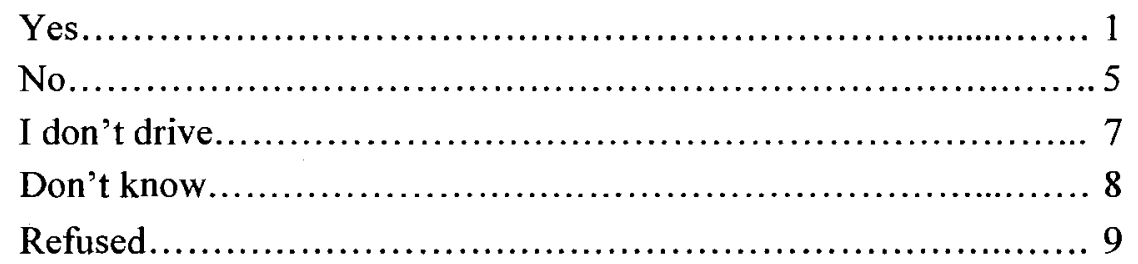

AF13A:

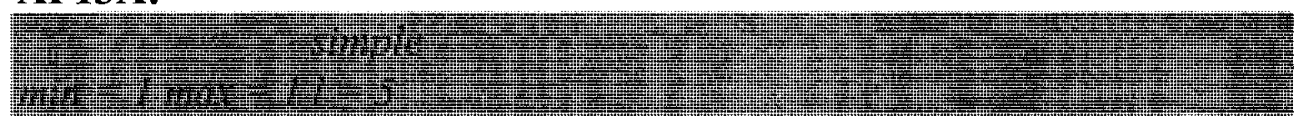

AF13A. How many hours after you had finished your last drink, did you drive? WRITE-IN NUMBER OF HOURS (TWO DECIMALS ACCEPTED)

$\$ R .208$

$\Rightarrow$ AF 14
si AF $13=\# 2-\# 5$

Number of hours.

Don't know. 99998

Refused. 
AF14:

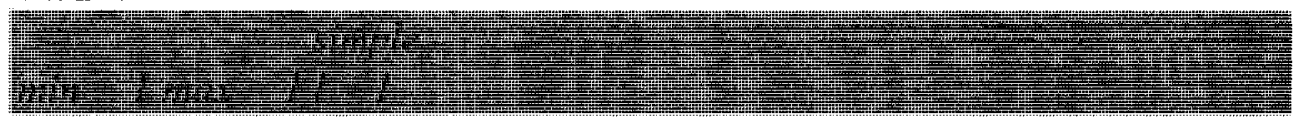

AF14. Were you a passenger in a car with someone else who had been drinking ? $\Rightarrow$ AF 15

si AF13=\#1

Yes.............................................................. 1

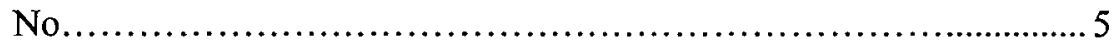

Don't know......................................................... 8

Refused..................................................... 9

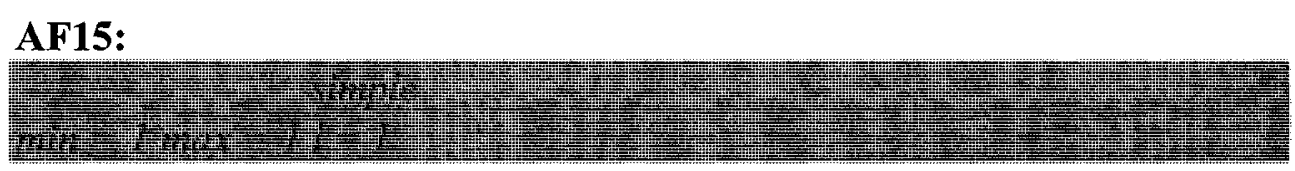

AF15. Did you do anything the last time you drank that you later regretted, for example, getting into an argument or fight with someone?

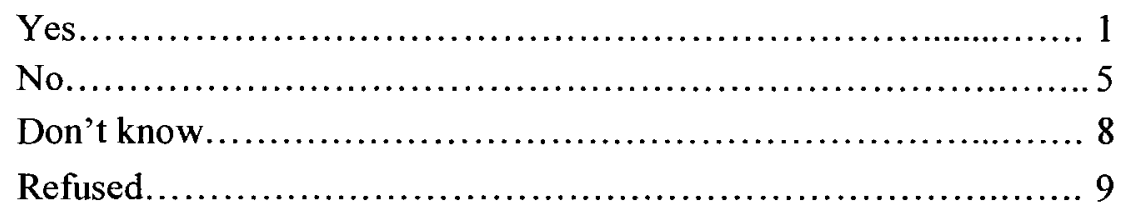

\section{AF15A:}

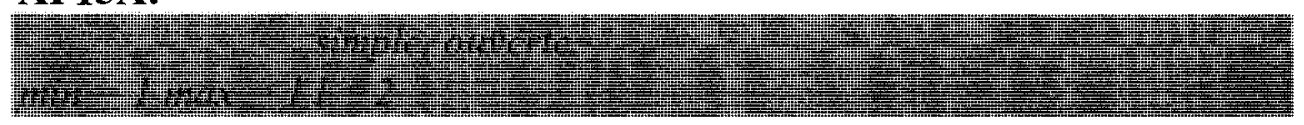

AF15A. What was it?

\section{$\Rightarrow \mathrm{AS} 1$ \\ si NON AF $15=\# 1$}

An argument.................................................. 01

A fight........................................................... 02

Something else (specify) ....................................... 03 o

Don't know.................................................... 98

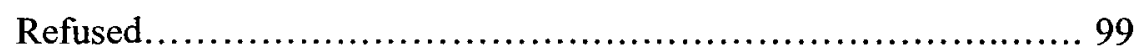




\section{APPENDIX B: Variable Information and Coding Decisions}

In order to provide the reader with a clearer understanding of the measures used in this study, discussion of the main variables, including their re-coding and/or construction from the original 2004 Canadian Addiction Survey (CAS) dataset provided by the Carleton Data Centre. The data used in this study was provided as an SPSS data file, and all data recodes and analyses were performed using the SPSS 10.0. The 2004 CAS dataset contained weighted data for the subsample under consideration, including socio-demographic and alcohol consumption variables, as well as variables related to the drinking context. Weighting of the data helps to ensure the CAS distributions are consistent with Census data for sex, age and province of residence for the sample. Employing weights is necessary in order to examination epidemiologically the association between heavy drinking and characteristics of the drinking context, and to enable inference to the total population of Canadians adults (Adlaf \& Ialomiteanu 2004: 12). General information pertaining to data preparation is presented first, followed by details related to sociodemographic coding, control variables, predictor variables, and drinking context variables.

\section{DATA PREPARATION}

Given the exploratory nature of this research, only data from the last occasion of drinking is used in analysis for this study. Utilization of the last drinking occasion is consistent with other studies that sought to examine the impact of relational and situational contexts of heavy drinking (Demers 1997). For the purpose of this study, questions pertaining to the last occasion of drinking consisted of AF1 to AF10 inclusively. From the original file provided by the Carleton Data Centre (cas2004.sav), all non-relevant variables were removed from the dataset, in order to create a smaller file from which to work with. Retained variables included those from the last drinking occasion (AF1 to AF15A) and major socio-demographic variables.

Previous research on Canadians has focused primarily on populations of Montreal adults (Demers 1997) and university-aged students (Demers et al. 2002). In order to pursue research on the impact of drinking contexts on heavy drinking by Canadian adults, a lower limit of 18 was set, with those individuals between the ages of 15 and 17 excluded from analysis. This resulted in $n=86$ cases being removed from analysis. As noted elsewhere, it was believed that individuals under the age of 18 would not reflect a range of social contexts, since drinking in bars and restaurants by younger individuals in Canada is prohibited, and given the desire to remain consistent with other research on drinking contexts, only adults aged 18 years or older were retained in the analysis.

Finally, two other inclusion criteria were considered. First, in order to capture those individuals consuming alcohol the last time they reported drinking, any individuals reporting no alcohol consumption ( $\mathrm{AF} 10=0$ ) were removed. This resulted in $n=2$ cases being removed from analysis. Second, solitary drinking occasions - that is, occasions where the respondent drank alone (AF7 $=0$ and $A F 8=0$ ) - were also excluded from analysis. These cases were excluded for conceptual and statistical reasons. Drinking alone removes an individual from social influences of other drinking partners or companions (Demers \& Bourgault 1996; Harford 1983). With a focus on exploring the influence of the drinking context on the propensity for heavy drinking, inclusion of solitary drinking occasions would necessarily remove any consideration of relational characteristics. Statistically, inclusion of these cases would also create a high number empty cells, and eventual exclusion at the logistic regression stage of analysis. A total of 67 cases were removed. This decision is consistent with other studies pertaining to the context of alcohol consumption (Demers 1997; Harford 1983; Demers et al. 2002). 
Following these inclusion criteria, a sub-sample of 2,160 Canadian adults remained. Statistical analyses were conducted on weighted data from the CAS, as the weighted distribution most accurately reflected the general Canadian population.

\section{SOCIO-DEMOGRAPHIC VARIABLES.}

\section{Province}

Data taken from original variable (PROV) provided in the 2004 CAS dataset. Variable indicated the province of residence of respondents captured in Panel $\mathrm{C}$ of the dataset. No alterations and/or recodes were made to this variable, and data analysis was based on the subsample used for this study $(n=2,160)$.

\begin{tabular}{|l|l|}
\hline PROV & DESCRIPTION \\
\hline 1 & Newfoundland \\
\hline 2 & Prince Edward Island \\
\hline 3 & Nova Scotia \\
\hline 4 & New Brunswick \\
\hline 5 & Quebec \\
\hline 6 & Ontario \\
\hline 7 & Manitoba \\
\hline 8 & Saskatchewan \\
\hline 9 & Alberta \\
\hline 10 & British Columbia \\
\hline
\end{tabular}

\section{Household Location}

Data taken from original variable (RURAL) provided in the 2004 CAS dataset. Variable indicated whether respondents resided in rural or non-rural areas in Canada. Determination of the location of household for the respondent was based on FSA ("Forward Sortation Area"), whereby the first 3 digits of the postal code indicated their location status. The variable was provided in binary fashion ( $1=$ rural; $0=$ non-rural), and no alterations and/or recodes were made to this variable. Data analysis was based on the sub-sample used for this study $(n=2,160)$.

\section{Marital status}

Data taken from original variable (MARSTAT4) provided in the 2004 CAS dataset. Variable indicated whether the respondent was married, was in a relationship in which they considered the other person a 'partner', were previously or never married. This variable was a derived variable combining responses to the question: "What is your current marital status ...?", in which a full list of options were provided to the respondent (see original items in CAS 2004 English Questionnaire). No alterations and/or recodes were made to this variable. Data analysis was based on the sub-sample used for this study $(n=2,160)$.

\begin{tabular}{|l|l|l|}
\hline MARSTAT4 & DESCRIPTION & CONDITION \\
\hline 1 & Married & MSCN $=1$ \\
\hline 2 & Partner & MSCN $=2$ \\
\hline 3 & Previously married & $\mathrm{MSCN}=3$ thru 5 \\
\hline 4 & Never married & $\mathrm{MSCN}=6$ \\
\hline
\end{tabular}

\section{Highest Education}

Data taken from original variable (EDUCAT4) provided in the 2004 CAS dataset. Variable indicated the highest level of education attained by respondents. This variable was a derived 
variable combining responses to the question: "What is the highest level of education you have completed?" The decision was made to include this variable as a descriptor of education of the sample, in order to remain consistent with previous reporting of the 2004 CAS (Adlaf et al. 2005). No alterations and/or recodes were made to this variable. Data analysis was based on the sub-sample used for this study $(n=2,160)$.

\begin{tabular}{|l|l|l|}
\hline EDUCAT4 & DESCRIPTION & CONDITION \\
\hline 1 & less than high school & SDED1 $=1$ thru 4 \\
\hline 2 & completed high school & SDED1 $=5$ \\
\hline 3 & some post-secondary (college or university) & SDEDI $=6$ thru 10 \\
\hline 4 & university degree & SDED1 $=11$ thru 14 \\
\hline
\end{tabular}

\section{Employment Status}

Data for this variable was taken from an employment status variable (EDUCAT4) provided in the 2004 CAS dataset. This variable was a derived variable combining responses to the question: "Are you presently...?", in which a full list of options were provided to the respondent (see original items in CAS 2004 English Questionnaire).

\begin{tabular}{|l|l|l|}
\hline EMPCAT8 & DESCRIPTION & CONDITION \\
\hline 1 & full-time & SDEM $1=1$ \\
\hline 2 & part-time & SDEM $1=2$ \\
\hline 3 & unemployed & SDEM $1=4$ \\
\hline 4 & retired & SDEM $1=5$ \\
\hline 5 & homemaker & SDEM $1=6$ \\
\hline 6 & student & SDEM $1=7$ \\
\hline 7 & self-employed & SDEM $1=8$ \\
\hline 8 & other & SDEM $1=0,3,10,11$ \\
\hline
\end{tabular}

The decision was made to recode categories of this variable, in order to provide relevant categories as they pertain to respondents from the sub-sample. The variable was first re-coded as a new variable (EMPLOY), with the 8 categories from the derived variable recoded into the following:

\begin{tabular}{|l|l|l|}
\hline employ & DESCRIPTION & CONDITION \\
\hline 1 & Currently employed & EMPCAT8 $=1,2,7$ \\
\hline 2 & Unemployed & EMPCAT8 $=3$ \\
\hline 3 & Retired & EMPCAT8 $=4$ \\
\hline 4 & Student & EMPCAT8 $=6$ \\
\hline 5 & other & EMPCAT8 $=5,8$ \\
\hline
\end{tabular}

This was done in order to provide a meaningful description of the status of individuals in relation to their employment, and to reduce the number of categories to those which are determinably different from other categories. Data analysis was based on the sub-sample used for this study $(n=2,160)$.

\section{Income adequacy}

Data taken from original variable (INCADEQ5) provided in the 2004 CAS dataset. The measure is based on a series of items pertaining to one's total household income or broad 
income category, and the number of individuals living in one's home. It relies on the following items (and questions) from the 2004 CAS Questionnaire:

- SDIN1 - Thinking about the total income for ALL HOUSEHOLD MEMBERS, could you please tell me how much income you and other members of your household received in the year ending DECEMBER 31ST 2002, before taxes? Please include income FROM ALL SOURCES such as savings, pensions, rent and unemployment insurance as well as wages. TO THE NEAREST THOUSAND DOLLARS, what was your TOTAL HOUSEHOLD INCOME before taxes and other deductions were made?

- SDIN2 - We don't need the exact amount; could you tell me which of these broad categories it falls into...?

- SD_3 (HH size)-Including yourself, how many people are currently living in your household?

\begin{tabular}{|l|l|l|l|}
\hline INCADEQ & DESCRIPTION & INCOME (revised) & HH SIZE \\
\hline 1 & \multirow{2}{*}{ Lowest income } & $<\$ 20,000$ & $1-2$ persons \\
\cline { 3 - 4 } & & $<\$ 30,000$ & 3 or more persons \\
\hline 2 & \multirow{2}{*}{ Lower middle income } & $\$ 20,000-\$ 29,000$ & $1-2$ persons \\
\cline { 3 - 4 } & & $\$ 30,000-\$ 49,999$ & $3-4$ persons \\
\cline { 3 - 4 } & & $\$ 30,000-\$ 59,000$ & 5 or more persons \\
\hline \multirow{3}{*}{3} & \multirow{2}{*}{ Upper middle income } & $\$ 30,000-\$ 59,000$ & $1-2$ persons \\
\cline { 3 - 4 } & & $\$ 50,000-\$ 79,000$ & $3-4$ persons \\
\cline { 3 - 4 } & & $\$ 60,000-\$ 79,000$ & 5 or more persons \\
\hline 4 & Highest income & $\$ 60,000+$ & $1-2$ persons \\
\cline { 3 - 4 } & & $\$ 80,000+$ & 3 or more persons \\
\hline 5 & Not stated & Not stated & Unknown \\
\hline
\end{tabular}

The decision was made to include this variable as a descriptor of 'income' of the sample, in order to remain consistent with previous reporting of the 2004 CAS (Adlaf et al. 2005). No alterations and/or recodes were made to this variable. Data analysis was based on the subsample used for this study $(n=2,160)$.

\section{CONTROL VARIABLES}

1. Gender.

Data for this control was taken from the original variable (SEX) provided in the 2004 CAS dataset. This variable indicated whether respondents were female or male, and was listed as a gender dummy variable in the dataset. The variable was provided in binary fashion $(1=$ male; $0=$ female), and no alterations and/or recodes were made to this variable. Data analysis was based on the sub-sample used for this study $(n=2,160)$, with subsequent analysis separating the sample according to the gender of the respondent (details provided previously).

2. Age.

Data for this control was taken from the original variable (AGE) provided in the 2004 CAS dataset. The age of the respondent was derived from the question: "What is your date of birth/ year of birth?", with responses being categorized in numeric fashion from 15 years of age and older. A number of derived variables were provided with the 2004 CAS dataset; however, given the analytic focus of this thesis on heavy drinking by adults, several recodes were made. First, the continuous age variable was transformed into roughly equal age categories for the adult population. The following syntax was employed: 


\section{RECODE AGE TO AGER (18 THRU 24=1) (25 THRU 34=2) (35 THRU 44=3) (45 THRU 54=4) (55 HIGHEST=5) (ELSE=SYSMIS)}

These categories were used to as part of the descriptive statistics of the sample provided in Table 5.1. To use as a control in the logistic regression analyses performed on the full subsample, as well as the separate samples of Canadian males and females, this variable was once again re-coded according to the following parameters:

\section{RECODE AGER TO AGEDUMMY $(1=0)(\mathrm{ELSE}=1)$}

This allowed for a binary measure of age to be created, composed of those individuals under 25 years of age and individuals 25 years of age and older. Data analysis was based on the sub-sample used for this study $(n=2,160)$, with subsequent analysis separating the sample according to the gender of the respondent (details provided previously).

\section{OUTCOME VARIABLE - HEAVY DRINKING}

Following a review of the literature, a decision was made to include a measure of heavy drinking as the outcome variable for this study. Previous studies have examined the role of situational and relational characteristics of the drinking context in contributing to heavy episodic or sessional drinking (Clapp et al. 2000; Demers 1997; Demers et al. 2002; Harford 1979). Consistent with this body of research - as well as work by Demers (Demers 1997; Demers et al. 2002) - this thesis employs a measure of 'heavy drinking' as the outcome measure of interest, or having consumed five or more drinks $(5+)$ on a their last occasion of drinking.

A dichotomous variable was constructed, based on whether the respondent consumed five or more drinks on the last drinking occasion. The data used in this study were provided in the 2004 CAS dataset, under a subset of questions for Panel C which asked: "Now thinking back of the last three occasions you drank ALCOHOL over the past 12 months. For each of these occasions... starting from the most recent occasion... "Data for this dependent variable was taken from the original variable (AF10) with the number of drinks the respondent consumed on their last occasion of drinking was derived from the question: How many drinks did you have? Responses were provided in numeric fashion. To create a dichotomous variable for heavy drinking, the following recodes were applied:

\section{RECODE AF10 TO NUMDRINK (1 THRU 4=0) (ELSE=1) $(98,99=$ SYSMIS)}

Recoding resulted in a 'dummy' variable encompassing those individuals who reported heavy drinking on their last occasion of alcohol consumption (5+ drinks), and those who did not. This outcome variable was employed in exploratory descriptive and logistic regression analyses examining the impact of relational and situational characteristics of the drinking context - both separate and combined effects - for all Canadian adults. The results for this analysis are presented in Chapter Five.

When examining the role of the drinking context in accounting for heavy drinking for Canadian men and women, a separate measure for heavy drinking - five or more drinks for men, and four or more drinks for women - was employed. This decision is consistent with a growing body of research showing similar blood-alcohol levels (BAL) for women consuming 
smaller quantities of alcohol (Johnson 1991; Lieber 1993), and having a greater likelihood of experiencing harm when consuming four drinks or more. As such, a gender specific measure of heavy drinking, which uses the consumption of five or more drinks by men, and four or more drinks by women on a single occasion, was employed to explore differences in the drinking context between men and women. The following recode was applied to create these outcome measures:

RECODE AF10 TO FEMDRINK (1 THRU 3=0) (ELSE=1) $(98,99=$ SYSMIS)

For descriptive and logistic analyses examining gender differences in the relationship between the drinking context and heavy drinking (Chapter Six), the data was run separately for men and women, employing the gender-specific measures for heavy drinking (NUMDRINK and FEMDRINK respectively). This was done employing the following syntax to the data file:

SELECT IF $(\mathrm{SEX}=1)$

SELECT IF $(\mathrm{SEX}=0)$

In the computations above, two separate data files were created. In the first, Canadian males were retained, and logistic analysis of the predictor variables on the outcome variable (NUMDRINK) was conducted. In the second, Canadian females were retained, and logistic analysis of the predictor variables on the outcome variable (FEMDRINK) was conducted.

\section{PREDICTOR VARIABLES - THE DRINKING CONTEXT}

From questions pertaining to where, when and with whom Canadians reported alcohol consumption on their last drinking occasion, a number of new variables were created to represent the drinking context.

\section{Relational Characteristics.}

\section{Relationship with Drinking Partners.}

Data for this variable was taken from the original variable (AF9) provided in the 2004 CAS dataset. The variable indicated the relationship with others in the drinking group on the respondent's last occasion of drinking. This variable was derived from the following question: What is your relationship to most of the other people you were drinking with? A number of responses were possible, including: (01) Family; (02) Co-workers; (03) Friends; (04) Someone else (specify); (05) Combination. Upon viewing frequencies of the data, it was determined that responses 04 (Someone else (specify)) would be removed from analysis. Only 10 responses were observed for this category, totaling less than 1 percent of responses. The small number of actual cases meant that responses for this variable were too low to obtain valid statistical significance during analysis. Furthermore, due to the lack of specificity with regards to the response of 'Someone else', and given a reasonable categorization of drinking relationships, it could be excluded from analysis.

In order to remove this category, and eliminate any missing cases, the following recode was conducted:

RECODE AF9 TO VARRELAT $(1=1)(2=2)(3=3)(5=4)(04,98,99=$ SYSMIS $)$ 
Data analysis was based on the sub-sample used for this study $(n=2,160)$, with subsequent analysis separating the sample according to the gender of the respondent (details provided previously). A total of 104 cases were removed due to the above criteria. In order to include this variable as part of the set of characteristics encompassing the relational context of alcohol consumption during logistic regression analysis, further re-coding was required. For multinomial logistic regression analysis, SPSS automatically coverts categorical variables into 'dummy' variables by removing the last category. In order to control which category is considered the reference category, dichotomous variables were created manually for drinking relationship (i.e., family $=1$; Other $=0$ ). As such, the variable was re-coded according to the following parameters:

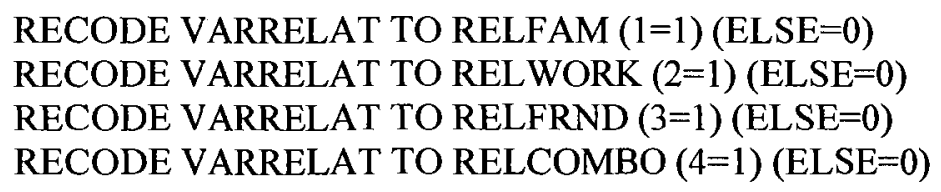

This created four separate 'dummy' variables that could encompass the relationships to people in the drinking party (i.e., last time drank, was with family). Responses for 'family' (RELFAM) as the drinking relationship were omitted in the logistic regression analyses, and considered as the reference category for this variable. The decision to include 'family' as the reference category for this variable was based on theory and previous research on drinking contexts. Drinking with family has long been associated with more moderate consumption of alcohol effect on heavy drinking (Calahan et al. 1969). Drinking with friends is preferred amongst most drinking, and is thought to increase the likelihood of heavy alcohol consumption (Hilton 1987; Harford 1983). Similarly, Demers et al. (2002), in their multilevel study of drinking contexts, used family as their reference category. It should be noted, however, that in their study, drinking with family represented only $10.8 \%$ of the relationships on respondent's last three drinking occasions, whereas in this thesis, the category represents $37.4 \%$ of relationships.

\section{Size of the Drinking Group.}

Research reviewed on drinking contexts show that drinking with larger groups can lead to heavier consumption of alcohol (Hennessy \& Saltz 1993; Single 1985). It is difficult to determine, however, at what size of drinking group is most associated with the consumption of five or more drinks on occasions of drinking. Inclusion of this variable within this thesis is consistent with a previous study of drinking contexts by Canadian students (Demers et al. 2002).

Data for this variable was taken from a combination of variables provided in the 2004 CAS dataset: variables AF7 and AF8. These variables indicated the number of men and women present during the respondent's last occasion of drinking. The following questions were posed to respondents: How many men were with you most of the time on this occasion? and How many women were with you most of the time on this occasion? Responses were provided in numerical form, as well as a response indicating the respondent "was alone" on their last drinking occasion. As noted previously, for theoretical purposes, cases involving solitary drinking occasions were removed prior to re-categorizing this variable. Cases containing missing data were removed with the following recode:

RECODE AF7 (98, 99=SYSMIS)

RECODE AF8 (98, 99=SYSMIS) 
In order to create a variable encompassing the total number of persons (men and women) present at the respondent's last occasion of drinking, responses for AF7 and AF8 were combined. To do so, the following variable was created:

\section{COMPUTE grpsize $=$ SUM(AF7, AF8)}

This provided, for each of the cases in the sample $(n=2,160)$, a sum of the men and women they were with during their last drinking occasion. Responses totalling ( $n=67$, or those reporting 0 men and 0 women) were eliminated from the dataset. The variable GRPSIZE was then recoded to reflect four separate categories for analysis according to the following parameters:

$$
\begin{aligned}
& \text { RECODE GRPSIZE TO GROUP1 }(1=1)(\mathrm{ELSE}=0) \\
& \text { RECODE GRPSIZE TO GROUP2T3 }(2 \text { TO } 3=1)(\mathrm{ELSE}=0) \\
& \text { RECODE GRPSIZE TO GROUP4T9 }(4 \text { TO } 9=1)(\mathrm{ELSE}=0) \\
& \text { RECODE GRPSIZE TO GROUP10P }(10 \text { TO } 90=1)(\mathrm{ELSE}=0)
\end{aligned}
$$

The decision to use these categories was based on previous research examining the drinking context (Demers et al. 2002). The study by Demers et al. (2002) used groups of 10 or more persons as the reference category for their logistic regression analysis, which for their sample, represented the second largest percentage of responses. In this thesis, groups of four to nine persons represented the largest percentage of responses, and as such, the decision was made to use this (GROPU4T9) as a reference category for the variable on "group size".

\section{Gender Composition.}

There were specific reasons for including a variable pertaining to the gender composition of the drinking group. First, this thesis relied upon two key Canadian studies (Demers 1997; Demers et al. 2002) which have previously examined the impact of the drinking context on heavy drinking in an effort to determine whether the interactions observed by these researchers could be replicated using data on the general Canadian adult population. Both studies included a measure for gender composition of the drinking group on the last drinking occasion, and all efforts were made here to include a similar measure. Second, research points to various effects on alcohol intake associated with different gender combinations. Some researchers have found that having opposite-sex drinking partners for men resulted in an observed moderating effect on alcohol consumption, with this effect occurring across varying public drinking locations (Demers 1997; Hennessy \& Saltz 1993). At the same time, younger men who drink with a same-gender reference partner are more likely to report heavy drinking, and drink more quickly (Demers 1997; Van der Goor et al. 1990). As such, the decision to include a variable on 'gender composition' was theoretical in nature.

Data for this variable was taken from a combination of variables provided in the 2004 CAS dataset: variables AF7 and AF8. These variables indicated the number of men and women present during the respondent's last occasion of drinking. The following questions were posed to respondents: How many men were with you most of the time on this occasion? and How many women were with you most of the time on this occasion? Responses were provided in numerical form, as well as a response indicating the respondent "was alone" on their last drinking occasion. As noted previously, for theoretical purposes, cases involving solitary drinking occasions were removed prior to re-categorizing this variable. Cases containing missing data were removed with the following recode:

RECODE AF7 (98, 99=SYSMIS) 
RECODE AF8 (98, 99=SYSMIS)

To create a variable encompassing whether or not the gender composition of the group was mixed or the same, a number of steps were completed. First, the original variables for the number of men (AF7) and women (AF8) were recoded to reflect same-gendered drinking groups for Canadian males and females. This was completed using the following parameters:

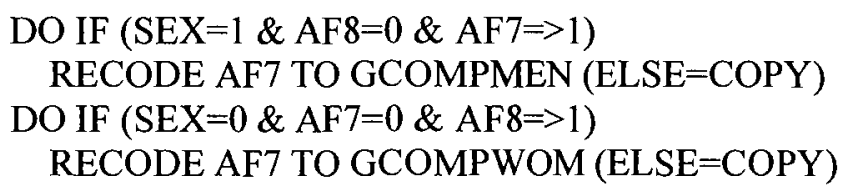

This resulted in the creation of two new variables indicating the number of men who reported drinking with only men on their last occasion of drinking ( $n=152$, GCOMPMEN) and the number of women who reported drinking with only women on their last occasion of drinking ( $n=50$, GCOMPWOM). Responses ranged between one and 20 same-gendered drinking partners for men, and between one and 12 same-gendered drinking partners for women. The second step involved the creation of 'dummy' variables to reflect the distinction between gender-same and gender-mixed drinking groups. To do so, the variables were re-coded according to the following parameters:

\section{RECODE GCOMPMEN TO GENMDUMM (1 TO 30=1) $($ ELSE $=0)$ RECODE GCOMPWOM TO GENWDUMM $(1$ TO $30=1)($ ELSE $=0)$}

Recoding allowed for a binary measure of men who drank with other men only (gendersame), and those who drank with a combination of men and women (gender-mixed), as well as one for women who drank with other women only (gender-same), and those who drank with a combination of women and men (gender-mixed).

The third step involved the creation of a single variable encompassing whether or not the individual reported drinking in gender-same or gender-mixed drinking groups. Again, this involved the creation of a binary variable. However, responses for the variable needed to be summed in order to derive the number of cases in which gender-same drinking groups were observed, as well as those in which gender-mixed drinking groups were observed. This was accomplished by the following:

\section{COMPUTE gendcomp $=$ SUM(GENMDUMM, GENWDUMM $)$}

Since the variables of GENMDUMM and GENWDUMM were recoded as binary measures (i.e., if not 1 , than 0 ), summing the variables produced final cases which indicated the drinking group was gender-same (response of 1 ) or gender-mixed (response of 0 ) for all cases under analysis $(n=2,160)$. Drinking in gender-mixed groups was taken as the reference category for logistic regression analyses, which was consistent with other research studying the drinking context (Demers et al. 2002). In their study, drinking in non-mixed or gendersame groups was observed in $21.5 \%$ of the sample, whereas in this thesis, drinking in samegendered drinking groups was observed in only $9.3 \%$ of the sample.

\section{Presence of Partner.}

The decision to include this variable in the study was theory driven: previous research has shown the presence of an individual's romantic partner to exhibit a protective effect on heavy drinking (Hennessy and Saltz 1993). Similarly, studies on the relationship between the 
drinking context and heavy drinking for Canadian students included a dichotomous measure for 'partner' (Demers et al. 2002).

Data for this independent variable was taken from the original variable (AF6) provided in the 2004 CAS dataset. This variable was derived from the following question: Was your spouse/partner/romantic(non-cohabiting) partner present on this occasion? This variable was used to as part of the set of characteristics encompassing the relational context of alcohol consumption. Responses were provided in yes/no fashion. As such, in order to employ descriptive and logistic regression analyses, the variable was re-coded according to the following parameters:

\section{RECODE AF6 TO PARTNER (1=1) (ELSE=0) (8, 9=SYSMIS)}

This allowed for a binary measure of whether or not the individual drank in the presence of their partner on their last occasion of drinking to be created. Drinking in a single location (response of "no") was taken as the reference category for logistic regression analyses, which was consistent with other research studying the drinking context (Demers et al. 2002).

\section{Situational Characteristics}

\section{Drinking Circumstances.}

Data for this variable was taken from the original variable (AF1) provided in the 2004 CAS dataset. The variable indicated the circumstances in which drinking took place. This included responses to the following question: Now thinking back of the last three occasions you drank ALCOHOL over the past 12 months. For each of these occasions... starting from the most recent occasion. Was this at...? (01) a party; (02) a get together; (03) daily life circumstances; (04) or other circumstances. In order to remove this category, and eliminate any missing cases, the following recode was conducted:

$$
\text { RECODE AF1 TO VARCIRC }(1=1)(2=2)(3=3)(4=4)(8,9=\text { SYSMIS })
$$

Data analysis was based on the sub-sample used for this study $(n=2,160)$, with subsequent analysis separating the sample according to the gender of the respondent (details provided previously). A total of 2 cases were removed due to the above criteria. In order to include this variable as part of the set of characteristics encompassing the situational context of alcohol consumption during logistic regression analysis, further re-coding was required. For multinomial logistic regression analysis, SPSS automatically coverts categorical variables into 'dummy' variables by removing the last category. In order to control which category is considered the reference category, dichotomous variables were created manually for drinking relationship (i.e., party $=1$; Other $=0$ ). As such, the variable was re-coded according to the following parameters:

$$
\begin{aligned}
& \text { RECODE VARCIRC TO CIRPARTY }(1=1)(\mathrm{ELSE}=0) \\
& \text { RECODE VARCIRC TO CIRGETTO }(2=1)(\mathrm{ELSE}=0) \\
& \text { RECODE VARCIRC TO CIRDLIFE }(3=1)(\mathrm{ELSE}=0) \\
& \text { RECODE VARCIRC TO CIROTHER }(4=1)(\mathrm{ELSE}=0)
\end{aligned}
$$

This created four separate 'dummy' variables that could encompass the circumstance in which drinking occurred (i.e., last time drank, was party). Responses for 'party' (CIRPARTY) as the drinking relationship were omitted in the logistic regression analyses, and considered as the reference category for this variable. The decision to include 'party' as 
the reference category for this variable was based on previous research on drinking contexts. Parties have long been associated with higher consumption of alcohol (Harford et al. 1980; Single \& Wortley 1993), and as such, it was anticipated that for this study population, drinking under this circumstance would also be associated with a higher proportion of heavy drinking. Logistic regression analyses on the contexts of heavy drinking by Montreal adults (Demers 1997) and Canadian students (Demers et al. 2002) used 'party' as the reference category when examining the circumstances of various drinking occasions. As these studies provide a basis from which to study the impact of the drinking context using national data on Canadian's drinking, the decision was made to use a similar reference category.

\section{Meal.}

The decision to include this variable in the study was theory driven: studies by Demers (1997) and Demers and colleagues (2002) used drinking without a meal as part of their model for the drinking context. This variable has not received much coverage in the research literature, but where the provision of food is noted, it has been associated with more moderate consumption of alcohol (Demers 1997; Simpura 1987).

Data for this independent variable was taken from the original variable (AF2) provided in the 2004 CAS dataset. This variable was derived from the following question: On this occasion, did you have a meal? This variable was used to as part of the set of characteristics encompassing the situational context of alcohol consumption. Responses were provided in yes/no fashion. As such, in order to employ descriptive and logistic regression analyses, the variable was re-coded according to the following parameters:

$$
\text { RECODE AF2 TO MEAL1 (ELSE=0) }(5=1)(8,9=\text { SYSMIS) }
$$

This allowed for a binary measure of drinking with a meal to be created, composed of those individuals who reported drinking with a meal, and those reporting no meal on their last occasion of drinking. Drinking in without a meal (response of "no") was taken as the reference category for subsequent analyses, as was consistent with the reference categories of other studies examining drinking with meals (Demers 1997; Demers et al. 2002).

\section{Day of the Week.}

Data for this variable was taken from the original variable (AF3) provided in the 2004 CAS dataset. The variable indicated the day of the week in which the respondent's last occasion of drinking occurred. This variable was derived from the following question: On what day of the week did this occasion occur? The variable was categorical in nature, with responses encompassing all seven days of the week (Monday to Sunday). In order to eliminate missing cases, the following recode was conducted:

\section{RECODE AF3 TO VARDAY $(1=1)(2=2)(3=3)(4=4)(5=5)(6=6)(7=7)$ $(8,9=$ SYSMIS $)$}

Data analysis was based on the sub-sample used for this study $(n=2,160)$, with subsequent analysis separating the sample according to the gender of the respondent (details provided previously). A total of 171 cases were removed due to missing data.

In order to include this variable as part of the set of characteristics encompassing the situational context of alcohol consumption during logistic regression analysis, further recoding was required. For multinomial logistic regression analysis, SPSS automatically coverts categorical variables into 'dummy' variables by removing the last category. In order 
to control which category is considered the reference category, dichotomous variables were created manually for each day of the week (i.e., Sunday $=1$; Other $=0$ ). As such, the variable was re-coded according to the following parameters:

$$
\begin{aligned}
& \text { RECODE VARDAY TO DAYMON }(1=1)(\mathrm{ELSE}=0) \\
& \text { RECODE VARDAY TO DAYTUES }(2=1)(\mathrm{ELSE}=0) \\
& \text { RECODE VARDAY TO DAYWED }(3=1)(\mathrm{ELSE}=0) \\
& \text { RECODE VARDAY TO DAYTHUR }(4=1)(\mathrm{ELSE}=0) \\
& \text { RECODE VARDAY TO DAYFRI }(5=1)(\mathrm{ELSE}=0) \\
& \text { RECODE VARDAY TO DAYSAT }(6=1)(\mathrm{ELSE}=0) \\
& \text { RECODE VARDAY TO DAYSUN }(7=1)(\mathrm{ELSE}=0)
\end{aligned}
$$

This created seven separate 'dummy' variables which could encompass the day of the week drinking occurred (i.e., last time drank, was on Sunday). Responses for 'Saturday' (DAYSAT) as the day of their last drinking occasion were omitted in the logistic regression analyses, and considered as the reference category for this variable. This decision is consistent with previous research. In a study of Canadian student populations, Demers and colleagues (2002) took Saturday as their reference, which was the most reported day of the week in their sample. Within this thesis, Saturday was also the most reported day for occasions of alcohol consumption. In a study of Montreal adults, Demers (1997) used a dichotomous variable of 'weekday/weekend', taking the former as the reference category. This resulted in higher OR for weekend drinking, which was to be expected.

\section{Drinking Location.}

Data for this variable was taken from the original variable (AF5) provided in the 2004 CAS dataset. The variable indicated the location in which the respondent's last occasion of drinking occurred. This variable was derived from the following question: Did the drinking take place at... (01) your home; (02) the home of someone else; (03) a restaurant; (04) a bar, disco or nightclub; (05) Other public place (Hotel, Social club); (06) or somewhere else (specify). Upon viewing frequencies of the data, it was determined that responses 05 (Other public place (Hotel, Social club)) and 06 (or somewhere else) would be removed from analysis. This was done for two reasons. First, due to the lack of specificity with regards to these categories, valid theoretical comparisons could not be made. Researchers have examined patterns of drinking in public places such as sporting events (Fisher \& Single 1987), outdoor public areas such as parks and/or parking lots (Herd \& Grube 1993), as well as other public contexts (Clark 1981b). None of these categories could be ascertained from the data provided. Second, the small number of actual cases involved $(n=125)$ meant that, even when collapsing the two categories, it represented less than $6 \%$ of the responses for this variable, and was too low to obtain valid statistical significance during analysis. In order to remove these two categories, and eliminate any missing cases, the following recode was conducted:

$$
\text { RECODE AF5 TO VARLOCAT }(1=1)(2=2)(3=3)(4=4)(05,06,98,99=\text { SYSMIS })
$$

Data analysis was based on the sub-sample used for this study $(n=2,160)$, with subsequent analysis separating the sample according to the gender of the respondent (details provided previously). A total of 126 cases were removed due to the above criteria. In order to include this variable as part of the set of characteristics encompassing the situational context of alcohol consumption during logistic regression analysis, further re-coding was required. For multinomial logistic regression analysis, SPSS automatically coverts categorical variables into 'dummy' variables by removing the last category. In order to control which category is 
considered the reference category, dichotomous variables were created manually for drinking location (i.e., your home $=1$; Other $=0$ ). As such, the variable was re-coded according to the following parameters:

$$
\begin{aligned}
& \text { RECODE VARLOCAT TO LOCYRHOM }(1=1)(\text { ELSE }=0) \\
& \text { RECODE VARLOCAT TO LOCOTHOM }(2=1)(\text { ELSE }=0) \\
& \text { RECODE VARLOCAT TO LOCREST }(3=1)(\text { ELSE }=0) \\
& \text { RECODE VARLOCAT TO LOCBAR }(4=1)(\text { ELSE }=0)
\end{aligned}
$$

This created four separate 'dummy' variables which could encompass the location where drinking occurred (i.e., last time drank, location was your home). Responses for 'your home' (LOCYRHOM) as the drinking location were omitted in the logistic regression analyses, and considered as the reference category for this variable. Research on drinking contexts has found public drinking places such as bars, clubs or taverns to be associated with heavier alcohol consumption (Harford 1983; Kairouz \& Greenfield 2007). At the same time, private or residential locations are also popular drinking areas (Single \& Wortley 1993). The decision to use 'your home' as the reference category is consistent with previous studies of Canadian populations (Demers 1997; Demers et al. 2002), which utilized "private home" and "at home" respectively as the reference categories for their logistic regression analyses.

\section{Multiple Locations.}

Data for this independent variable was taken from the original variable (AF4) provided in the 2004 CAS dataset. This variable was derived from the following question: On this occasion, did drinking occur at one location or in more than one location? This variable was used to as part of the set of characteristics encompassing the situational context of alcohol consumption. Responses were provided in yes/no fashion. As such, in order to employ descriptive and logistic regression analyses, the variable was re-coded according to the following parameters:

\section{RECODE AF4 TO MULTLOC $(1=0)(2=1)($ ELSE=SYSMIS)}

This allowed for a binary measure of drinking at 'multiple locations' to be created, composed of those individuals who reported drinking at only one location, and those reporting drinking at multiple locations. Drinking in a single location (response of "no") was taken as the reference category for logistic regression analyses. 


\section{REFERENCES}

Adlaf, E. M., Begin, P. \& Sawka, E. (eds.) (2005) Canadian Addiction Survey (CAS): A national survey of Canadians' use of alcohol and other drugs: Prevalence of use and related harms: Detailed report. Ottawa: Canadian Centre on Substance Abuse.

Adlaf, E. \& Ialomiteanu, A. (2004) Canadian Addiction Survey 2004: Microdata eGuide. Ottawa, ON: Canadian Centre on Substance Abuse.

Adrian, M. (2003). "How can sociological theory help our understanding of addictions?" Substance use \& misuse, 38(10) 1385-1423.

Agassi, J. (2004). "Methodological individualism". Philosophy of the Social Sciences, 34(2) 316-319.

Alvesson, M. \& Sköldberg, K. (1999) "Introduction: the intellectualization of method", in Reflexive Methodology: New Vistas for Qualitative Research, London, UK: Sage publications.

Arfken, C. (1988) "Temporal patterns of alcohol consumption in the United States. Alcoholism: Clinical and Experimental Research, 12(1): 137-142.

Auth, J. B. \& Warheit, G. J. (1982-1983) "Estimating the Prevalence of Problem Drinking and Alcoholism in the General Population: An Overview of Epidemiological Studies. Alcohol Health and Research World, 7: 11-21.

Babor, T. F., Longabaugh, R., Zweben, A, Fuller, F. K., Stout, R. L., Anton, R. F., \& Randall, C. L. (1994) Issues in the definition and measurement of drinking outcomes in alcoholism-treatment research". Journal of Studies on Alcohol: 101111.

Babor, T., Caetano, R., Casswell, S., Edwards, G., Giesbrecht, N., Graham, K. et al. (2003) Alcohol: No ordinary commodity. Oxford: Oxford University Press.

Babor, T. (2004) "Admirable Ends, Ineffective Means: Comments on the Alcohol Harm Reduction Strategy for England". Drugs: education, prevention and policy, 11(5): 361-365.

Baer, J., Stacy, A., \& Larimer, M. (1991) "Biases in the Perception of Drinking Norms among College Students". Journal of Studies on Alcohol, 52(6): 580-586.

Beck, U. (1992) Risk Society: Towards a New Modernity. London, UK: Sage Publications. 
Beck, U. (1999) World Risk Society. Malden, MA: Blackwell Publishers Inc.

Beck, U. \& Beck-Gernsheim, E. (2002) Individualization: institutionalized individualism and its social and political consequences. London, UK: Thousand Oaks.

Beck, U. \& Willms, J. (2004) Conversations with Ulrich Beck. Malden, MA: Blackwell Publishers Inc.

Bloomfield, K., Stockwell, T., Gmel, G., \& Rehn, N. (2003) "International Comparisons of Alcohol Consumption", Alcohol Research \& Health, 27(1): 95-109.

Blum, T. \& Roman, P. (1997) "Employment and drinking", in Wilsnack, R. W. \& Wilsnack, S. C. (eds.) Gender and alcohol: Individual and social perspectives). Piscataway, NJ, US: Rutgers Center of Alcohol Studies: pp. 379-394.

Bondy, S., Rehm, J., Ashley, J. Walsh, G., Single, E., \& Room, R.. (1999) "Low-risk Drinking Guidelines: The Scientific Evidence". Canadian Journal of Public Health, 90(4): 264-270.

Borsari, B. (2004) "Drinking Games in the College Environment: A Review". Journal of Alcohol and Drug Education, 48(2): 29-51.

Britton, P (2004) "The relation of coping strategies to alcohol consumption and alcoholrelated consequences in a college sample". Addiction Research and Theory, 12(2): 103-114.

Brown, S. (1985) "Expectancies versus background in the prediction of college drinking patterns". Journal of Consulting and Clinical Psychology, 53: 123-130.

Brown, S., Christiansen, B., \& Goldman, S. (1987) "The alcohol expectancy questionnaire: An instrument for the assessment of adolescent and adult alcohol expectancies". Journal of Studies on Alcohol, 48: 483-491.

Caetano, R. \& Herd, D. (1988) "Drinking in Different Social Contexts Among White, Black, and Hispanic Men". The Yale Journal of Biology and Medicine, 61: 243-258.

Calahan, D., Cisin, I., \& Crossley, H. (1969) American Drinking Practices. Monograph no. 6, Rutgers Center of Alcohol Studies, New Brunswick, New Jersey.

Canadian Centre on Substance Abuse (2004) Canadian Addiction Survey 2004: Microdata eGuide. Ottawa: Canadian Centre on Substance Abuse.

Canadian Institute for Health Information (2003) Women's Health Surveillance Report: A Multidimensional Look at the Health of Canadian Women. Chapter 7: Women and Substance Use Problems. CIHI: Ottawa.

Casswell, S. (1994) "Moderate drinking and population-based alcohol policy". 
Contemporary Drug Problems, 21(2): 287-299.

Canadian Centre on Substance Abuse (1000) "Legal Drinking Age by Province, in Canada". Canadian Profile 1999. Retrieved February 9, 2006 from http://www.ccsa.ca/CCSA/EN/Topics/Legislation/LegalDrinkingAgeByProvCan.ht $\underline{\mathrm{m}}$

Casswell, S., Zhang, J. F., \& Wyllie, A. (1993) "The Importance of Amount and Location of Drinking for the Experience of Alcohol-Related Problems". Addiction, 88(11): 1527-1534.

Center for Substance Abuse Treatment (CSAT) (1999) Brief Interventions and Brief Therapies for Substance Abuse, Treatment Improvement Protocol (TIP). Series, Number 34, DHHS Pub. No. (SMA) 99-3353. U.S. Government Printing Office, Washington, DC.

Clapp, J. D., Shillington, A. M. \& Segars, L. B. (2000) "Deconstructing Contexts of Binge Drinking Among College Students". American Journal of Drug and Alcohol Abuse, 26(1): 139-154.

Clark, W. B. (1966) "Operational definitions of drinking problems and associated prevalence rates". Quarterly Journal of Studies on Alcohol, 27(4): 648-668.

Clark, W. B. (1981a) "The contemporary tavern", in Israel, Y., Glaser, F., Kalant, H., Popham, R., Schmicht, W. \& Smart, R. (eds.) Research Advances in Alcohol and Drug Problems, Vol. 6. New York, NY: Plenum Press: 425-470.

Clark, W. B. (1981b) "Public drinking contexts: Bars and taverns", in Harford, T. \& Gaines. L (eds.) Social Drinking Contexts. NIAAA Research Monograph No. 7, DHHS Publication No. (ADM) 81-1097, Washington: Government Printing Office: 8-33.

Clark, W. B. (1985) "Alcohol use in various settings", in Public Drinking and Public Policy: Proceedings of a symposium on observation studies held at Banff, Alberta, Canada, April 26-28, 1984, (eds.) Single, E. \& Storm, T. Toronto: University of Toronto Press.

Collins, R. L. \& Marlatt, G. A. (1981) "Social modeling as a determinant of drinking behavior: The effects of social interaction and model status on the selfadministration of alcohol". Addictive Behaviors, 6: 233-239.

Connolly, G.M., Casswell, S., Stewart, J. \& Silva, P.A. (1992) "Drinking context and other influences on the drinking of 15-year old New Zealanders". British Journal of Addictions, 87: 1029-1036. 
Cooney, A., Dobbinson, S., \& Flaherty, B., (1994) 1992 Survey of Drug Use by NSW Secondary School Students. NSW Drug and Alcohol Directorate, NSW Department of Health, In-House Report Series. NSW Department of Health: Sydney.

Cox, W. M., \& Klinger, E. (1988) “A motivational model of alcohol use”. Journal of Abnormal Psychology, 97: 168-180.

Curran, P., Harford, T., \& Muthen, B. (1996) "The relation between heavy alcohol use and bar patronage: A latent growth model". Journal of Studies on Alcohol, 57(4): 410-418.

Cunningham, J. A. \& Mäkelä, P. (2003) "Comparing drinking patterns in Finland and Ontario (Canada)". Contemporary Drug Problems, 30: 685-699.

Cutler, R. \& Storm, T. (1975) "Observational study of alcohol consumption in natural settings: The Vancouver Beer parlor". Journal of Studies on Alcohol, 36: 11731183.

Danzinger, Kurt (1990) Constructing the Subject: Historical Origins of Psychological Research. Cambridge: Cambridge University Press.

Dawson, D.A. (1996) "Temporal Drinking Patterns and Variation in Social Consequences" Addiction, 91(11): 1623-1635.

Dean, M. (1997) "Sociology after Society", in D. Owen (Ed.) Sociology after Postmodernism, London, UK: Sage: pp. 205-228.

Dean, M. (1999) Governmentality: power and rule in modern society. Thousand Oaks, CA: Sage.

Dean, M. (2002) "Liberal government and authoritarianism". Economy and Society, 31(1):37-61.

Delk, E.W. \& Meilman, P.W. (1996) "Alcohol use among college students in Scotland compared with norms from the United States". Journal of American College Health, 44(6): 274-281.

Demers, A. (1997) "When at risk? Drinking contexts and heavy drinking in the Montreal adult population". Contemporary Drug Problems, 24: 449-471.

Demers, A. \& Bourgault, C. (1996) "Solitary drinking as a non-pathological behaviour", Addiction, 91(10): 1505-1516.

Demers, A., Kairouz, S., Adlaf, E., Gliksman, L., Newton-Taylor, B. \& Marchand, A. (2002) "Multilevel analysis of situational drinking among Canadian undergraduates", Social Science and Medicine, 55(3): 47-56. 
DeWit, D. J., Silverman, G., Goodstadt, M. \& Stoduto, G. (1995) "The Construction of Risk and Protective Factor Indices for Adolescent Alcohol and other Drug Use". The Journal of Drug Issues, 25(4): 837-863.

Diez-Roux, A.V. (1998) "Bringing Context Back into Epidemiology: Variables and Fallacies in Multilevel Analysis". American Journal of Public Health, 88(2): 222.

Donnermeyer, J.F. \& Park, D.S. (1995) “Alcohol use among rural adolescents: Predictive and situational factors". International Journal of Addictions, 30: 459-479.

Dowdall, G.W., \& Wechsler, H. (2002) "Studying college alcohol use: widening the lens, sharpening the focus". Journal of Studies on Alcohol, Supplement(14): 14-22.

Driessen, H. (1992) "Drinking on masculinity: alcohol and gender in Andalusia", in Gefou-Madianou, D. (Ed.) Alcohol, Gender and Culture, London, UK: Routledge: 71-79.

Duncan, C., Jones, K., \& Moon, G. (1996) "Health-related behaviour in context: A multilevel modelling approach". Social Science \& Medicine, 42: 817-830.

Duff, C. (2004) "Drug use as a 'practice of the self': is there any place for an 'ethics of moderation' in contemporary drug policy?". International Journal of Drug Policy, 15: 385-393.

Duffy, J. C. (2003) "Association between aspects of drinking pattern and experience of alcohol-related problems". Addiction Research and Theory, 11(3): 195-205.

Economist 01/08/2005: 49.

Epstein, E., Kahler, C., McCrady, B., Lewis, K., \& Lewis, S. (1995) “An empirical classification of drinking patterns among alcoholics: binge, episodic, sporadic, and steady". Addictive Behaviors, 20(1): 23-41.

Erickson, P (1999) "Introduction: The Three Phases of Harm Reduction. An Examination of Emerging Concepts, Methodologies, and Critiques". Substance Use \& Misuse, 34(1): $1-7$.

Ettore, E. (2004) "Revisioning women and drug use: gender sensitivity, embodiment and reducing harm". International Journal of Drug Policy, 15: 327-335.

Farrington, D. P. \& Loeber, R. (2000) "Some benefits of dichotomization in psychiatric and criminological research". Criminal Behaviour and Mental Health, 10(2): 100122.

Ferrence, R.G. (1980). "Sex differences in the prevalence of problem drinking", in O.J. Kalant (ed.), Research advances in alcohol and drug problems. Vol. 5: Alcohol and drug problems in women. New York: Plenum: pp. 69-124. 
Fillmore, K.M. (1984). "“When angels fall': Women's drinking as cultural preoccupation and as reality", in S.C. Wilsnack \& L.J. Beckman (eds.), Alcohol problems in women: Antecedents, consequences, and intervention. New York: Guilford Press: pp. 7-36.

Finnigan, F., Hammersley, R., Millar, K. (1998) "Effects of Meal Composition on Blood Alcohol Level, Psychomotor Performance and Subjective State after Ingestion of Alcohol". Appetite, 31: 361-375.

Fisher, H. \& Single, E. (1987) "Beer in the Ballpark". Paper presented at the National Alcoholism Forum on Alcohol and Sports, Cleveland, OH: April 24, 1987.

Fitzgerald, J. \& Mulford, H. (1978) "Distribution of alcohol consumption and problem drinking: comparison of sales records and survey data". Journal of Studies on Alcohol, 39(5): 879-893.

Fromme, K. \& Orrick, D. (2004) "The Lifestyle Management Class: A Harm Reduction Approach to College Drinking". Addiction Research and Theory, 12(4): 335-351).

Garabedian, K. (2006) A study on the drinking patterns of male and female employees in Alberta: The impact of work environment and job stress. Dissertation, Department of Sociology \& Anthropology. Carleton University: Ottawa.

Gibbons, S., Wylie, M.L., \& Echterling, L. (1986) "Situational factors related to rural adolescent alcohol use". International Journal of Addictions, 21: 1183-1195.

Giddens, A. (1991) Modernity and self-identity: self and society in the late modern age. Cambridge, UK: Polity Press.

Giddens, A. (2000) Runaway world: how globalization is reshaping our lives. New York, NY: Routledge.

Giesbrecht, N. (1999) "Reducing the risks associated with drinking among young adults: promoting knowledge-based perspectives and harm reduction strategies". Addiction, 94(3): 353-355.

Goddard, E. (1997a) Young Teenagers and Alcohol in 1996. Volume 1, England (London, Office for National Statistics).

Goddard, E. (1997b) Young Teenagers and Alcohol in 1996. Volume 2, Scotland (London, Office of National Statistics).

Goode, E. (1994) Moral panics: the social construction of deviance. Oxford, UK: Cambridge.

Gotoh, M. (1994) "Alcohol dependence of women in Japan". Addiction, 89(8): 953-954. 
Government of Canada (2007) Backgrounder: National Anti-Drug Strategy. November 20, 2007. Retrieved November 21, 2007 from http://www.nationalantidrugstrategy.gc.ca/back-fich/doc2007 $11 \quad 20 \quad 1 . \mathrm{html}$

Graham, K., LaRocque, L., Yetman, R., Ross, T. \& Guistra, E. (1980) “Aggression and barroom environments", Journal of Studies on Alcohol, 41: 277-292.

Graham, K. \& Homel, R. (1997) "Creating Safer Bars" in M. Plant, E. Single, \& T. Stockwell (eds.) Alcohol: minimising the harm: what works? London, UK: Free Association Books.

Graham, K., Osgood, D., Zibrowski, E., Purcell, J., Gliksman, L., Leonard, K., et al. (2004) "The effect of the Safer Bars programme on physical aggression in bars: Results of a randomised control trial". Drug and Alcohol Review, 23: 31-41.

Greenfield, T. \& Room, R. (1996) "Situational norms for drinking and drunkenness: trends in the US adult population, 1979-1990". Addiction, 92(1): 33-47.

Grossman, M., Coate, D., \& Arluck, G. M. (1987) "Price sensitivity of alcoholic beverages in the Unites States: Youth alcohol consumption", in Holder, H. (ed.) Control Issues in Substance Abuse Prevention: Strategies for States and Communities. Advances in Substance Abuse, Supplement 1 (Greenwich, CT, JAI Press).

Guba, E. \& Lincoln, Y. (1998) "Competing Paradigms is Qualitative Research", in N. Denzin and Y. Lincoln (Eds.) The Landscape of Qualitative Research: Theories and Issues. London: Sage: pp. 19-31.

Gusfield, J. (1981) The culture of public problems: drinking-driving and the symbolic order. Chicago, IL: University of Chicago Press.

Hacking, I. (1999) The Social Construction of What? Cambridge, MA: Harvard University Press.

Harford, T. (1979) "Contextual drinking patterns among men and women", in A. Frank (Ed) Currents in Alcoholism, Vol. 4. New York: Grune and Stratton.

Harford, T., Wechsler, H., \& Rohman, M. (1980) "Social activity and drinking patterns", in Galanter, M. (ed.) Currents in Alcoholism, Vol. 7. New York: Grune and Stratton.

Harford, T. (1983) "A Contextual Analysis of Drinking Events", The International Journal of the Addictions, 18(6): 825-834.

Harnett, R., Thom, B., Herring, R. \& Kelly, M. (2000) "Alcohol in Transition: Towards a Model of Young Men's Drinking Styles". Journal of Youth Studies, 3(1): 61-77. 
Heath, D. B. (2000) Drinking Occasions: Comparative Perspectives on Alcohol and Culture. International Center for Alcohol Policies Series on Alcohol in Society. Ann Arbor, MI: Sheridan Books.

Hennessy, M. \& Saltz, R. (1993) "Modeling Social Influences on Public Drinking". Journal of Studies on Alcohol. 54: 139-145.

Herd, D. \& Grube, J. (1993) “Drinking contexts and drinking problems among black and white women". Addiction, 88: 1101-1110.

Hilton, M. (1987) "Drinking Patterns and Drinking Problems in 1984: Results from a General Population Survey". Alcoholism: Clinical and Experimental Research, 11(2): 167-175.

Holyfield, L., Ducharme, L.J., \& Martin, J.K. (1995) "Drinking contexts, alcohol beliefs and patterns of alcohol consumption: evidence for a comprehensive model of problem drinking”. Journal of Drug Issues, 25: 783-798.

Homel, R., Mcllwain, G., \& Carvolth, R. (2004). "Creating safer drinking environments", in N. Healther \& T. Stockwell (eds.), The essential handbook of treatment and prevention of alcohol problems. Chichester, UK: John Wiley and Sons: pp. 235254.

Jessor, R. (1982) "Some problematic aspects of research on drinking contexts", in Social Drinking Contexts, NIAAA Research Monograph No. 7, DHEW Publication No. (ADM) 82-1097; U.S. Government Printing Office: Washington, DC: 228-233.

Johnson, S. (1991) "Recent research: Alcohol and women's bodies", in P. Roth (Ed.) Alcohol and Drugs are Women's Issues: A Review of the Issues. Vol. 1: 32-42.

Johnston, L., O'Malley, P., Bachman, J. (1996) National Survey Results on Drug Use From the Monitoring the Future Study 1975-1994: Vol 2. College Students and Young Adults. US Department of Health and Human Services. NIH Publication No 96-4027.

Jones-Webb, R., Short, B., Wagenaar, A., Toomey, T., Murray, D., Wolfson, M., \& Forster, J., (1997) "Environmental predictors of drinking and drinking-related problems in young adults". Journal of Drug Education, 27(1): 67-82.

Kairouz, S., Gliksman, L., Demers, A., \& Adlaf, E.M. (2002) "For All These Reasons I Do... Drink: A Multilevel Analysis of Contextual Reasons for Drinking among Canadian Undergraduates". Journal of Studies on Alcohol, 63(5): 600-608.

Kairouz, S. \& Adlaf, E.M. (2003) "Schools, students and heavy drinking: a Multilevel Analysis", Addiction Research and Theory, 11(6): 427-439. 
Kairouz, S. \& Greenfield, T.K. (2007) "A comparative multi-level analysis of contextual drinking in American and Canadian adults", Addiction, 102: 71-80.

Kelly, Peter (2001) "Youth at Risk: processes of individualisation and responsibilization in the risk society", Discourse: studies in the cultural politics of education, 22(1): $23-33$

Kendell, R. E., de Roumanie, M., \& Ritson, E.B. (1983) "Influences of an increase in excise duty on alcohol consumption and its adverse effects". British Medical Journal, 287: 809-811.

Kilty, K. (1980) "Situational Context and the Meaning of Drinking". The International Journal of the Addictions, 15(7): 1021-1033.

Kleinbaum, D. (1994) Logistic Regression: A Self-Learning Text. New York, NY: Springer-Verlag.

Knibbe, R., Van de Goor, I., \& Drop, M. (1993) "Contextual influences on young people's drinking rates in public drinking places: An observational study". Addiction Research, 1:269-278.

Knupfer, G. (1984) "The risks of drunkenness (or, Ebrietas Resurrecta): A comparison of frequent intoxication indices and of population subgroups as to problem risks". British Journal of Addiction, 79: 185-196.

Knupfer, G., Fink, R., Clark, W. B., \& Goffman, A. S. (1963) Factors related to amount of drinking in an urban community. California State Department of Public Health, Berkeley, CA.

Kraft, J., Blum, T., Martin, J., \& Roman, P. (1993) "Drinking Patterns and the Gender Mix of Occupations: Evidence from a National Survey of American Workers". Journal of Substance Abuse, 5: 157-174.

Kranzler, H. R., Babor, T. F., \& Lauerman, R. J. (1990) "Problems associated with average alcohol consumption and frequency of intoxication in a medical population". Alcoholism: Clinical and Experimental Research, 14: 119-126.

Leifman, H. (2002) "A comparative analysis of drinking patterns in six EU countries in the year 2000". Contemporary Drug Problems, 29(3): 501-548.

Lemmens, P. \& Knibbe, R. (1993) "Seasonal Variation in Survey and Sales Estimates of Alcohol Consumption". Journal of Studies on Alcohol, 54: 157-163.

Levi-Martin, J. (1999) "The myth of the consumption-oriented economy and the rise of the desiring subject", Theory and Society, 28: 425-453. 
Li, G, Smith, G. S., \& Baker, S. P. (1994) "Drinking behavior in relation to cause of death among US adults". American Journal of Public Health, 84(9): 1402-1406.

Lieber, C. (1993) "Women and alcohol: Gender differences in metabolism and susceptibility", in E. Lisansky-Gomber \& T. Nirenberg (Eds.) Women and Substance Abuse. Norwood, NJ: Ablex Publishing: 1-17.

Loxley, W., Gray, D., Wilkinson, C., Chikritzhs, T., Midford, R., \& Moore, D. (2005) "Alcohol policy and harm reduction in Australia". Drug and Alcohol Review, 24(6): 559-568.

Mäkelä, P., Fonager, K., Hibell, B., et al. (2001) "Episodic heavy drinking in four Nordic countries: A comparative survey". Addiction, 96(11): 1575-1588.

Matano, R. A., Koopman, C., Wanat, S., Whitsell, S. D., Borggrefe, A. \& Westrup, D. (2003) "Assessment of binge drinking of alcohol in highly educated employees". Addictive Behaviors, 28: 1299-1310.

Mayer, R., Forster, J., Murray, D., Wagenaar, A. et al. (1998) "Social Settings and Situations of Underage Drinking". Journal of Studies on Alcohol, 59(2): 207-215.

McCreanor, T. Moewaka Barnes, H., Gregory, M., Kaiwai, H., \& Borell, S. (2005) "Consuming identities: Alcohol marketing and the commodification of youth experience". Addiction Research and Theory, 13(6): 579-590.

McDonald, M. (1994) "Introduction: a socioanthropological view of gender, drink and drugs", in McDonald, M. (Ed.) Gender, Drink and Drugs, Providence, RI: Berg: 131 .

Measham, F. (1996). "The "Big bang" approach to sessional drinking: Changing patterns of alcohol consumption amongst young people in North-West England." Addiction Research, 4: 283-299.

Measham, F. (2002) “"Doing gender"-"Doing drugs": conceptualizing the gendering of drug cultures”. Contemporary Drug Problems, 29: 335-373.

Measham, F. (2004a) "The decline of ecstasy, the rise of 'binge' drinking and the persistence of pleasure". The Journal of Community and Criminal Justice, 51(4): 309-326.

Measham, F. (2004b) "Play space: historical and socio-cultural reflections on drugs, licensed leisure locations, commercialization and control". International Journal of Drug Policy, 15: 337-345.

Measham, F. (2006) "The new policy mix: Alcohol, harm minimization, and determined drunkenness in contemporary society", International Journal of Drug Policy, 17: 258-268. 
Measham, F., Aldridge, J., \& Parker, H. (2001) Dancing on drugs: Risk, health and hedonism in the British club scene. London: Free Association Books.

Measham, F., \& Brain, K. (2005). "'Binge' drinking, British alcohol policy and the new culture of intoxication." Crime, Media, Culture: An International Journal, 1:262283.

Menard, S. (2001) Applied Logistic Regression Analysis. Series: Quantitative Applications in the Social Sciences $\left(2^{\text {nd }} E d\right)$. Thousand Oaks, CA: Sage Publications Inc.

Midanik, L. T., \& Robin R. (1992) "The epidemiology of alcohol consumption". Alcohol Health \& Research World, 16(3): 183-191.

Midanik, L. \& Clark, W. B. (1994) "The demographic distribution of US drinking patterns in 1990: description and trends from 1984". The American Journal of Public Health, 84(8):1218-1222.

Millar, K., Hammersley, R., \& Finnigan, F. (1992) "Reduction of alcohol-induced performance impairment by prior ingestion of food". British Journal of Psychology, 83: 261-278.

Mosher, J. F. (1999) "Alcohol policy and the young adult: Establishing priorities, building partnerships, overcoming barriers". Addiction, 94(3): 357-369.

Mulford, H.A. \& Miller, D.E. (1959) "Drinking in Iowa: I. Sociocultural distribution of drinkers: With a methodological model for sampling evaluation and interpretation of findings". Quarterly Journal of Studies on Alcohol. 20: 704-726.

Mulford, H.A. \& Miller, D.E. (1960a) "Drinking in Iowa: sociocultural distribution of drinkers". Quarterly Journal of Studies on Alcohol, 20: 483-499.

Mulford, H.A. \& Miller, D.E. (1960b) "Drinking in Iowa: III. A scale of definitions of alcohol related to drinking behavior. IV. Preoccupation with alcohol and definitions of alcohol, heavy drinking and trouble due to drinking". Quarterly Journal of Studies on Alcohol. 21: 267-291.

Muncie, J. (2002) "A new deal for youth?: Early intervention and correctionalism", in Crime Prevention and Community Safety, (eds.) G. Hughes, E. McLaughlin \& J. Muncie. London, UK: Sage.

Murdoch, D. \& Phil, O. (1984) "Awareness of Situational Effects on Drinking". Journal of Clinical Psychology, 40(2): 617-618. 
Mustonen, H. \& Mäkelä, K. (1999) "Relationships between characteristics of drinking occasions and negative and positive experiences related to drinking". Drug and Alcohol Dependence, 56: 79-84.

National Alcohol Strategy Working Group (2007) Reducing Alcohol-Related Harm in Canada: Toward a Culture of Moderation. Ottawa, ON: Alberta Alcohol and Drug Abuse Commission, Canadian Centre on Substance Abuse, Health Canada.

Neighbors, C., Larimer, M., Lostutter, T., B. Woods (2006) "Harm reduction and individually focused alcohol prevention". International Journal of Drug Policy, 17: 304-309.

Neve, R. J., Lemmens, P. H., \& Drop, M. J. (2000) "Changes in Alcohol Use and Drinking Problems in Relation to Role Transitions in Different Stages of the Life Course". Substance Abuse, 21(3): 163-178.

Nezlek, J. B., Pilkington, C. J., \& Bilbro, K. G. (1994) "Moderation in excess: Binge drinking and social interaction among college students". Journal of Studies on Alcohol. 55(3): 342-351.

Northwest Territories Health and Social Services (January 2006) NWT Addiction Survey. Northwest Territories Health and Social Services. Available online at http://www.hlthss.gov.nt.ca/pdf/reports/mental health and addictions/2006/english lnwt_addiction_survey.pdf

O'Hare, T. (1998) "Alcohol expectancies and excessive drinking contexts in young adults". Social Work Research, 22(1): 44-50.

O'Malley, P. (1999) "Governmentality and the risk society". Economy and Society, 28(1): 138-148

O'Malley, P. (2002) “Drugs, risks and freedoms: Illicit drug 'use' and 'misuse' under neo-liberal governance", in Crime Prevention and Community Safety, (eds.) G. Hughes, E. McLaughlin, and J. Muncie. London, UK: Sage Publications

O'Malley, P. (2004) Risk, uncertainty and government. London, UK: GlassHouse.

O'Malley, P. \& Valverde, M. (2004) "Pleasure, Freedom and Drugs: The Uses of 'Pleasure' in Liberal Governance of Drug and Alcohol Consumption". Sociology, 38(1): 25-42.

Orcutt, J. D. (1991) "The social integration of beers and peers: Situational contingencies in drinking and intoxication", in Society, Culture and Drinking Patterns Reexamined, (eds.) Pittman \& White. New Brunswick, NJ: Rutgers Center for Alcohol Studies. 
Parker, D. \& Harford, T. (1992) "The Epidemiology of Alcohol Consumption and Dependence Across Occupations in the United States". Alcohol Health \& Research World, 16(2): 97-105.

Parker, H. (2003) "Editorial: Pathology or Modernity? Rethinking Risk Factor Analyses of Young Drug Users". Addiction Research \& Theory, 11(3): 141-144.

Parker, H. (2005) "Normalization as a barometer: recreational drug use and the consumption of leisure by younger Britons". Addiction Research and Theory, 13(3): 205-215.

Parker, H. Williams, L., \& Aldridge, J. (2002) "The normalization of 'sensible' recreational drug use: further evidence from the north west England Longitudinal study". Sociology 36(4): 941-964.

Parker, H., Aldridge, J., \& Measham, F. (1998) Illegal Leisure: The normalization of adolescent recreational drug use. London, UK: Routledge.

Pearce, N. (1996) "Traditional epidemiology, modern epidemiology, and public health". American Journal of Public Health, 86(5): 678-683.

Pertanen, J. (1975) "On the role of situational factors in alcohol research: Drinking in restaurants vs. drinking at home". Drinking and Drug Practices Surveyor, No. 10. March 16, 1975.

Plant, M., Single, E., \& Stockwell, T. (1997) Alcohol: minimising the harm: what works? London, UK: Free Association Books.

Plant, M. (2005) Women's Hour, Radio 4, 13 January.

Poole, N. \& Dell, C. A. (2005) Girls, Women and Substance Abuse. Canadian Centre on Substance Abuse.

Quigley, B.M., \& Collins, R.L. (1999) “The modelling of alcohol consumption: A metaanalytic review". Journal of Studies on Alcohol, 60: 90-98.

Rehm, J., Ashley, M., Room, R., et al. (1996) "On the emerging paradigm of drinking patterns and their social and health consequences". Addiction, 91: 1615-1621.

Rehm, J., Baliunas, D., Brochu, S., Fischer, B., Gnam, W., Patra, J., Popova, S., Sarnocinska-Hart, A., Taylor, B., Adlaf, E., Recel, M., \& Single, E., (2006) The Costs of Substance Abuse in Canada 2002: Highlights. Ottawa, ON: Canadian Centre on Substance Abuse.

Reid, J. B. (1978) "Study of drinking in natural settings", in Marlatt, G. A. \& Nathan, P.E. (eds.) Behavioral Approaches to Alcoholism. NIAAA-RUCAS Alcoholism 
Treatment Series, No. 2, New Brunswick, N.J.: Rutgers Center of Alcohol Studies: pp. 58-74.

Riley, D., Sawka, E., Conley, P., Hewitt, D., Mitic, W., Poulin, C., Room, R., Single, E., \& Topp, J. (1999) "Harm Reduction: Concepts and Practice. A Policy Discussion Paper". Substance Use \& Misuse, 34(1): 9-24.

Roberts, C., Kingdon, A., Frith, C. \& Tudor-Smith, C. (1997) Young People in Wales: Lifestyle Changes, 1985-96. Cardiff, Health Promotion Wales.

Robson, G. \& Marlatt, G. A. (2006) "Harm reduction and alcohol policy". International Journal of Drug Policy, 17(4;) SI255- SI257.

Rogers, J. D. \& Greenfield, T. K. (1999) "Beer drinking accounts for most of the hazardous alcohol consumption reported in the United States". Journal of Studies on Alcohol, 60: 732-739.

Roman, P. M. (Ed.) (1991) Alcohol: The Development of Sociological Perspectives on Use and Abuse. New Brunswick, NJ: Rutgers Center of Alcohol Studies.

Room, R. (1990) "Measuring alcohol-consumption in the United States - Methods and Rationales". Research Advances in Alcohol and Drug Problems, 10:.39-80.

Room R. (1992) "The impossible dream? Routes to reducing alcohol problems in a temperance culture". Journal of Substance Abuse, 4: 91-106.

Room, R. (1996) "Alcohol consumption and social harm - conceptual issues and historical perspectives". Contemporary Drug Problems, 23: 373-388.

Room, R. (1997) "Alcohol, the individual and society: what history teaches us". Addiction, 92(Supplement 1): S7-S11.

Room, R. (2003) "Paths forward between prohibition and laissez-faire". Addiction, 98(6): $721-723$.

Room, R. (2004) "Alcohol and harm reduction, then and now". Critical Public Health, 14(4): 329-344.

Room, R., Bondy, S. J., Ferris, J. (1995) "The risk of harm to oneself from drinking, Canada 1989'. Addiction, 90(4): 499-513.

Room, R., Graham, K., Rehm, J., Jernigan, D., \& Monteiro, M. (2003) "Drinking and Its Burden in a Global Perspective: Policy Considerations and Options". European Addiction Research, 9: 165-175.

Rose, N. (1993) "Government, authority and expertise in advanced liberalism". Economy and Society, 22(3): 283-299. 
Rose, N. (1996) "The death of the social? Re-figuring the territory of Government". Economy and Society, 25(3): 327-356.

Rosenthal, R. \& Rubin, D. B. (1982) “A simple, general purpose display of magnitude of experimental effect". Journal of Educational Psychology, 74(2): 166-169.

Sanchez-Craig, M., Wilkinson, D., \& Davila, R., (1995) “ Empirically based guidelines for moderate drinking: 1-year results from three studies with problem drinkers". American Journal of Public Health, 85: 823-828.

Saunders, J., Aasland, O. et al (1993) "Development of the Alcohol Use Disorders Identification Test (AUDIT): WHO collaborative project on early detection of persons with harmful alcohol consumption BII." Addiction, 88: 791-804.

Schulenburg, J., Wadsworth, K. N., O’Malley, P. M., Bachman, J. G., \& Johnston, L. D. (1996) "Adolescent risk factors for binge drinking during the transition to young adulthood: Variable- and pattern-centered approaches to change". Developmental Psychology, 32, 659-674.

Schultz, J., Weiner, H. \& Westcott, J. (1980) "Retardation of ethanol absorption by food in the stomach". Journal of Studies on Alcohol, 41: 861-870.

Selvin, S. (1995) "Statistical Models in Epidemiology". Journal of the American Statistical Association, 90(430): 798.

Simpura, J (1987) "Studying norms and contexts of drinking". Contemporary Drug Problems, 18(3): 477-498.

Single, E. (1985) "Studies of Public Drinking: An Overview", in Public Drinking and Public Policy: Proceedings of a symposium on observation studies held at Banff, Alberta, Canada, April 26-28, 1984, (eds.) Single, E. \& Storm, T. Toronto: University of Toronto Press.

Single, E. (1994) "Implications of potential health benefits of moderate drinking for specific elements of alcohol policy: towards a harm-reduction approach for alcohol". Contemporary Drug Problems, 21: 273-285.

Single, E. (1996) "Harm reduction as an alcohol-prevention strategy". Alcohol Health \& Research World, 20(4): 239-244.

Single, E (1997) "The Concept of Harm Reduction and its Application to Alcohol: the $6^{\text {th }}$ Dorothy Black Lecture". Drugs: education, prevention and policy, 4(1): 7-16.

Single, E. \& Wortley, S. (1993) "Drinking in various settings as it relates to demographic variables and level of consumption: Findings from a national survey in Canada". Journal of Studies on Alcohol, 54: 590-599. 
Single, E., Robson, L., Xie, X. et al. (1996) The Costs of Substance Abuse in Canada: A Cost Estimation Study. Ottawa, ON: Canadian Centre on Substance Abuse.

Skog, O. (1981) "Drinking behavior in small groups: The relationship between group size and consumption", in: Harford, T.C. \& Gaines, L.S. (Eds.), Social Drinking Contexts. National Institute on Alcohol and Alcoholism. Research Monograph 7 , Rockville, Maryland: 121-137.

Skog, O. (1985) "The Collectivity of Drinking Cultures: A Theory of the Distribution of Alcohol Consumption". British Journal of Addiction, 80: 83-99.

Smart, R. \& Ogborne, A. (1996) Northern Spirits: A Social History of Alcohol in Canada. Toronto, ON: Addiction Research Foundation.

Sommer, R. (1965) "The Isolated Drinker in the Edmonton Beer Parlor". Quarterly Journal of Studies on Alcohol, 26(1): 95-110.

Stockwell, T., Blaze-Temple, D., \& Walker, C. (1990) "The case for introducing standard drink labelling on all alcohol containers". Medical Journal of Australia, 153: 61-62.

Stockwell, T., Lang, E., \& Rydon, P., (1993) "High-risk Drinking Settings - The Association of Serving and Promotional Practices with Harmful Drinking". Addiction, 88(11): 1519-1526.

Stockwell, T. (1997) "Liquor outlets and prevention policy: the need for light in dark corners". Addiction, 92(8): 925-930.

Stockwell, T. (2003) “An excellent review, but how is 'harm reduction' to be defined? Comment on Chapter 8: Modifying the Drinking Context", Addiction, 98: 13581359.

Sulkunen, P., Rantala, K., \& Määta, M. (2004) "The ethics of not taking a stand: dilemmas of drug and alcohol prevention in a consumer society - a case study". International Journal of Drug Policy, 15: 427-434.

Svare, G., Miller, L., \& Ames, G. (2004) "Social Climate and Workplace Drinking among Women in Male-Dominated occupation”. Addictive Behaviors, 29: 16911698.

Treno, A. J., Alaniz, M. L. \& Gruenewald, P. J. (2000) "The use of drinking places by gender, age and ethnic groups: an analysis of routine drinking activities". Addiction, 95(4): 537-551.

Trewin, D. \& Lee, G (1988) "International comparisons of telephone coverage", in R. M. Groves, P. P. Biemer, L. E. Lyberg, J. T. Massey, W. L. Waksberg (Eds.), Telephone Survey Methodology (pp. 9-24). New York: John Wiley \& Sons. 
Trice, H. \& Sonnenstuhl, W. (1988) "Drinking Behavior and Risk Factors Related to the Work Place: Implications for Research \& Prevention". The Journal of Applied Behavioral Science, 24(4): 327-346.

Valverde, M (1998) Diseases of the will alcohol and the dilemmas of freedom. Cambridge, UK: Cambridge University press.

van Bouwel, J. (2003) "Individualism and Holism, Reduction and Pluralism: A Comment on Keith Sawyer and Julie Zahle". Philosophy of the Social Sciences, 34(4): 527535 .

Van der Goor, L.A.M, Knibbe, R.A. \& Drop, M.J. (1990) “Adolescent drinking behaviour: An observational study of the influence of situational factors on adolescent drinking rates". Journal of Studies on Alcohol, 51: 548-555.

Wechsler, H. \& Isaac, N. (1992) ““'Binge” drinkers at Massachusetts colleges: prevalence, drinking styles, time trends, and associated problems". Journal of the American Medical Association, 267: 2929-2931.

Wechsler, H., Isaac, N., Grodsten, F., \& Sellers, D. (1994a) "Continuation and initiation of alcohol use from the first to the second year of college". Journal of Studies on Alcohol, 55(1): 41-45.

Wechsler, H., Davenport, A., Dowdall, G., Moeykens, B., \& Castillo, S (1994b) "Health and behavioral consequences of binge drinking in college: a national survey of students at 140 campuses". Journal of the American Medical Association, 272: 1672-1677.

Wechsler, H., Dowdall, G., Davenport, A., \& Rimm, E. (1995) "A gender-specific measure of binge drinking among college students", American Journal of Public Health, 85(7): 982-985.

Wechsler, H., Molnar, B., Davenport, A., \& Baer, J. (1999) "College alcohol use: A full or empty glass?" Journal of American College Health, 47(6): 247-254.

Wechsler, H., Kuo, M., Lee, H., \& Dowdall, G. (2000) "Environmental correlates of underage alcohol use and related problems of college students". American Journal of Preventive Medicine, 19(1): 24-29.

Welling, P., Lyons, B., Elliott, M. \& Amidon, G. (1977) "Pharmacokinetics of alcohol following single dosed to fasted and non-fasted subjects". Journal of Clinical Pharmacology, 17: 199-206.

Wieczorek, W.F., Miller, B.A., \& Nochajski, T.H. (1992) "Multiple and single location drinking among DWI offenders referred for alcoholism evaluation". American Journal of Drug and Alcohol Abuse, 18(1): 103-116. 
Wilsnack, S. \& Wilsnack, R. (1991) “Epidemiology of Women's Drinking”. Journal of Substance Abuse, 3: 133-157.

Wilsnack, R., Vogeltanz, N., Wilsnack, S. et al. (2000) "Gender differences in alcohol consumption and adverse drinking consequences: Cross-cultural patterns. Addiction, 95(2): 251-265.

Witkiewitz, K. \& Marlatt, G. (2006) "Overview of harm reduction treatments for alcohol problems". International Journal of Drug Policy, 17: 285-294.

York, J. \& Welte, J. (1994) "Gender comparisons of alcohol consumption in alcoholic and non-alcoholic populations". Journal of Studies on Alcohol, 55: 743-750.

Yukon Department of Health and Social Services (2005) Yukon Addictions Survey (YAS): Preliminary Results 2005 - A survey of Yukoners' use of alcohol and other drugs. Yukon Department of Health and Social Services and the Yukon Bureau of Statistics. Available online at: http://www.hss.gov.yk.ca/downloads/yas2005.pdf

Zinberg, N. (1984) Drug, set and setting: The basis for controlled intoxicant use. New Haven: Yale University Press. 